



\title{
SPECULATING TYPOLOGIES
}

A SALE FOR VIABILITY

\author{
by \\ Ishan Patel \\ B.Arch.Sc., Ryerson University, 2016 \\ A thesis \\ presented to Ryerson University \\ in partial fulfillment of the \\ requirements for the degree of \\ Master of Architecture \\ in the Program of \\ Architecture
}

Toronto, Ontario, Canada, 2018.

(c) Ishan Patel 2018 
$\Xi$ 


\section{AUTHOR'S DECLARATION}

I hereby declare that I am the sole author of this thesis. This is a true copy of the thesis, including any required final revisions, as accepted by my examiners.

I authorize Ryerson University to lend this thesis to other institutions or individuals for the purpose of scholarly research

I further authorize Ryerson University to reproduce this thesis by photocopying or by other means, in total or in part, at the request of other institutions or individuals for the purpose of scholarly research.

I understand that my thesis may be made electronically available to the public. 
$\geq$ 


\section{SPECULATING TYPOLOGIES}

A SALE FOR VIABILITY

Ishan Patel

Master of Architecture 2018

Architecture Program, Ryerson University

\section{A B S T R A C T}

Inherently all that is designed is obsolete. The ambition to create an efficient society is followed by a continuous debate over the necessary and the unnecessary built forms. Architecture of the city is a result of satisfying the public desires that change through the inherent obsolescent nature of a progressive society. By accepting obsolescence as an inevitable state, the characteristics of the designed typologies can be preserved to withstand the changes occurring within the city.

Speculative futures discussed in writings and designs promote both dystopic and utopic state of architecture. By critiquing the usefulness of the built form through these two lenses, a framework that sustains the lifestyles in a technologically dependent society can be developed. Speculating Typologies explores architecture as an adaptive system that conserves the characteristics of obsolete typologies to create programs that will always be necessary within the urban fabric of the city. 
$\sum$ 
Dr. June Komisar Thesis Supervisor

Dr. Kendra Schank Smith Second Reader

Baruch Zone

Program Representative

My friends, and second family

\section{ACKNOWLEDGMENT}

For the completion of this work, I would like to express my sincere gratitude and thank the following individuals as this would not have been possible without all of your support.

For your guidance, support, and constant availability to discuss my work with enthusiasm aiding to hone my true interests in this thesis. Your discussions and support truly made this journey from the beginning of my bachelor's degree to the end of my masters unforgettable, and, most of all, enjoyable. Thank you for believing in me, my discoveries, and my direction through all the ups and downs over the last two years.

For your continuous input on my design, numerous research references to further guide my thesis development, and opening my mind to new topics of discussion. Thank you for your discussions and questions that helped me bring clarity to my thoughts and design process.

For your challenging input and helpful criticism on my thesis that helped me to understand and narrow the design intentions that I aimed to achieve. Thank you for your feedback at every presentation which further helped my design and myself to evolve for the better.

For their constant laughs, encouragement, and support that kept me sane throughout the last two years. Thank you for all the unforgettable experiences that I will always cherish and for having the patience to listen to me at any given time. Cheers.

My Family For their support and encouragement throughout this long journey. Thank you for believing in the life that I chose and for being by my side every step of the way. 
TABLE OF CONTENT

Author's Declaration

Abstract

Acknowledgements

vii

Table of Contents

viii

List of Figures

$x$

1.0 Introduction

2.0 Overview

3.0 Obsolescence

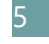

3.1 Turning Obsolete 6

3.2 Memento Mori 10

3.3 Typological Issue 12

$\begin{array}{lll}3.4 & \text { Selective Obsolescence } & 14\end{array}$

4.0 Near Future

4.1 Science Fiction 20

4.2 Utopia 24

4.3 Dystopia 26

4.4 Speculative Futures $\quad 29$

5.0 Design Research 33

5.1 Science Fiction Novels 34

5.1.1 J. G. Ballard 34

5.1.2 The Concentration City: Instincts 35

5.1.3 Billennium: Space 37

5.1.4 High-rise: Division 39

5.1.5 Kingdom Come: Retail 41

5.2 Precedent and Architectural Analysis 43

5.2.1 The Arcade Providence: Adaptive Reuse 43 
5.2.2 Kowloon Walled City: Density 45

5.2.3 Songpa Micro-housing: Living 47

5.2.4 Common Grounds: Compartmentalization 49

6.0 Design Project

6.1 History of malls

54

6.2 Site History

66

6.3 Observations 82

6.4 Speculative Scenarios 88

6.4.1 Toronto $2070 \quad 88$

6.4.2 An Urban Village 90

6.4.3 A Consumer Museum 94

$6.5 \quad$ Near future 96

6.5.1 Housing 96

6.5.2 Retail 100

$\begin{array}{lll}6.6 & \text { Program Exploration } & 101\end{array}$

$\begin{array}{lll}6.7 & \text { Project Documents } & 105\end{array}$

7.0 Conclusion

$\begin{array}{lll}8.0 & \text { Appendix } & 207\end{array}$

Bibliography 


\section{LIST OF FIGURES}

Figure 3.1 J.N.L. Durand, Table 20 of Précis des leçons d'architecture donnés à l'École polytechnique, $1802 / 5$

Source: $\quad$ Ellis, Eugenia V. "Technique and (re)Production: the Shift from Script to Print to Hypermedia." Drexel Research (2002): 1-9. https://www.researchgate.net/ JNL-Durand-Table-20-of-Precis-des-lecons-darchitecture-donnes-a-IEcole_ fig1_28675372

Figure 3.2 Reinterpretation of performance versus time graph, Architecture and Waste: A (Re)planned Obsolescence

Source: Georgoulias, Andreas, Hanif Kara and Leire Asensio-Villoria. Architecture and Waste: A (Re)planned Obsolescence (Barcelona: Actar, 2017).

Figure 3.3 Building material life expectancy, Project Japan: Metabolism Talks

Source: Cairns, Stephen, and Jane M. Jacobs. Buildings Must Die: A Perverse View of Architecture (Cambridge: The MIT Press, 2014)

Figure 3.4 Uncompleted works of Metabolism movement

A. "Tower-shaped Community", Kiyonori Kitutake, 1958

B. "Incubation Process", Arata Isozaki, 1962

C. "Wall City", Kisho Kurokawa, 1959

Source: Bell, Jonathan. "Project Japan: Rem Koolhaas and Hans Ulrich Obrist." Wallpaper, August 21, 2015. Accessed June 10, 2018. https://www.wallpaper.com/ architecture/project-japan-rem-koolhaas-and-hans-ulrich-obrist

Figure $3.5 \quad$ Future projection of architectural typologies

Source: Ishan Patel

Figure 3.6 Proposed obsolescence cycle

Source: Ishan Patel

Figure 4.1 A collection of science fiction novels

A. New York 2140, Kim Stanley Robinson 
Source: n.d. "New York 2140." Amazon. Accessed June 10, 2018. https://www.amazon. com/New-York-2140-Stanley-Robinson-ebook/dp/B01KT7YTO6

B. Ready Player One, Ernest Cline

Source: $\quad$ n.d. "Ready Player One." Amazon. Accessed June 10, 2018. https://www.amazon. co.uk/Ready-Player-One-Ernest-Cline/dp/0099560437

C. Millennium People, J.G. Ballard

Source: $\quad$ n.d. "Millennium People." Good Reads. Accessed June 10, 2018. https://www. goodreads.com/book/show/12885844-millennium-people

D. Revoir Paris l'Exposition, Schuiten et Peeters

Source: $\quad$ n.d. "Revoir Paris L'Exposition." Librairie du Moniteur. Accessed June 10, 2018 http://www.librairiedumoniteur.com/revoir-paris-I-exposition-schuitenpeeters,fr,4,9782203090231.cfm

E. The Naked World, Eli K. P. William

Source: $\quad$ n.d. "The Naked World." Amazon. Accessed June 10, 2018 https://www.amazon. ca/Naked-World-Book-Jubilee-Cycle/dp/1940456525

F. High-rise, J. G. Ballard

Source: $\quad$ n.d. "High-rise." Good Reads. Accessed June 10, 2018 https://www.goodreads. com/book/show/12331767-high-rise

G. Central Station, Lavie Tidhar

Source: $\quad$ Peper, Eliot. "Central Station." Chicago Review of Books, October 26, 2016. Accessed June 10, 2018. https://chireviewofbooks.com/2016/10/26/in-central-stationlavie-tidhar-imagines-tel-aviv-in-the-far-future/

H. Company Town, Madeline Ashby

Source: $\quad$ Sugah, Jamie. "The Characters Completely Made Company Town." The Geekiary, June 2, 2016. Accessed June 10, 2018. http://thegeekiary.com/companytown-review/34688

I. Ninth City Burning, J. Patrick Black

Source: Black, J. Patrick. "Behind the Book: Ninth City Burning." Riveted, March 2, 2017. 
Accessed June 10, 2018. https://rivetedlit.com/2017/03/02/behind-the-bookninth-city-burning/

J. The Windup Girl, Paolo Bacigalupi

Source: $\quad$ n.d. "The Windup Girl." Good Reads. Accessed June 10, 2018. https://www. goodreads.com/book/show/6597651-the-windup-girl

K. Cash Crash Jubilee, Eli K. William

Source: $\quad$ n.d. "Cash Crash Jubilee." Amazon. Accessed June 10, 2018. https://www.amazon. ca/Cash-Crash-Jubilee-Book-Cycle/dp/1940456622

L. Kingdom Come, J. G. Ballard

Source: $\quad$ McGarth, Rick. "It's An, Ad, Ad, Ad World." Ballardian, July 25, 2007. Accessed June 10, 2018. http://www.ballardian.com/its-an-ad-ad-ad-world

Figure 4.2 A collection of works completed by Archigram

A. "The Plug-in City", Peter Cook, 1964

Source: Özakat, Emre. "The Flowers Children of Architects." Designblog, October 25, 2016. Accessed June 10, 2018. http://designblog.rietveldacademie. $\mathrm{nl} /$ ?tag= archigram

B. "The Walking City", Rob Herron, 1964

Source: Janku, Eranda. "Guest Post: Archigram's "Walking City" Concept." Walking the City. March 31, 2011. Accessed June 27, 2018. http://walkingthecityupolis.blogspot. com/2011/03/guest-post-archigrams-walking-city.html

C. "Computer City", Dennis Crompton, 1964

Source: $\quad$ n.d. "Speculative Urbanism." Geo Futures, June 10, 2013. Accessed May 25, 2018. http://geofutures.arch.rpi.edu/2013/06/urban-futurism-precedent-research/

Figure 4.3 Thomas More's Utopia, 1516

Source: $\quad$ n.d. "Thomas More's Utopia." British Library. Accessed June 25, 2018. http://www. bl.uk/learning/timeline/large126618.html

Figure 4.4 Pruitt-Igoe, Minoru Yamasaki, 1954

Source: $\quad$ Fiederer, Luke. "AD Classics: Pruitt-Igoe Housing Prooject/ Minoru Yamasaki." 
ArchDaily, May 15, 2017. Accessed June 19, 2018. https://www.archdaily. com/870685/ad-classics-pruitt-igoe-housing-project-minoru-yamasaki-stlouis-usa-modernism

Figure 4.5 Ponte City, Manfred Hermer, 1975

Source: $\quad$ Brown, Ryan Lenora. "South Africa's Tower of Dreams." Slate, February 6, 2015. Accessed June 19, 2018. http://www.slate.com/articles/news_and_politics/ roads/2015/02/ponte_city_in_south_africa_s_tallest_apartment_building_was_ built.html

Figure 4.6 A collection of dystopian works in media and text

A. "Blade Runner", 1982

Source: Adcroft, Katharine, Megan Munsie, and Peta Clancy. "The science and fiction behind Blade Runner." Phys.org, August 31, 2015. Accessed July 2, 2018. https://phys.org/news/2015-08-science-fiction-blade-runner.html

B. "The Fifth Element", 1997

Source: Muir, John K. "Sci-Fi Cityscapes \#4: The Fifth Element (1997); circa the 23rd Century." John Kenneth Muir's Reflection on Cult Movies and Classic TV, January 19, 2013. Accessed July 3, 2018. http://reflectionsonfilmandtelevision. blogspot.com/2013/01/sci-fi-cityscapes-4-fifth-element-1997.html

C. "Valerian and the City of a Thousand Planets", 2017

Source: $\quad$ Sciretta, Peter. "Interview: Luc Besson Reveals The Secrets Behind That Stunning 'Valerian' Trailer." Slash Film, November 10, 2016. Accessed July 3, 2018. https://www.slashfilm.com/luc-besson-valerian-interview/

Figure 4.7 Competition entries for Fairy Tales 2017: Architecture Storytelling

A. "Last Day", Mykhailo Ponomarenko

B. "The City Walkers", Terrence Hector

Source: Howarth, Dan. "Sci-fi landscape illustrations accompany winning story in architectural fairytale competition." Dezeen, February 9, 2017. Accessed July 3, 2018. https://www.dezeen.com/2017/02/09/sci-fi-landscape-illustrations- 
accompany-mykhailo-ponomarenko-winning-story-architectural-fairy-talecompetition-blank-space/

Figure 5.1

Source:

Figure 5.2

Source:

Figure 5.3

Source:

Figure 5.4

Source:

Figure 5.5

Source:

Figure 5.6

Source:

Figure 5.7

Source:

Figure 5.8

Source:

Figure 5.9

Source:

Figure 5.10

Source:
Diagrammatic interpretation of "The Concentration City"

Ishan Patel

Physical model of "The Concentration City" interpretation

Ishan Patel

Physical model interpretation of "Billennium"

Ishan Patel

Physical model of "Billennium" interpretation

Ishan Patel

Physical model interpretation of High-rise

Ishan Patel

Physical model of High-rise interpretation

Ishan Patel

Physical model interpretation of Kingdom Come

Ishan Patel

Physical model of Kingdom Come interpretation

Ishan Patel

Exterior façade

Berger, Chris. "America's First Shopping Mall is Now Stuffed with Micro Homes."

Curbed, August 29, 2014. Accessed November 10, 2017. https://www.curbed. com/2014/8/29/10054364/americas-first-shopping-mall-is-now-stuffedwith-micro-homes

View from retail level

n.d. "Retail Level." Downtown Providence. Accessed November 10, 2017. http:// downtownprovidence.com/wp-content/uploads/2013/12/DSCN1767.jpg 
Figure $5.11 \quad$ Interior mezzanine view

Figure 5.12 Interior unit view

Source: $\quad$ n.d. "Grown Smart Rhode Island Honors the Micro Lofts at The Arcade Providence." Northeast Collaborative Architects. Accessed November 10, 2017. http:// ncarchitects.com/nca-pinboard/grow-smart-rhode-island-honors-the-microlofts-at-the-arcade-providence/

Figure 5.13 Third level floor plan

Source:

n.d. "Third Floor Plan." The Arcade Providence. Accessed November 10, 2017. http://arcadeprovidence.com/micro-lofts/third-floor-plan/

Figure 5.14 Kowloon Walled City exterior

Figure 5.15 Kowloon Walled City aerial view

Source: $\quad$ Chan, Wilfred. "Kowloon Walled City: In Hong Kong, it was the densest place on Earth." CNN Travel, January 2, 2015. Accessed September 21, 2017. https:// www.cnn.com/travel/article/kowloon-walled-city/index.html?gallery=0

Figure 5.16 Ruins left behind from Kowloon Walled City removal

Source:

n.d. "Kowloon Walled City." Tes Teach. Accessed September 21, 2017. https://www. tes.com/lessons/Tlymv2btYIHmoA/hk-heritage

Figure 5.17 Terrance view overlooking the City's border

Source:

Chan, Wilfred. "Kowloon Walled City: In Hong Kong, it was the densest place on Earth."

Figure 5.18 Diagrammatic cross section of the City

Source: $\quad$ n.d. "Detailed Cross-section of the Kowloon Walled City Cretaed by Japanese Researchers." Spoon \& Tamago, October 28, 2014. Accessed September 21, 2017. http://www.spoon-tamago.com/2014/10/28/detailed-cross-section-ofthe-kowloon-walled-city-created-by-japanese-researchers/

Figure 5.19 Songpa Microhousing exterior

Figure 5.20 View looking above up from the mezzanine

Figure $5.21 \quad$ Bridges connecting various programs 
Source: Kwok, Natasha. "SsD architecture uses adaptable unit blocks in songpa micro housing in seoul." Design Boom, December 4, 2015. Accessed February 4, 2018. https://www.designboom.com/architecture/ssd-architecture-songpamicro-housing-seoul-korea-12-04-2015/

Figure 5.22 Second level floor plan

Figure 5.23 Songpa Microhousing section

Source: $\quad$ n.d. "Songpa Micro Housing/ SsD." ArchDaily, December 11, 2014. Accessed February 4, 2018. https://www.archdaily.com/576302/songpa-micro-housingssd

Figure 5.24 Common Ground exterior

Source:

n.d. "Common Ground/ URBANTAINER." ArchDaily, February 17, 2017. Accessed January 28, 2018. https://www.archdaily.com/805302/common-groundurbantainer

Figure 5.25 Common Grounds entrance

Figure 5.26 Roof shopping level

Figure 5.27 Indoor shopping view

Figure 5.28 Common Ground section

Source: $\quad$ n.d. "Common Ground/ URBANTAINER." ArchDaily, February 17, 2017. Accessed January 28, 2018. https://www.archdaily.com/805302/common-groundurbantainer

Figure 6.1

"The Suburban Labyrinth", Victor Gruen

Source:

Gruen, Victor. From Centers for the Urban Environment: Survival of the Cities (New York: Van Nostrand Reinhold Company Inc., 1973).

Figure 6.2 Trajan Market, Rome, 110

Source: $\quad$ Sennett, Richard. "Imperial Rome: Trajan's Market, interior of the aula." Flickr, September 3, 2009. Accessed February 12, 2018. https://www.flickr.com/ 
photos/richardsennett/4206781859/in/photostream/

Figure 6.3 Foire St. Germain, Paris, 1462

Source: $\quad$ n.d. "La foire Saint Germain." Histoires de Paris, January 28, 2017. Accessed February 12, 2018. https://www.histoires-de-paris.fr/foire-saint-germain/

Figure 6.4 Royal Exchange, London, 1566-68

Source: $\quad$ n.d. "Courtyard of the Royal Exchange." Old Book Illustrations. Accessed February 12, 2018. https://www.oldbookillustrations.com/illustrations/london-royalexchange/

Figure 6.5 The First Arcade, Les Galerie de Bois, Paris, 1786

Source:

n.d. "Passages Couverts et Galeris de Paris." Paris Révolutionnaire, June 28, 2013. Accessed February 12, 2018. http://www.parisrevolutionnaire.com/spip. php?article192

Figure 6.6 Au Bon Marché, Paris, 1852

Source: n.d. "Le Bon Marché, premier grand magasin en France." Citeco. Accessed February 12, 2018. https://www.citeco.fr/10000-ans-histoire-economie/revolutionsindustrielles/le-bon-marche-premier-grand-magasin-en-france

Figure 6.7 "The Vicious Circle", Victor Gruen

Figure 6.8 "Multi-functional Centre", Victor Gruen

Source:

Gruen, Victor. From Centers for the Urban Environment: Survival of the Cities.

Figure 6.9 Southdale Mall, 1956

Source: Grahame, James. "The World's First Modern Shopping Mall." Retro Thing, December 19, 2008. Accessed January 12, 2018. http://www.retrothing. com/2008/12/the-worlds-firs.html

Figure 6.10 Shopping Timeline

Source: Ishan Patel

Figure 6.11 Power Centres and Enclosed Malls located within GTA

Source: Ishan Patel

Figure 6.12 Existing North elevation collage and program location 
Source: Ishan Patel

Figure 6.13 Existing South elevation collage and program location

Source: Ishan Patel

Figure 6.14 Existing East elevation collage and program location

Source: Ishan Patel

Figure 6.15 Existing West elevation collage and program location

Source: Ishan Patel

Figure 6.16 Eaton's main store, 1920

Source: $\quad$ n.d. "Christmas Shopping." Leslieville Historical Society. Accessed January 12, 2018. https://leslievillehistory.com/christmas-shopping/

Figure 6.17 Lobby of the Cineplex Eaton Centre, 1970

Source: $\quad$ Taylor, Doug. "Toronto's old Cineplex Eaton Centre Cinema." Historic Toronto, February 26, 2014. Accessed October 28, 2017. https://tayloronhistory. com/2014/02/26/torontos-old-movie-theatresthe-cineplex-eaton-centre/

Figure 6.18 Eaton Centre public space view 1

Source:

MyVideoMedial. "Toronto, Eaton Centre and the PATH- Canada HD Travel Channel." YouTube, June 1, 2013. Accessed October 28, 2017. https://www. youtube.com/watch?v=nuABkPh_YbU

Figure 6.19 Eaton Centre public space view 2, 1990s

Source: n.d. "The Eaton Centre Turns 35 Years Old." BlogTO. Accessed October 15, 2017. https://www.blogto.com/city/2012/02/the_eaton_centre_turns_35_years_old/

Figure 6.20 Previewing the Eaton's store design, 1975

Source: Bradburn, Jamie. "Histroricist: Opening the Eaton Centre." Torontoist, February 11, 2017. Accessed October 21, 2017. https://torontoist.com/2017/02/historicistopening-the-eaton-centre/

Figure 6.21 Site of Eaton Centre in Yonge-Dundas area, 1974

Source: Spremo, Boris. "Site of Eaton Centre in Yonge- Dundas area." Toronto Public Library. Accessed October 19, 2017. https://www.torontopubliclibrary.ca/ 
detail.jsp?Entt=RDMDC-TSPA_0109959F\&R=DC-TSPA_0109959F

Figure 6.22 View of central atria, 2017

Source: Ishan Patel

Figure 6.23 Stills from observation recordings

Source: Ishan Patel

Figure 6.24 Observation points' location

Source: Ishan Patel

Figure 6.25 Observation of charts from conducted study

Source: Ishan Patel

Figure 6.26 Pacific Mall, Toronto, Canada

Source: Ishan Patel

Figure 6.27 Times Square, Hong Kong

Source: $\quad$ Dewolf, Christopher. "Hong Kong is the most Shopping Mall-crazy city on Earth. Is that a bad thing?" Zolima CityMag, April 27, 2017. Accessed July 9, 2018. https://zolimacitymag.com/hong-kong-is-the-most-shopping-mall-crazycity-on-earth-is-that-a-bad-thing/

Figure 6.28 Burlington Arcade, Mayfair, London

Source: $\quad$ n.d. "Burlington Arcade." London Town. Accessed February 2, 2018. http://www. Iondontown.com/LondonInformation/Business/Burlington_Arcade/9572/

Figure 6.29 Galleria Vittorio Emanuele II, Milano, Italy

Source: $\quad$ Redazione. "Galleria Vittorio Emanuele II, asta super esclusiva per aggiudicarsi due locali: le cifre." Milano Today, October 30, 2017. Accessed February 1, 2018. http://www.milanotoday.it/cronaca/galleria-asta-locali.html

Figure 6.30 Passage St.Petersburg, Sankt-Peterburg, Russia

Source: $\quad$ n.d. "Impressionen St. Petersburg." Fernsuchtblog, June 5, 2015. Accessed February 1, 2018. https://fernsuchtblog.de/impressionen-st-petersburg/

Figure 6.31 Utopia, Pedestrians shopping close to Queens Station

Source: Ishan Patel 
Figure 6.32 Utopia, View from third level overlooking tenants' businesses and private residence spaces

Source: Ishan Patel

Figure 6.33

Dystopia, Pedestrians transitioning close to Queens Station

Source:

Ishan Patel

Figure 6.34

Dystopia, View from third level overlooking museum showrooms and stepped social space

Source: Ishan Patel

Figure 6.35 Census data graphs

Source: Ishan Patel

Figure 6.36 Near Future Toronto Summary

Source: Ishan Patel

Figure 6.37 Site study with proposed program

Source:

Ishan Patel

Figure 6.38

Interconnected residential typology exploration

Source:

Ishan Patel

Figure 6.39

Internal circulation core for the residential neighbourhoods

Source:

Ishan Patel

Figure 6.40

Transient shopping experience amongst different retail layout

Source:

Ishan Patel

Figure 6.41

Shopper circulation path throughout the exploration

Source:

Ishan Patel

Figure 6.42

Site massing exploration

Source:

Ishan Patel

Figure 6.43

Master plan tower programs

Source:

Ishan Patel

Figure 6.44

Master plan neighbourhood layout

Source:

Ishan Patel 
Figure 6.45 Master plan retail layout

Source: Ishan Patel

Figure 6.46 Existing massing

Source: Ishan Patel

Figure 6.47 Near future neighbourhood intervention

Source: Ishan Patel

Figure 6.48 New intervention coexisting along the existing façade

Source:

Ishan Patel

Figure 6.49

New ramped entry points

Source:

Ishan Patel

Figure 6.50

Elongated retail form housing the pop-up stores

Source:

Ishan Patel

Figure 6.51

Circulation alongside the new interventions

Source:

Ishan Patel

Figure 6.52

Neighbourhood block information

Source:

Ishan Patel

Figure 6.53

Unit type 1 layout

Source:

Ishan Patel

Figure 6.54

Unit type 2 layout

Source:

Ishan Patel

Figure 6.55

Unit type 3 layout

Source:

Ishan Patel

Figure 6.56

Unit type 4 layout

Source:

Ishan Patel

Figure 6.57

Unit type 5 layout

Source:

Ishan Patel

Figure 6.58

Unit type 6 layout

Source:

Ishan Patel 
Figure 6.59 Unit type 7 layout

Source: Ishan Patel

Figure 6.60 Unit type 8 layout

Source: Ishan Patel

Figure $6.61 \quad$ Unit type 9 layout

Source: Ishan Patel

Figure 6.62 Unit type 10 layout

Source: Ishan Patel

Figure 6.63 Block 4: Proposed level 1

Source: Ishan Patel

Figure 6.64 Block 4: Proposed level 1-1

Source: Ishan Patel

Figure 6.65 Block 4: Proposed level 2

Source: Ishan Patel

Figure 6.66 Block 4: Proposed level 3

Source: Ishan Patel

Figure 6.67 Block 4: Proposed level 4

Source: Ishan Patel

Figure 6.68 Block 4: Proposed level 5

Source:

Ishan Patel

Figure 6.69

Block 4: Proposed level 6

Source:

Ishan Patel

Figure 6.70

Block 4: Proposed level 7

Source:

Ishan Patel

Figure 6.71

Block 4: Proposed rooftop level

Source:

Ishan Patel

Figure 6.72

Block 3: Proposed level 1

$=$ Source:

Ishan Patel 
Figure 6.73

Source:

Figure 6.74

Source:

Figure 6.75

Source:

Figure 6.76

Source:

Figure 6.77

Source:

Figure 6.78

Source:

Figure 6.79

Source:

Figure 6.80

Source:

Figure 6.81

Source:

Figure 6.82

Source:

Figure 6.83

Source:

Figure 6.84

Source:

Figure 6.85

Source:

Figure 6.86

Source:
Block 3: Proposed level 1-1

Ishan Patel

Block 3: Proposed level 2

Ishan Patel

Block 3: Proposed level 3

Ishan Patel

Block 3: Proposed level 4

Ishan Patel

Block 3: Proposed level 5

Ishan Patel

Block 3: Proposed level 6

Ishan Patel

Block 3: Proposed level 7

Ishan Patel

Block 3: Proposed level 8

Ishan Patel

Block 3: Proposed rooftop level

Ishan Patel

Block 4: West street elevation

Ishan Patel

Block 4: East street elevation

Ishan Patel

Block 4: East elevation beyond the existing façade

Ishan Patel

Block 4: North street elevation

Ishan Patel

Block 4: South street elevation

Ishan Patel 
Figure 6.87

Source:

Figure 6.88

Source:

Figure 6.89

Source:

Figure 6.90

Source:

Figure 6.91

Source:

Figure 6.92

Source:

Figure 6.93

Source:

Figure 6.94

Source:

Figure 6.95

Source:

Figure 6.96

Source:

Figure 6.97

Source:

Figure 6.98

Source:

Figure 6.99

Source:

Figure 6.100

$\geq$ Source:
Block 4: Axonometric South-East

Ishan Patel

Block 4: Axonometric North-West

Ishan Patel

Block 4: Section A-A

Ishan Patel

Block 4: Section B-B

Ishan Patel

Block4: Social Program Axonometric

Ishan Patel

Available shipping container options

Ishan Patel

Pop-up circulation core

Ishan Patel

Pop-up food vendor option 1

Ishan Patel

Pop-up food vendor option 2

Ishan Patel

Pop-up medium size shop option 1

Ishan Patel

Pop-up medium size shop option 2

Ishan Patel

Pop-up large size shop option 1

Ishan Patel

Pop-up large size shop option 2

Ishan Patel

Retail Block 3-4: Proposed level 1

Ishan Patel 
Figure 6.101 Retail Block 3-4: Proposed level 2

Source: Ishan Patel

Figure 6.102 Retail Block 3-4: Proposed level 3

Source: Ishan Patel

Figure 6.103 Retail Block 3-4: Proposed level 4

Source: Ishan Patel

Figure 6.104 Retail Block 3-4: Proposed level 5

Source: Ishan Patel

Figure 6.105 Retail Block 3-4 South elevation

Source: Ishan Patel

Figure 6.106 Retail Block 3-4 North elevation

Source: Ishan Patel

Figure 6.107 Retail Block 3-4 West elevation

Source: Ishan Patel

Figure 6.108 Retail Block 3-4 East elevation

Source: Ishan Patel

Figure 6.109 Retail Block 3-4 Section C-C

Source: Ishan Patel

Figure 6.110 Retail Block 3-4 Section D-D

Source: Ishan Patel

Figure 6.111 Retail Block 3-4 Exploded Axonometric

Source: Ishan Patel

Figure 6.112 Retail Block 3-4 PATH Level Axonometric

Source: Ishan Patel

Figure 6.113 View 1 of Block 4 Micro apartment neighbourhood across Yonge Street

Source: Ishan Patel

Figure 6.114 Block 4 South Entry

Source: Ishan Patel 
Figure 6.115 Block 4 North Entry, Shuter Street

Source: Ishan Patel

Figure 6.116 View 2 of Block 4 Micro apartment neighbourhood across Yonge Street

Source: Ishan Patel

Figure 6.117 Approach to Block 4 Micro apartment neighbourhood on Yonge Street

Source: Ishan Patel

Figure 6.118 Block 4 Private tenant space between existing and new façade

Source: Ishan Patel

Figure 6.119 Interior Atrium

Source: Ishan Patel

Figure 6.120 Block 4 Rooftop

Source: Ishan Patel

Figure 6.121 Block 3-4 Retail South Entrance

Source: Ishan Patel

Figure 6.122 Block 3-4 Retail Level 2 View

Source: Ishan Patel

Figure 6.123 Block3-4 Retail Level 3 View

Source: Ishan Patel

Figure 6.124 Block 3-4 Retail PATH View 1

Source: Ishan Patel

Figure 6.125 Block 3-4 Retail PATH View 2

Source: Ishan Patel

Figure 6.126 Residential typology exploration model

Source: Ishan Patel

Figure 6.127 Retail typology exploration model

Source: Ishan Patel

Figure 6.128 Site Model

> Source: Ishan Patel 
Figure 7.1 Collage of Speculating Typologies: Adapting Retail

Source: Ishan Patel

Figure 8.1 Program exploration with existing structure

Source: Ishan Patel

Figure 8.2 Conceptual exploration of flexible structure

Source: Ishan Patel

Figure 8.3 Existing level 1

Source: Ishan Patel

Figure 8.4 Existing level 2

Source: Ishan Patel

Figure 8.5 Existing level 3

Source: Ishan Patel

Figure 8.6 Existing level 4

Source: Ishan Patel

Figure 8.7 1 Dundas Street West: Typical floor plan

Source: Ishan Patel

Figure 8.8 20 Queen Street West: Typical floor plan

Source: Ishan Patel

Figure 8.9 250 Yonge Street: Typical floor plan

Source: Ishan Patel

Figure 8.10 Earlier master plan layout

Source: Ishan Patel

Figure 8.11 Diagrammatic interpretation of "The Fun Palace"

Source: Ishan Patel

Figure 8.12 Physical model of "The Fun Palace" interpretation Source: Ishan Patel 
Figure 8.13 Physical model interpretation of "Clusters in the air"

Source: Ishan Patel

Figure 8.14 Physical model of "Clusters in the air" interpretation

Source: Ishan Patel

Figure 8.15 Markhthal Rotterdam exterior

Source: $\quad$ n.d. "Markhthal Rotterdam/ MVRDV." ArchDaily, October 8, 2014. Accessed October 25, 2017. https://www.archdaily.com/553933/markthal-rotterdammvrdv

Figure 8.16 View of the second market level

Source: n.d. "Markhthal Rotterdam." Greensparrow. Accessed October 25, 2017. http:// www.greensparrow.nl/2014/10/markthal/

Figure 8.17 Aerial view between the entrance and retailer

Source: $\quad$ n.d. "Markhthal Rotterdam." Hufton + Crow. Accessed October 25, 2017. http:// www.huftonandcrow.com/projects/gallery/markthal-rotterdam/

Figure 8.18 Residential balconies

Source: $\quad$ Fredrickson, Trent. "MVRDV- designed Markthal Housing + Market Hall opens in Rotterdam." Design Boom, October 1, 2014. Accessed October 25, 2017. https://www.designboom.com/architecture/mvrdv-markthal-rotterdamopens-10-01-2014/

Figure 8.19 Markhthal Rotterdamn section

Source: $\quad$ n.d. "Market-Hall Rotterdam." Pinterest. Accessed October 25, 2017. https://www. pinterest.ca/pin/96968198205145571/

Figure 8.20 Nagakin Capsule Tower exterior

Source: Lisa, Ana. "Now you can rent a room in Japan's Nakagin Capsule Tower via Airbnb." Inhabitat, August 8, 2015. Accessed September 20, 2017. https:// inhabitat.com/now-you-can-rent-a-room-in-japans-nakagin-capsule-towervia-airbnb/kisho-kurokawa-modular-nakagin-capsule-tower-at-airbnb-4/

Figure $8.21 \quad$ Nagakin Capsule Tower construction (top left) 
Source: $\quad$ n.d. "Nakagin Capsule Tower (1972) by Kisho Kurokawa." Urban Trop Urbain. Accessed September 19, 2017. http://www.urbain-trop-urbain.net/ post/30836486168/machitsukuri-nakagin-capsule-tower-1972-by

Figure 8.22 View from one of the residential units

Source: n.d. "Nakagin Capsule Tower." Medium, October 10, 2017. Accessed September 19, 2017. https://medium.com/@marchio.bricchio/nakagin-capsule-towerc070d36a307a

Figure 8.23 Unit layout around the central circulation core

Source:

n.d. "Nakagin Capsule Tower, Tokyo 1969-72." Metalocus, December 10, 2011. Accessed September 19, 2017. https://www.metalocus.es/en/news/nakagincapsule-tower-tokyo-1969-72

Figure 8.24 Axonometric of micro apartment

Source: $\quad$ n.d. "Nakagin Capsule Tower to undergo earthquake-resistant inspection." Japan Property Central, February 16, 2016. Accessed September 20, 2017. http:// japanpropertycentral.com/2016/02/nakagin-capsule-tower-to-undergoearthquake-resistant-inspection/

Figure 8.25 Existing Structure of Eaton Centre

Source: Ishan Patel

Figure 8.26 Sectional Exploration Drawing

Source: Ishan Patel

Figure 8.27A Program Exploration Drawing

Source: Ishan Patel

Figure 8.27B Program Exploration Drawing

Source: Ishan Patel

Figure 8.28 Earlier retail form exploration

Source: Ishan Patel 


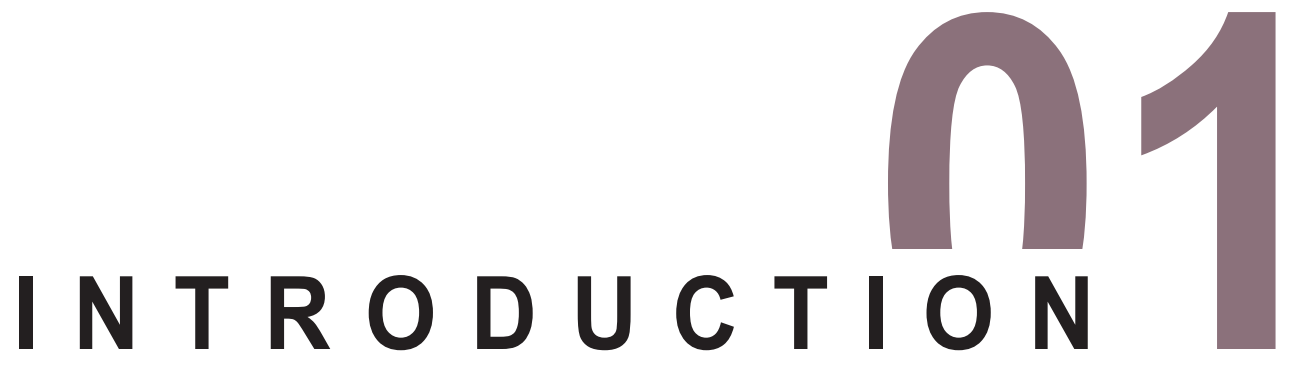

The need to create an efficient commercial and residential program drives the current built environment in hopes to support the accelerated culture and changes in occupancy. This program is created either through new construction or improvement of the existing construction, both of which are driven by the city and population growth. At the same time, many of our existing buildings are considered obsolete.

What makes a recent building, for example, a twentyyear-old structure, obsolete? Is it the appearance or the program? Some spaces are labeled uninviting, unpleasant, or even useless depending on how the program functions. Human needs are unpredictable and the architectural solutions proposed to serve their physical realm are short term, hence the programs become obsolete earlier on than the accounted life span of the built environment itself.

The effects of growth and change on the urban setting can be observed clearly. A small quaint coffee shop, once inviting to its neighbours, is now a large triple-storey café that buzzes with the city dwellers. A mid-rise structure, once a defining element at a major intersection, is replaced by a glazed twenty-storey office tower. Railway tracks are expanded to accommodate the incoming suburban dwellers and, in reaction the railway station is adapted and made larger to accommodate these dwellers. In one form or another, the existing construction is constantly transformed or replaced with an outlook on the future businesses and users.

Many types of jobs have also succumbed to new lifestyles brought about by technological changes. During the twentieth century we have seen the end of human computers, milkmen, ice cutters, and lamp lighters to name just a few. In addition, due to the progress being made in the 21st century, particularly in the digital realm, items including public pay phones, dial-up internet, CDs, and classified advertisements are now things of the past. Just like jobs and commodities, some building types will also become obsolete. For example, services provided by post offices and banks are slowly becoming obsolete due to a rise in automated systems. The determination of when a structural type will become obsolete is difficult, however, the way we handle its remains is something we can control. Such investigations are useful in order to understand the issues in dealing with purpose-built, relatively inflexible structures. They need to be observed before they become obsolete, in order to understand and resolve the circumstances that may be implicated with its overall usage in the future.

There are some programs essential to inhabitants' lives, and as a result, a few types of architecture are adapted by necessity, to accommodate changes in technology and 
lifestyle. Hospitals are constantly remodeled to provide optimum comfort and care according to latest trends and technologies. Museums transform according to exhibits to display works of both past and present, where, occasionally, new additions are constructed for space or new amenities. Schools continue to improve their educational model by allowing access to new equipment and remodeled rooms to instill students with skillsets necessary for their future. These architectural types are shaped by human input and depend on the daily standards and its relations with technology, the program requires constant care to avoid underserving its users; the physical forms that support these programs will therefore continue to transform in shape and size. Some other building types, however, have programs that either disappear, transform, or are increasingly becoming virtual.

The process of obsolescence can be defined differently based on the user and the subject in question. The word originally relates to the Latin word obsolèscere, meaning to fall into disuse, and to understand its negative foundation is to study its remains and alternative methods that work towards prolonging its lifespan. Alternatively, the disuse can also be understood by experimenting and purposely turning a program obsolete, which in reaction would permit control over a speculative design process that targets a specific program's future viability.
This research investigates the role of building's obsolescence in a post-industrial society set in an urban environment. It uses shopping centres as a central typology to design programs necessary to sustain inhabitants of the city who are living in the aftermath of mass production and the automation of numerous jobs. Postobsolescence adapts the elements necessary to create an enclosed community within a densifying urban grid, an urban village. The inhabitants in this scenario become key players in its transformation after the construction in order to continuously monitor and maintain its viability. This includes their personal businesses, growth of greenery, circulating visitors, use of public spaces, and security. Flexibility and social input are closely tied in this exploration, and work constantly to prolong the building's life span before becoming obsolete yet again. In addition, an opposite scenario, where the role of shopping centres has completely become obsolete, is explored to study the extreme results this typology may face. 
Chapter Three, Obsolescence, discusses the inevitability of all structures becoming obsolete. Obsolescence is not a new idea. It is part of the discourse dedicated to reinventing the services and goods provided to a large group of people. For example, every year there is the release of smartphones boasting about new capabilities, however its battery, framework, and apps have the tendency to malfunction due to its limited lifespan. Replacements, upgrades, and disposal are all part of consumer society, and are a result of manufacturers that intentionally shorten the product's lifespan to increase consumer demand. There is no escaping this state, but an attempt to mitigate it can be made.

In architecture, a number of tactics, including adaptive reuse and restoration, are used to delay built obsolescence by implementing a new program that is more viable at that moment in time. Another tactic is, constructing a structure that is always in motion, reacting to internal and external changes, attempting to slow the inevitability of becoming obsolete. The notion itself is intertwined with time; the more progress we make to achieve a technologically driven society, the faster we begin to detach from the built environment. Hypothetically, work and its tasks can be obsolete if physical interaction did not play an integral role in our lifestyle, especially if machines are able to complete the same work to near perfection. The same can be said about architecture and the possibility of it becoming self-sustained to automatically support any form of expansion and efficiently run its core. This stage of urban development, however, would leave the inhabitants in disarray; hence the social inputs are necessary in the construction of the physical environment.

Chapter Four, Near Future, explores the relationship between written works and the physical realm. The science fiction explored in this research postulates accelerated cultural changes due to both technological and scientific advancements. This speculative literature and cinematography expands on the potential to transform the future, for better or for worse. In the case of science fiction, the city's design plays an integral role in the stories, and gives the reader a positive or a negative outlook for comparison with existing conditions. It is, however, optimistic to dream of a better future for all when the probability of lives becoming worse in the near future is higher based on the contemporary changes in the daily lifestyle. The chapter will discuss both utopian and dystopian aspects of science fiction to further understand the underlying principles that guide the speculative scenarios. The ultimate goal of this chapter is not to research the innovations made within each story, but rather to discuss the human and architectural conditions that arise from both obstacles and opportunities.

Chapter Five, Design Research, explores the visions 
discussed in science fiction writings and existing architectural forms in order to better understand the plausibility and transformative process of speculative structures that can actively be used. Preservation of cultural values through built form has been a subject of discussion for a long period of time as a result of designers and historians valuing the history of the city. However, the discussion to create space that can either overcome or accept the inevitable condition of obsolescence has been examined since before the Modern movement. The commentary throughout these explorations reinterprets the discussed designs, evaluating their effectiveness as methods to prolong a building's usage according to newer envisioned living standards. This process closely parallels the beginning of any architectural work, where a theoretical idea is synthesized into documents that support the physical vision. In addition, by analyzing the implications of futurist visions in science fiction as a series of drawings and models alongside existing precedents, the difficulties facing the future architectural typologies may be revealed.

The final chapter, Chapter Six, synthesizes the research as a community-centric proposal in a densified urban core founded on speculations of how a designer should approach planning for the future. It can be speculated that because of the advancements made in technology and shortage of space, the need for human interaction to accomplish daily tasks will be eased in the distant future, and in reaction would place programs like retail and residential in a vulnerable state. The architectural form that emerged is a result of mitigating eventual obsolescence in the urban shopping mall typology, which is adapted and overlaid with multiple neighbourhoods and a new retail program to prolong the structural lifespan. 


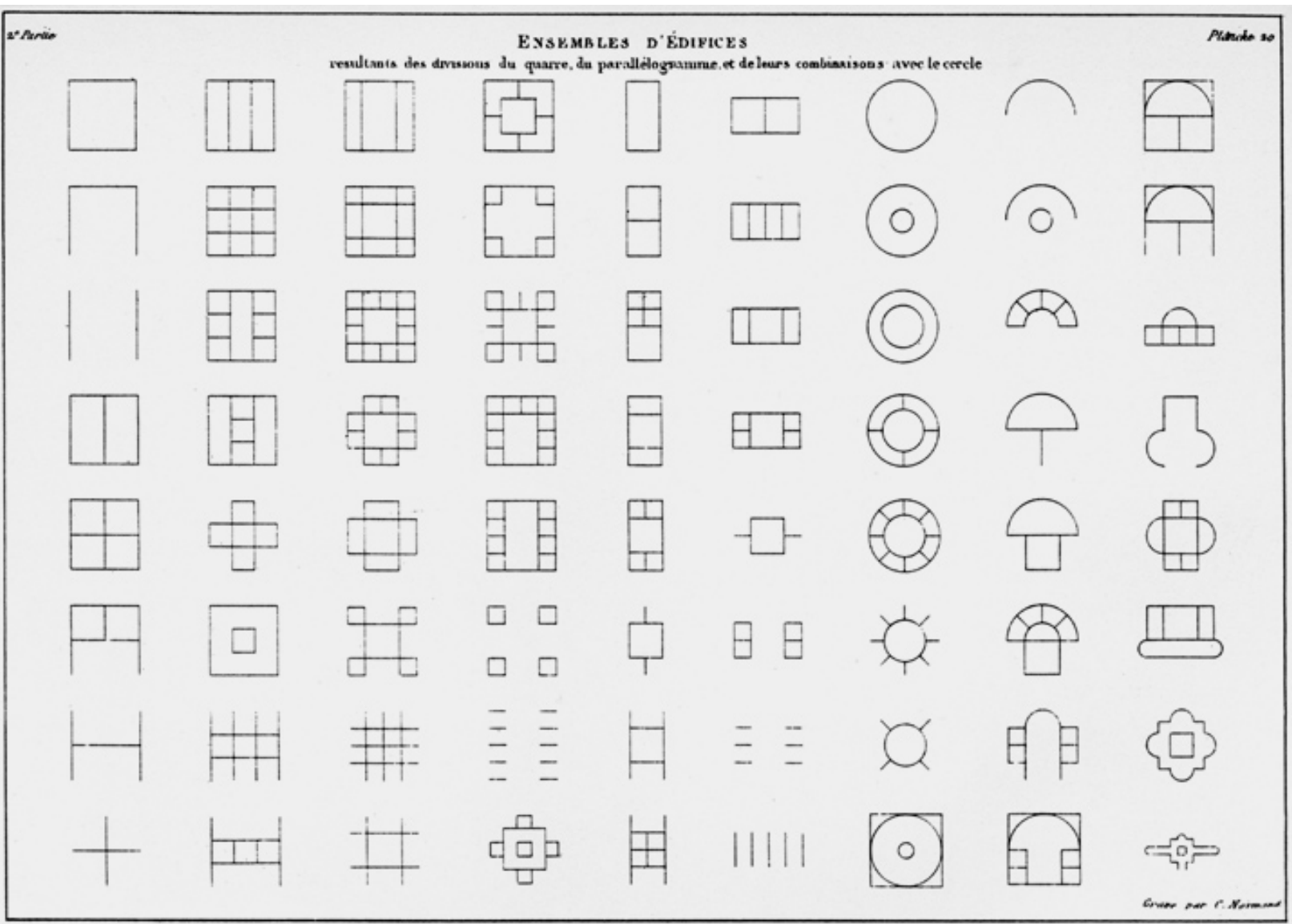

"You never change something by fighting the existing reality. To change something, build a new model that makes the existing model obsolete."

- Buckminster Fuller 


\subsection{OBSOLESCENCE}

\subsection{TURNING OBSOLETE}

Obsolescence is defined as a loss in utility or value of property that results over time from intrinsic limitations or external circumstances. It is engaged with the change of functions over time, and this relationship extends beyond designers' intentions and individuals' experience of place. ${ }^{1}$ Architecture, in this case, is viable dependent upon its usefulness and quality of form; it is practical so long as it is able to serve the original program. What is labelled obsolete, however, is dependent upon who the users are and their needs. Technology has changed the way a user experiences and receives information, making old methods obsolete -online platform replacing paper delivery, for example. In addition, because of the technology has become an integral part of the public life, the living standards that define us have altered over time as an achievable possibility for all users.

Fig.3.1 J.N.L. Durand, Table 20 of Précis des leçons d'architecture donnés à l'École polytechnique, 1802/5

J. N. L. Durand attempts to standardise construction by proposing a set of rules that define the basic elements of various structures, which would result in reduced costs and accelerated production.

The physical space, in this scenario, is now in competition with the digital world that has the potential to outlive the built forms and provide the same program that was once contained in a designed space. As such, the rate at which technology advances in comparison to the twentieth century is now correlated with the built context and its future. Surely, the events leading up to obsolescence in architecture are an amalgamation of various occurrences beside advances in technology, but technological developments are one area that is easily observed. Everything designed embodies a certain level of 


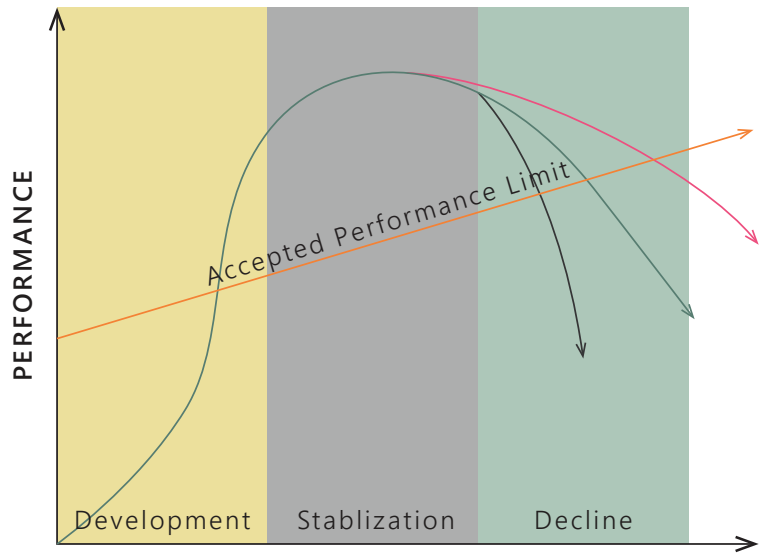

TIME

- Regular Lifespan

- Planned Obsolescence

- Selective Obsolescence

Fig.3.2 Reinterpretation of performance versus time graph, Architecture and Waste: A (Re)planned Obsolescence

An adapted version of material obsolescence graph to understand the inevitable obsolescence of built forms over time. imperfection and over time its users begins to take notice to its flaws. The changes in demographics, culture, market, personal aspirations, and other factors such as the fatigue of materials intrinsic to built form, are all, in one way or another, responsible for this imperfection of built form that leads to an obsolete state.

Built context now is ruled by the solutions that address immediate requirements rather than solutions for the near future. There are a set of guidelines that dictate the construction detail by detail, whether it is the insulation value, minimum room sizes, or the quality of materials. It is an attempt to create something adequate that will inherently be imperfect after construction due to future innovations and requirements.

The origins of obsolescence and its manifestation in the field of architecture is difficult to trace; it was not regarded as a universal problem until the twentieth century. ${ }^{2}$ Before this time, contentment and durability were the building norms, where the job was to produce and provide to users what was needed. However, after realizing the obsolete condition, the design process faced a challenge where the goal was not only to provide what was necessary, but also ensure its long-term functionality. The Metabolist movement, for example, celebrated technological advancements that envisioned designs of the cities of a temporal nature by making structure 
and inhabitable space both flexible and transformable. On the other hand, the preservationist movement was forged around resisting the demolition of buildings that were considered of significance to the history of shared history and architectural creativity itself. ${ }^{3}$ There was a time when evolving and maintaining urban fabric was a constant struggle, however the construction approach has become more conscious of embodied energy and the importance of preserving the existing buildings. However, our relationship with technology has opened up new possibilities that were hard to fundamentally envision before.

The relationship between obsolescence and city building are further noticed by its inhabitants. Large portions of people who reside in Toronto, for example, are not born here, nor do they remain there for a long periods of time due to cost limitations. As the city's population continues to increase, the architecture required to accommodate this influx of people constantly alters. Demolition is architecture's natural enemy. It is sometimes reasoned but other times unpredictable. Physical deterioration is natural after a period of time, for example at the end of a material's lifespan, whereas events like war and natural disasters are exceptional. When a building falls out of time incrementally or quietly, those who conduct their everyday lives in its vicinity are obliged to tolerate it. ${ }^{4}$ Even buildings with purpose sometimes fail and are abandoned when the functional capacity and space usage declines against the planned projection. Buildings that have inadequate space are also threatened. The built form become useless gradually, step-by-step, alongside the changing nature of work, commerce, education and the needs of the public realm. The form itself may stay in place, but it is the intended use that is out of time.

Obsolescence is not a failure in design, but rather an opportunity to implement improved strategies for architecture to accommodate change for the near future. For example, product design the 1960s showcased a form of expendability inherent in many products; a symbol of the modern age, a decade of disposability. ${ }^{5}$ Obsolescence was positively celebrated in a consumerist society through flexibility and dissociation. Similarly, in the field of architecture, obsolescence needs to be treated as a tool to speculate possible failures that impose improvements on existing programs to deal with near future situations.

This thesis considers obsolescence as a tool to create a roadmap to revive the functionality of decaying typologies for future viability. Through a speculative outlook on city development and use of space, characteristics of uselessness are explored in relation to typological character, user experience and habitation needs.

Cities have become sites of massive redevelopment, 
$3 \emptyset$ fluorescent tube

7 computer and copier

13 furniture and fixture

14 VIVD freezer and refrigerator

16 WIVID carpet

18 WVIVIVID kitchen unit

25 suspended ceiling

31 hydraulic passenger elevator

37 steel profiled sheet cladding

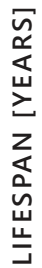

47

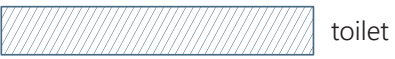

74

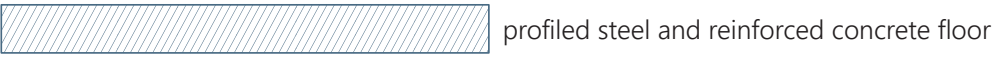

82

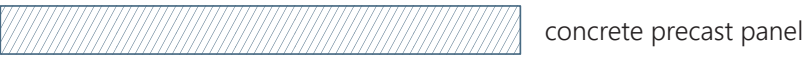

$75-100$

CONCRETE FRAME BUILDING

$75-100$

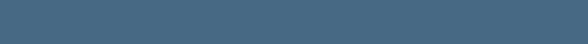

STEEL FRAME BUILDING

92 timber pitched roof

125

BRICK AND STONE BUILDING

133

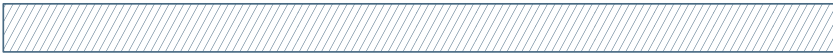

brick and stone wall

165

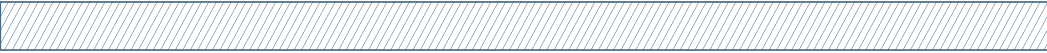
concrete block

170

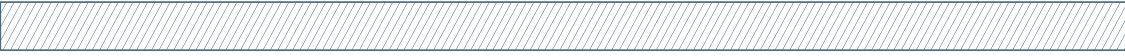
foundation 
targeting investors and users by constructing programs that are more attractive and produce higher profit in the consumer market. ${ }^{6}$ In this process of construction, demolition, absence, or other sorts of change, the users perceive their environment in a state of flux. I am arguing in this thesis that designing for the near future needs to be, flexible and opportunistic and does not need to demolish whole sectors to construct new ones.

\subsection{MEMENTO MORI}

By constructing with quality materials, the lifespan of built structures has improved, especially since the structures in the contemporary age can be restored seamlessly. However, there are conditions that eventually begin to advance the decomposition of the materials. Compounded with that are changes in the intended program. Memento mori, a term widely used in the field of arts, means to remember you must die. It holds meaning through signs and symbols that depict death through paintings in the form of a skull, hourglass, clock, rotting flowers, etc. In reference to architecture, the deteriorating materials, decreased public traffic, empty spaces, peeling paint, or poorly maintained programs function like memento mori, all of which are signs of a structure being inappropriate for contemporary and future use.

Buildings have characteristics that remind us of death and decay; the ways in which they are treated -vary considerably. For example, presently the ancient Roman ruins are in state of decay yet are constantly cared for in order to be continuously open as tourist destinations. Its memento mori is slowly being erased to function in a contemporary society by serving its inhabitants. On the other hand, project like Pruitt-Igoe, a high-rise public housing project meant to serve as low-income housing, was demolished when its character was transformed by crime and low maintenance. Both of the projects are vastly different in comparison, however, their initial intention was to serve the users appropriately to remain viable at the given time. Memento mori was a reflection of its use overtime either by external or internal forces. The attraction of this negative state in architecture is that it suggests the possibility for a better program, enabling the users to occupy a higher quality space than before. Decay and destruction of buildings is not a death sentence for architecture, but rather a path to a new way of existing in the city fabric. ${ }^{7}$

A great deal of work has been done to predict or avoid the memento mori that is present in the designed works. In the book Project Japan: Metabolism Talks by Rem Koolhaus and Han Ulrich Obrist, the life expectancies of typical building materials are compared against one another to broaden the perspective of the built context and its existence in the physical realm (figure 3.3). They 

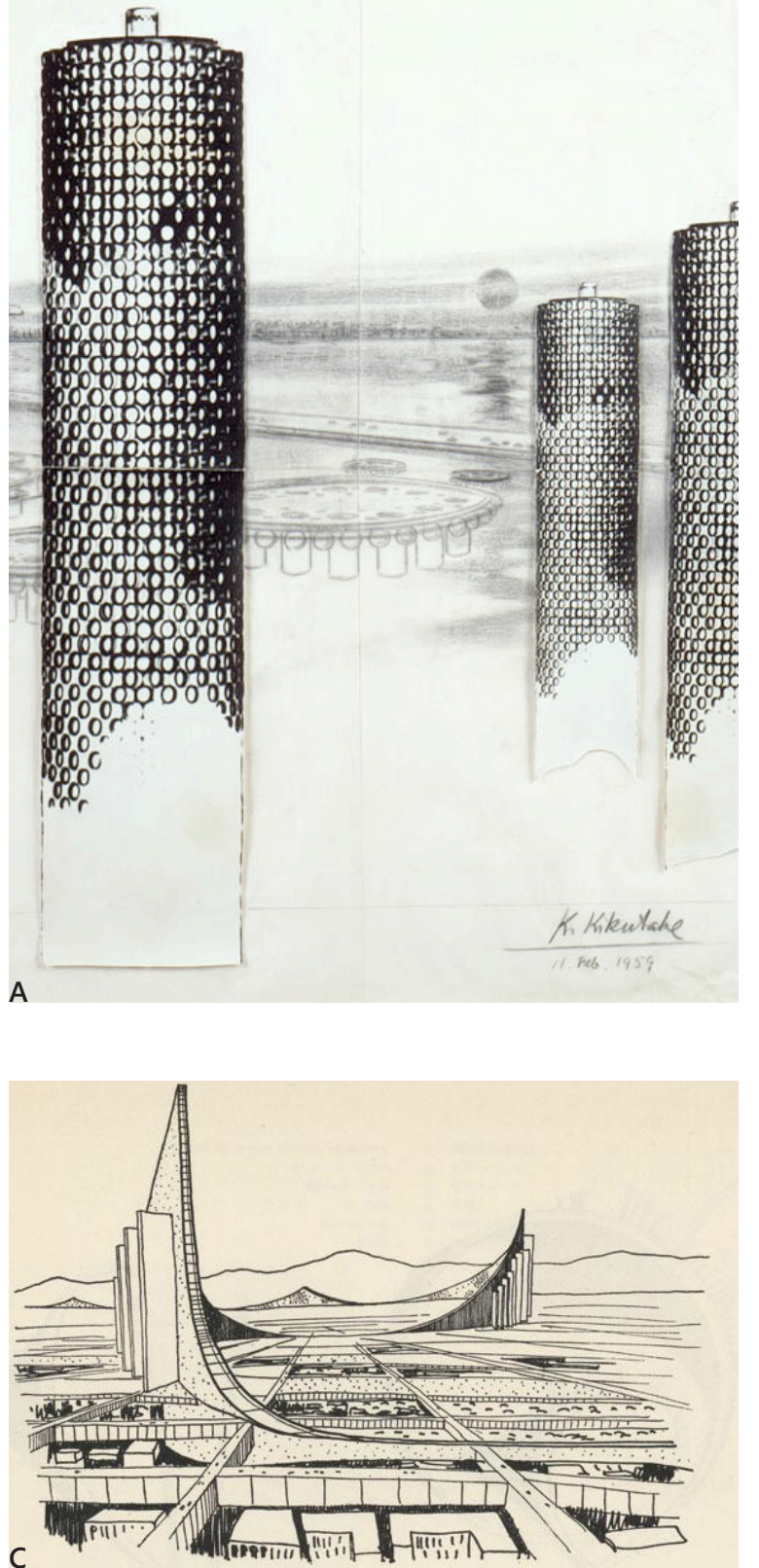

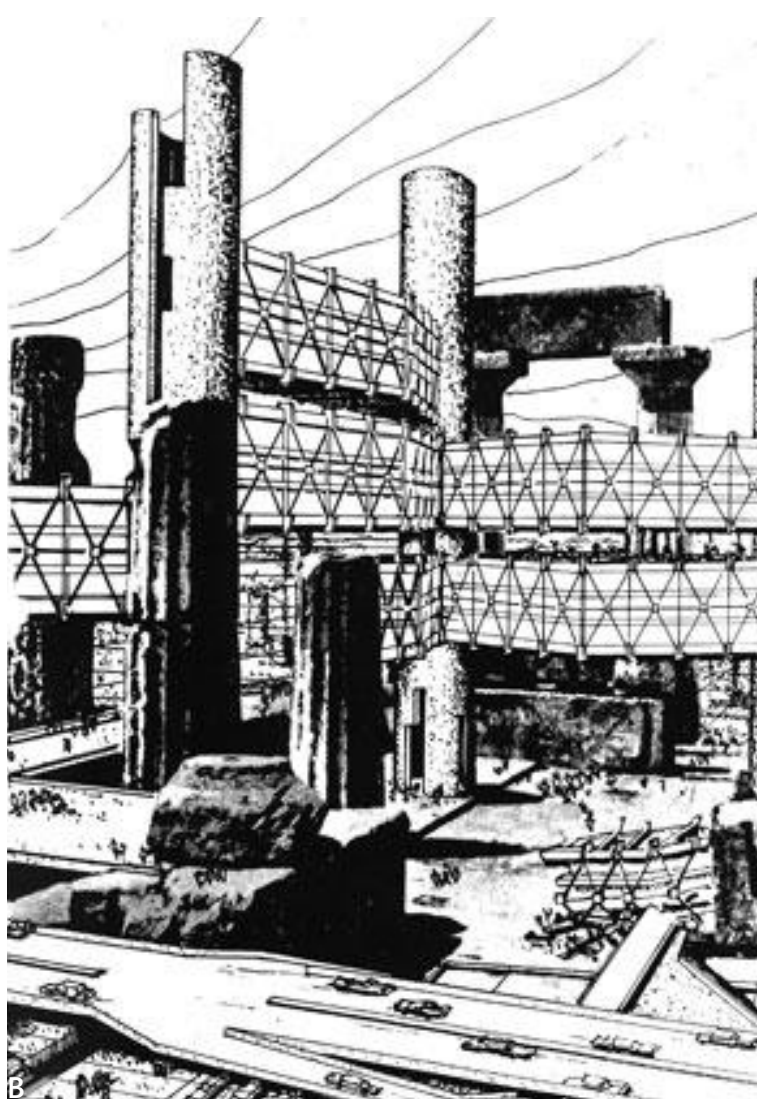

Fig.3.4 Uncompleted works of Metabolism movement
A. "Tower-shaped Community", Kiyonori Kitutake, 1958
B. "Incubation Process", Arata Isozaki, 1962
C. "Wall City", Kisho Kurokawa, 1959 
affirm that, "for a group of apprentice architects, artists, and designers, led by a visionary, the dire situation of [destroyed post war architecture] was not an obstacle but an inspiration to plan and think."8 Metabolism was perhaps the last Utopian movement in the field of architecture that celebrated growth and expansion of the city alongside its physical remains (figure 3.4). In addition, there are also cultural approaches that recreate the built form periodically to avoid any long-term damages. Traditional wood construction of the Shinto shrine was based on Buddhism's cyclical life view, an essential Japanese acceptance of evanescence, to avoid a range of catastrophes from earthquakes and fires to recent wartime bombing. ${ }^{9}$ The memento mori observed by the users is an animation of architectural hauntings, where its details, the decaying conditions and devaluing program, are scrutinized to allow the next construction to be better and not resonate its death.

\subsection{TYPOLOGICAL ISSUE}

During the eighteenth century, conventions of stylistic imitation and truth-to-nature in Western architecture were replaced by concepts of abstraction and objectivity. ${ }^{10}$ To reference developments of certain context and understand spaces in comparative terms, a systematic classification of architecture was considered necessary to further develop and understand the needs of the users which varied depending upon the program. By the early nineteenth century, the introduction of 'type' as a conceptual means and 'typology' as a formal means of comparison in architecture provided complementary ideas through which both existing knowledge of built form and modern concepts could be consolidated. ${ }^{11}$ Obsolescence of particular architectural typologies can be a product of changes occurring in the use of land, technology, and economics existing within the city. In place of existing typologies, new typologies have the promise to outperform the existing. The rate at which buildings obsolesce varies according to type and place, since there is great variety in changes in lifestyle, industry, etc. from one city to the next. However, "nowadays almost every building becomes obsolete before it is ready to fall down," declared Peter Cowan, who theorized obsolescence as a process of devaluation that can temporally be halted through rebuilding or adaptation. ${ }^{12}$ However, more often than not, obsolescence is a combination of human decisions and externalities rather than simply the consequence of natural forces that devise the form's end. The process can be paused, yet in the end it is unavoidable.

The possibility of certain typologies obsolescing as society becomes technologically dependent is not completely out of the question. Today's accelerated world privileges standardized architecture that fulfills the cravings of a modern lifestyle, and presents a challenge 


\section{OBSOLETE \\ expendable \\ POST OFFICE}

TYPOLOGIES

drone delivery

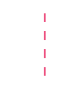

\section{BANK}

virtual accessibility

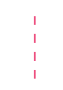

\section{CHURCH}

religious beliefs

\section{TAXI GARAGES}

automation<smiles>CCI</smiles>

\section{HOTEL}

private rentals

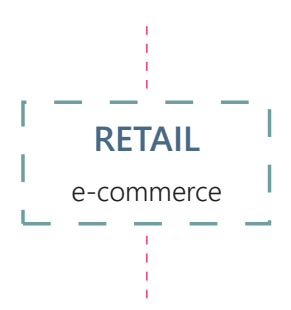


for the architectural typologies as a program and its users constantly adapt in order to survive in the ever-changing fabric of the city. ${ }^{13}$

Automation continues to improve our lifestyles, providing us with greater leisure time and activities through the replacement of physical labour. In essence, technological innovation results in a reduction in human aided physical labour and the buildings that support it. For instance, the services provided by post offices have diversified over the last fifteen to twenty years and are now involved in financial services, providing a link between the community, government and big utilities. ${ }^{14}$ Once known as the building that housed letter-carrying services has now expanded its reach to compete against the decline in mail volume which is now supported by the digital platform. In reaction, it has also placed the services provided by postal workers under threat due to usage of drone delivery systems. On one hand, it dissociates with the social network that once connected the inhabitants of the city. On the other hand, it generates an opportunity for a new typology to support the advanced post office operations, an automated drone warehouse. The speculation here is not suggestive of an immediate change, but rather a gradual change that will slowly infill the built form in question to accommodate the new required program.

By understating the existing and unforeseen issues facing the architectural typologies, one gains a broader perspective on the positive and negative outcomes attached to its dynamic nature. According to Michael Guggenheim, a sociologist of science and technology and architecture has a quick recourse to the metaphor of surgery, healing, and recuperation, where a building's reanimation is considered an organ transplant that inadvertently could be rejected. ${ }^{15} \mathrm{~A}$ program, in this case, is a merger between different components that service the users in its abnormal state. For Antoine Picon, a trained engineer, architect, and historian, architectural typologies are both a territory of emptiness and consumption, and he metaphorically compares them to the buy-and-throwaway nature of the shopping centre and garbage dump. ${ }^{16}$ Both Guggenheim and Picon argue for a design that acclimates to the dynamic nature of the user and the city. Speculative deductions on typologies, based on existing patterns, therefore, can give a deeper understanding on how they can be reformed now in order to be vigilant to shifts occurring in both the social and urban fabric. But the draconian reality that exists within most contemporary cities is that construction and deconstruction are the guiding principles defining the city fabric.

\subsection{SELECTIVE OBSOLESCENCE}

Provided that the changes are occurring in the building typologies and their immediate setting, it is important 
PLANNED OBSOLESCENCE

\section{SELECTIVE}

OBSOLESCENCE

looks at the workable characteristics of

$$
\text { declining programs to devise a }
$$

strategy for different or similar usage
EXTRACTION

PRODUCTION

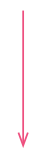

DISTRIBUTION

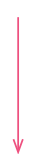

CONSUMPTION

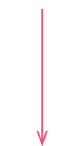

DISPOSAL
STYLE

OBSOLESCENCE

personal perspective on use of designed space that is unable to compete against spaces with same program

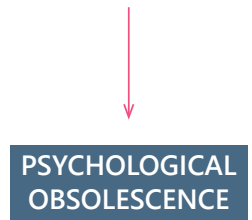

strategy that persuades the users to replace a program to not feel ashamed or of lesser value

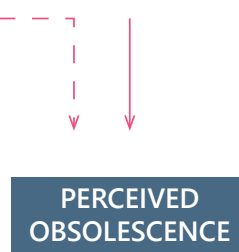

misconception to inhabit an updated program, even when the existing program functions well

10 
to separate the different types of obsolescence to understand their purposes. Programmed spaces now are expected to accommodate more than one program to permit various uses to continuously attract users. This change is due to consumer culture, or the awakening of human need to seek something of greater value; adoration towards what space is able to provide mutates into a resentment of a past that is now outdated and obsolete. ${ }^{17}$ The relationship between what is needed and what is dispensable is unstable in the current society and is manipulated through the consumerist market. As life becomes increasingly electronically mediated, it becomes important to examine the nature of engagement, where the empathy encountered is not with each other but through manufactured artifacts. ${ }^{18}$ Yet, the only manufacturing that has occurred is in form of technology that continues to assist and upgrade itself to better serve the daily human activities.

The Oxford Dictionary defines planned obsolescence as, "a policy of producing consumer goods that rapidly become obsolete and require replacing. This is achieved by frequent changes in design, termination of the supply of spare parts, and the use of non-durable materials." ${ }^{19}$ Today, invention and production of products with fixed lifespans plays a crucial role in the dynamic fabric of a growing city. Vance Packard, in his book The Waste Makers, asserts that the deliberate shortening of product lifespans is unethical, both in its profit-focused manipulation of consumer spending, and its devastating ecological impact through the nurturing of wasteful investment. ${ }^{20}$ In this case, both logical and psychological obsolescence makes obvious the redundancy of human transactions due to the possibility of a product of the same type existing or being made having a greater value. Style obsolescence, a sub-category of planned obsolescence for example, does not focus on any one style or particular trend, but rather the constant change in appearance of styles and trends under one categorized product. ${ }^{21}$ There are, of course, implementable strategies, to reduce this wastefulness resulting from obsolete products, which includes use of recycled materials over the use of pure ones. In relation to architecture, this can be observed through the act of preservation and reuse of existing building materials on site to reduce the overall embodied energy required to create a new program that better supports the users.

Selective obsolescence is an overarching principal that occurs prior to the disposal phase of products manufactured to become obsolete (figure 3.6). Originating from Latin word Sélēctus, to choose or to single out, the term defines an attempt to understand the aspects of progress that adheres to user's demands and growth at a specific time. Most obvious changes can be observed in our immediate use of building spaces. Houses that were built for large families are now too large for the modern 
family, churches have diminished congregations as the current generation strays away from religion, stables for horses are no longer necessary in the city due to automation, and even conversion of old factories to lofts is now very typical. ${ }^{22}$ There are, however, characteristics in each of these examples that are carried forward to manufacture a space that is beneficial to both the users and the city. Large single-family homes have the potential to house either multiple families or private recreational programs, transportation storage leverages inhabitants' comfort to travel and generates profit for the owners of urban garages, the weakened relationship with religion provides the opportunity to exploit large, open spaces for commercial programs like theatres, and factories have both space and light galore that is appealing to many people for their housing. Instead of allowing the complete eradication of built form, the current manufacturers of building spaces are selective about the obsolete artifact's characteristics that provide optimum user comfort, but most of all maximum profit. As the value of obsolescing typologies are confronted, the need for a design that delays further decay and loss becomes important in Speculating Typologies: A Sale for Viability.

\section{END NOTES}

1

Daniel M. Abramson. Obsolescence: An Architectural History (Chicago: The University of Chicago Press, 2016), 4.

2 Ibid., 14

3 Stephen Cairns and Jane M. Jacobs. Buildings Must

Die: A Perverse View of Architecture (New York: The MIT Press, 2014), 40.

4 lbid., 111.

Nigel Whiteley. "Toward a Throw-Away Culture. Consumerism, 'Style Obsolescence' and Cultural Theory in the 1950s and 1960s." Oxford Art Journal 10, no. 2 (1987): 3. http:// www.jstor.org/stable/1360444.

Sharon Zukin. Naked City: The death and life of authentic urban places (New York: Oxford University Press, 2010), 2.

Cairns and Jacobs. Buildings Must Die: A Perverse View of Architecture, 2.

n.d. "Back to the Future: Visionary architecture in postwar Japan." Taschen. 2017. Accessed November 15, 2017. https://www.taschen. com/pages/en/catalogue/architecture/ all/06769/facts.koolhaas_obrist_project_ japan_metabolism_talks.htm.

Abramson. Obsolescence: An Architectural History, 72.

10 Sam Jacoby. "Type versus typology." The Journal of Architecture 20, no. 6 (2015): 931. doi:10.1080/ 
13602365.2015.1115600.

11 lbid.

12

Abramson. Obsolescence: An Architectural History, 73.

13 Whiteley. "Toward a Throw-Away Culture. Consumerism, 'Style Obsolescence' and Cultural Theory inthe 1950s and 1960s," 17.

14 Stuart Crainer. "Digital Post and Beyond: The Future Post Office?" Business Strategy Review 22, no. 2 (2011): 8. doi:10.1111/j.14678616.2011.00743.x.

Zukin. Naked City: The death and life of authentic urban places, 13.

Antoine Picon and Karen Bates. "Anxious Landscapes: From the Ruin to Rust." Grey Room, no. 1 (2000): 75. http://www.jstor.org/ stable/1262551. Jonathan Chapman. "Design for (Emotional) Durability." Design Issues 25, no. 4 (2009): 34. http://www.jstor.org/stable/20627827.

18 Ibid., 31.

19

n.d. "Planned Obsolescence." Oxford Dictionaries.

Accessed November 15, 2017. https:// en.oxforddictionaries.com/definition/ planned_obsolescence. Chapman. "Design for (Emotional) Durability," 30. Whiteley. "Toward a Throw-Away Culture. Consumerism, 'Style Obsolescence' and

Cultural Theory inthe 1950s and 1960s," 20. Francis M. Jones. "A Study in Obsolescence." The Town Planning Review 38, no. 3 (1967): 189. http://www.jstor.org/stable/40102561. 

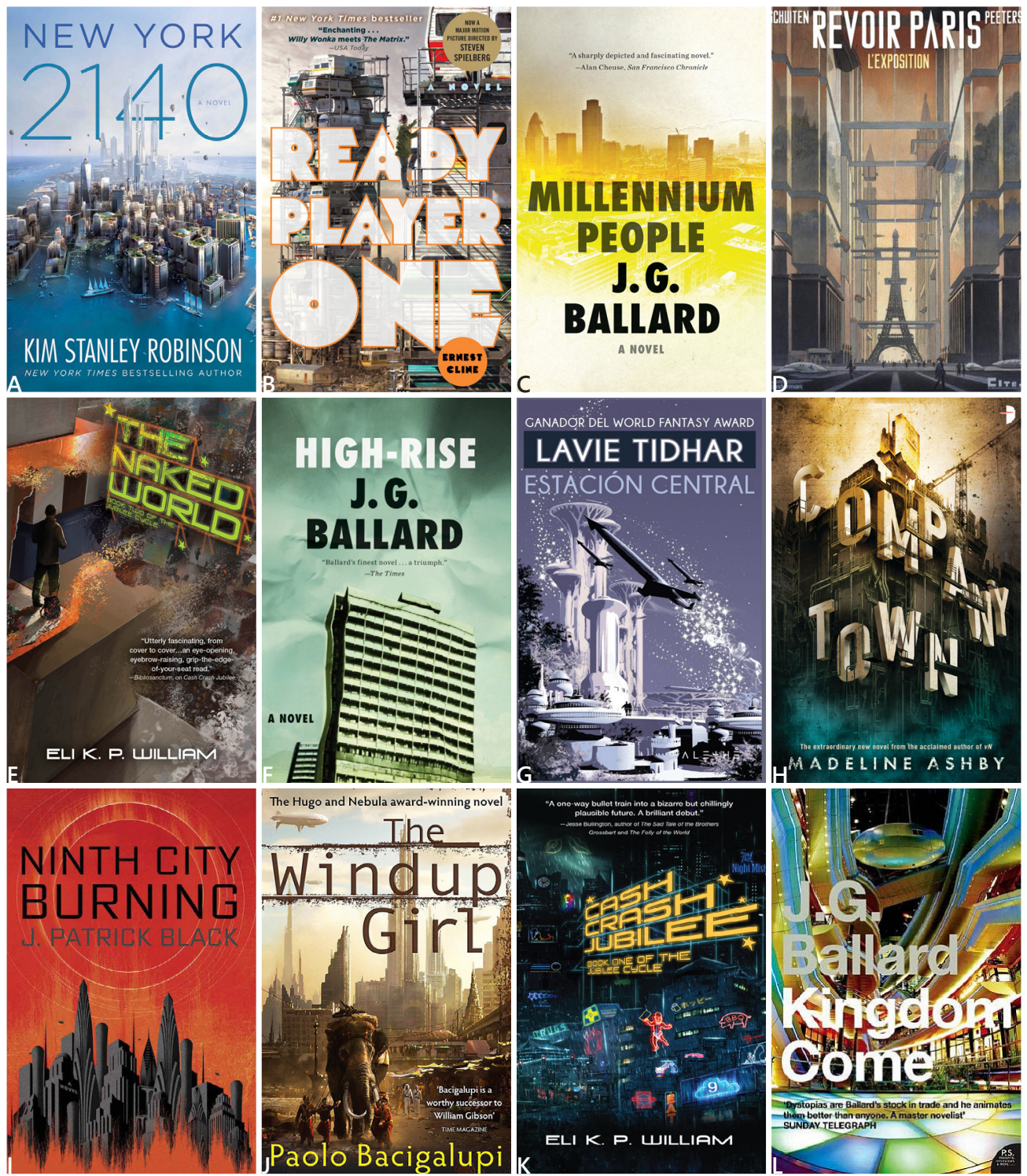

"Science Fiction deals with improbable possibilities, fantasy with plausible impossibilities."

- Miriam Allen deFord

\section{NEAR F U U R E}




\subsection{NEAR FUTURE}

\subsection{SCIENCE FICTION}

Founded on speculative futures, the conversations discussed in science fiction literature and media are responding to the changes in society and altering them to an extreme state for discussion. The study of science rationalizes information of the physical or material world obtained from its systematic observations. Fiction, on the other hand, moulds a dialogue that allows the readers to envision a possibility of something that might exist. Hence, science fiction is a speculation of a near or a distant future based on the observations made in the contemporary world. These speculations, in one way or another, attempt to imagine secure and fulfilling futures, or unsure and dangerous futures to raise awareness on the evolving consequences of day-to-day activities. It focuses on the potential long-term outcomes of current progress, and strives to provide diverse visions of how people will inhabit the designed spaces. Its predictions are made compelling by the research conducted in multiple

Fig.4.1 A collection of science fiction novels
A. New York 2140, Kim Stanley Robinson
B. Ready Player One, Ernest Cline
C. Millennium People, J.G. Ballard
D. Revoir Paris l'Exposition, Schuiten et Peeters
E. The Naked World, Eli K. P. William
F. High-rise, J. G. Ballard
G. Central Station, Lavie Tidhar
H. Company Town, Madeline Ashby
I. Ninth City Burning, J. Patrick Black
J. The Windup Girl, Paolo Bacigalupi
K. Cash Crash Jubilee, Eli K. William
L. Kingdom Come, J. G. Ballard 

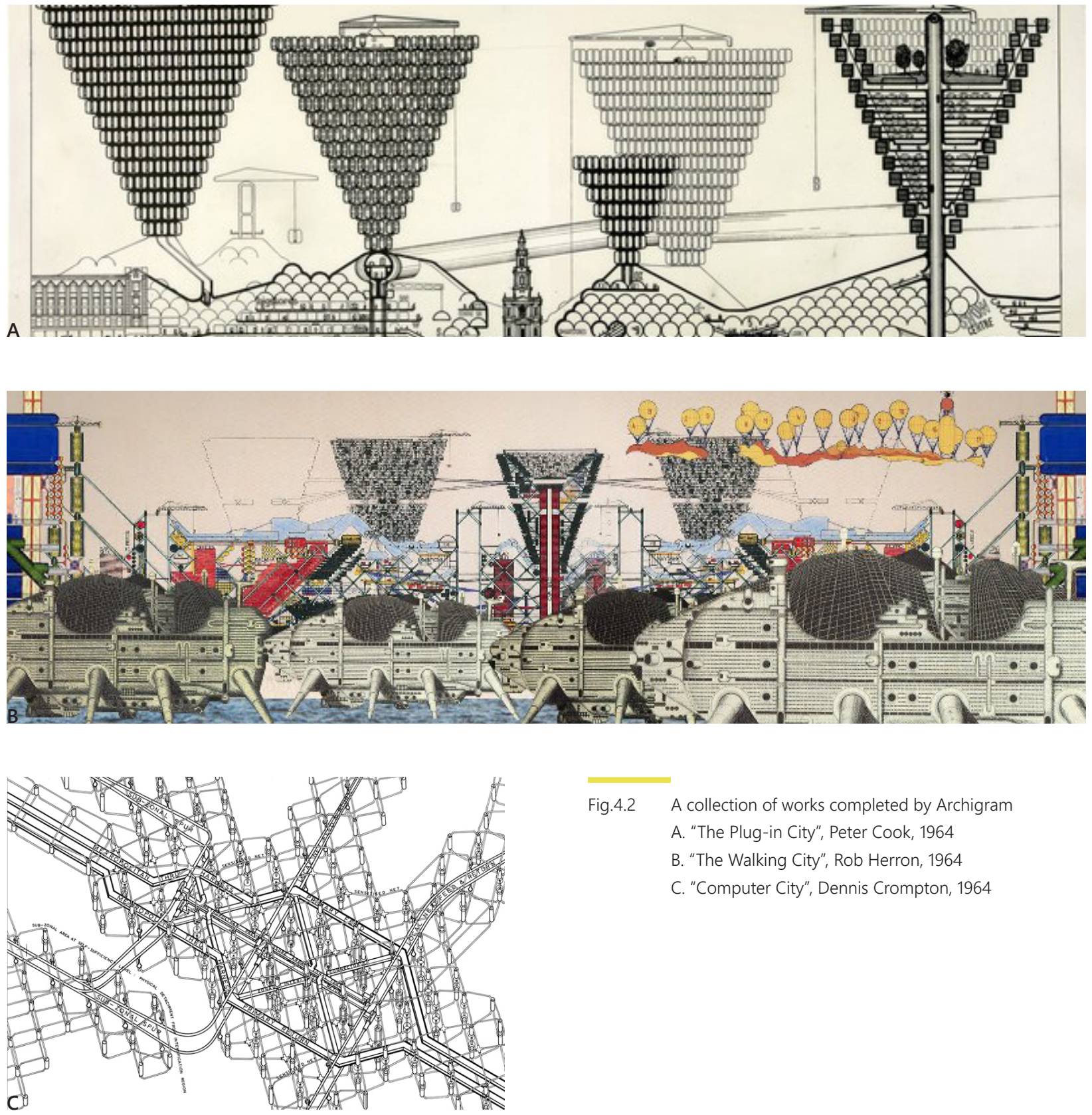

Fig.4.2 A collection of works completed by Archigram

A. "The Plug-in City", Peter Cook, 1964

B. "The Walking City", Rob Herron, 1964

C. "Computer City", Dennis Crompton, 1964 
Planners and designers of architecture and urban environments are similar to the creators of various alternatives suggested by science fiction. Both hope to make their visions a reality, but it is the planners' dream to have theirs less shortsighted and conservative. ${ }^{1}$ Planners' visions, now, are more practical and a solution to fulfil current or anticipated demands. Essentially, all the designed work being proposed is for the near future because of the time required from pre-design to building operations. However, more often than not, these design solutions are less than useful because the problem it attempts to solve could have easily evolved or disappeared naturally, thus rendering parts of the built design obsolete as a result. It has an overlay of confidence that assumes a fixed fail proof future. To propose a design that has the foresight to withstand any possible resistance and overcome the existing challenges, the visions proposed by science fiction creators and designers need to intermingle and envision a larger picture of the city spaces. These projections would not be sufficiently robust nor account for existing issues, but rather be a future version of these issues that is measurable by the current economic, demographic, and some environmental variables. ${ }^{2}$ The speculative futures being proposed by the writers have an unrealized potential that could potentially offer better planning for the future than the work of planners and architects. These thought experiments could be exploited by the design world. Such visions are seen embedded in animation, virtual reality, the internet, and electronics.

In the modern era, exploration into futures can be traced to the end of World War II, when possible future became a crucial topic in a fast changing society in search of direction. ${ }^{3}$ Many saw it as an opportunity for a breakthrough and something from which to draw reassurance, and others saw it as a form to restore and adapt to the existing conditions at the time (figure 4.2). The post-modern designs aimed to save society from itself by presenting to the public the ideal spaces and items for living, recreation, and work in a more orderly and equitable way that would encourage consumer culture. ${ }^{4}$ However, as discussed in the previous chapter, the consumer culture is committed to the idea of obsolescence that continues to shape and support human activities. Scenarios of possible futures discussed in science fiction writing push this concept of planned obsolescence to its extreme to realize its ultimate circumstances. Furthermore, the architectural designs discussed in the writing summarises these circumstances to allow the readers to envision how the space in that speculative future would be inhabited. Through reacting to such representation, the city and designed space can be strategically improved to better the circumstances that people will face in the actual future. These literary representations of cities are thought experiments asking a specific question: what will happen if planned obsolescence was the circumstance of the near 


\section{VTOPIAE INSVLAE FIGVRA}

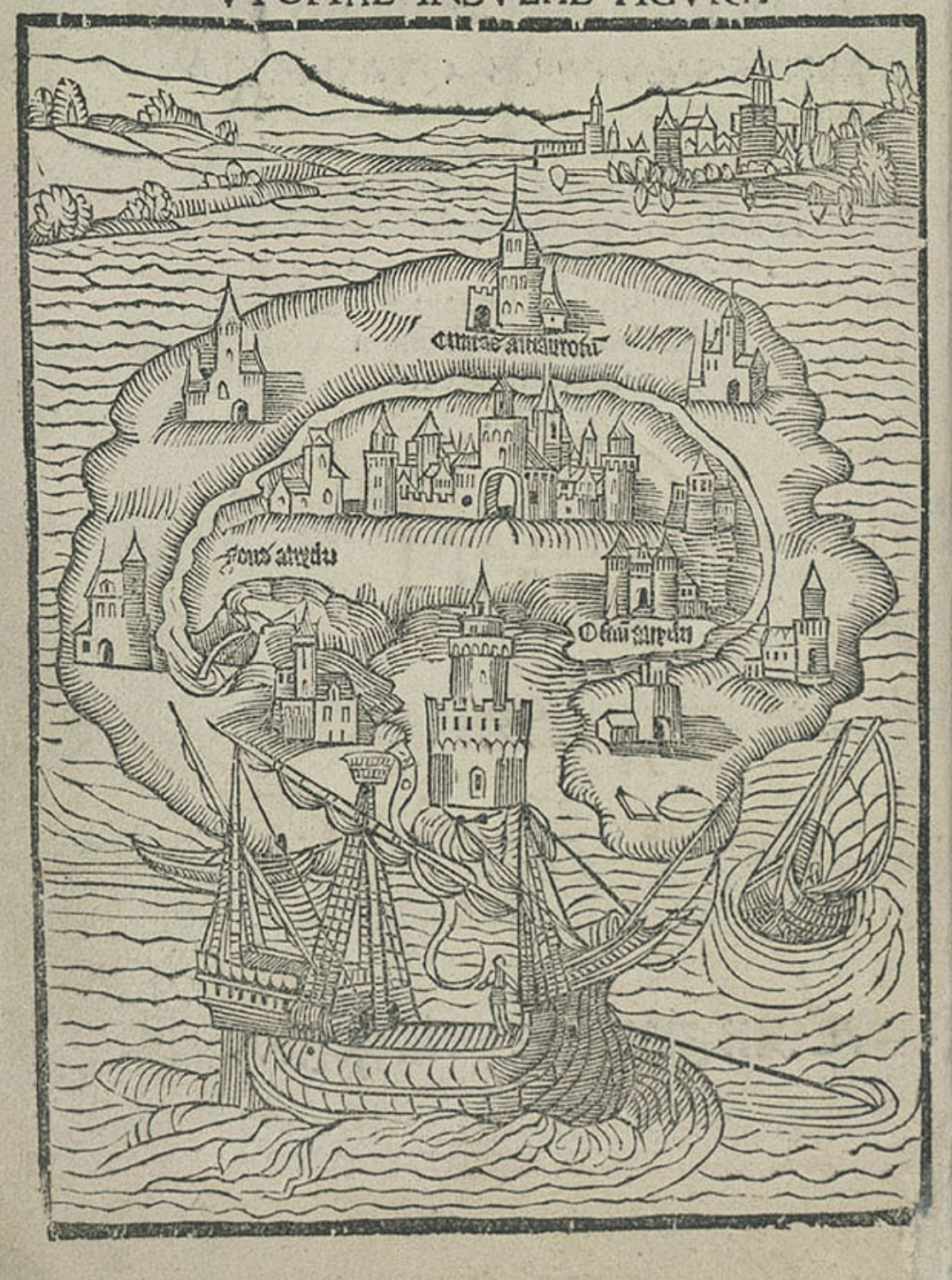


future? In the end, the discussion can be divided into two categories: utopia and dystopia.

\subsection{UTOPIA}

An optimistic vision of perfection that exists or could exist in the future is called utopia. It derives from the Greek words meaning 'no-place' and 'good-place', but the actual term was first coined by the British writer and statesman Thomas More in 1516 to describe an imaginary island, where a self-contained community shared a common culture and way of life (figure 4.3). ${ }^{5}$ In science fiction literature, it is a sub-genre that gives the readers a sense of hope in contrast to the dreaded downfalls the present progress could have within cities. Even when utopias are discussed in the speculative future literature in the last couple of decades, it is away from Earth, and is rather explored on spaceships or different planets that are untouched by colonization. It is moulded from the idea that the existing world for certain lacks or is missing something to provide its users. It is a perfect parody of reality that critiques the need for improvement. Today's utopia is based on a myth, which is primarily a form of desire expressed by the public. ${ }^{6}$

Can a utopia be approached? Once could argue that the nature of the capitalist system does not promote a way to create a utopia. There are people doing less well and there are people doing better, but no one is really achieving a utopian lifestyle. Similarly, there is architecture that services it users at a minimum capacity or provides extra services for better habitation, however none of the designed works are able to serve its users equally and optimally.

The inherent desire to value something which is perfect or at least grander than what already exists, dilutes the larger picture of society that services its inhabitants equally under optimal conditions.

In novels, utopian thought can be categorized as two types: one that designs how the future should or could be, and the other that makes reference to an optimal landscape meant to inspire action for change in our world. ${ }^{7}$ The first one projects a definite design without a clear guideline of how it was built. It was simply always there in the story's landscape and everyone interacts within it. On the other hand, the second type references a brighter tomorrow at a distant horizon that inspires the characters to pursue it. For the characters, it is a dream state that they have a chance to achieve. In addition, almost every description of an ideal society references an existing architectural stage upon which it unfolds. ${ }^{8}$ An immediate comparison between the imaginary and the existing entices the readers to further uncover the inevitable end. They cannot stop looking for answers in the described utopias. Ernst Bloch, a Marxist 

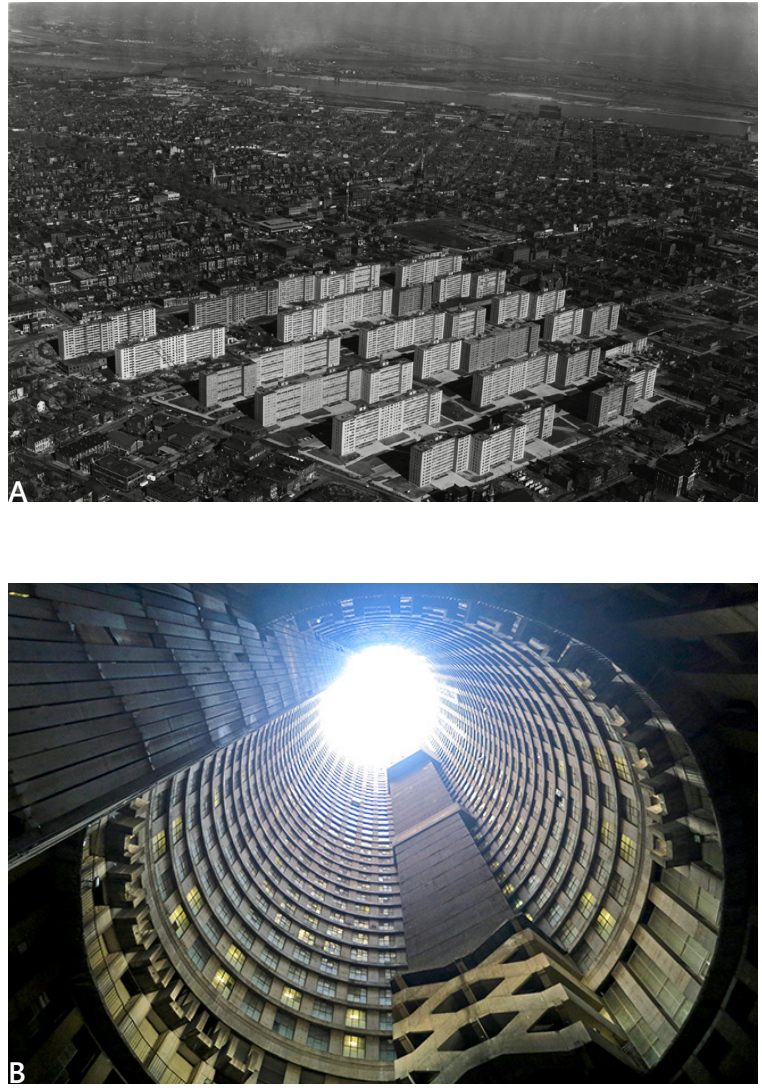

Fig.4.4 Pruitt-Igoe, Minoru Yamasaki, 1954

Fig.4.5 Ponte City, Manfred Hermer, 1975 philosopher, once said, "only the beginnings of a different society will make true architecture possible again", and I am arguing that the landscapes of science fiction represents those societies. ${ }^{9}$ Utopian visions arguably describe something unique about human longing and desire, attempting to look beyond what already exists. The term is both pathological to suggest that it is beyond redemption, and constitutive to enable an imaginary belief based on a set of ideals, which provide conditions better than the existing. ${ }^{10}$ Even in a dystopic story, a utopia still exists, at a distance, a negative of the dystopia, away from the chaos. The longing to achieve something grander than contemporary society draws the readers to hope that one day their imagination will mature and everything will be perfect, or approach perfection.

The traces of utopia, however, are not only bound in text, but also appear in other forms. This especially includes the activities of ordinary citizens that somehow manage to remain free of the dual cancers of advertising and consumption, which often deprive individuals and communities of whatever lingering agency they may have. ${ }^{11}$ The term also serves as a defense measure for any experiments done throughout the physical existence. According to Hilde Heynen, a professor of architectural theory at Katholieke Universiteit, Leuven, "modern architecture's utopian ambition was its most harmful attribute." ${ }^{\prime 2}$ Its' shortcomings in architectural explorations 
were described as something utopic, a set of progressive ideas that were reshaping the landscape. The question that Heynen puts forward is a reason that can describe its failings. Its idealism promised a better world, socially, physically and politically, and was intended to become the counterpoint to a wide range of reforms. ${ }^{13}$ However, as we know now, not all of the ideas put forward during that time were successful, even if the approaches were utopic at heart. Residential projects like Pruitt-Igoe and Ponte City are a few of the examples that envisioned a better living condition for the people, however their failures are more recognized than the visions that generated them (figure $4.4,4.5)$. When utopian projects become plans for action without a feedback loop of assessment, they ultimately tend to resemble the science fiction prognostication of technological utopianism or the totalizing qualities of absolutist utopias, than any desirable ideal good city or society. ${ }^{14}$ Not all conflicts from utopian schemes can be resolved and not all can be expected to be productive. The role of utopia, in the physical realm, arises after the results of the experiment are collected, since a project can only be called utopia after it is proven to be successful.

\subsection{DYSTOPIA}

The futures discussed in science fiction writings are often set in a dystopia, an imagined setting where everything is unpleasant from both the characters' and reader's perspective. This described space is deliberately made worse in comparison to what existed before, and is captivating to explore, since such writings are warning against the undesirable future developments that could occur in certain conditions. It attempts to describe the outcomes of darker issues that are often acknowledged but are or cannot be resolved, such as overpopulation, warfare, pandemic, natural disasters, or poverty. J. G. Ballard, for example, envisioned dystopian, obsolescing world-cities, where every cubic foot is commoditized, and the whole setting is rotting from inside out. ${ }^{15}$ Other authors like Vance Packard skewered the throwaway spirit of the consumer life, where in the novel The Waste Makers buildings were sustaining a periodic teardowns and rebuilding through a special paper-mâché that simplified the process of planned obsolescence and new production. ${ }^{16}$ The inhabitants described in dystopian stories are at the mercy of something that cannot be avoided, such as shifts in technology and lifestyle, bombardments of advertisements, and a changing built context. Characters extend their capabilities to rebalance their lives within the presented situation. In general, the existing dystopic states within the city are a result of a failed utopic vision that could not be realized after a thoughtful process. When failure in design is presented physically, there is an uproar towards the unprecedented uselessness. 

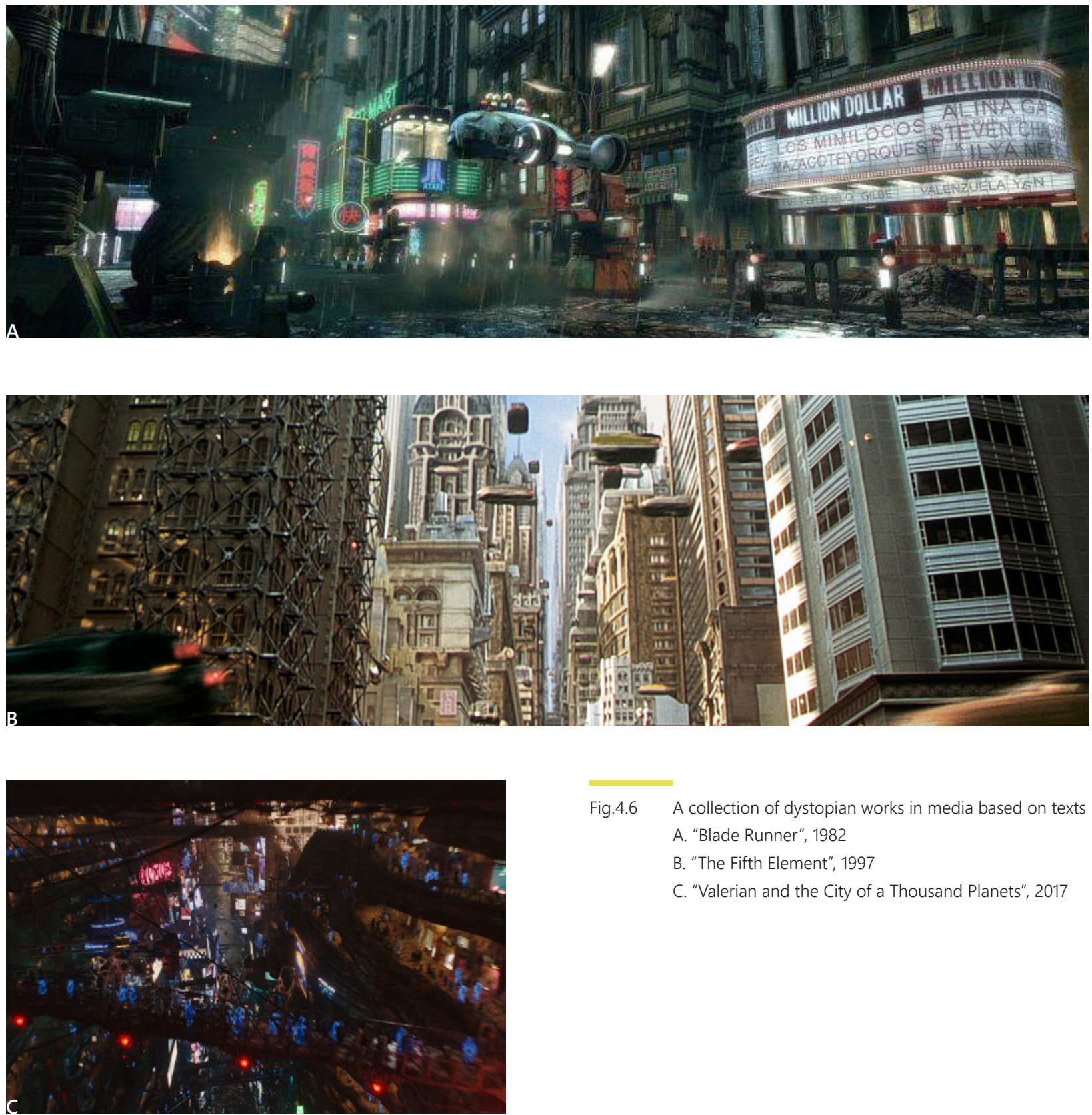

Fig.4.6 A collection of dystopian works in media based on texts A. "Blade Runner", 1982

B. "The Fifth Element", 1997

C. "Valerian and the City of a Thousand Planets", 2017 
The world of literature is free to entertain various consequences with a set of customized rules that most times are not applicable in the built world. However, the formal conversation of its outcomes and solutions are applicable in the real world as a list of precautions for urban developments. Architectural experiments are unpredictable, there is no definite outcome, but its shortcomings, when tested in such thought experiments, are lessons that can better assist the next construction project.

Dystopic visions are possible future states, and in novels they are constructs of mishaps related to human actions. They reference present societies' approach to the future, which is largely guided by the terrors of the twentieth and early twenty-first centuries (figure 4.6). The dystopian texts, more often than not, begin amidst the chaos at a site that already exists or can be referenced in the real world, where the conditions are far worse to recognize the unseen aspects of the everyday routine. Although all dystopian texts offer some affiliation with utopian tendencies whether it as a very worst of social alternative, to create a horizon of hope, or appear as dystopian allies. ${ }^{17}$ The narrative, typically, offers a flexible political and architectural system that can better create a compelling fictional reality for the readers. It usually begins directly in the bad new world, and yet even without dislocating elsewhere, the element of textual estrangement remains in effect, since the focus is frequently on a character who questions the dystopic society. ${ }^{18}$ This character is always immersed in the discussed reality as a loyal subject, but overtime begins to pick away at the system for a grander vision. In addition, an antagonist who embraces the dystopic system also takes actions against the protagonist to defend the system. As mentioned, these fictional landscapes illuminate the present shortcomings, hence are limited by what already exists or is possible or to what might emerge out of the present if taken to its logical extreme, unhindered by any mediating checks of balances. ${ }^{19}$ Thus, the stories and their realities have a predictable trajectory that may or may not become our reality.

In terms of the built context, the world is becoming more defined by cities- cities that continue to increase in number, in the number of inhabitants, in average building height, and in consumption. ${ }^{20}$ In addition, experimenting with something new to develop a new kind of architecture is a method of the past. With the turning of the millennium, narratives that had stressed the end gave way to narratives of what comes after. ${ }^{21}$ The post-modern architectural style focused more on improving and combining the new discoveries made in the past at a rapid pace, to create something unpredictable and unique from what existed. In comparison, the present developments are somewhere between a utopia and a dystopia, and is driven by the 


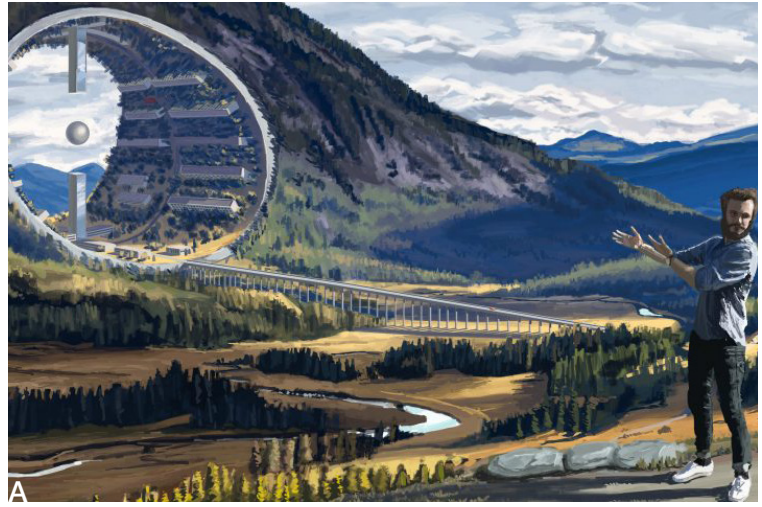

greed of achieving a positive outcome. However, the vision to create utopia is an optimistic one, since it is also shaped by the strong dystopian narratives and apocalyptic visions that prevailed in the late 1990s.22 The compact nature of city developments is overflowing with possible inconsistencies, but it also has a chance to prosper the everyday lives of the inhabitants. Architects and planners of machines, industrial production and theories feel an attraction towards an optimized organization of everything from private life to labour, and because of what these developments are able to suggest they are irresistible. ${ }^{23}$ If dystopian narratives did not address the thirst and extremes of this irresistibility, the value it means to educate the readers with would be meaningless. Dystopia is a combination of failings of the present exaggerated into the future, and since architecture is made in the present to accommodate the current environment, the possibility of knowingly creating a dystopia is far less than a utopia.

Fig.4.7 Competition entries for Fairy Tales 2017: Architecture Storytelling

A. "Last Day", Mykhailo Ponomarenko

B. "The City Walkers", Terrence Hector

\subsection{SPECULATIVE FUTURES}

In his essay 'Function and Sign: The Semiotics of Architecture', Umberto Eco supports the diminishing capacity of architects for thinking of architecture beyond the limitations of its given conditions, and the dangers of it not being able to flourish in the current system. ${ }^{24}$ On the other hand, the worlds described in science fiction are either good or bad, but are free from the existing system 
and can mature in any way possible. Moving forward, the future is not definite, and since it is a result of booming trends it is prone change as a result of such trends.

One can speculate, dream and hope about the ideal city. In Western thought, Plato initiated the great tradition of utopia to think about the desirable, the not-yet-achieved future. ${ }^{25}$ And since then, the attempts to reach a form of utopia have continued, both in texts and built contexts. Speculating forward obscures the many differences among a whole range of possible relations to the future. ${ }^{26}$ However, each speculation provides a distinct insight of what we could expect in a form of hope.

The planning process required for a single grand vision of the future needs both direction and logic, distilling a vast array of information from academic disciplines about dynamics that have shaped the world and how those forces might be harnessed to create new opportunities, threats, and uncertainties. ${ }^{27}$ To realize a vision distilled from this array of information is a futurist's dream, and in comparison planners can be viewed as more shortsighted, having to deal with the immediate condition. To be fair to planners, often they are institutionally caged in a cautious and conservative role and they do not wish to appear too off-the-wall to policymakers who want concrete answers and have budget constraints. ${ }^{28}$ In addition, as mentioned before, the current city developments are a result of improving and combining the discoveries made over time. The attempts to create utopia in the past are considered radical because of their failures, and in comparison the current approaches lack that form of radical approach in the physical construction. To please the existing set of laws and not be diverted by failures, the exploration for a future city is largely conceptualized digitally or discussed in speculative texts.

One of the problems with creating a speculative future is to acknowledge that there actually are problems to solve. The pre-planning tasks before design normally help to resolve conflicting possibilities and help explore any speculations from the gathered information, however the attention devoted to exploring the future is considered problematic by some with the advent of postmodernism. ${ }^{29}$ It is not due to lack of evidence, but rather lack of the willingness to experiment options.

Cities are constantly under pressure to advance and create infrastructure necessary for inhabitants, and also to not fall behind globally. At the same time, many architecture firms do participate in a new wave of utopian proposals including, but not limited to, artificial islands, mountain skyscrapers, pig-cities, inhabited ruins, new domesticities, and entirely new cities (figure 4.7). ${ }^{30}$ Projects like this draw out an array of speculations that seek to invent or reinvent the environment similar to science fiction landscapes. 
The future of built world will rely heavily on alternatives explored in these speculations.

Potentially, populous cities will grow denser overtime and shrinking cities will eventually not exist but return to farmland, unless they are strategically located. Therefore, it would follow that in densifying cities, buildings will continue to grow taller to accommodate the influx of people, making construction, destruction, and maintenance an ever-present norm for architectural design in these cities. In reaction, this will increase the opportunity to mitigate the obsolescence of the existing buildings to promote programs that are more appropriate to accommodate the speculated demands.

Architects are faced with the following questions:

Are we able to design a structure that is constantly being transformed by its users?

Is it possible to create a haven for users that wish to explore and expand their private businesses in a city where everything can be mass produced?

What programs can be added to best support the endeavours of the inhabitants to allow the existing space to be viable in the future?

\section{END NOTES}

1 Sam Cole. "Dare to Dream: Bringing Futures into Planning." APA Journal 67, no. 4 (2001): 372. doi:10.1080/01944360108976246.

$2 \quad$ Ibid., 373.

$3 \quad$ lbid., 375.

4 D. Kevin O'Neill. "When Form Follows Fantasy: Lessons for Learning Scientists From Modernist Architecture and Urban Planning." The Journal of the Learning Sciences (Taylor \& Francis Group) 25, no. 1 (2016): 136. doi:10.1080/105 08406.2015.1094736.

5 Christina Contandriopoulos. "Architecture and Utopia in the 21st-Century." Journal of Architectural Education 67, no. 1 (2013): 3. doi: 10.1080/10464883.2013.771021.

Smaranda Maria Todoran. "Addendum to the Arcadian Myth: Science Fiction and Contemporary Utopian Discourse in Architecture." Philobiblon 21, no. 1 (2016): $121 . \quad$ http://ezproxy.lib. ryerson.ca/login?url=https://searchproquest-com.ezproxy.lib.ryerson.ca/ docview/1803443102? accountid=1363.

Arnaldo Cecchini. "The future of the city from Science to Science Fiction and back (and beyond)." City, Territory and Architecture 1, no. 5 (2014): 2. doi:10.1186/2195-2701-1-5. 
Architecture?" Architectural Research

Quarterly 16, no. 4 (2012): 339. doi:10.1017/

S1359135513000225.

$9 \quad$ lbid

Nathaniel Coleman. "The Problematic of Architecture and Utopia." Utopian Studies 25, no. 1 (2014): 10. doi:10.5325/ utopianstudies.25.1.0001. Ibid., 15.

Coleman. "Utopia and Modern Architecture?," 340.

Nathaniel Coleman. "Building Dystopia." Rivista MORUS- Utopia e Renascimento, no. 4 (2017):

182. http://www.revistamorus.com.br/index. php/morus/article/view/180/157.

Coleman. "Utopia and Modern Architecture?," 343.

Daniel M. Abramson. Obsolescence: An Architectural

History (Chicago: The University of Chicago

Press, 2016), 108.

16 Ibid.

Tom Moylan. Scraps of the Untained Sky: Science Fiction, Utopia, Dystopia (Colorado: Westview Press, 2000), 147. lbid., 148.

Coleman. "Building Dystopia," 186.

Cecchini. "The future of the city from Science to Science Fiction and back (and beyond)," 6 .
Contandriopoulos. "Architecture and Utopia in the 21st-Century," 3.
22
Ibid.

Coleman. "Building Dystopia," 189.

Coleman. "Utopia and Modern Architecture?," 339. Cole. "Dare to Dream: Bringing Futures into Planning," 374.

Robert Briggs. "The future of prediction: speculating on William Gibson's metascience-fiction." Textual Practice 27, no. 4 (2013): 674. doi:http://dx.doi.org/10.1080/095 0236X.2012.738702.

Cole. "Dare to Dream: Bringing Futures into Planning," 381-2.

Ibid., 373.

Samuel Nunn, Colin Warren, Robert Warren, and Stacy Warren. "The Future of the Future in Planning: Appropriating Cyberpunk Visions of the City." Journal of Planning Education and Research 18, no. 1 (1988): 50. doi:10.1177/0739456X9801800105.

Contandriopoulos. "Architecture and Utopia in the 21st-Century," 3. 
"Everything is becoming science fiction. [...] What the writers of modern science fiction invent today, you and I will do tomorrow-or, more exactly, in about ten years' time."

- J. G. Ballard

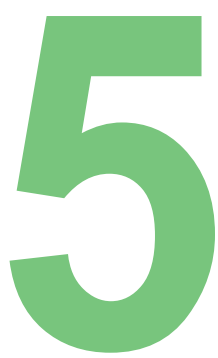




\subsection{SCIENCE FICTION}

\section{1 .1 J. G. BALLARD}

Science fiction as a genre has become a tool to publicize ideas about the possible dangers of progress. The ideal conditions for living became a topic of interest in the postwar years, especially because of destructive technology developed for World War II. James Graham Ballard, who was interned in a Japanese prison camp during World War II, focused on a singular, disastrous, natural or scientific event in each of his novels, which exhibited his interest in what was new in the present. ${ }^{1}$ His career spanned six decades, and toyed with the psychology of humanity through the dystopic state of current events that, more often than not, depicted the dehumanization and decay of society. The term 'Ballardian' was coined in honour of his writing to denote anything resembling or suggestive of the conditions described in his novels and stories, especially dystopian modernity, bleak man-made landscapes, and the psychological effects of technological, social or environmental developments. ${ }^{2}$

The protagonist of his stories uncommonly prefer the chaos over the peace that existed at the beginning. There are no attempts to avert the disaster, but rather attempts to further indulge them as the stories progress. "My fiction is all about one person, all about one man coming to terms with various forms of isolation." ${ }^{\prime 3}$ The novels' suspense continues to tighten as the events unfold and add more character to the previous disaster. In addition, the way in which his characters react is natural, and there is often no explanation to support their psychological state which always existed beneath the surface. ${ }^{4}$ The speculations portrayed here are a surreal reflection of what may occur in reality after multiple lapses in judgement.

The dystopic landscapes in Ballard's illustrate the extreme outcomes that may result from present day developments and actions. Shopping malls, business parks, office spaces, suburbs, apartments, and more are presented in a hyperorganized state with human activities that together foreshadow possible futures. ${ }^{5}$ These descriptions of places are an attempt to reimagine a new form of urban and suburban spaces, which are riddled with multiple complex cultural and social relationships. One of the great secrets of modern life is that we do not actually want what we want, and therefore the environment is always in flux both in reality and reflected in novels. ${ }^{6}$ Dissatisfaction fuels the characters to take actions that would otherwise be unjustified. Ballard's disaster stories are upbeat and optimistic, even though some people or everyone will die or be integrated into the discussed events. ${ }^{7}$ The characters' blandness at the beginning enhances the imagination into new fields that create a captivating near future reality. To understand how to project into the near future for this project, a number of his stories were selected and explored further to understand the discussed architectural typologies. 


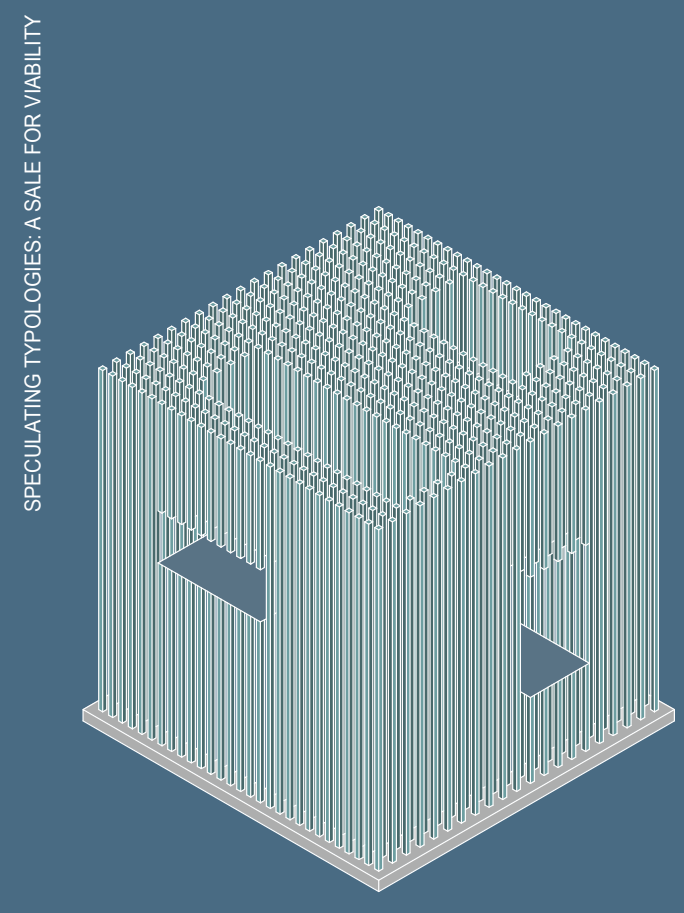

Fig.5.1 Diagrammatic interpretation of story "The Concentration City"

Fig.5.2 Physical Model of "The Concentration City" interpretation

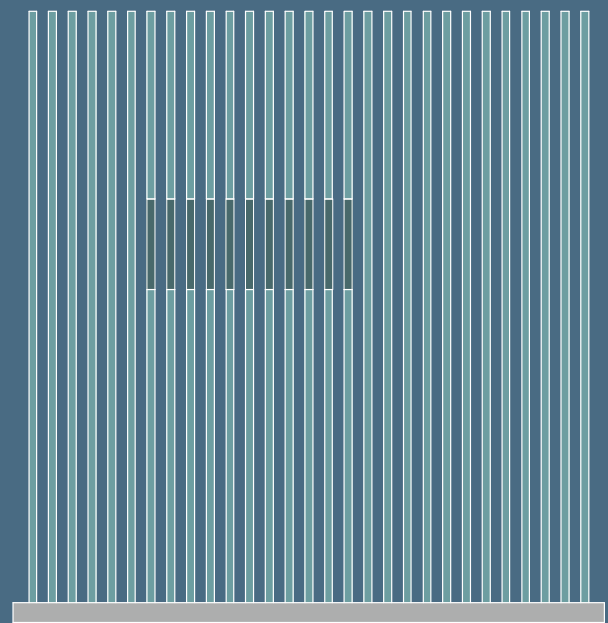

5.1

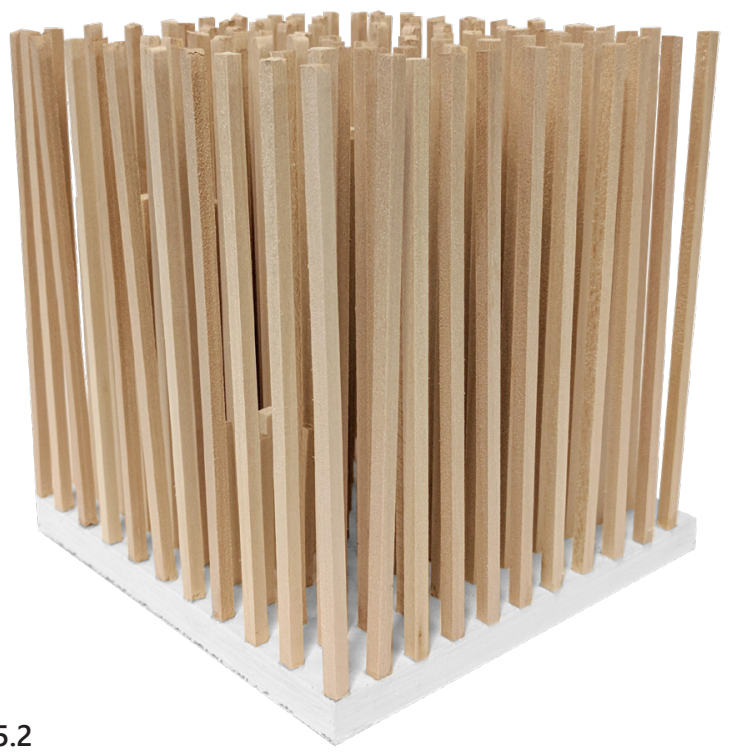


"There must be free space somewhere, the City must have bounds."

- J. G. Ballard, "The Concentration City"

\title{
5.1.2 "THE CONCENTRATION CITY"
}

\author{
BY J. G. BALLARD
}

\section{INSTINCTS}

The dystopic short story "The Concentration City" depicts a future in which a single megalopolis has overtaken the entire Earth. Due to its dense nature, the male protagonist, Franz, is in search of the mythical notion of the empty space. In this terrifying vision of the city, the programs are stretched both horizontally and vertically in a selfsufficient state, where elevators and streets connect all its levels. The obsession to find free space beyond the city's walls drives Franz to travel out of the city by train to reach a space on which he can freely fly. The city envisioned here is imperfect and undergoes constant redevelopments due to its poor structural integrity. This results in periodic collapses with at times up to half a million casualties.

Free space is a notion not known by the inhabitants of the city, since they have only experienced this dense urban environment. Franz's search for the empty space is ludicrous in the eyes of the inhabitants, who labelled his aspirations the result of a mental illness. Even his long travel brought him back to the starting point, since the city has no boundaries to begin with. The story reveals underlying themes about space, government, construction methods, overpopulation, and human nature.

Our instincts at one point or another crave the grander things in life. In Franz's case, the lack of space to fly away from the dense setting drives him to search for openness. This leads to the question what would happen if this city 


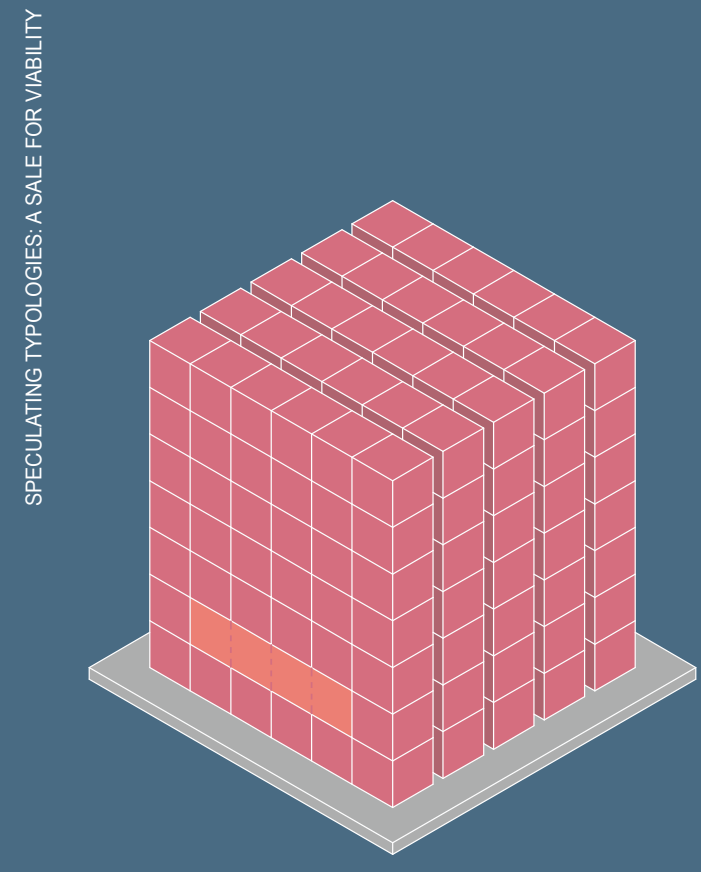

Fig.5.3 Diagrammatic interpretation of "Billennium"

Fig.5.4 Physical model of the "Billennium" interpretation

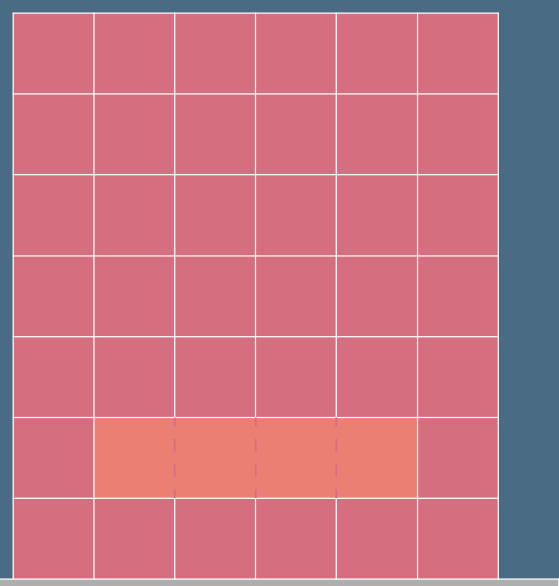

5.3

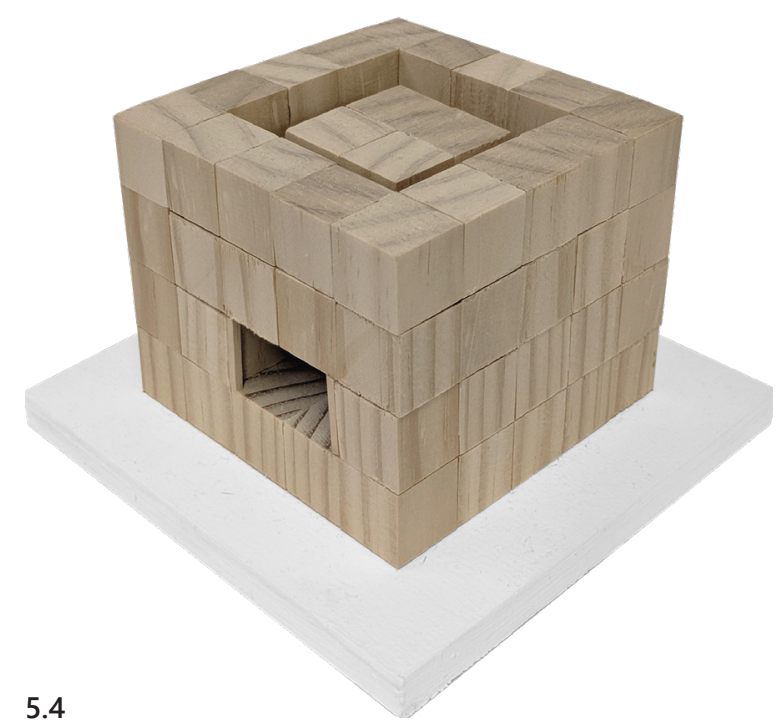


"For an hour they exchanged places, wandering silently around the dusty room, stretching their arms to feel its emptiness grasping at the sensation of absolute spatial freedom."

- J. G. Ballard, "Billennium"

\subsection{3 "B ILLENNIUM"}

BY J. G. BALLARD

\section{SPACE}

The short story "Billennium" by Ballard, presents a time in which the biggest threat facing the human race is overpopulation and not war, unlike what many would assume considering the current events of our society. Instead, the world population has stretched to such a length that the space provided to inhabitants continuously shrinks according to the bylaws set by the city council. Most of the inhabitants live in a crowded city in order to preserve the bordering agricultural production to avoid food shortages. Due to the ever-increasing number of inhabitants that occupy the city, the city council has limited each individual to 3.5 square metres of space, which is also set to decrease in the future.

Loss of privacy and shrinking living quarters have frustrated Ballard's protagonists, John Ward and Henry Rossiter, who hope to rent more space as roommates in order to escape the pedestrian congestion on the streets. The old infrastructure of the city has been destroyed to make space for new cubicle homes that shelter each individual. This society is money hungry and continuously craves profit, where some landlords have proposed to fit two inhabitants within the 3.5 square metres and rent out janitorial storage as living quarters. In addition, the tenants are subjected to rent increases, when the protagonists can barely get by on their current income.

Profit is a strategic move to earn more in an ideal situation, however in the case of the story the landlords are benefitting off tenants' need for accommodation in a terribly dense city. Even when John and Henry are able to find appropriate accommodations, with a hidden room behind a false wall, their impulse is to pay less rent by allowing more tenants to stay with dividers that slowly eclipses their initial desire to be free from the outer world. They recreated the tiny cubicle units even if they wished to escape from space shortages in a dense urban environment, failing to surely create pressure on the inhabitants to preserve what they already have to make profit over a spacious lifestyle. The exploration here creates the packed cubicle units with larger units placed in-between to allow more space for the people who can afford it. By creating units of different sizes, a clear hierarchy can be formed between what is standard and grander. The rent earned on these units can differ based on the occupants, since the larger units can be divided for profit with partition walls. And based on the tenant's wage, a grander lifestyle is possible for those who can afford it.

The story brings out this question: is it ethical to create units of various sizes for an overpopulated city that struggles to accommodate all its inhabitants? Could a creative form of tiny living be the answer to shelter everyone? 


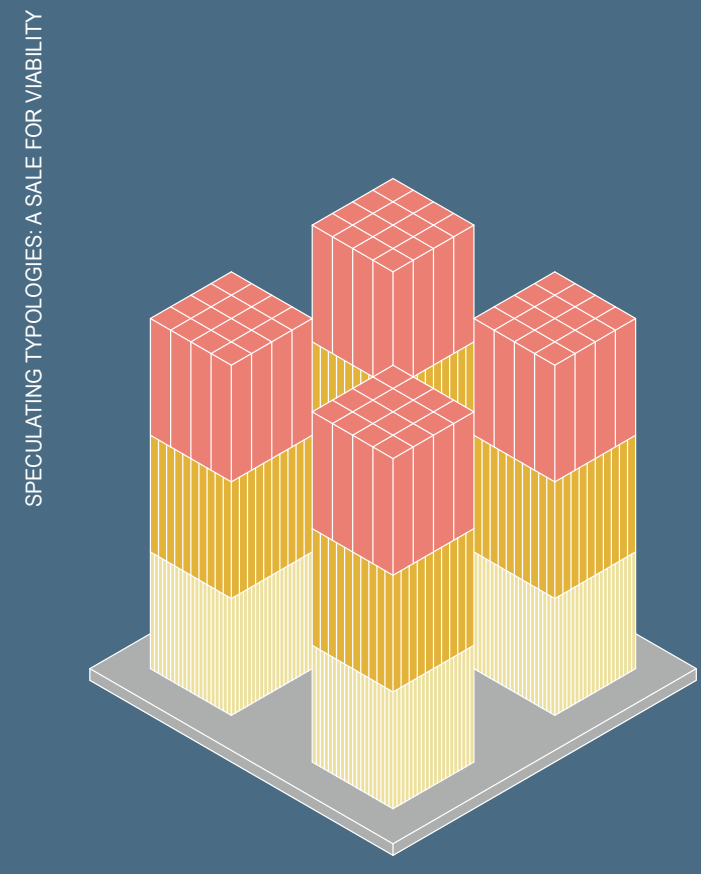

Fig.5.5 Diagrammatic interpretation of High-rise

Fig.5.6 Physical model of the High-rise interpretation

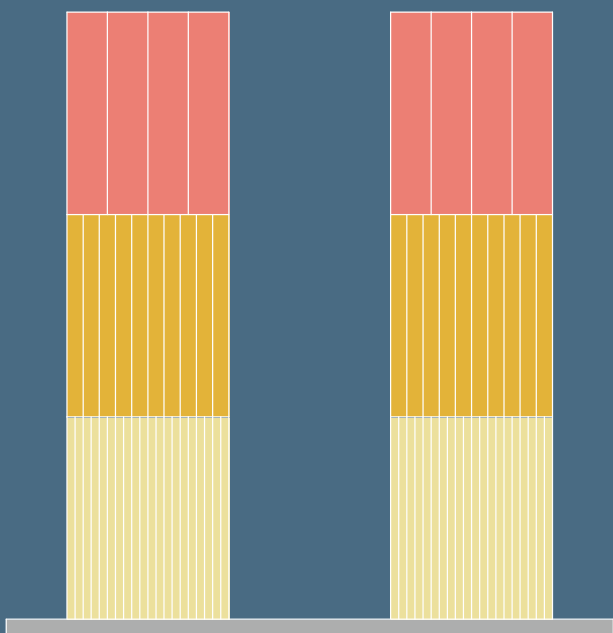

5.5

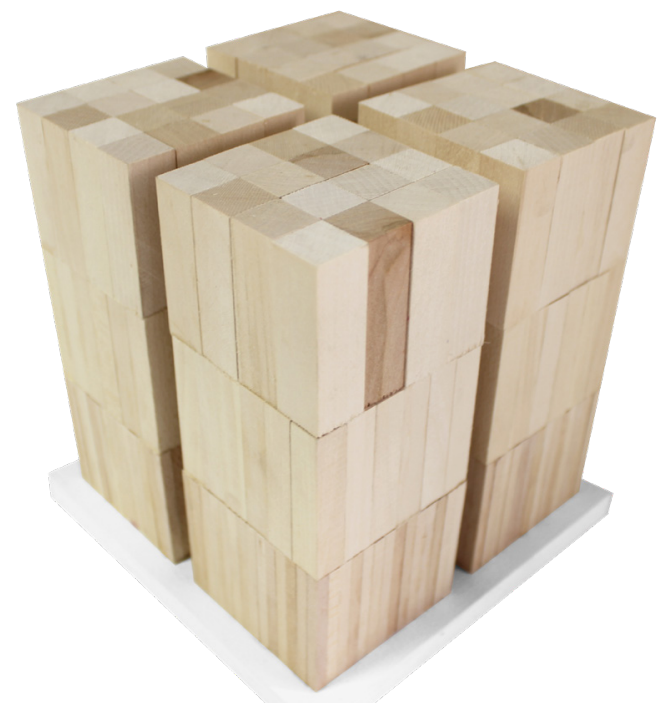


"In a sense life in the high-rise had begun to resemble the world outside - there were the same ruthlessness and aggression concealed within a set of polite conventions."

$$
\text { - J. G. Ballard, High-Rise }
$$

\subsubsection{HIGH-RISE}

BY J. G. BALLARD

\section{DIVISION}

Ballard's novel High-rise discusses an isolated environment of a modern forty-storey apartment complex which over time begins to fail and blur the moral line between right and wrong among its residents. It is filled with a wide range of personalities, who are successful and unsuccessful professionally, and thrive in the psychological pressures faced in a high-rise lifestyle. The tower serves as a utopian dream that is self-sufficient, like a small vertical city, with all its amenities. It is divided into three sections based on the class system, by amenity, and services in-between, where the desirability of space is dependant upon the floor level. The chaos of High-rise is unfolded through the lenses of three residents, one from each section, that accept and later reject the moral framework set by the residence as, metaphorically, the Pandora's box begins to open inwards one by one.

This small city continuously indulges each of the 2,000 tenants individually in isolation with a set of laws like a high-tech prison. These rules bind the tenants' true nature in line to allow a peaceful coexistence. However, as the story progresses, the failures and rejections faced from the once sufficient amenities, such as pools and stores, slowly brings out tenants' animalistic urges to ensue chaos. In addition, the division of tenants in each section creates a form of hierarchy, where no one cared about the individuals more than two levels below them.
The building serves as a platform for the pursuit of a free, modern lifestyle, however, against all odds the residents who were once united seamlessly in a utopic dream, without hesitation begin to chip away at the façade of perfection the building enabled. Its inevitable chaos begins with the murder of a dog in a swimming pool, and continues to unfold rapidly through random violence, power outages, and sexual molestation. The exploration here describes the attractiveness of a modern apartment complex alongside social inequalities that eventually shatter the architect's vision of the future into something barbaric. The tenants are content with what is being offered, however, with no connection to the outside world, and everything being available within the proximity, the overall framework of the apartment become a liveable prison. Which leaves us with the question, should buildings have their own set of social systems? And does detachment from the outside world always lead to an immoral lifestyle? 


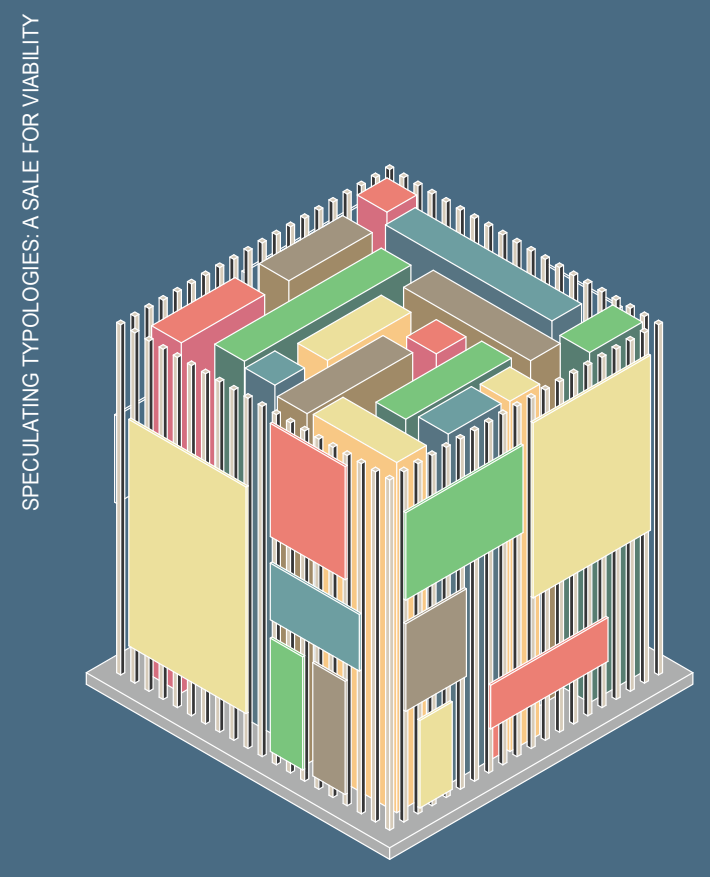

Fig.5.7 Diagrammatic interpretation of Kingdom Come
Fig.5.8 Physical model of the Kingdom Come interpretation

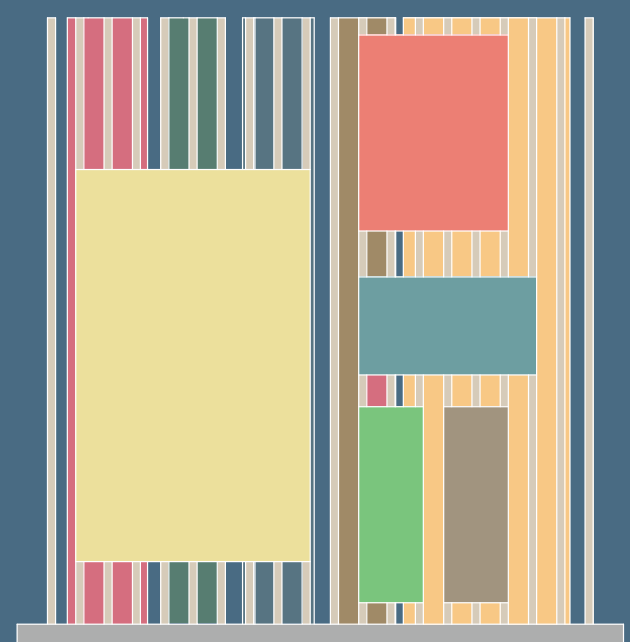

5.7

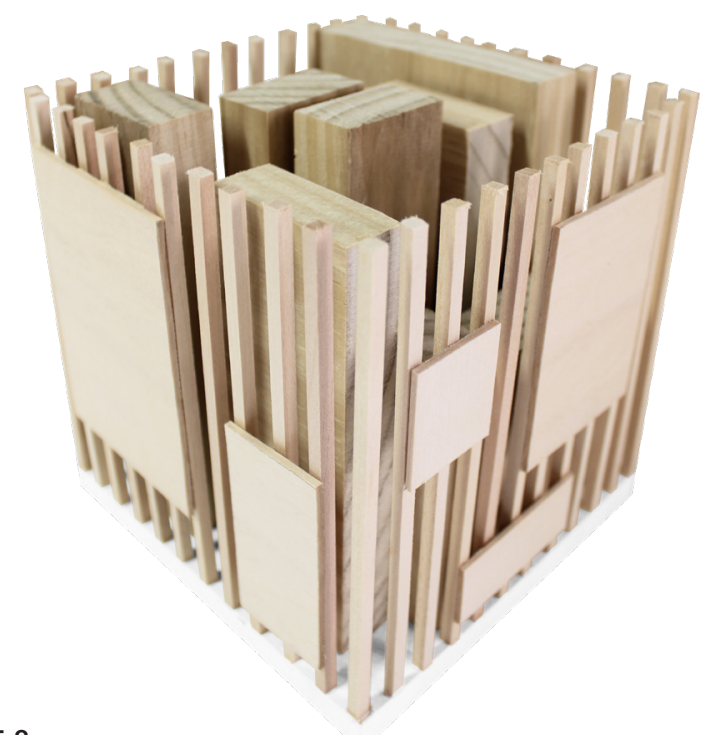

5.8 
"'This isn't just a shopping mall. It's more like a...' 'religious experience?' 'Exactly! It's like going to church. And here you can go every day and you get something to take home"

\section{- J. G. Ballard, Kingdom Come}

\subsubsection{KINGDOM COME}

BY J. G. BALLARD

\section{RETAIL}

Ballard's novel Kingdom Come is an account of consumer culture at an extreme that has made everyone a fascist. Shopping is a spiritual experience and Brooklands' MetroCentre is the cathedral. The initial premise of the story states that consumerism is essential in a modern society, where people should continuously spend rather than save. The consumers in this case are the suburban citizens, who are essentially children as they are easily bored and need action. There is nothing to do besides shopping to find daily satisfaction in these suburbs and rooting for the local sports team to boost one's adrenaline. Therefore, when the shopping centre closes for the afternoon, and locals' adrenaline level are at peak after the evening sports game, the only way to express these feelings is through racist violence on the streets.

For the protagonist, Richard Pearson, who at the start of the story lost his father in a shopping centre shooting, is in search for suburban violence's main instigator. Soon he realizes that the violence is caused by everyone rather than a single entity. Everyone is bored. The problem with the shopping ritual is that it is a momentary satisfaction and is followed by disappointment and emptiness after going home. People go to the shopping centre in search for something worthwhile to invest into; it is a collectively celebrated ritual.

Pearson with his advertisement background cannot resist the temptation to experiment with the social system of the suburbs and partners up with David Cruise, a local cable host who had a great influence over the suburban citizens, to instigate a system that combines consumerism and fascism. This new system does not have a message, rather it is a method to empower people's dreams, fears, hopes, and needs. Insanity in ordering everyone is the only way to move forward and to distract the public enough to control the violence. Cruise, symbolically as a führer, attempts to guide the people through the vast shopping desert, where boredom has led many to elective psychopathy. The concept of escaping a shopping mall is absurd, everyone needs to compulsively buy everything they can or else they fail as a citizen. However, there is a limit to the number of household amenities, pieces of clothing, or even vehicles one can purchase, so what happens when you reach that limit? This novel brings forth the question does consumerism define all that we are today, and should we escape it? 

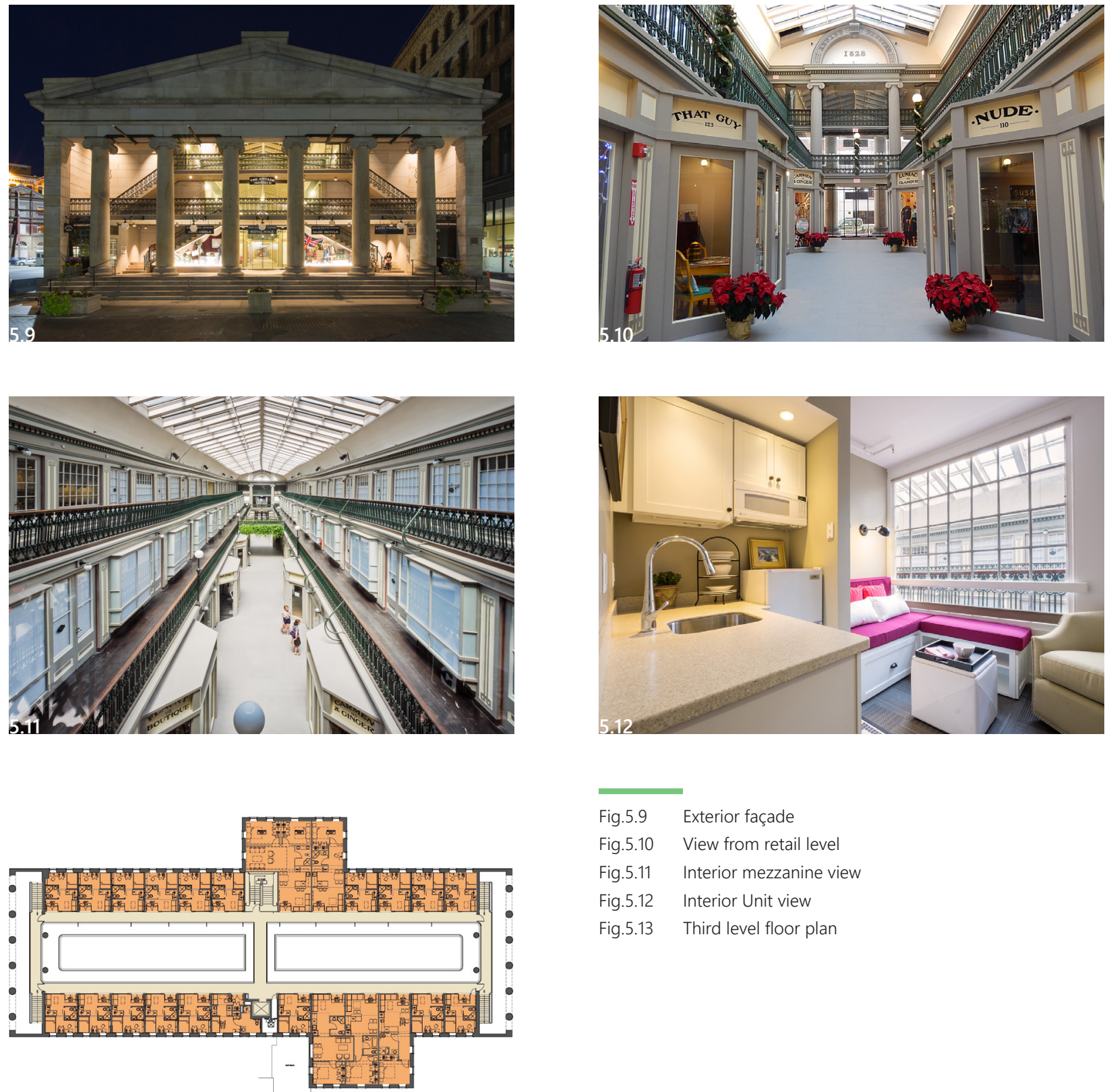

Fig.5.9 Exterior façade

Fig.5.10 View from retail level

Fig.5.11 Interior mezzanine view

Fig.5.12 Interior Unit view

Fig.5.13 Third level floor plan 
"Not only does it [the central atrium] provide filtered light to the units, but it becomes the 'public street' connecting neighbors."

- Michael Abbott

\subsubsection{ARCADE PROVIDENCE}

NORTHEAST COLLABORATIVE ARCHITECTS [NCA]

\section{ADAPTIVE REUSE}

A site built for the purpose of social interaction and the purchase of commercial goods has now become part of the micro-loft movement. The Arcade Providence, constructed in Providence, Rhode Island in 1828, was once the oldest indoor shopping mall in the United States. ${ }^{8}$ The idea of shops being laid out in rows inside of an enclosed environment was, at the time, considered a novelty, in comparison to the independent stores located on the outside. Shopping was redefined as a form of sheltered entertainment, where users had the option to either stroll through the stores or engage in a dialogue with others in the central open corridor.

The current housing shortages in growing cities invite city planners and architects to rethink the use of space and providing an opportunity to create micro livingunits. Micro-lofts are the next big housing trend in the United Kingdom, Poland, China, Japan, and in American metropolises, measuring from fifteen to forty square metres. $^{9}$

A second issue in cities is preservation, which has been widely discussed since the post-war period. Strategies for historic structures to be made economically viable enable some degree of preservation in urban environments. In the case of Arcade Providence, the three-storey Greek Revival facility has been transformed into seventeen retail units of nineteen square metres and micro-lofts that range

between twenty-one and forty-two square metres. ${ }^{10}$ By designing micro apartments that preserve the building and provide housing, this project addresses both issues. The units were made rentable in a price range of $\$ 850$ to $\$ 1,500 .{ }^{11}$ Each unit includes kitchenette, shower stall, living space, bedroom, and window openings that permit natural lighting from the glass enclosed core. The units, however, are not equipped with stoves or ovens since the local building code prohibit the use of these cooking devices in the designed unit sizes. ${ }^{12}$

The project's uniqueness lies in the programming of residential units within a facility that is mostly composed of open common space and retail. Northeast Collaborative Architects designed the units in accordance to the minimum standard of living in Providence. The final design advertises a lifestyle that many single households are increasingly accepting due to convenience and affordability, an urban community. The idea of living in proximity to recreational facilities and work is becoming preferable to suburban living conditions that require long commutes. Designing of one micro-loft facility will not solve the housing crisis, but the revival of underused commercial infrastructure is a great way to form communities in cities. 

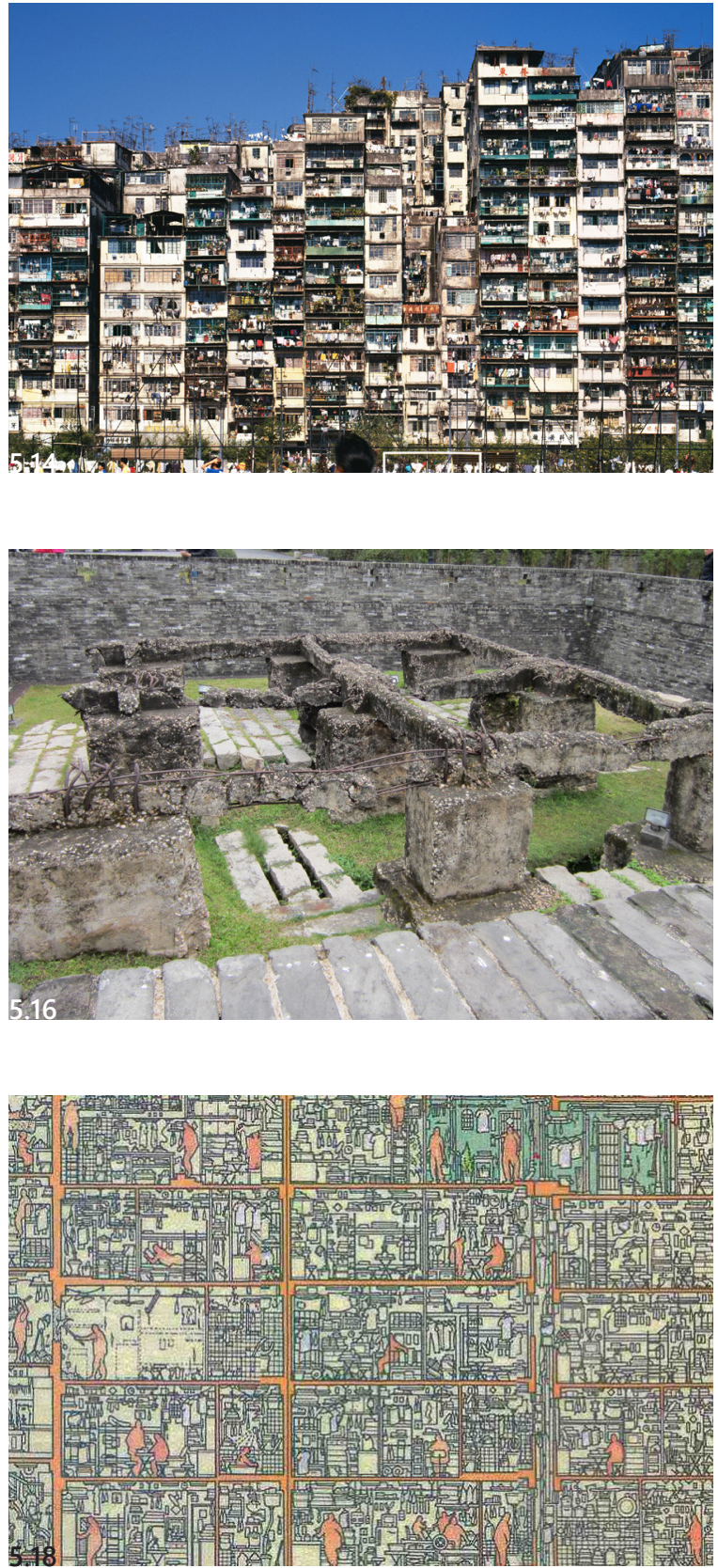
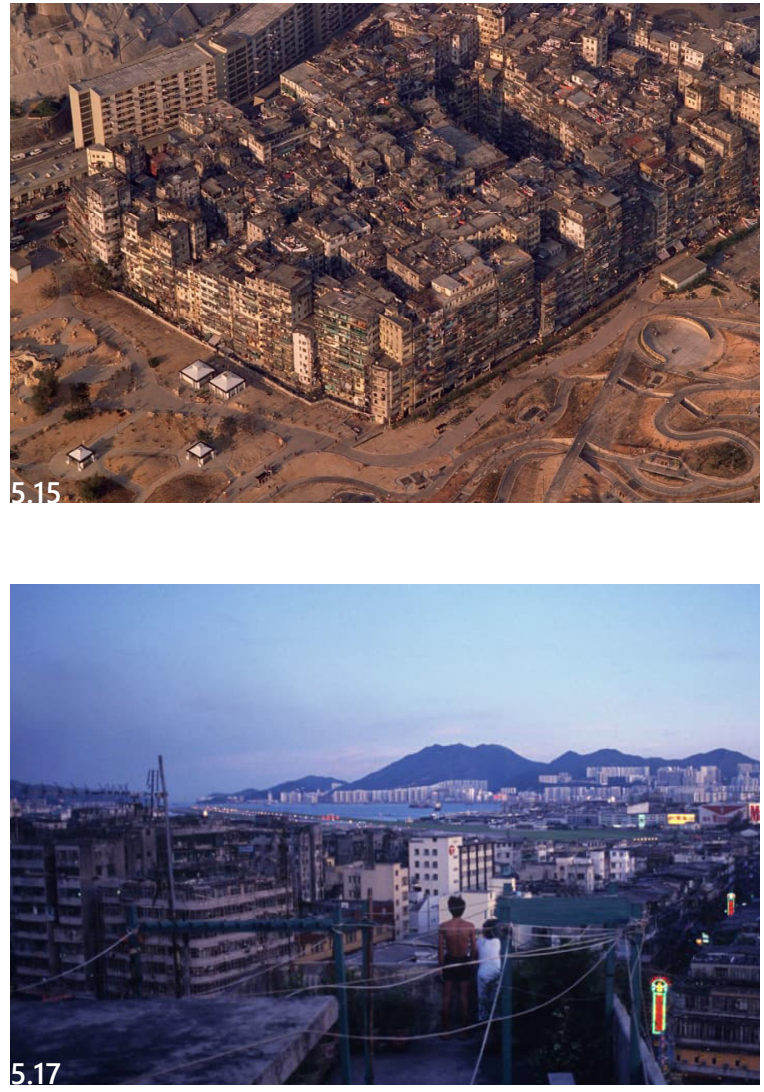

Fig.5.14 Kowloon Walled City exterior

Fig.5.15 Kowloon Walled City aerial view

Fig.5.16 Ruins left behind from Kowloon Walled City removal

Fig.5.17 Terrance view overlooking the City's border

Fig.5.18 Diagrammatic cross section of the city 
"Every available nook and cranny was inhabited, while the connecting alleys, stairways and corridors were reduced to an absolute minimum."

- Ian Lambot

\subsubsection{KOWLOON WALLED CITY}

\section{DENSITY}

Kowloon Walled City was known as the world's most densely populated place, a lawless zone and the "city of darkness." But to its residents it was an affordable refuge in a densifying city. Built as a fort by the Chinese government in 1846, the Kowloon Walled City was originally designed to keep the British expansion beyond the island of Hong Kong. ${ }^{13}$ Throughout the twentieth century, people moved to this six-acre area out of lack of options and to escape or take advantage of lack of law present behind the walls. ${ }^{14}$ The available space slowly began to densify through the construction conducted by the inhabitants. To maximize the available space, 350 or more buildings of ten to fourteen storeys were interconnected tightly with bridges and stairways for circulation.

As the city grew and the population rose to around 40,000 people, at its peak, it became clear that this form of living was unsustainable, hence the mid-1960s and onwards slowly witnessed the involvement of the Hong Kong authorities. ${ }^{15}$ The circulation of the City, including stairs, alleys and corridors, evolved unplanned, although, in the end a map of the City was developed to navigate the livable labyrinth. Its electrical and hydro source were initially available to accommodate the number of users at the time, however illegal electrical connections and water deliverymen were a common sight as the number of inhabitants increased. ${ }^{16}$ The increasing height of the typology was unavoidable and was built without any architectural and engineering input, and in the end morphed into a form that broke all of the building standards to accommodate the needs of the people.

The city not only survived until 1993, but rather thrived in its lawlessness. The majority of the units present in the City were apartments of differing size and quality with area between twenty to twenty-five square metres. ${ }^{17}$ These units were adaptable for the residents' due to the absent zoning standards and the flexible structure. This allowed the space to be used for any program, including a factory, residence, workshop, and more. ${ }^{18}$ The sheer density of the city brings to question the present urban development that continues to shrink the residences to accommodate everyone. Its practicality continued to grow stronger in its disharmonious evolution in an unplanned manner by the occupants, in the end creating a dense maze that was loved and used by its residents in extreme close proximity. 

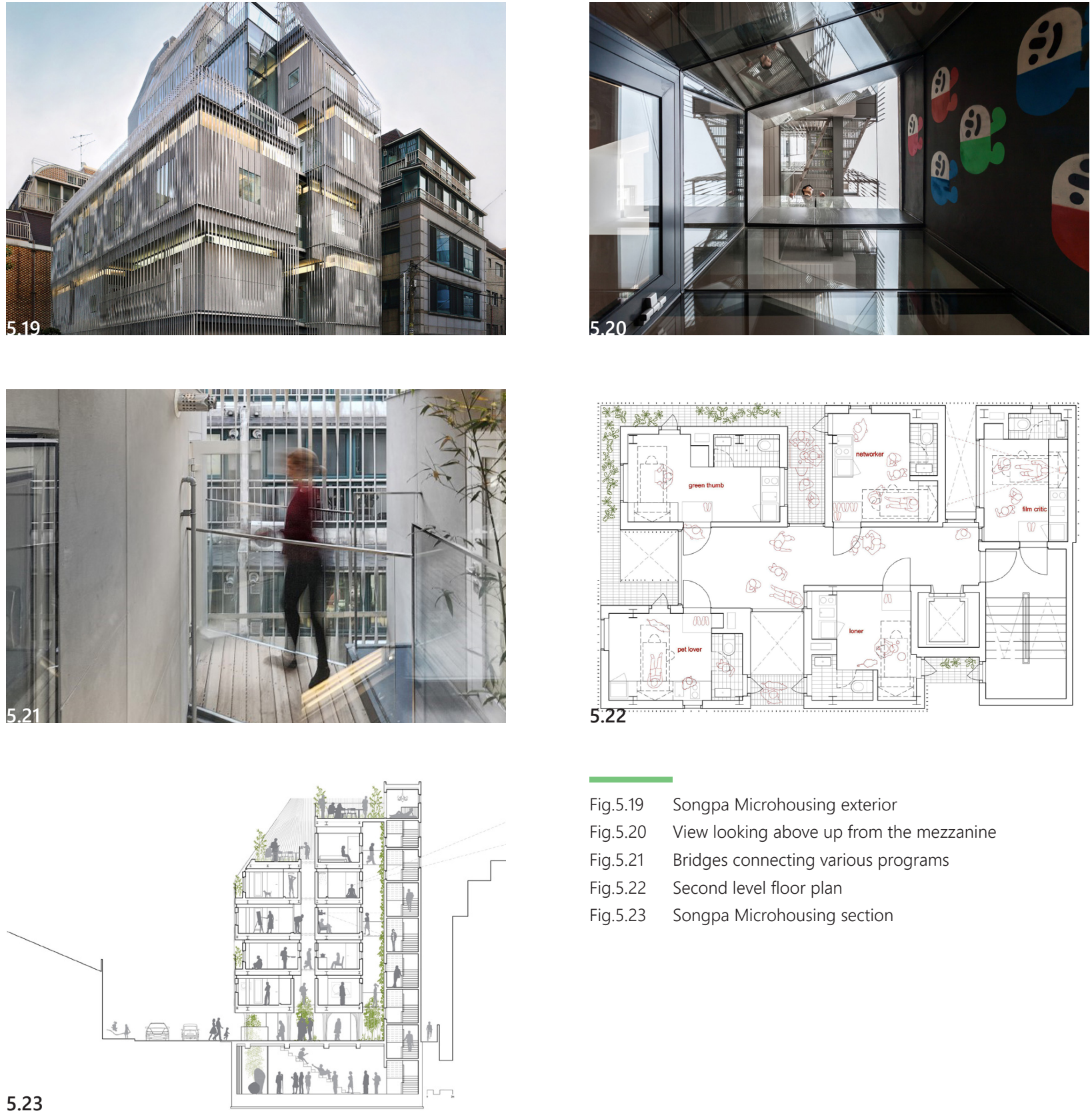

Fig.5.19 Songpa Microhousing exterior

Fig.5.20 View looking above up from the mezzanine

Fig.5.21 Bridges connecting various programs

Fig.5.22 Second level floor plan

Fig.5.23 Songpa Microhousing section 
"The idea is to take a small area and make it into a comfortable living environment that can be adapted according to changing needs."

- Jinhee Park, Principal Architect, SsD

\subsubsection{SONGPA MICRO-HOUSING}

SSD

\section{I V ING}

Affordable housing is a global problem as cities continue to densify with increasing housing costs and population. The viability of a functioning house is dependent upon its social and physical spaces, and when the unit types get smaller, like with micro-housing, the danger of decreasing social value increases. In South Korea, similar to many cultures, young adults traditionally leaned towards a joint family household after marriage, as a result of the increasing the demand for multi-bedroom housing units in multiple neighbourhoods. The decrease in population and increase in one- and two-person households, however, has brought forward change in the Korean society, which developers have rushed to accommodate through low interest construction loans to built microhousing apartments. ${ }^{19}$

Micro-housing is not a foreign concept for the Korean housing market, since many unique types like goshiwon, oneroomtel, livingtel, and officetel already exist to cater to a portion of their population. ${ }^{20}$ Songpa micro-housing, like ambiguous gel around a tapioca pearl, creates a soft social intersection between public/private and interior/ exterior. ${ }^{21}$ The project treats public spaces used by the tenants and size of the units as two separate ideas that are fused through a careful layout. The size of the unit is smaller than Seoul's more typical 200- to 300-square-foot micro-housing, which also makes them more affordable. ${ }^{22}$ The units can be used for various functions including galleries, work space, study area and more to encourage the occupants to live with flexibility and to not move out.

Each unit is very limited in size, however, they create the feeling of spaciousness. They are very compact and contains everything an individual would need, including kitchen, bathroom and laundry machine, alongside a Murphy bed and pull out table, yet they do not feel claustrophobic. ${ }^{23}$ Every unit, in addition, is naturally lit with glazed openings along the top edges. The fourteen units occupy six storeys in an urban setting, and are arranged carefully to create a variety of public, semi-public, semi-private, and private spaces that can be creatively occupied. ${ }^{24}$ These spaces are enclosed by weaved stainless steel cladding that controls visibility to the outside world and occupant privacy. Downsizing has become a popular trend among young adults and older generations, and the project presents a modern approach to the micro living condition in a densifying urban area. Micro apartments are commonly mistaken as being claustrophobic, however this airy design contradicts that very belief. 

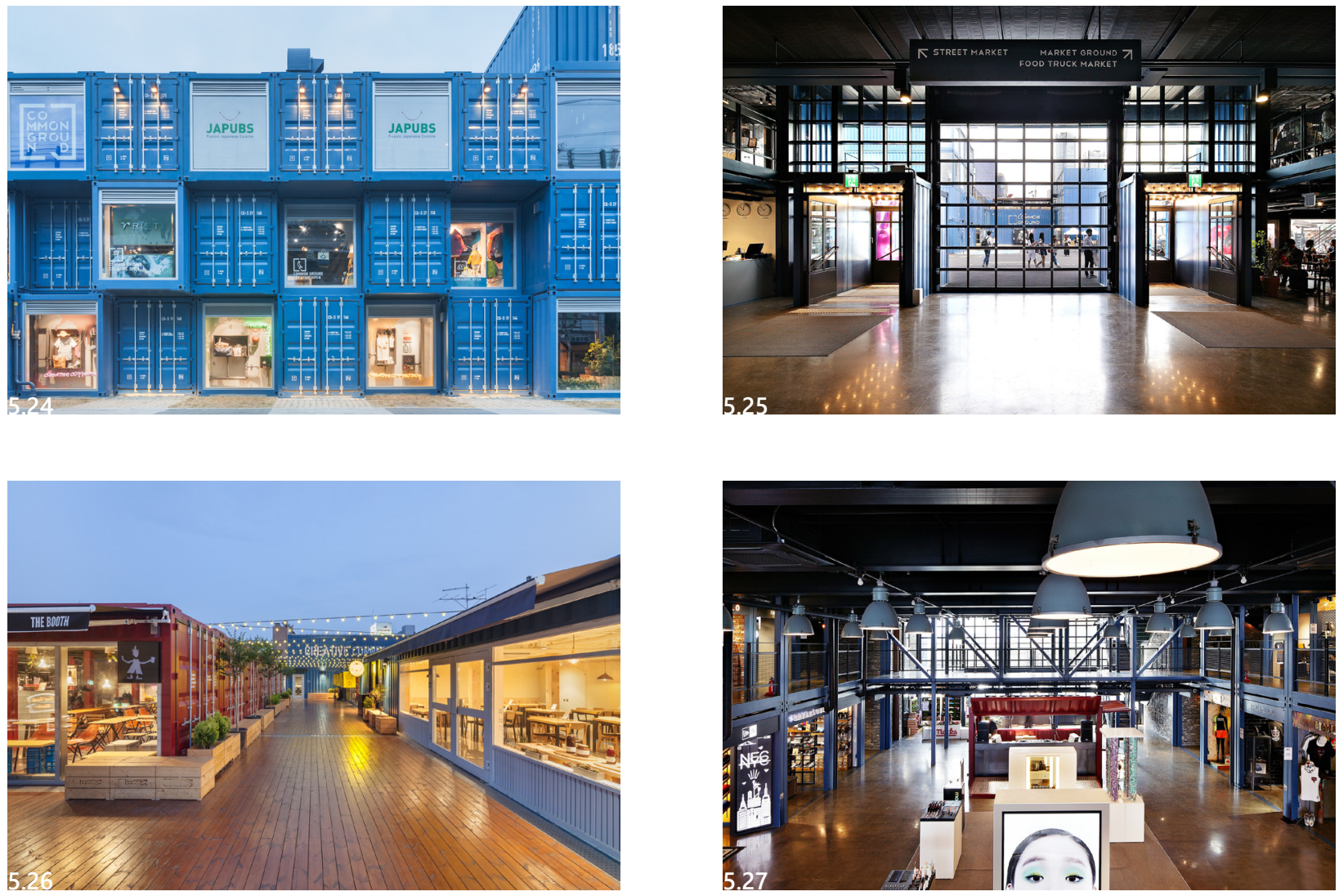

Fig.5.24 Common Grounds exterior

Fig.5.25 Common Grounds entrance

Fig.5.26 Roof shopping level

Fig.5.27 Indoor shopping view

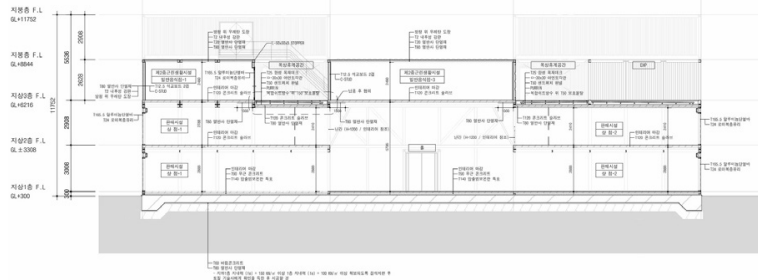

Fig.5.28 Common Grounds section 


\subsubsection{COMMON GROUNDS}

URBANTAINER

\section{COMPARTMENTALIZATION}

Shopping is a human activity that satisfies needs and desires, and will continue to exist in various forms. Each business advertises itself differently to attract possible consumers to buy their products. The factors that create a good shopping environment are based on the versatile products, arrangements, and overall attractiveness. But as part of this work to attract customers, shopping trends change fairly quickly creating cravings to get a hold of every new product that hits the market. The shops themselves need to attract customers. I am proposing that the guidelines for the future of such shops is to adopt a system that is attention grabbing, flexible enough to be transported, and spacious enough to accommodate distributers.

One such example is, Common Ground, that uses a prefabricated shipping containers as shopping modules on unused land, located in the middle of a city to create a vibrant shopping environment. This brand features trendy food culture, and a wide palette of shops and activities that connect people together with valuable exchange in mind. ${ }^{25}$ There is often an assumption that shipping container architecture is a low-quality structure lacking design consideration, however, their treatment here highlights them further by encasing the interior with further industrial treatment, enclosing the consumers within a 200 shipping container structure. ${ }^{26}$ Its impermanence is advantageous for the owners because of a short land

lease, and hypothetically the owner can easily move the shopping mall elsewhere within a decade with ease. Not only is it easy to transport, but also quick to construct.

In order to maximize the efficiency of the rectangular plot, Common Ground's the program is based on a centre square that connects two differently programmed buildings: street market and market hall. ${ }^{27}$ The containers have a dual function to create an impact both on the busy exterior and open interior, and also serve as the structure in the vertical construction. The way in which they are designed enables multiple occupancies that can continue to be reused either as shops or even offices if they are no longer needed in the mall. All areas are also open for regular cultural events and create a space in which visitors not only consume, but actively participate. ${ }^{28}$ Shopping malls commonly tend to trap the consumers in a neverending shopping maze to maximize the profit. However, Common Ground was conceptualized to be more open and flexible in comparison with the terraces, central square, and indoor public areas. 


\section{END NOTES}

1 Leonard Orr. "The Utopian Disasters of J. G. Ballard." CLA Journal 43, no. 4 (2000): 479. http://www.jstor.org/stable/44325010.

2 Wilson D. Harlan. J. G. Ballard (Modern Masters of Science Fiction) (Champaign: University of Illinois Press, 2017), 10. https://ebookcentralproquest-com.ezproxy.lib.ryerson.ca/lib/ ryerson/detail.action?doclD $=5161247$.

$3 \quad$ lbid., 9.

$4 \quad$ John Fletcher. "James Graham Ballard." In British Novelists Since 1960, edited by Jay L. Halio. Dictionary of Literary Biography Vol. 14. Detroit: Gale, 1983. Literature Resource Center (accessed June 10, 2018). http://link.galegroup. com/apps/doc/H1200002384/LitRC?u=rpu_ main\&sid $=$ LitRC\&xid $=49808 d 5$ c .

5 Philip Hancock, André Spicer, and Zhongyuan Zhang. "Hyper-Organizational Space in the Work of J. G. Ballard." Organization 15, no. 6 (2008): 896. doi:https://doi-org.ezproxy.lib. ryerson.ca/10.1177/1350508408095819.

Becca Rothfeld. "J.G. Ballard's Eerily Accurate Dystopias." The New Republic, March 14, 2018. Accessed June 10, 2018. https://newrepublic. com/article/147456/jg-ballards-eerilyaccurate-dystopias.

7 Orr. "The Utopian Disasters of J. G. Ballard," 480.

8 Thomas S. Andolfo, M. A. I., and S. R. A. "The "Mall"

9

in "Mall"." Valuation 18, no. 3 (2013): 12. http:// ezproxy.lib.ryerson.ca/login?url=https:// search-proquest-com.ezproxy.lib.ryerson.ca/ docview/1448810422? accountid=13631. 
Ian Lambot. "Self Build and Change: Kowloon Walled City, Hong Kong." Architectural Design 87, no. 5 (2017): 127. doi:10.1002/ad.2225.

18 Ibid., 129.

19 Helen Roxburgh. "Seoul occupancy: city adapts to accommodate its singletons." Financial Times, April 28 2017. Accessed March 3, 2018. https:// www.ft.com/content/b9440e12-25ba-11e7a34a-538b4cb30025.

20

n.d. "Songpa Micro Housing / SsD." ArchDaily, December 11, 2014. Accessed March 3, 2018. https://www.archdaily.com/576302/songpamicro-housing-ssd.

n.d. "Songpa Micro-Housing." SsD. Accessed March 4, 2018. http://www.ssdarchitecture. com/works/residential/songpa-microhousing/. n.d. "Songpa Micro Housing / SsD."

Roxburgh. "Seoul occupancy: city adapts to accommodate its singletons."

n.d. "Songpa Micro-Housing." World-Architects, August 17, 2015. Accessed March 3, 2018. https://www.world-architects.com/it/ architecture-news/reviews/songpa-microhousing.
Young Kim and Lauren Teague. "Urbantainer breaks down the negative stereotypes of modular building." Frame, March 21, 2017. Accessed March 5, 2018. https://www.frameweb.com/ news/urbantainer-breaks-down-the-negativestereotypes-of-modular-building.

n.d. "Common Ground / URBANTAINER." ArchDaily, February 16, 2017. Accessed March 6, 2018. https://www.archdaily.com/805302/ common-ground-urbantainer.

28 n.d. "Common Ground." Archello. Accessed March 6, 2018. https://archello.com/project/ common-ground. 


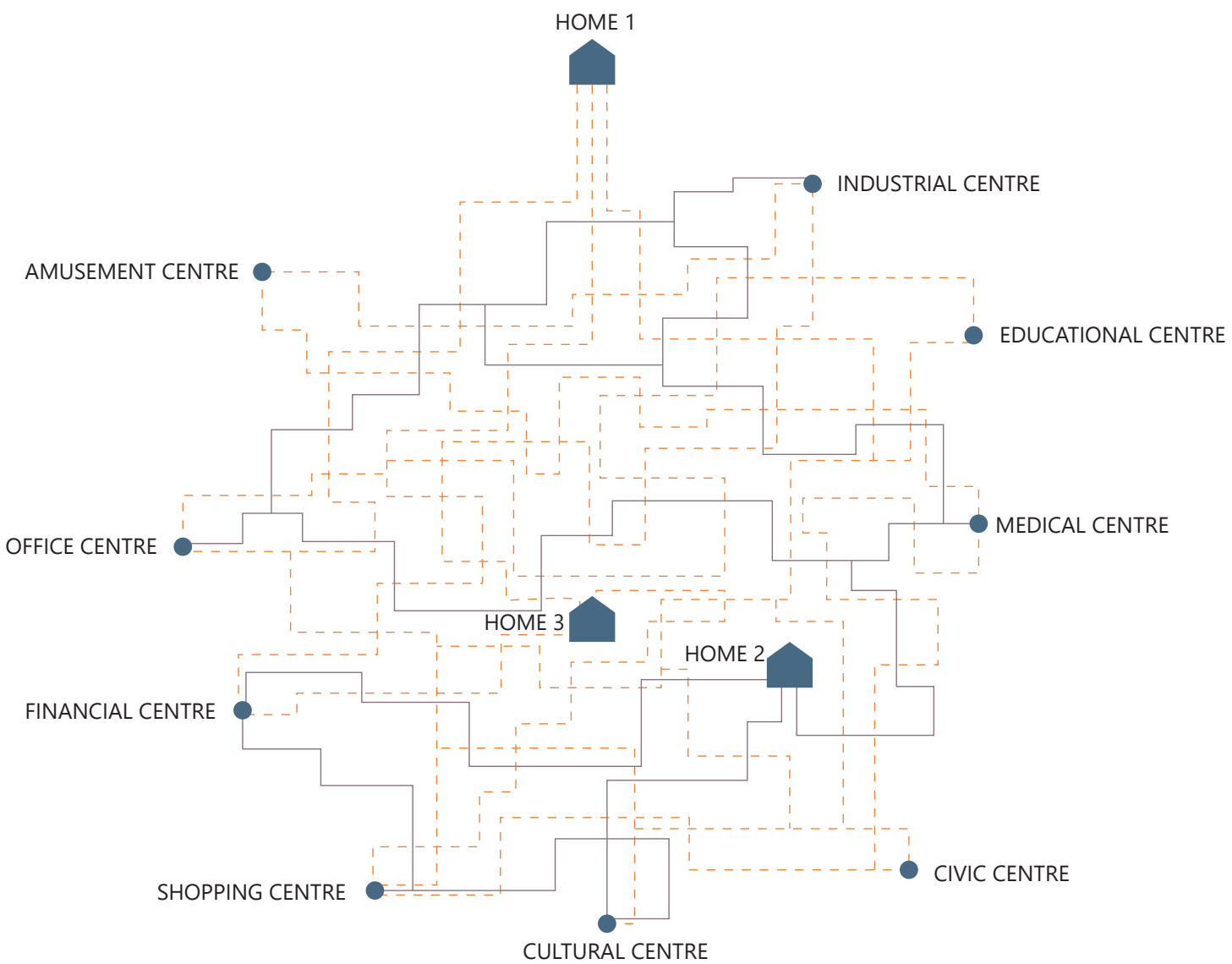

"'This isn't just a shopping mall. It's more like a...' 'religious experience?' 'Exactly! It's like going to church. And here you can go every day and you get something to take home"

- J. G. Ballard, Kingdom Come

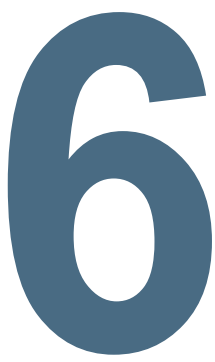




\subsection{DESIGN PROJECT}

\subsection{HISTORY OF MALLS}

The history of retail, similar to human evolution, has consistently been evolving to better assist the consumers in each era. It holds multiple meanings depending on the time, methods, and culture, but according to the Oxford Dictionary, retail is a sale of goods to the public in relatively small quantities for the use of consumption rather than for resale. ${ }^{1}$ Currently, we should distinguish whether the sale is being conducted physically or digitally and the way it is experienced because this impacts the physical world. The consumers of the twentieth century bought their products from a "brick and mortar store," and since then, the method has drastically changed.

Shopping is continually being reinvented, reformulated, and reshaped to keep up with the subtlest changes in the society. ${ }^{2}$ This includes the suburban boom of the 1950s after the Second World War, inventions and items created during, before and after the industrial revolution, and

Fig.6.1 "The Suburban Labyrinth", Victor Gruen

If home is the primary place, and work is a second place, then a third place anywhere else one goes to be around other people - to build community, to hang out, to feel connected. changes in how the ideal lifestyle is defined. The products that people once readily produced by themselves, such as food and clothing, are now available in bulk at specific stores. These stores were designed to entice the consumers to linger and set their impulses free. It is a typology founded on a culture of consumerism that is fuelled by the capitalist system. Existing as a cluster, a strip, or standalone space, this form of architecture has become an integral part of human life. Not only is shopping melting into everything, but everything is melting into shopping. ${ }^{3}$ It 


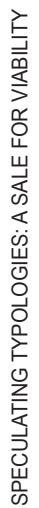
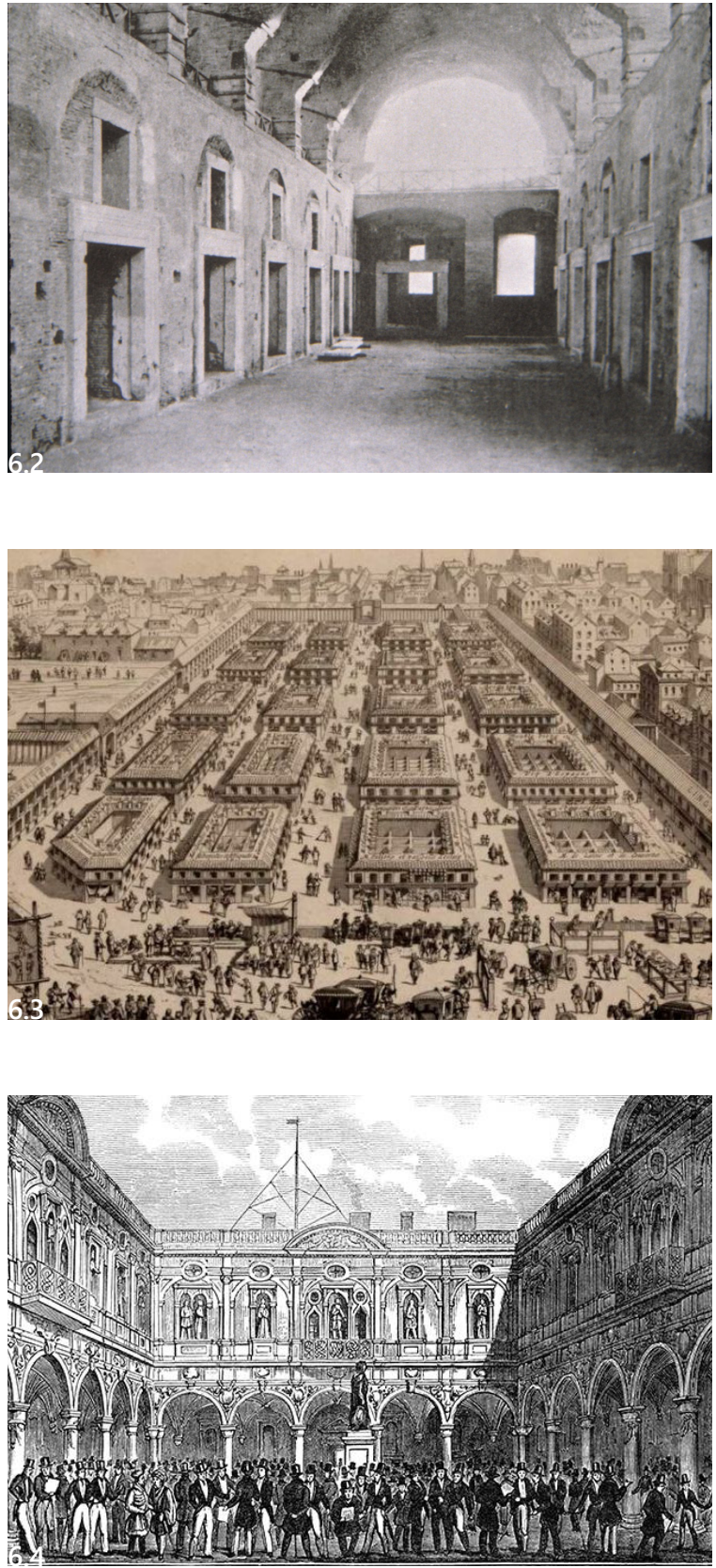
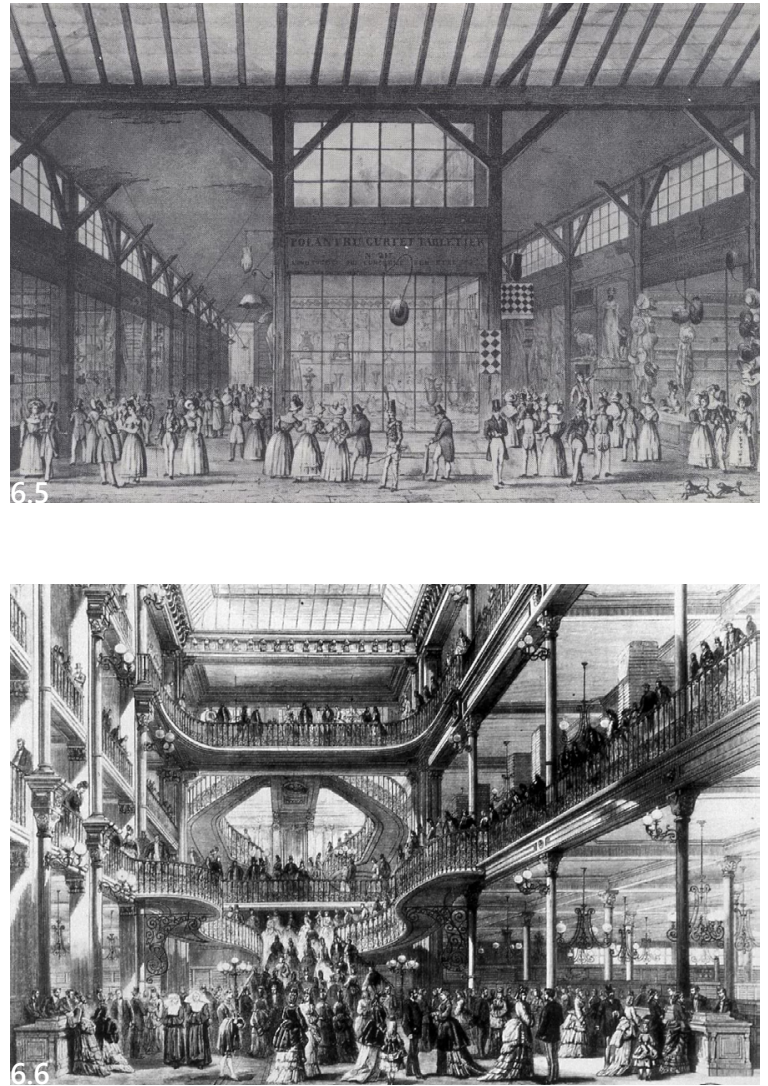

Fig.6.2 Trajan Market, Rome, 110

Fig.6.3 Foire St. Germain, Paris, 1462

Fig.6.4 Royal Exchange, London, 1566-68

Fig.6.5 The First Arcade, Les Galerie de Bois, Paris, 1786

Fig.6.6 Au Bon Marché, Paris, 1852 
has a tight grip over human life due to the values assigned to all of the activities and products. However, regardless of its value, a trip to the store for a shirt can easily end the with purchase of a different product. There is no escape from its planned obsolescence that drives the market with new products periodically to explore from one stall to the next with friends, family, or alone.

Shopping is an activity that includes decision making and can easily be swayed by the beautified consumerist architecture. Shops try to look beautiful, welcoming, and are attractively laid out to encourage the consumers to compulsively purchase. ${ }^{4}$ In previous generations, prior to the internet's existence, which makes searches and reviews of products more easily accessible, people relied on advertisements, reviews and in-store experiences or personal feedback from other users before any purchase. The act of purchasing, that once used to be a public performance, can now be a solo act by the consumer at any location. However, whether it is a shopping street, a bazaar, or a department store, commercially oriented typologies were always intended to connect with population centres and were designed for public accessibility. ${ }^{5}$ The connectivity found between shopping and city has historical lineage that can be traced back to the Greek agora, Roman imperial for a, or even bazaars found in the Middle East. Places like Trajan Market, the Grand Bazaar, and Les Galeries de Bois have become some of the famous predecessors for the current shopping culture. In addition, architectural elements like the French arcade, from the nineteenth century, had created a new level of sheltered sophistication, which was further enhanced after the mechanical inventions of the modern age permitting the physical expansion of the space. ${ }^{6}$ The path paved by the shopping culture clearly establishes itself as the driving force for any city development, a place around which the public congregates, socializes, and even trades.

Shopping has a firm grip on the surrounding spaces, buildings, and city culture. ${ }^{7}$ Its formal qualities are dependent upon the period in which it exists, since they transform alongside the technologies and advancements made during that period. This includes, but is not limited to, creation of currency, the arcade, printing, road systems, lighting, glazing, advertisement, cash registers, credit cards, air conditioning, skylights, supermarkets, and shopping malls. The Harvard Design School: Guide to Shopping, developed under the supervision of Rem Koolhaas, studies the shopping culture more in depth along its technological and urban influences. According to Victor Gruen, best known as the pioneer of the indoor shopping mall design, retailing could produce a new Renaissance that married commercialism and culture, business and beauty. ${ }^{8}$ It has become a delicate profit making formula that allows the people to spend more time within a certain perimeter, since the more time spent in the given mall tend to result 


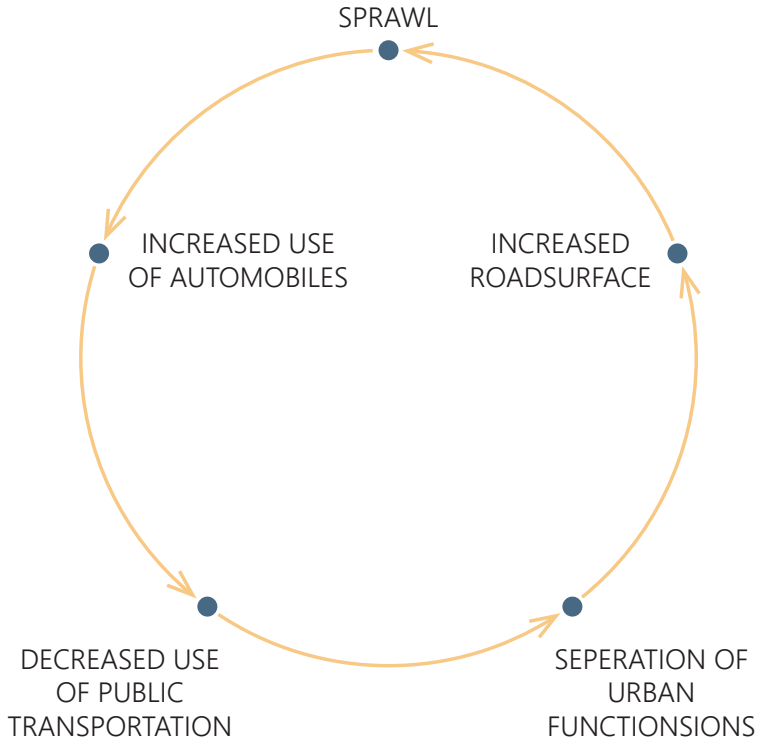

6.7

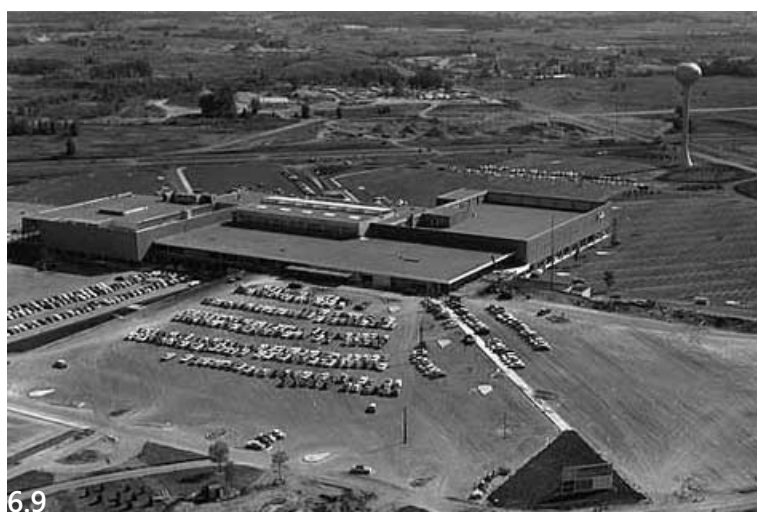

N
HOME 1

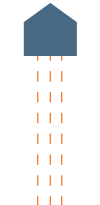

MULTIFUNCTIONAL CENTRE

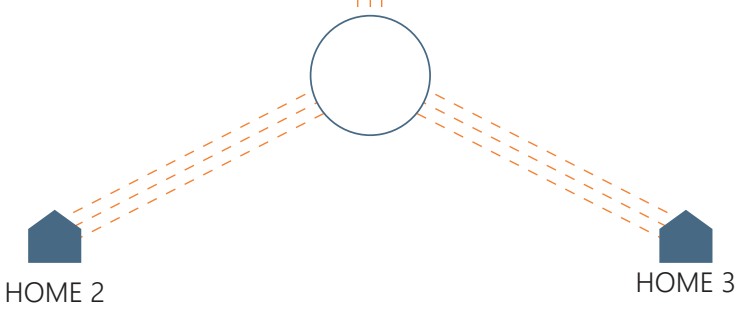

HOME 2
6.8

Fig.6.7 "The Vicious Circle", Victor Gruen

Fig.6.8 "Multi-functional Centre", Victor Gruen

Fig.6.9 Southdale Mall, 1956

Gruen saw his structure as an architectural panacea that would resolve environmental, commercial, and sociological problems with the creation of a single building, the shopping mall. A design that would get people out of their cars to walk indoors in an environment full of greenery and shops. 
in a larger profit. The appealing display windows and bright signage are placed before the public in a manner so that the observer has a desire for them, and enters the store to make the purchase. ${ }^{9}$ They are also a trademark for individual stores that normally exist as a collection of sites. All in all, this typology not only identifies with the public, but also defines the city it exists in.

Victor Gruen, an Austrian born architect, is responsible for introducing the most common form of consumerist typology that exists today, the indoor shopping mall. Individual stores did not matter to him, but what did matter was the stage and scale for retailing in a large context. ${ }^{10}$ However, the department store in many ways can account for the beginning of modern consumerism. The Industrial Revolution enabled mass production at a rapid rate, that in turn created exclusive brands and offers that served the public with multiple options. To distribute these products, they were categorized by brands and presented to the public under one roof, the department store. On the other hand, in the case of the shopping mall, rather than shopping taking place in the city, the city is taking place within the shopping experience. ${ }^{11} \mathrm{~A}$ single shopping mall is now a carefully laid out formula built of multiple stores that complement one another to continuously generate profit. The idea was originally brought to Europe in a pictorial fashion from the bazaars of the Middle East, and exhibits multiple influences: classical colonnades, markets and basilicas. ${ }^{12}$ The most important distinction between the shopping conducted prior to shopping malls and after is the parking lot and the ownership of space. The malls are located within an accessible radius that can be reached on foot, by car or any other form of transit. Even though it accommodates numerous tenants, the owner has a profit driven mindset that carefully screens each tenant. However, what many shopping mall designers had forgotten is the original idea behind its creation. Gruen intended for his mall to be, "a small complete neighbourhood with as many amenities as possible with several hundred residential units, shopping facilities, and institutional facilities such as churches, community buildings." ${ }^{13}$ It was an enclosed city, but also a product itself that was being marketed to the users.

The first climate-controlled indoor mall, the Southdale Center in Edina, Minnesota, was opened in the 1950s to realize Gruen's ideas for the new neighbourhood clusters (figure 6.9). The client, J. L. Hudson, one of Detroit's leading department stores, was seeking space expansion, and Gruen took this as an opportunity to introduce a new form of retail that required far greater cooperation among tenants than previous strip malls. ${ }^{14}$ As an Austrian immigrant, the inspiration that drove Gruen to create the indoor mall was of the town centre, and these new indoor spaces were to be a reflection of that by acting as a civic space for modern community participation. However, in 


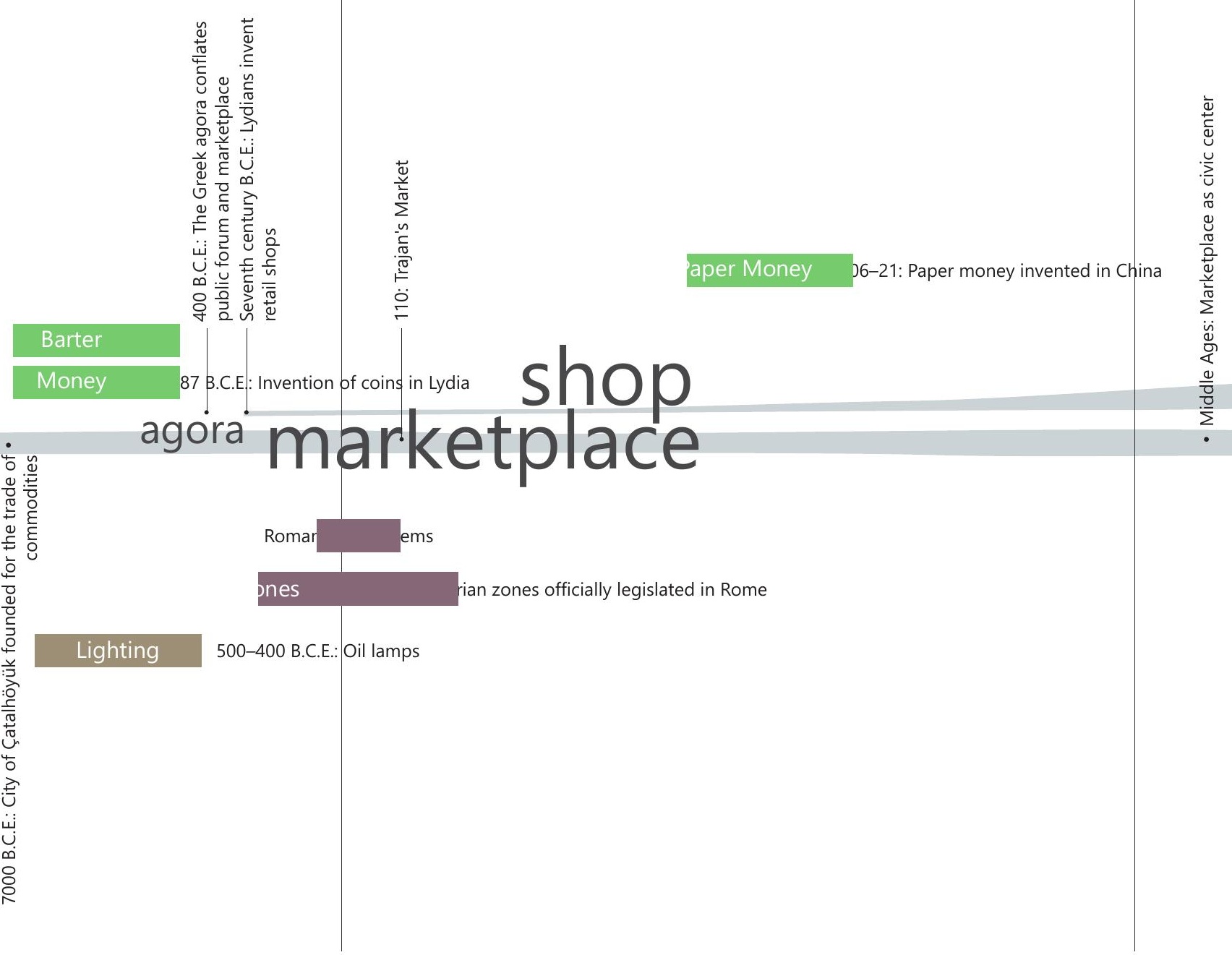




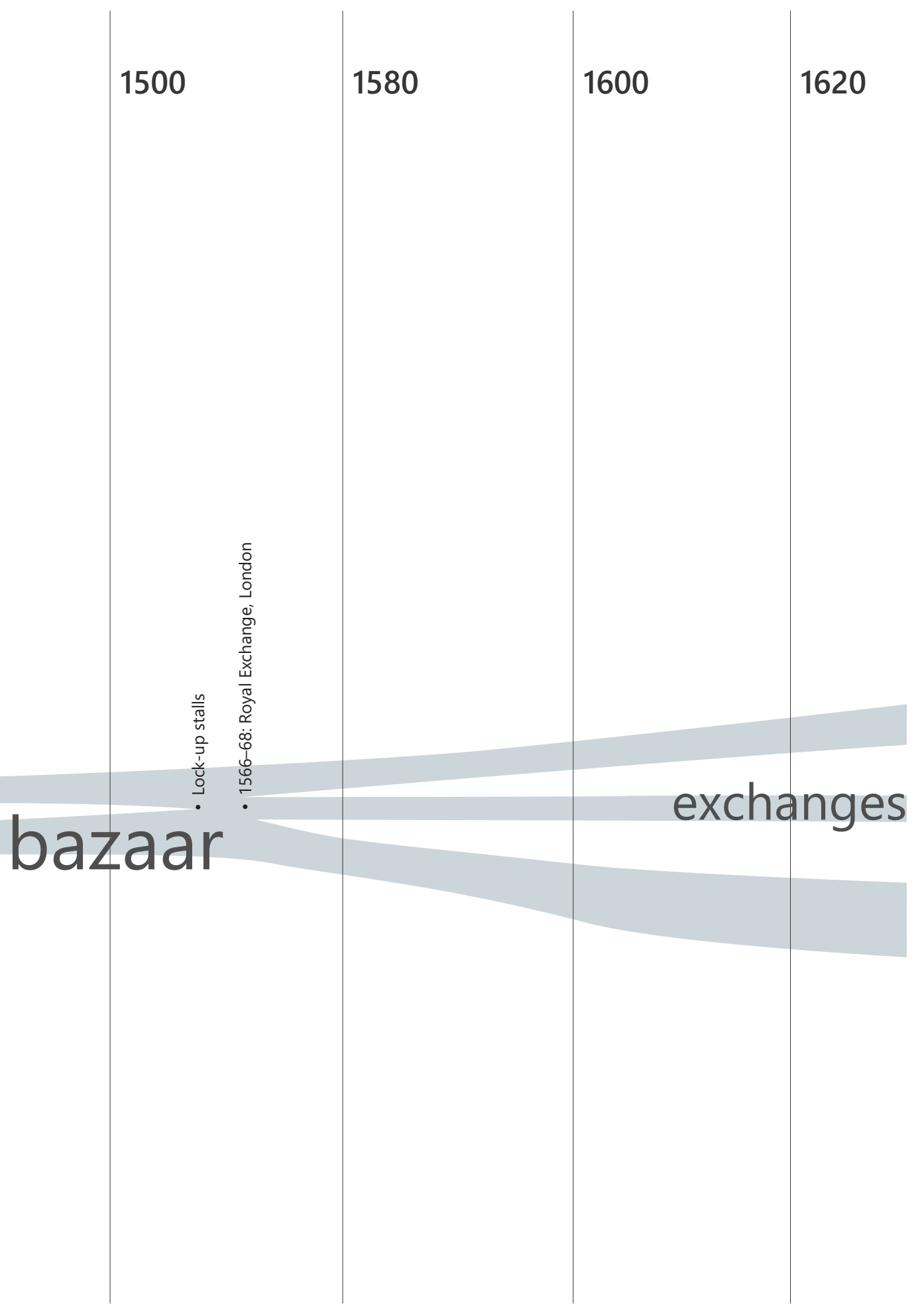

0
0 
642: First gear-driven mechanical calculator

7th century: use of credit leads to explosion in number of shops

\section{Magazine advertising 1666: First newspaper advertising supplement, London Gazette}

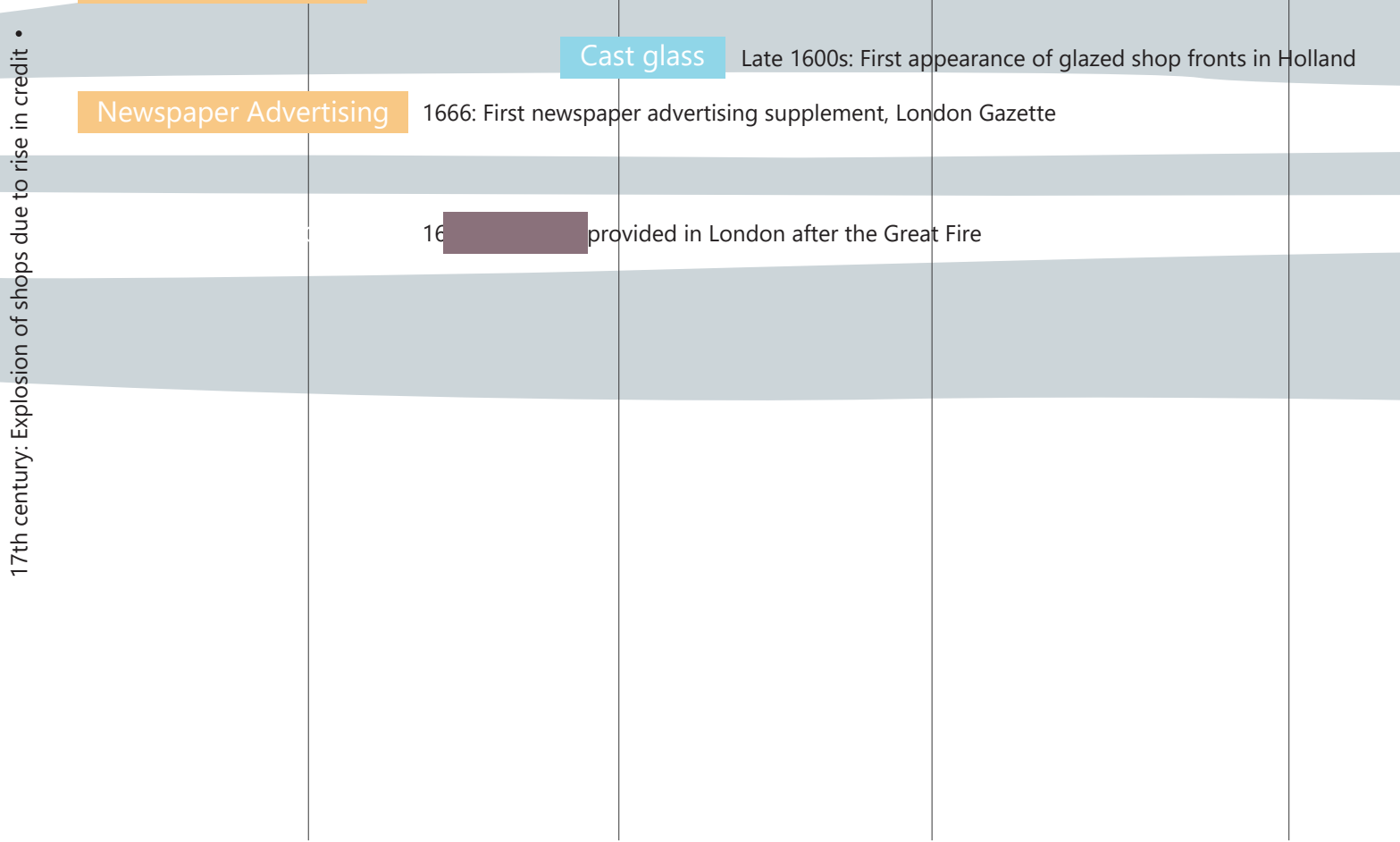




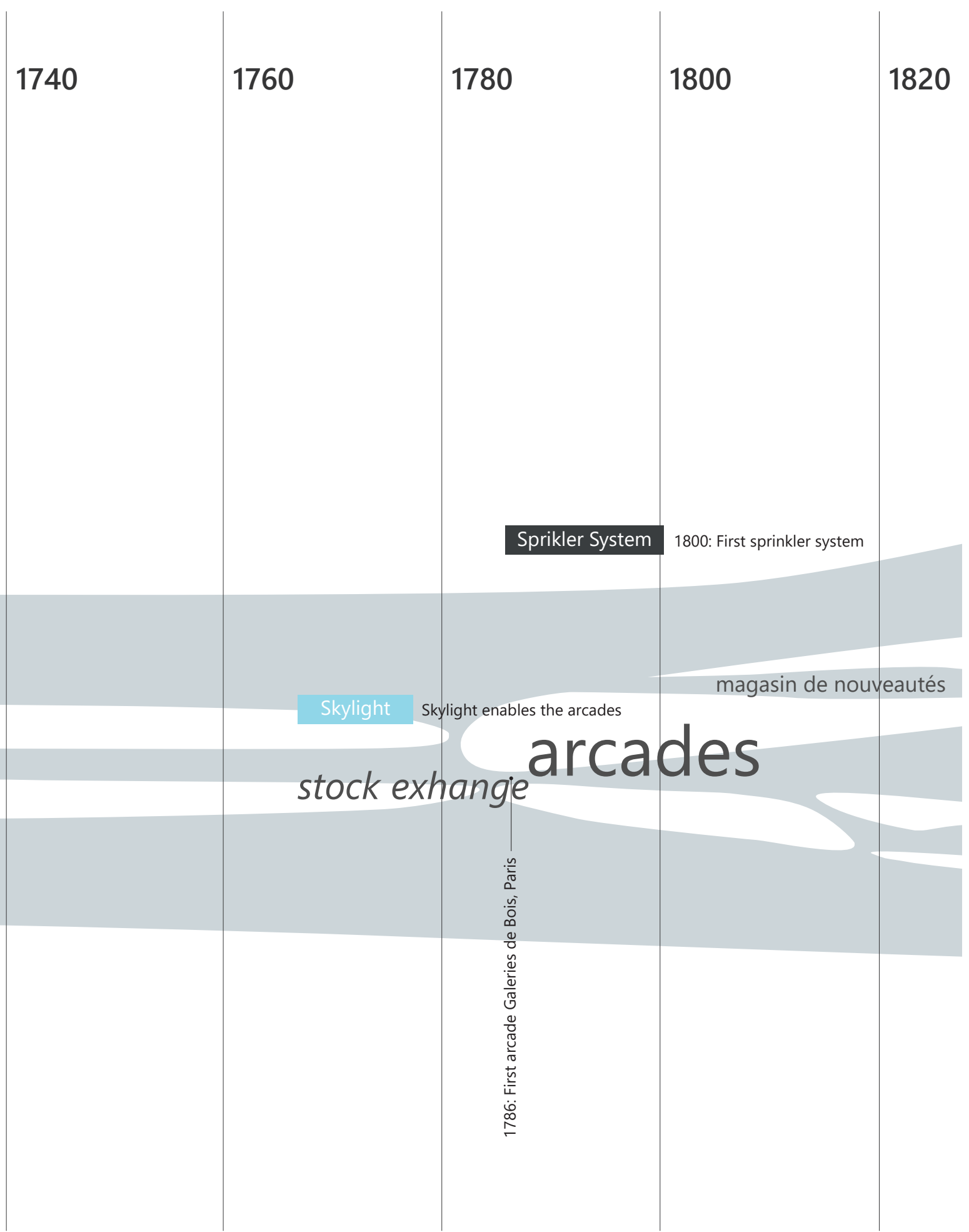




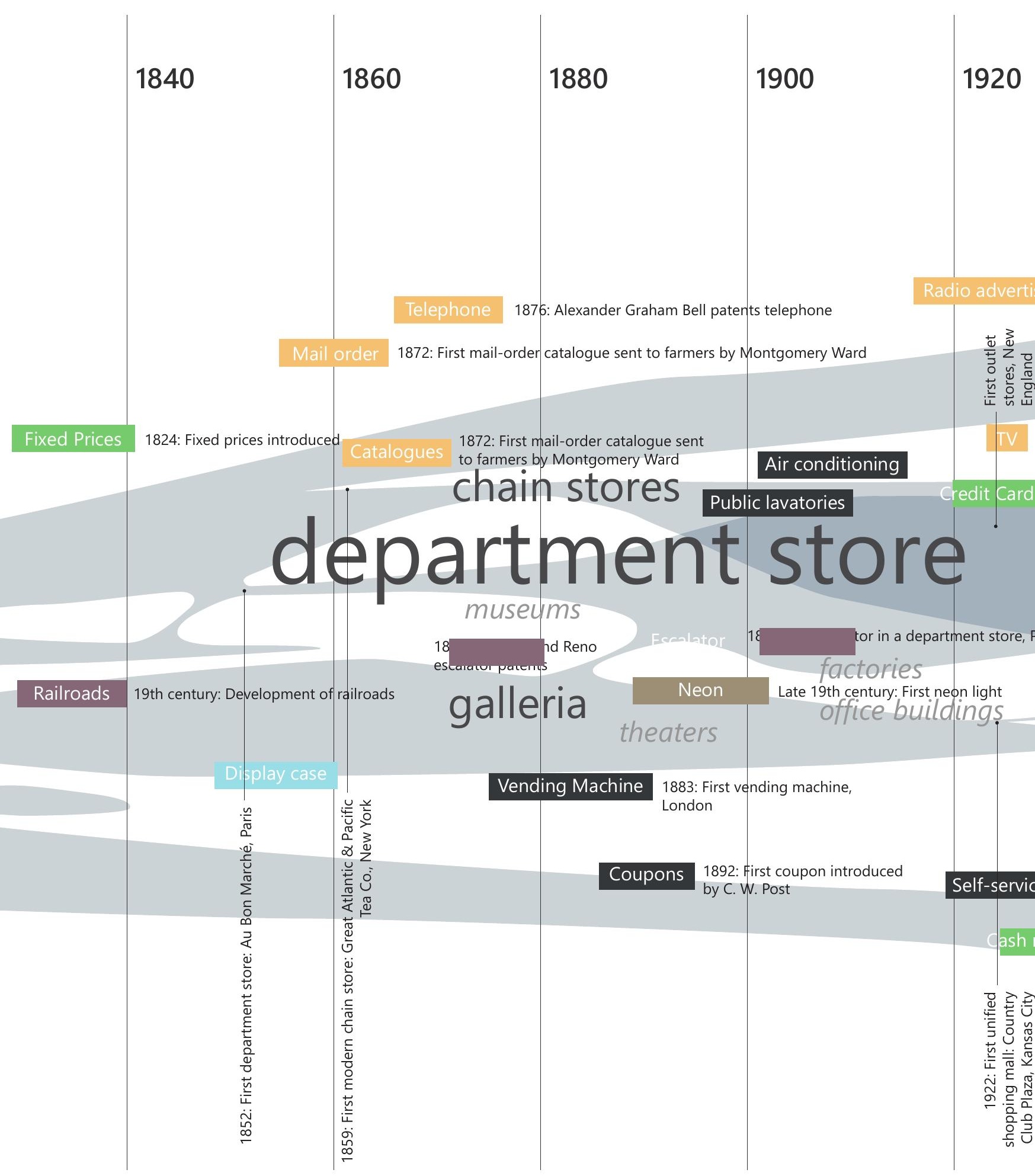




\section{omputers}

entertainment shopping

1926: First working television

mail order/catalogue shopping

\section{amazon}

\section{category killers}

\section{Walmart}

920s: Credit cards first used in the $\checkmark . S$. for individual companies franchise
ATM 970s: First automated teller machines

Debit card

aris

\section{shopping}

19 In superhighway: Bronx

19
Riv

\section{e supermarket}

Mid-20th century: Electrically driven mechanical cash register

hypermarket
superstore

railway station shopping

strip mall

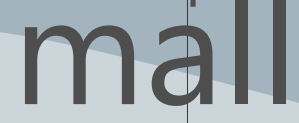

\section{convenience store}

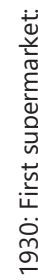

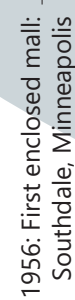

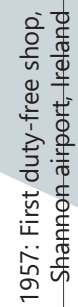

airport shopping

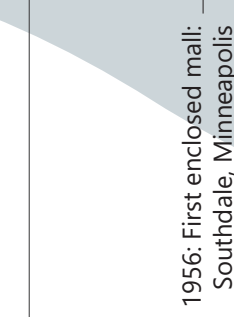




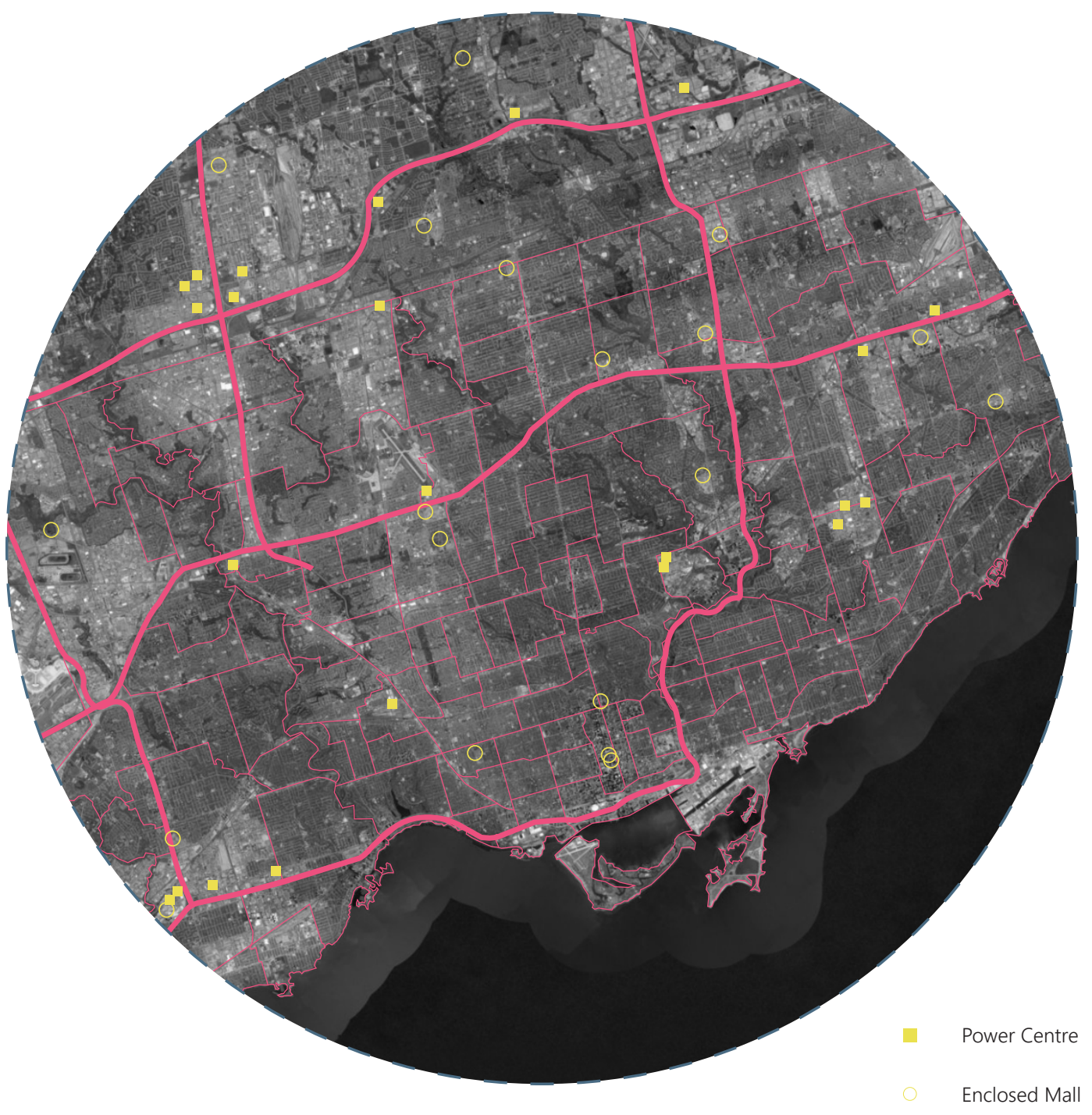

BIG-BOX STORE retail outlets typically three or more times larger than other comparable stores

OUTLET MALL type in which manufacturer sell their products directly to the public through their own stores

POWER CENTRE three or more big-box retailers with shared parking lot and ancillary commercial services
REGIONAL CENTRE

STRIP MALL

VERTICAL MALL enclosed with stores facing inwards offering general merchandise and services

stores arranged in a row on an open area alongside a sidewalk and a large parking lots 
the opinion of architect Rem Koolhaas, these spaces are complexes of junk space, the trash of modernization, since this form of architecture almost exclusively serves the market and conveys no contents beyond consumerism; a space that serves purely commercial purposes. ${ }^{15}$ Modernization has so far been the peak of what design, science and engineering has to offer to humanity, and this includes the ability to morph the physical realm to better suit the human desires. Continuity of program usage is the essence of junk space, that exploits any invention that enables expansion and deploys seamless infrastructure: escalator, air conditioning, sprinkler, fire shutter, hot-air curtain. ${ }^{16}$ On the other hand, not using the full potential of science goes against everything that human evolution is about, to continuously discover, adapt and apply knowledge. Shopping malls maybe a collection of numerous stores anchored on its ends to create an inward perspective, but it is an epitome to the capitalist life that envelopes all of us. A template that was meant to be community collective space that has now become a trademark for a seemingly better lifestyle.

\subsection{SITE HISTORY}

The Eaton Centre, since its inception in 1967, has been both criticized and praised, yet, it has become one of the defining landmarks of Toronto. Inspired by the Galleria Vittorio Emanuele II in Milan, the main feature of the building, the arcade, was to act as a lively indoor street, where all the retailers could be accessed with ease. ${ }^{17}$ The enclosed arcade attracts thousands of visitors every day, which includes both shoppers and city dwellers seeking passage. Functionally, the below-grade connection between the subway stations and the PATH are successful in allowing comfortable circulation through the city during undesirable weather. Meanwhile the retail options available throughout the three levels satisfy consumer needs. It is known internationally for its vast multi-storey space that is naturally lit throughout the year. Named after the Eaton's department store, previously located at the intersection of Yonge Street and Queen Street East before its closure, the Eaton Centre construction was broken down into two phases that opened in 1977 and 1979 respectively. ${ }^{18}$ Its current layout promotes an active streetscape that is highlighted by an array of storefronts competing against one another for daily profit. It is a place to gather, socialize, celebrate, transition, and shop.

The building is bordered by busy street activity, making it the ideal location for a shopping experience. In the 1960s, Eaton's announced its plans to occupy the downtown blocks with a proposal to demolish the Old City Hall and Church of the Holy Trinity. However, that battle was lost soon after and a proposal that avoided the demolition was approved. ${ }^{19}$ The site itself is composed of multiple city blocks, that once accommodated the Eaton stores 
点
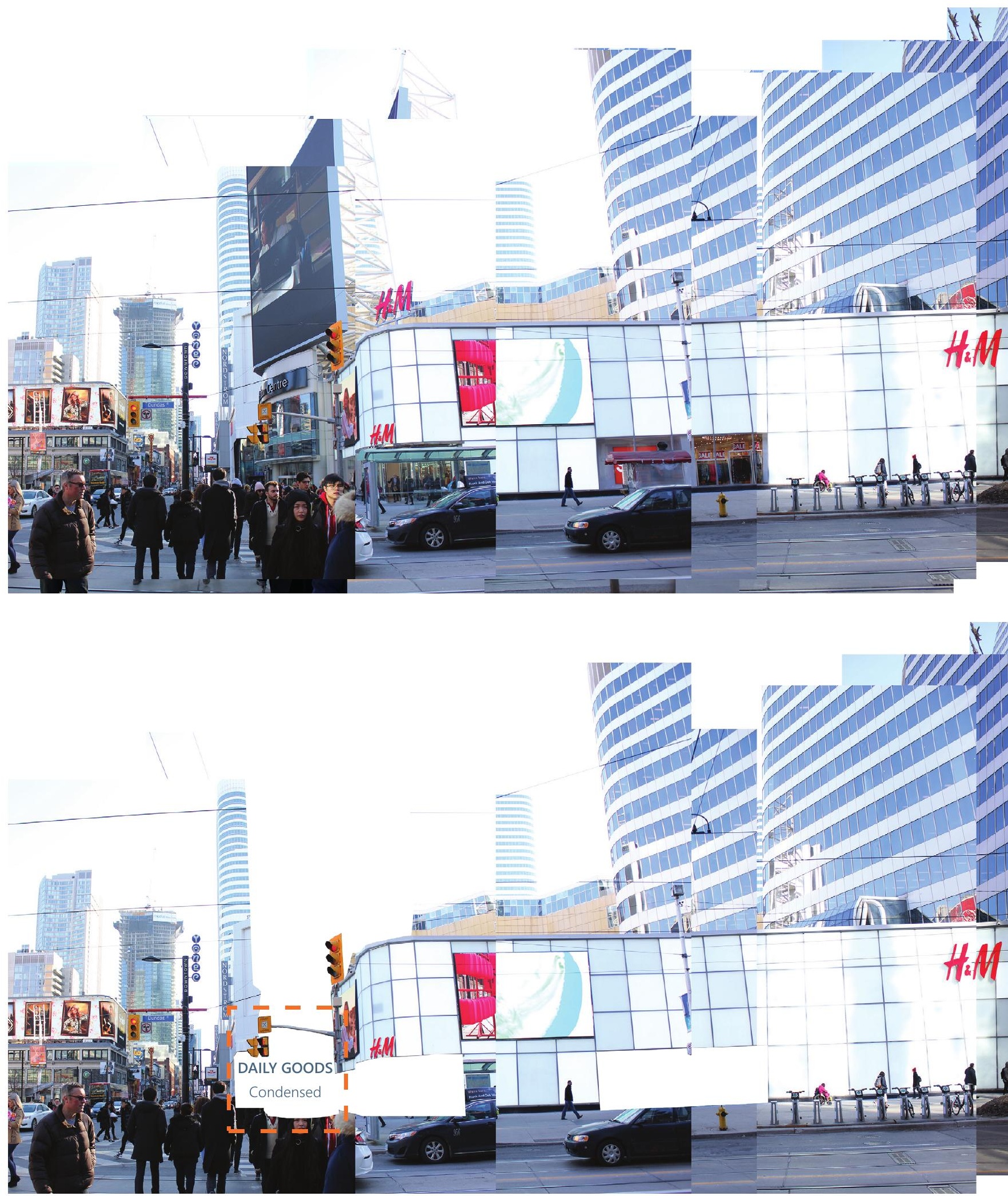

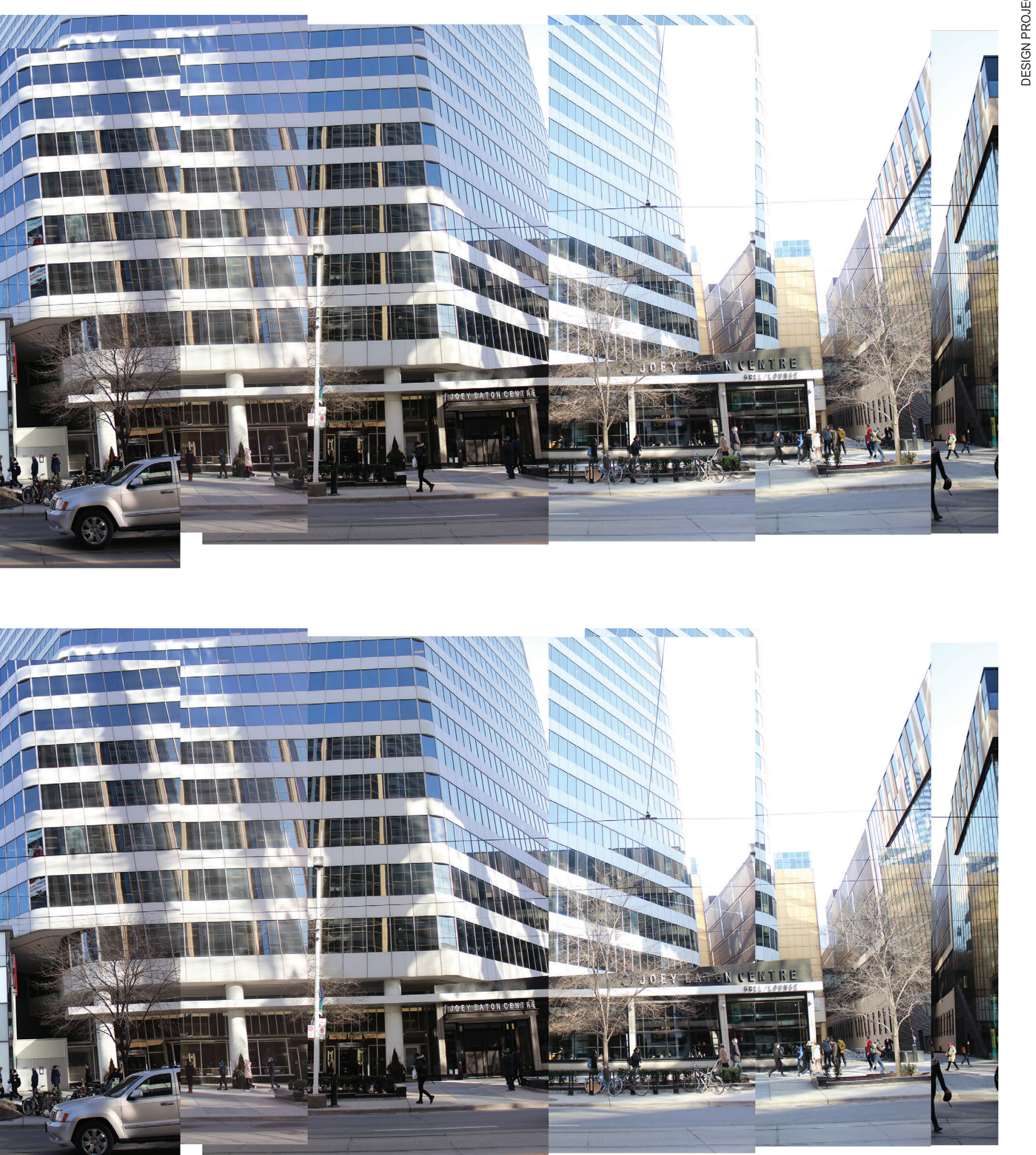

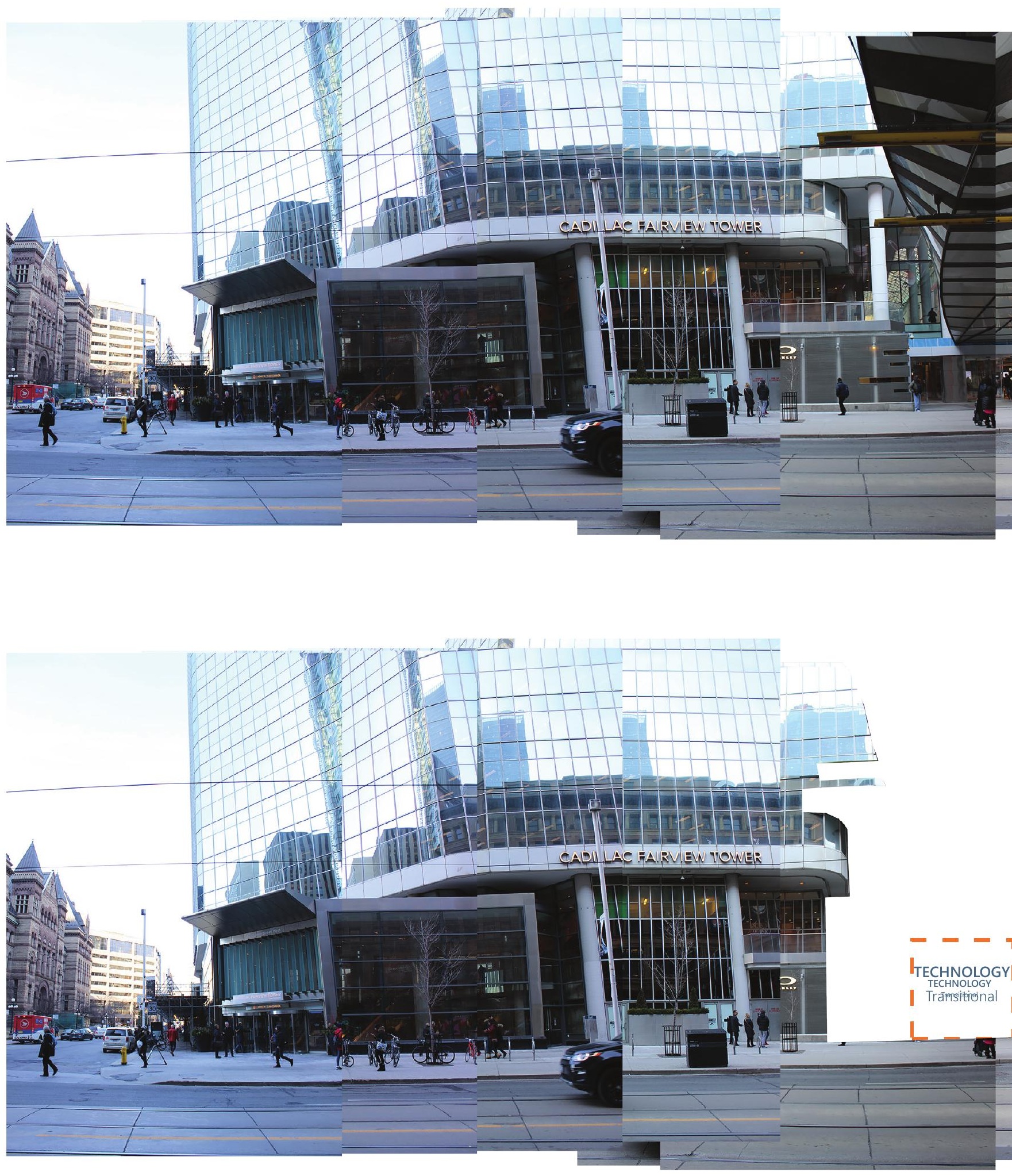


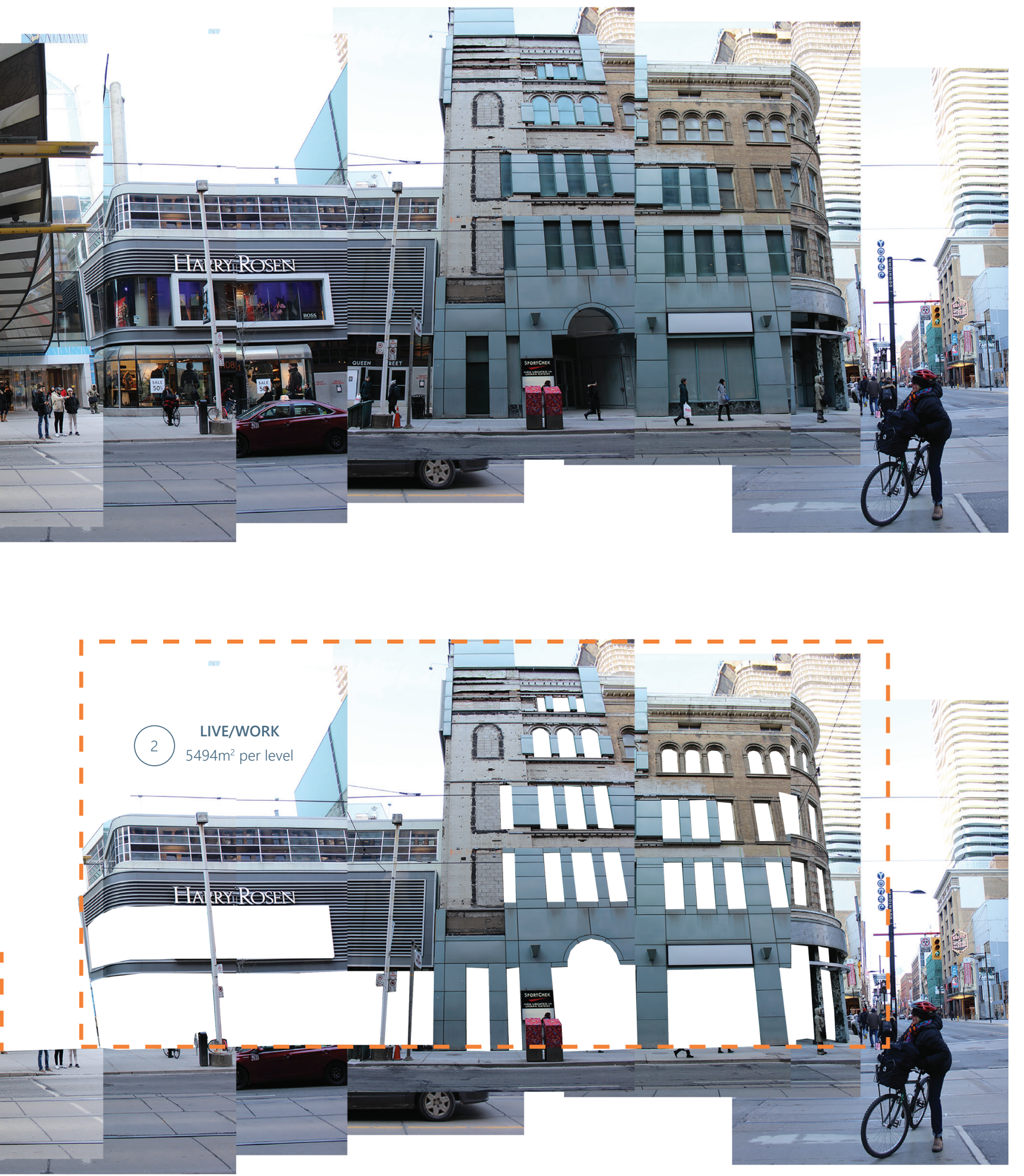



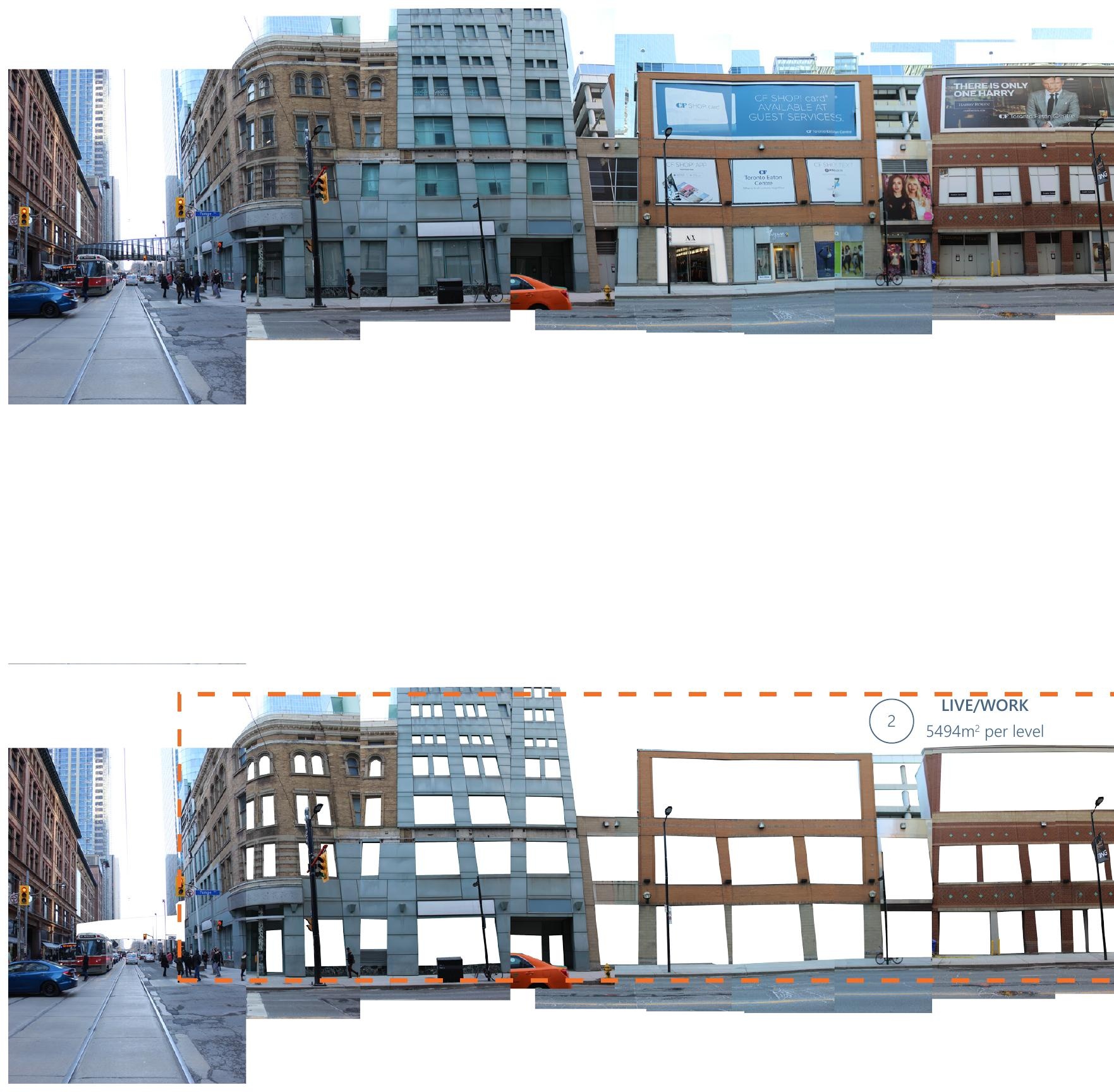

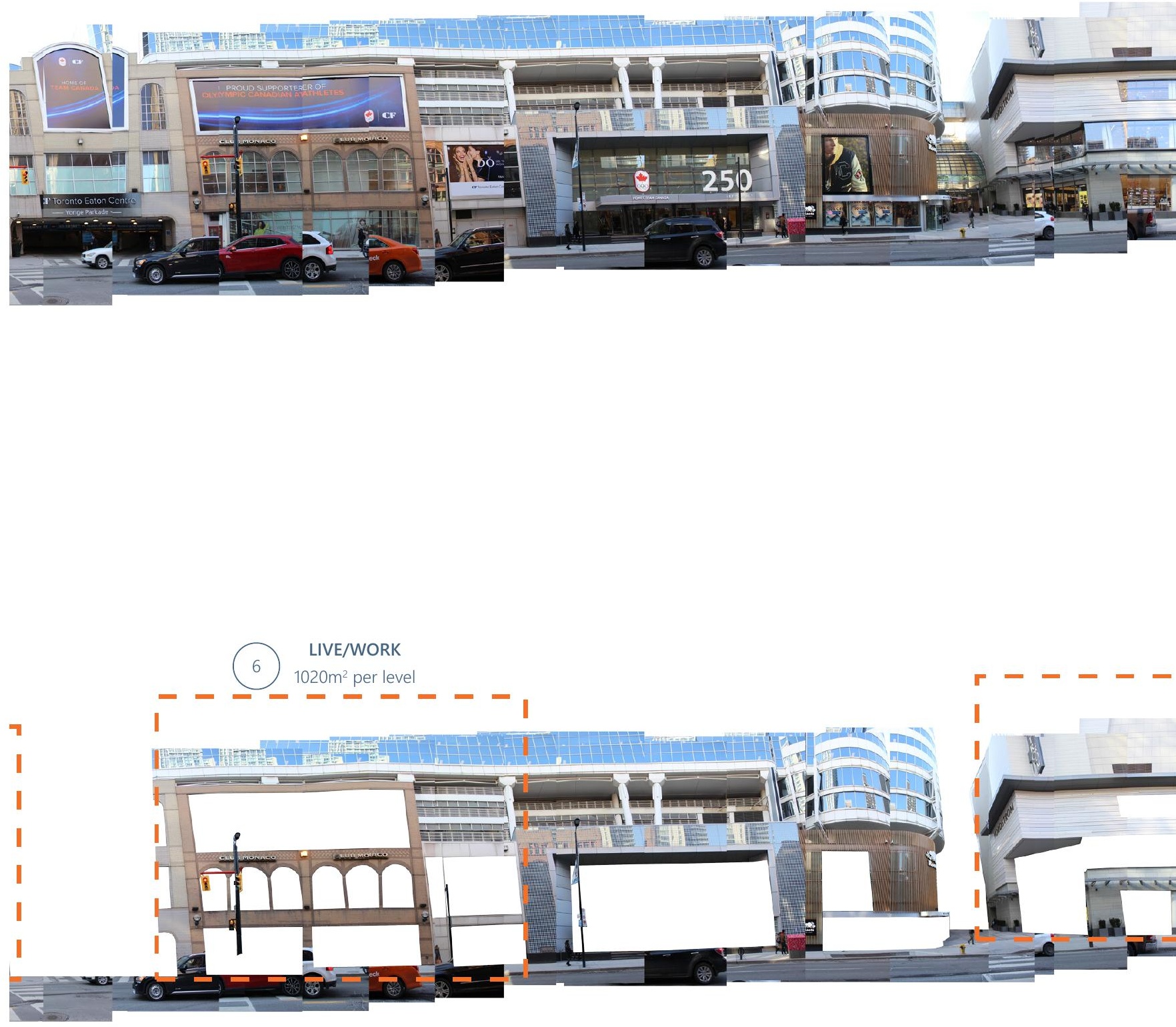

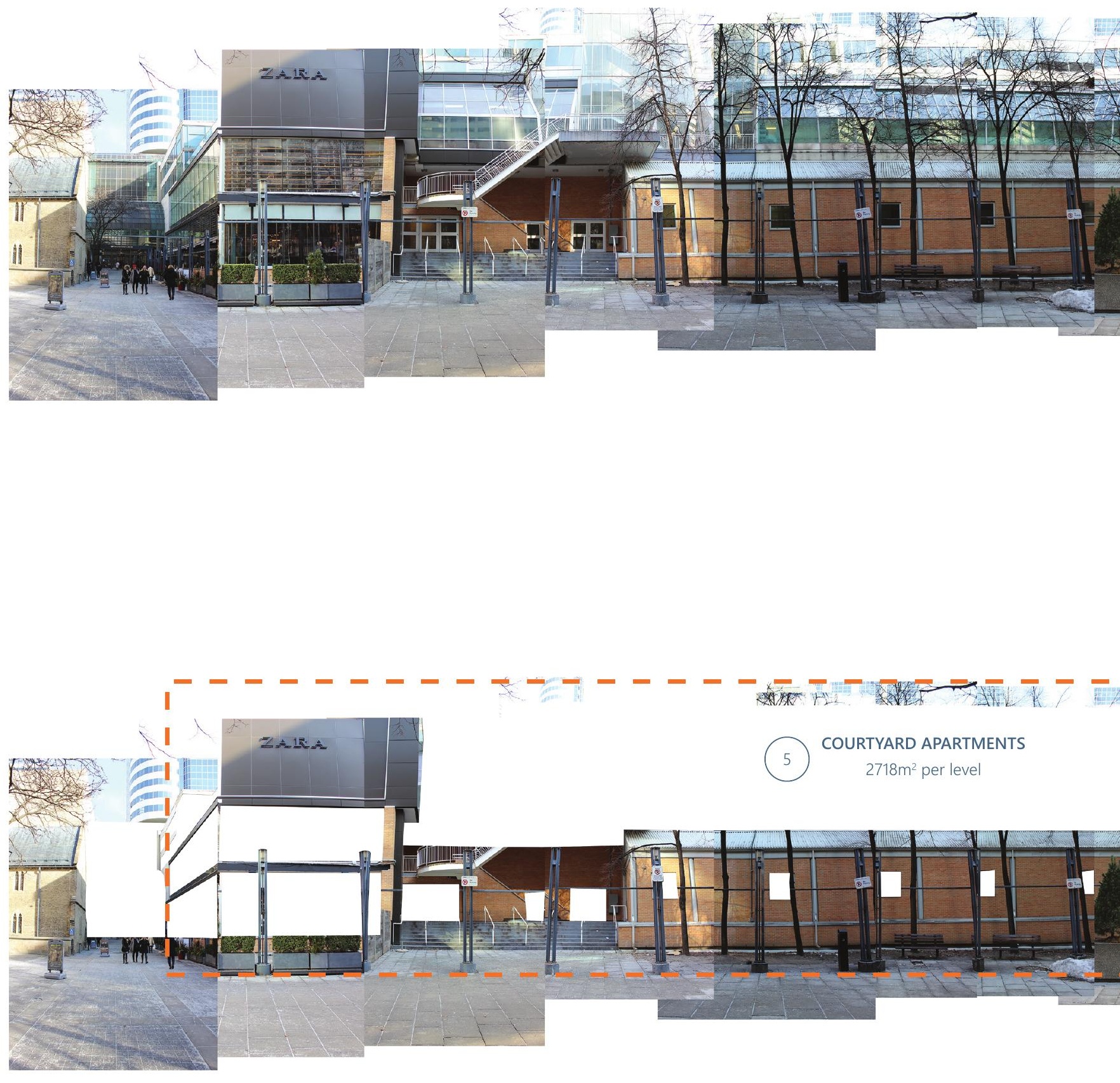

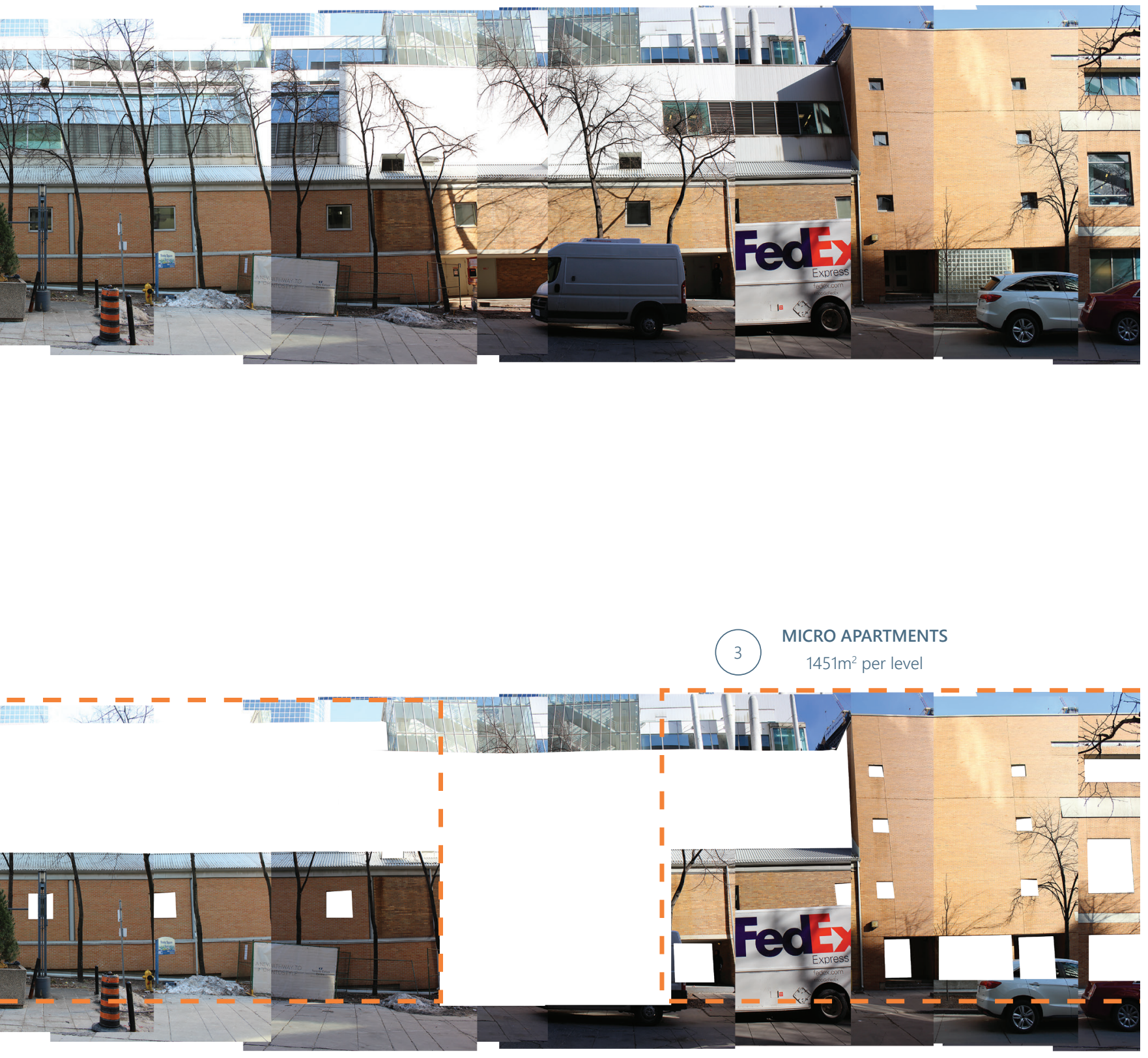

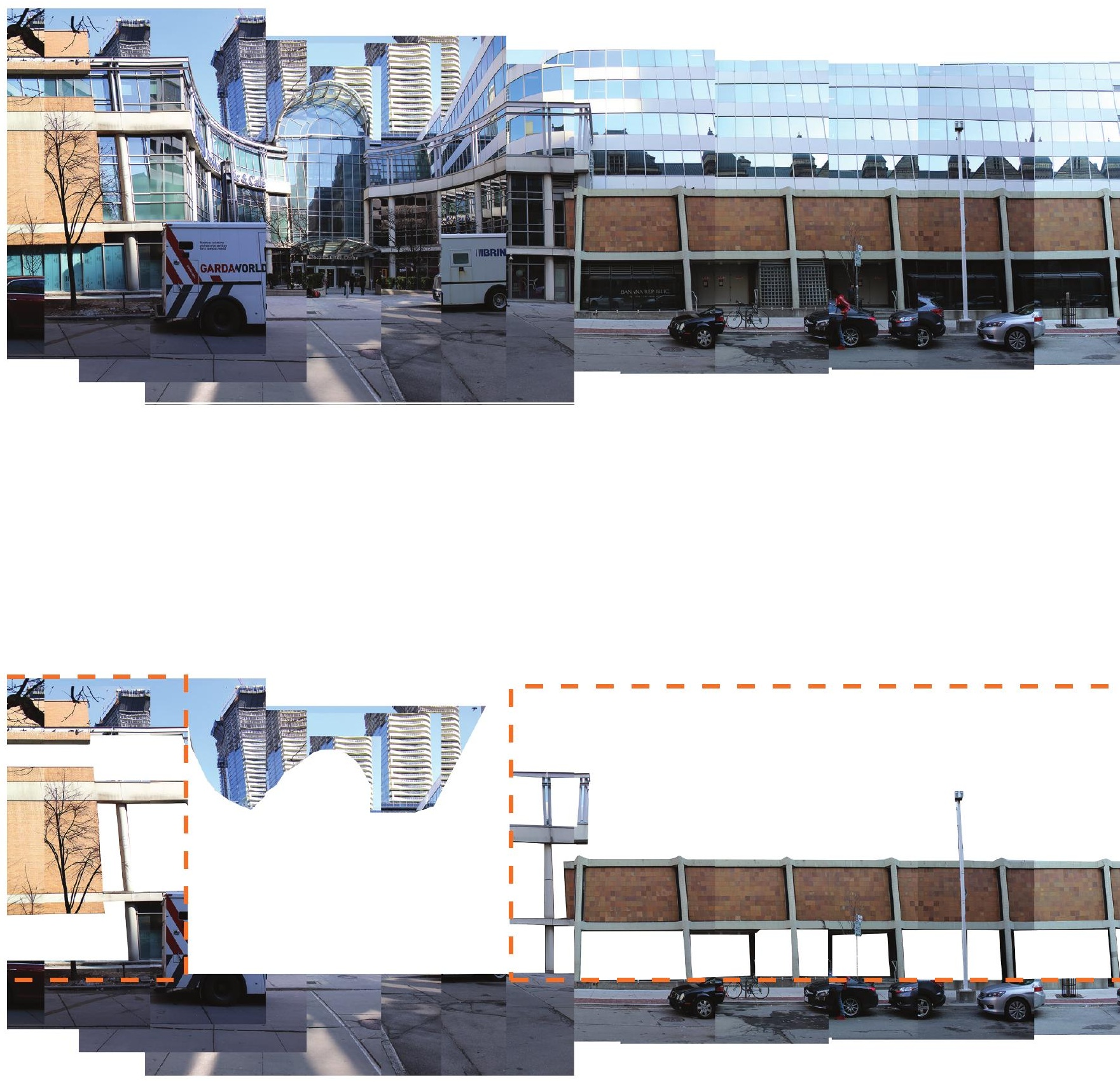

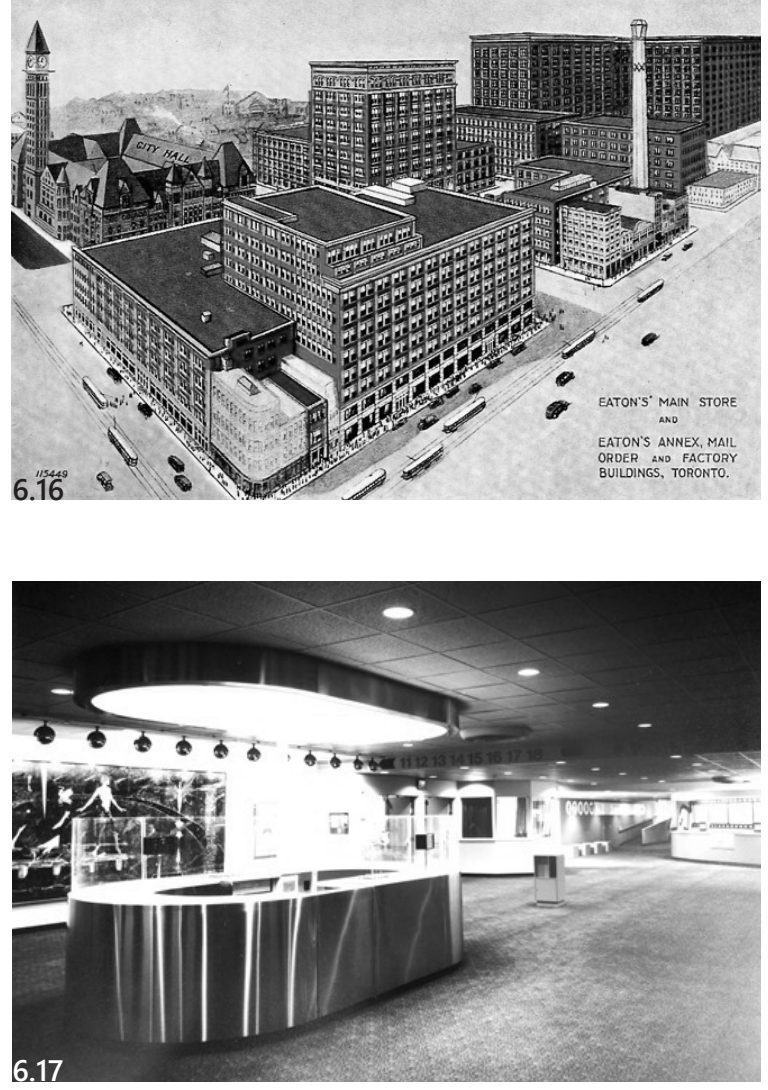

の

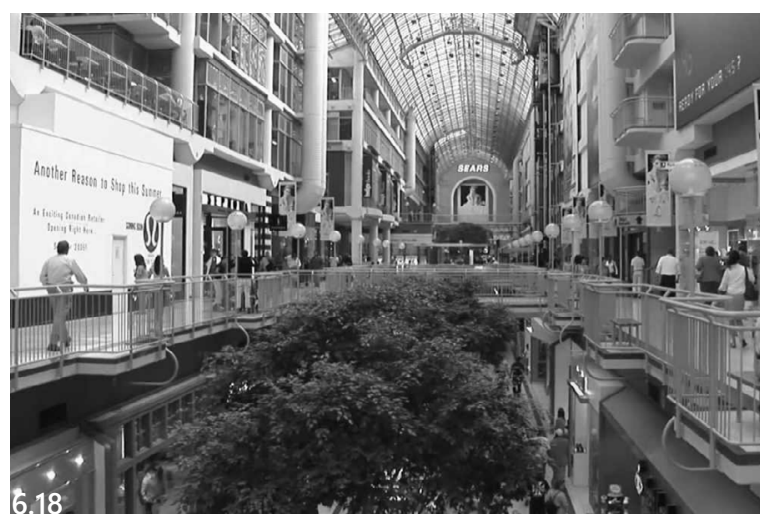

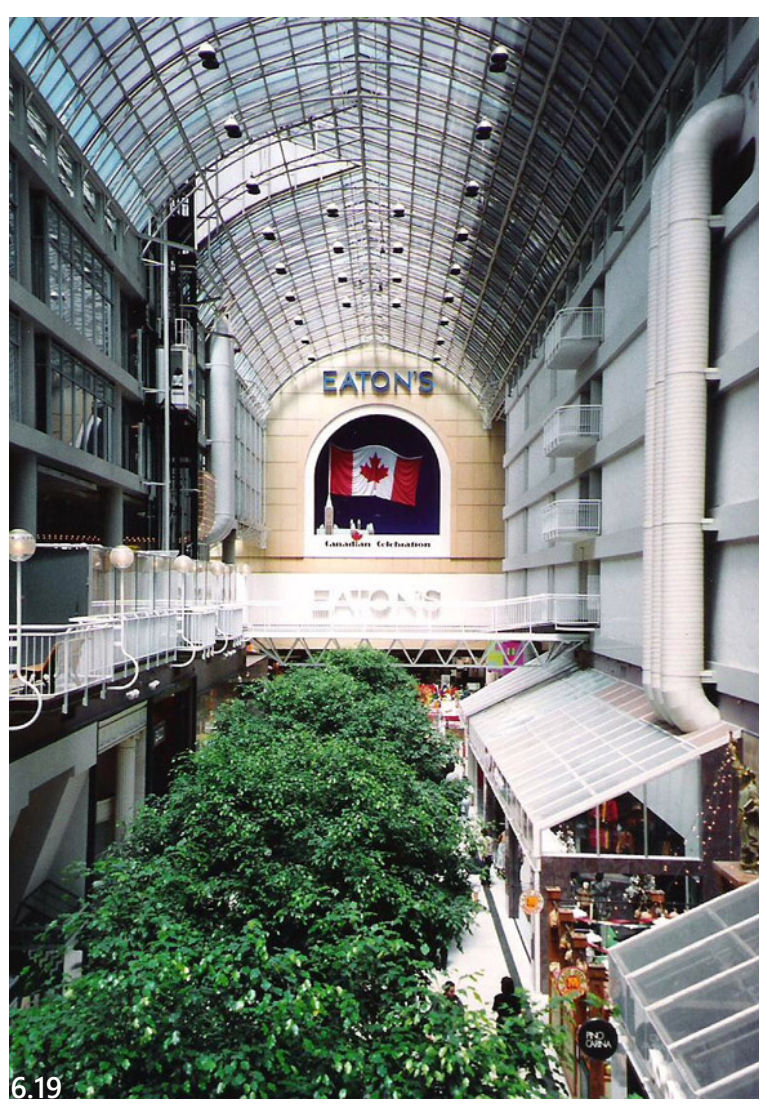

Fig.6.16 Eaton's main store, 1920

Fig.6.17 Lobby of the Cineplex Eaton Centre, 1970

Fig.6.18 Eaton Centre public space view 1

Fig.6.19 Eaton Centre public space view 2, 1990s 
and production. A project of this magnitude could not be treated as a single building, since it had to relate in different ways to the surrounding streets, and create multiple visible entry points..$^{20}$ In addition, another problem faced by Zeidler and $\mathrm{B}+\mathrm{H}$ Architects during the design phase was of the grade change of approximately five metre from Dundas Street East towards Queen Street East. To resolve this problem, the mall was angled slightly in the opposite direction, instead of sloping the levels parallel to the grade, which allowed for fewer level changes and prevented unusable spaces, and permitted entry to each level. ${ }^{21}$ The northern portion was completed first with the transfer of the Eaton's store and new programs including offices and retail spaces. Afterwards, with the completion of the southern program the mall was officially completed, existing both above and below grade with multiple openings lit by the large atrium. It stretches 260 meters in length, 8 to 16 meters in width, and roughly 29 meters in height. ${ }^{22}$ Overall, the centre is cohesively connected with three subway entries, parking for almost 2,000 cars, and six public entries at grade. ${ }^{23} \mathrm{On}$ the other hand, the three office towers located along the border have their own entries, and span up to 36-storeys hosting offices for a number of businesses. The structure of the final design, both for the shopping centre and the towers, is flexible enough to accommodate new tenants within its perimeter, where even the parking garage has the potential to be converted into additional commercial space, and the roof has the ability to support garden apartments. ${ }^{24}$ Its location, organization of tenants, and interior atmosphere are the important driving factors that continue to make this space viable.

The anchor stores are the other key players at Eaton Centre that entice the public to move from one end to the other, while potentially taking detours in-between to other stores and the food court. Tenants that exist in-between are sandwiched by Nordstrom to the north and the Hudson's Bay Company to the south. The only continuous connection to the Hudson's Bay Company, however, is the pedestrian bridge, and if it were to be removed the pressure to keep the mall viable would fall on Nordstrom alone. Furthermore, in comparison to the façades at Milan which are highly regular and symmetrical, the Eaton Centre's the façades are more of a structural framework that has become distinctly secondary to the push and pull of function within the bays. ${ }^{25}$ The framework is displayed both in the interior and exterior, mimicking the Centre Pompidou, which was also constructed around the same time as Eaton Centre. Street façades within the urban core play an important role to not only advertise the interior program, but to display various products to fuel the streets with users. It is not only part of the environment, but has an obligation to the city to be vibrant enough to be viable. The Yonge Street façade on the east side faces a typical North American low-rise urban commercial district, and 
THESTARTOF SOMETHINGGREAT
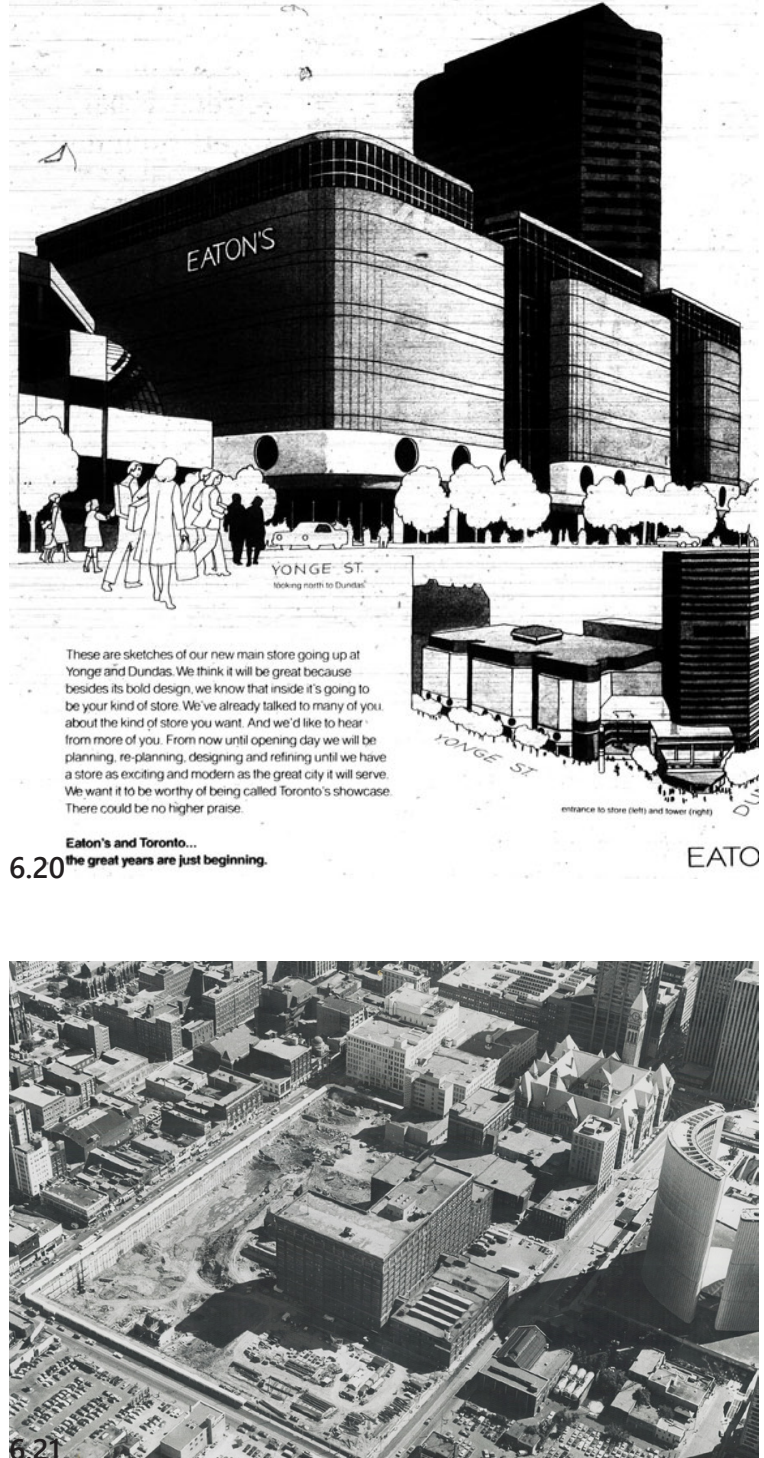

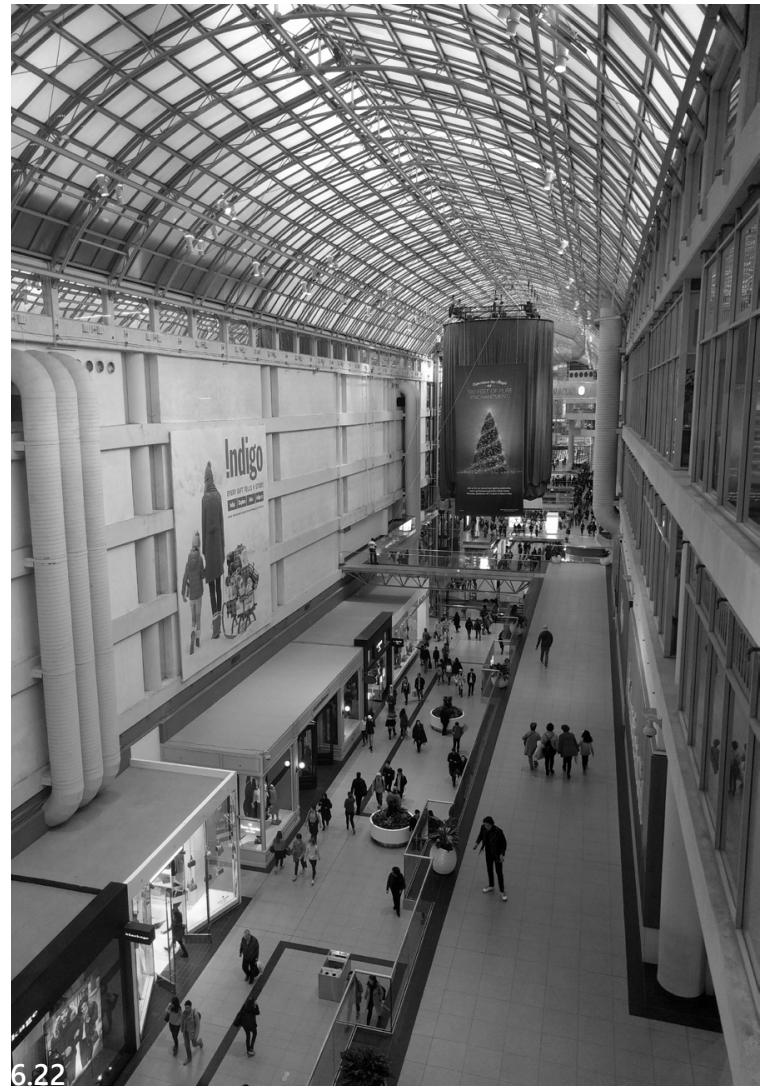

Fig.6.20 Previewing the Eaton's store design, 1975

Fig.6.21 Site of Eaton Centre in Yonge-Dundas area, 1974

Fig.6.22 View of central atrium, 2017 
accepts it in this spirit by continuing the concept of street advertisement, even if in reality it serves no real function aside from covering the parking garage. ${ }^{26}$ In comparison, the west façade is not as vibrant, as it is not located on a major street, but does continue to carry some of the mall elements over to easily identify the building. All in all, shopping malls are in a way cathedrals to consumerism, and with the Eaton Centre overall form it accomplishes exactly that.

\subsection{OBSERVATION}

To understand the current usage of space and the users, a video study was conducted on the week of October 30th between Monday and Friday from six different observation points at every level. These recordings were later analyzed to compare and reveal the qualities of the current shopping environment existing in this urban mall. The observation points were located at the same spot at every level, close to either a major entry, large namebrand store, or a social space to have a minimum number of people present in every frame.

The patterns observed here were be different depending on the day, holiday, and hour. However, for the purpose of this observation and analysis, the recordings were conducted at two different hours, 12:00 PM and 6:00 PM, when public activities are at its peak. From the analysis, it is safe to assume that the majority of the people present were there for the urban experience, as deduced from higher pedestrian activity present under the arcade. The discount rates and new releases of products, that promote the businesses, had formed a crowd near popular brands like Apple and Microsoft. Smaller booths representing both large and small brands were staggered centrally to easily test their products among potential shoppers, where the ones located near the atrium were more appealing among the people.

The ratio of people entering and exiting the stores was less than a quarter of the total number of people present in each frame. The majority of the people were using the Eaton Centre as a sheltered circulation route that connected to its main street borders: Yonge Street, Dundas Street West and Queen Street West. In addition, the Eaton Centre has become a subject that everyone is incited to profile online, from its large sculptures during the Christmas time to its long line ups during a new product releases. It is a place to gather, socialize, celebrate, transition, and shop. The pedestrian traffic and store profit, however, are not predictable, where discounted prices are the main tool to attract higher store inflow.

As deduced from the concentration of people coming and going within each of the frames, the current pedestrian traffic condition is revealed, where the ratio of people 

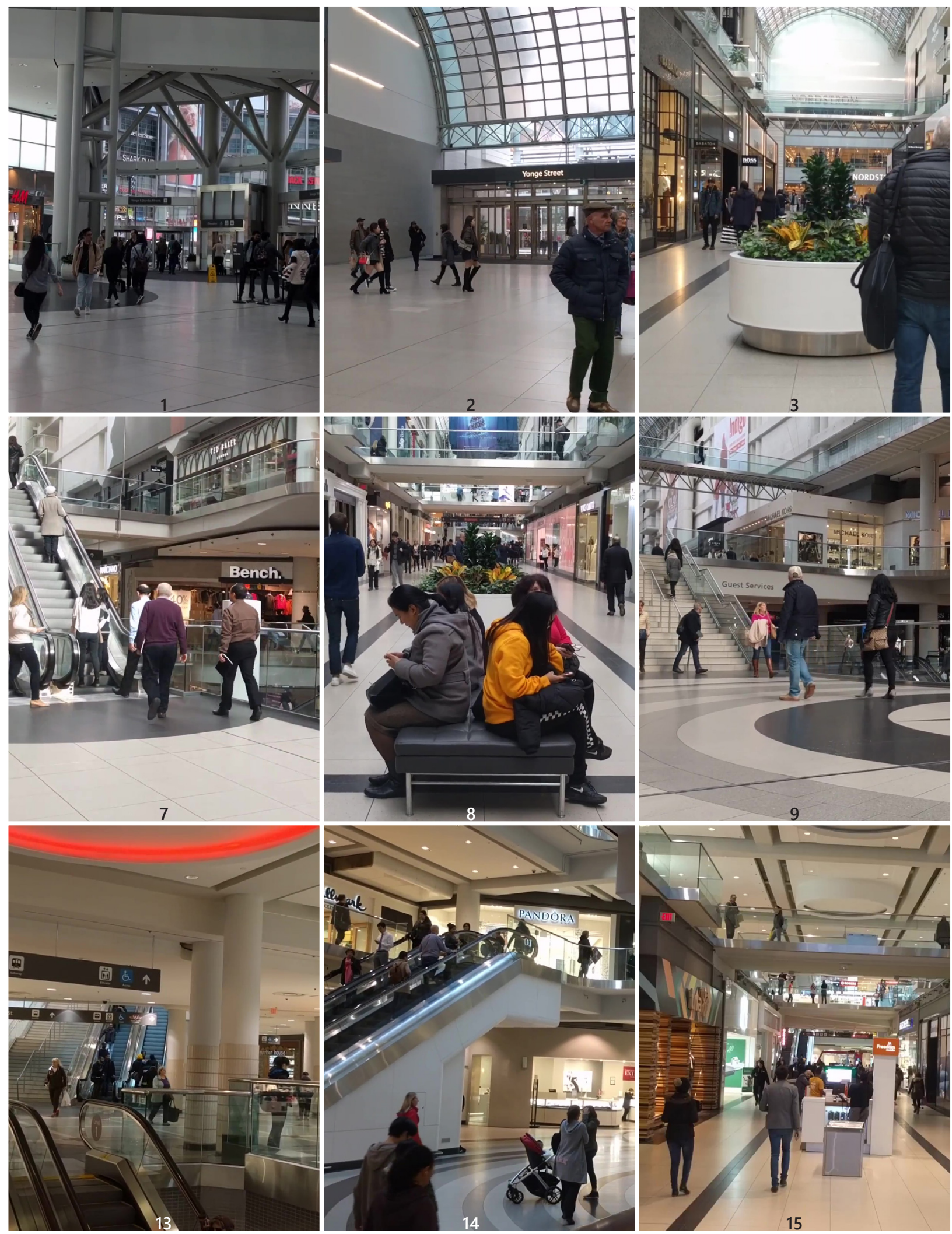

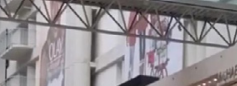

7
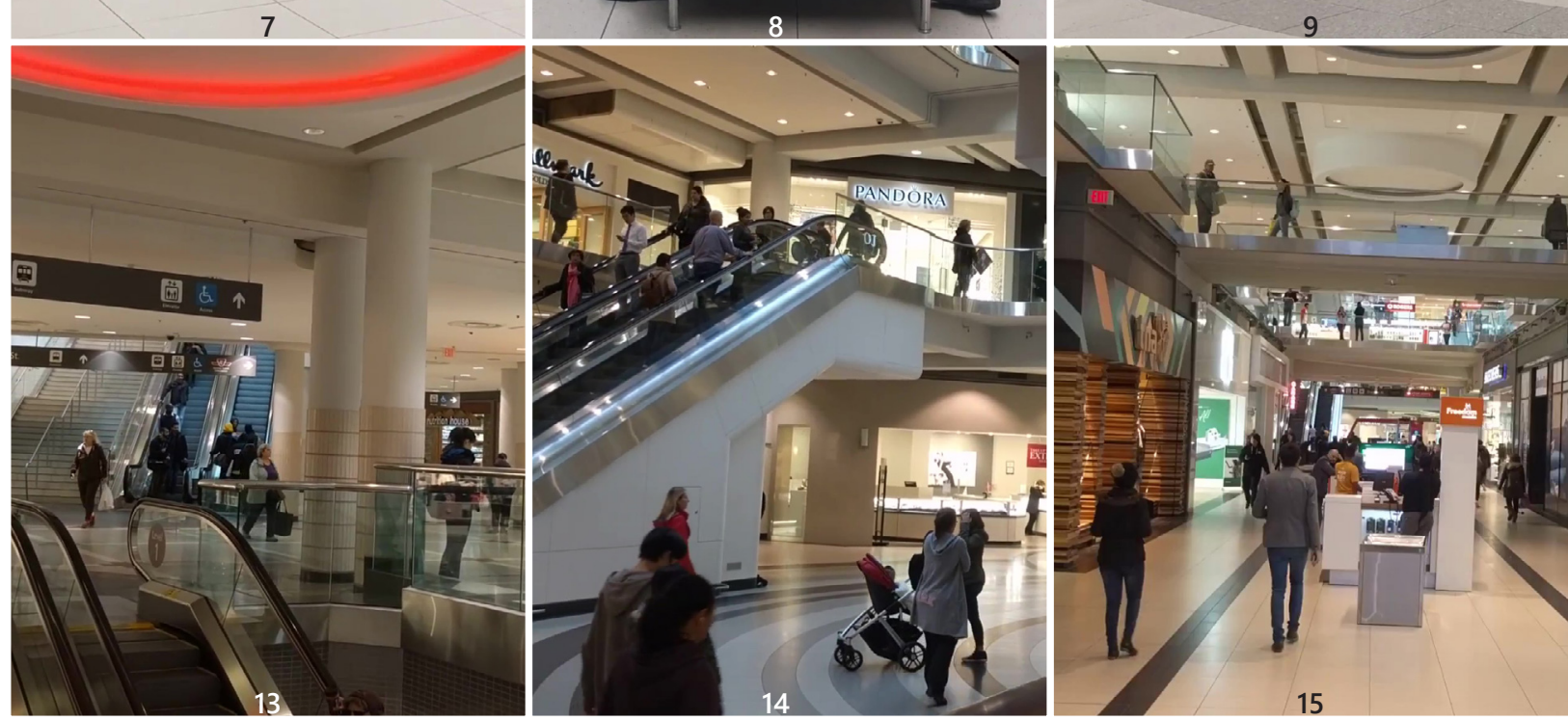


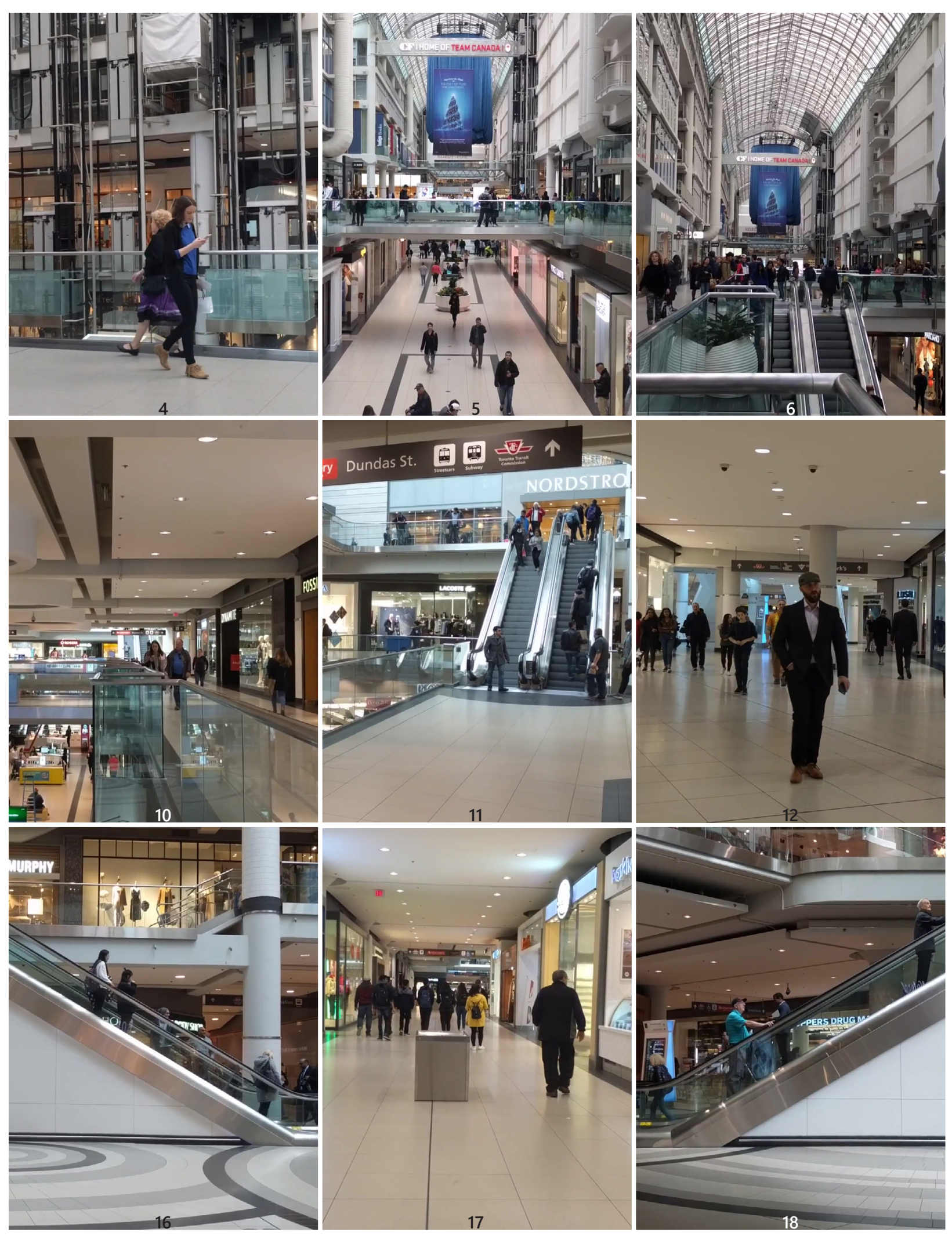




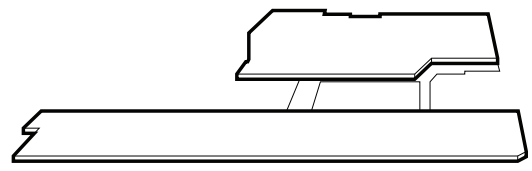

L3

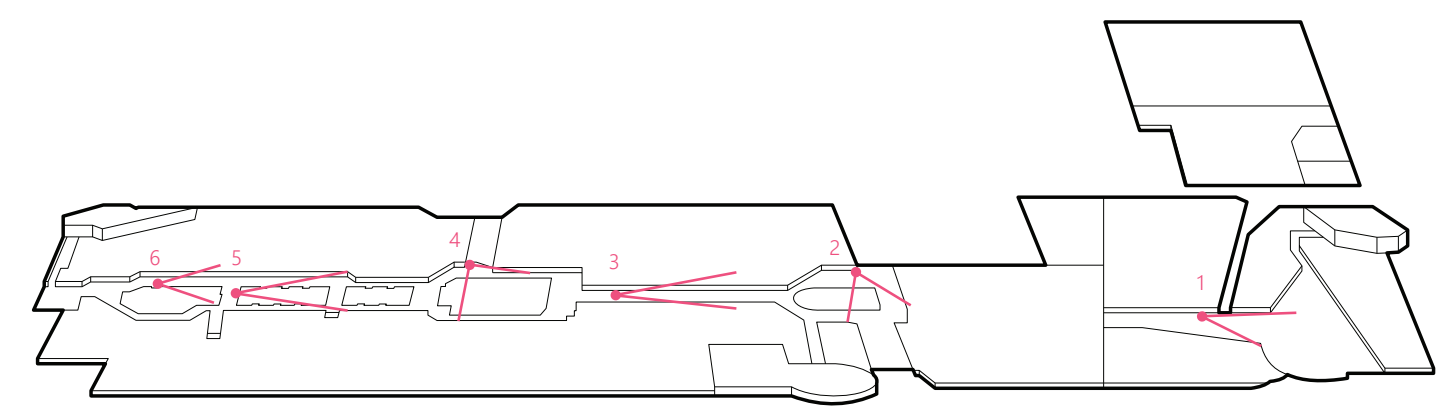

L2

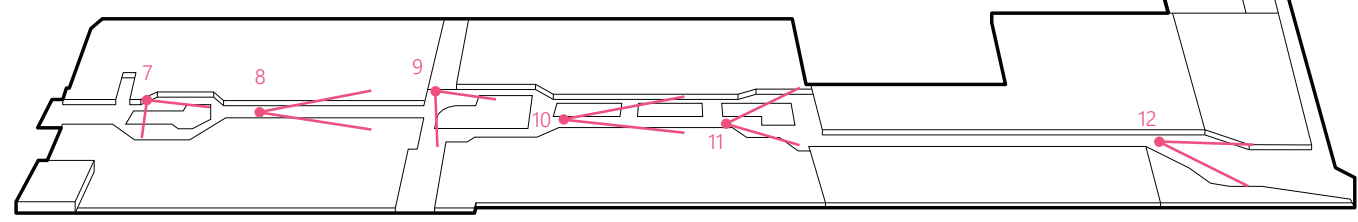

L1

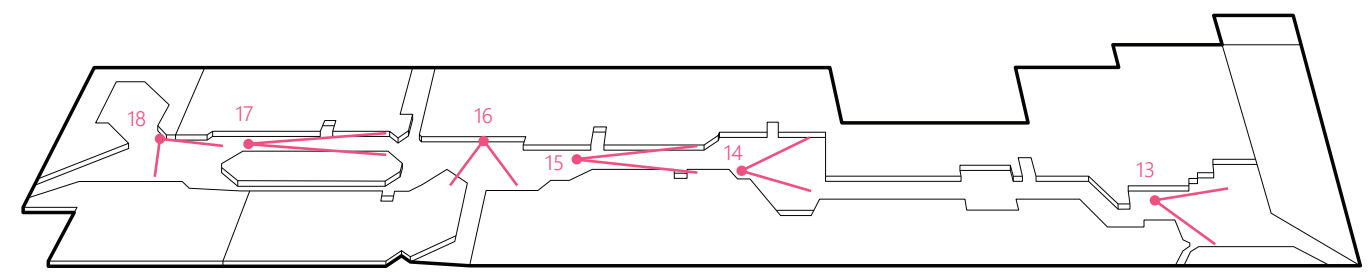

UE

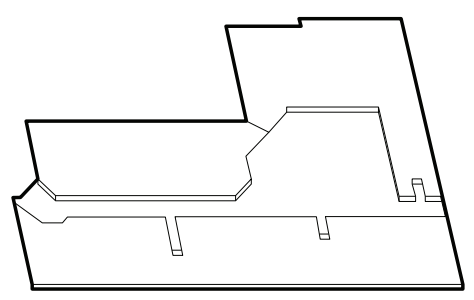


SHOPPERS VS. NON-SHOPPERS

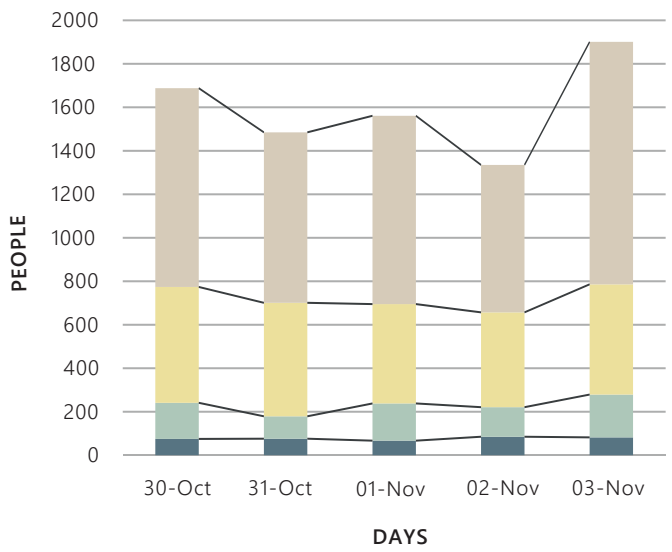

$\begin{array}{ll}\text { SHOPPERS } & \text { NON-SHOPPERS } \\ \text { - 12:00 PM } & 12: 00 \mathrm{PM} \\ \text { 6:00 PM } & 6: 00 \mathrm{PM}\end{array}$

PEOPLE IN FRAME

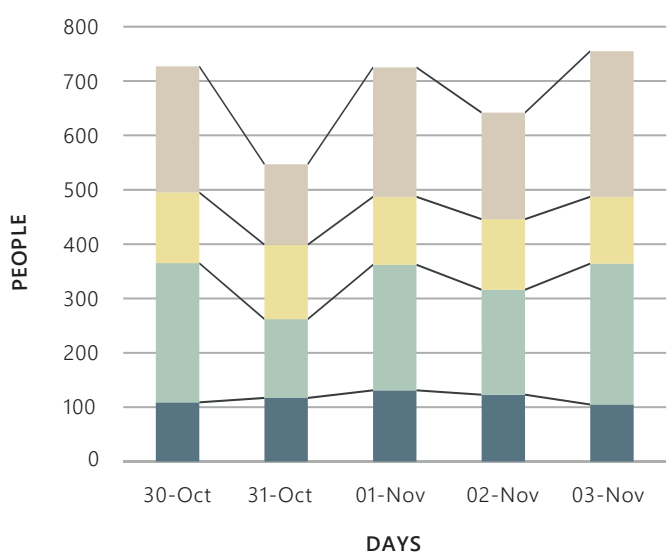

INCOMING OUTGOING

- 12:00 PM 12:00 PM

- 6:00 PM $\quad$ 6:00 PM

STORE TRAFFIC

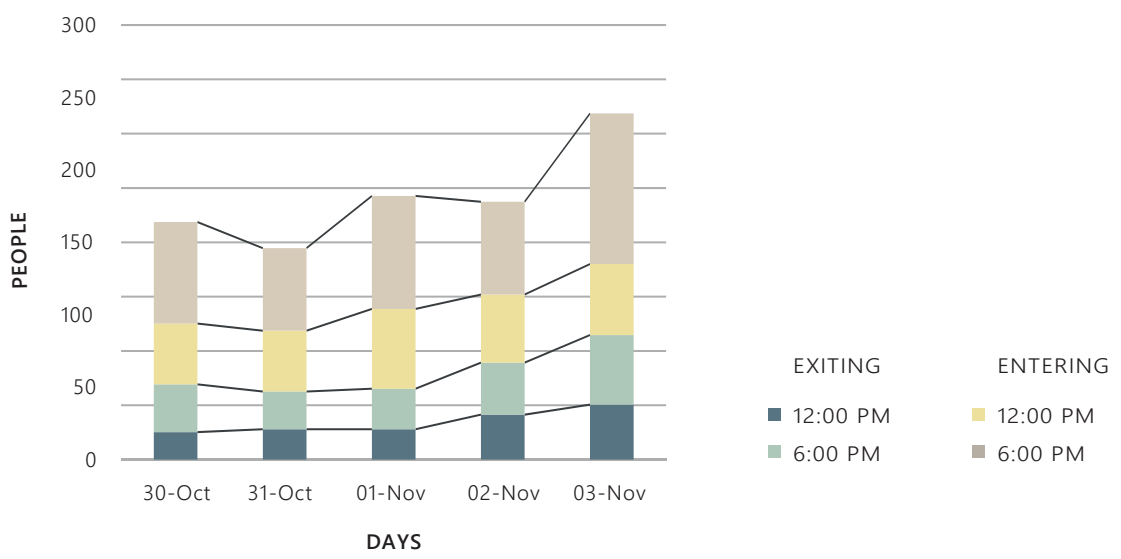

Fig.6.25 Observation of charts from conducted study 

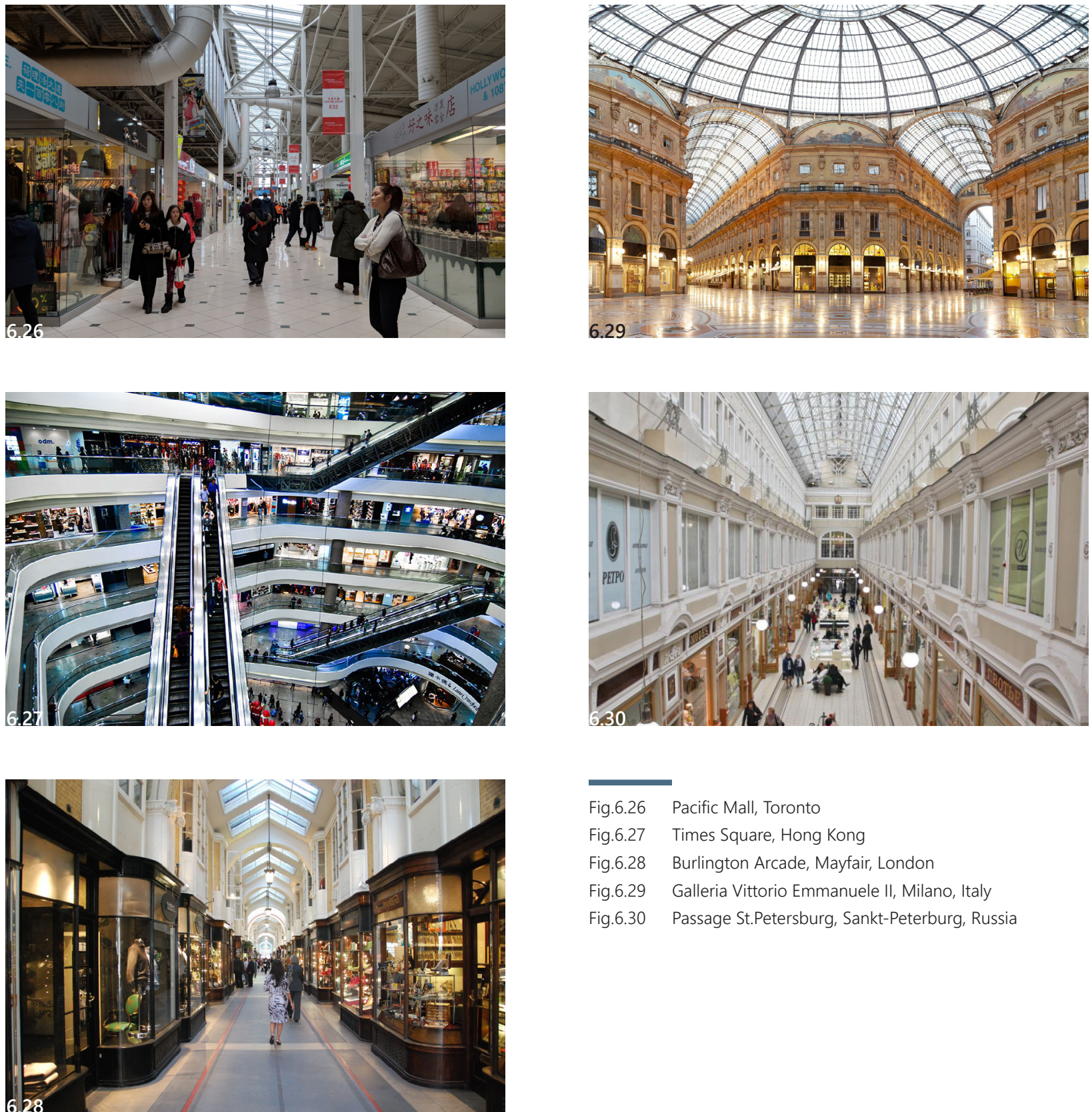

Fig.6.26 Pacific Mall, Toronto

Fig.6.27 Times Square, Hong Kong

Fig.6.28 Burlington Arcade, Mayfair, London

Fig.6.29 Galleria Vittorio Emmanuele II, Milano, Italy

Fig.6.30 Passage St.Petersburg, Sankt-Peterburg, Russia 
present was higher along popular stores, like Apple and Nordstrom, and entry points, like the PATH and main streets. The need to pause and observe storefronts is an essential part of the shopping experience, however the users here are more transient and more often than not they breeze past the stores to reach a set destination. In addition, the available seating is more concentrated near the atrium, and rarely allow the option to rest between the transitions. Hence, the rate at which people move is determined by both their destination and detours.

Its active environment attracts an array of users, like families, businesspeople, students, and etc., throughout the business hours. The presence of a shopping bag was chosen to differentiate between shoppers and nonshoppers among the array of users, since it is impossible to predict whether a user will shop along their set route. Similarly to the people entering and existing the stores, the number of shoppers was lower than expected, yet noticeably higher alongside stores releasing new products and offering discounted prices. Human nature is unpredictable when studied within a physical consumer marketplace, but is easily enticed by quality and lower prices.

This observation revealed a number of areas that need to be improved for users, and the ways in which they respond to certain conditions. The spaces that do not have access to the atrium were quicker in their transitions than the social spaces that did. There was an influx of users at each level, both indecisive and curious to explore the shops under the atrium, who take comfort in an indoor shopping experience away from the busy urban setting filled with automobiles and high-rises.

\subsection{SPECULATIVE SCENARIOS}

\section{4 .1 TORONTO 2070}

By exploring the architectural typology, more specifically shopping malls, through the lends of science fiction inspired by current advances, a deeper understanding of how they should be designed and approached can be revealed.

To better understand the effect of speculative design, the Eaton Centre's future was explored through two lenses: utopia and dystopia. As mentioned in previous chapters, technology has become an inseparable part of daily lifestyle, where even menial tasks are completed with its assistance. However, the progress being made in the technological field is a double-edged sword that can either better the city or lead to its downfall. Job viability is the first one at risk because human labour is nothing in comparison to the strength, speed, and actions of the machines. Cashiers, drivers, factory workers, finance 


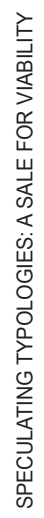

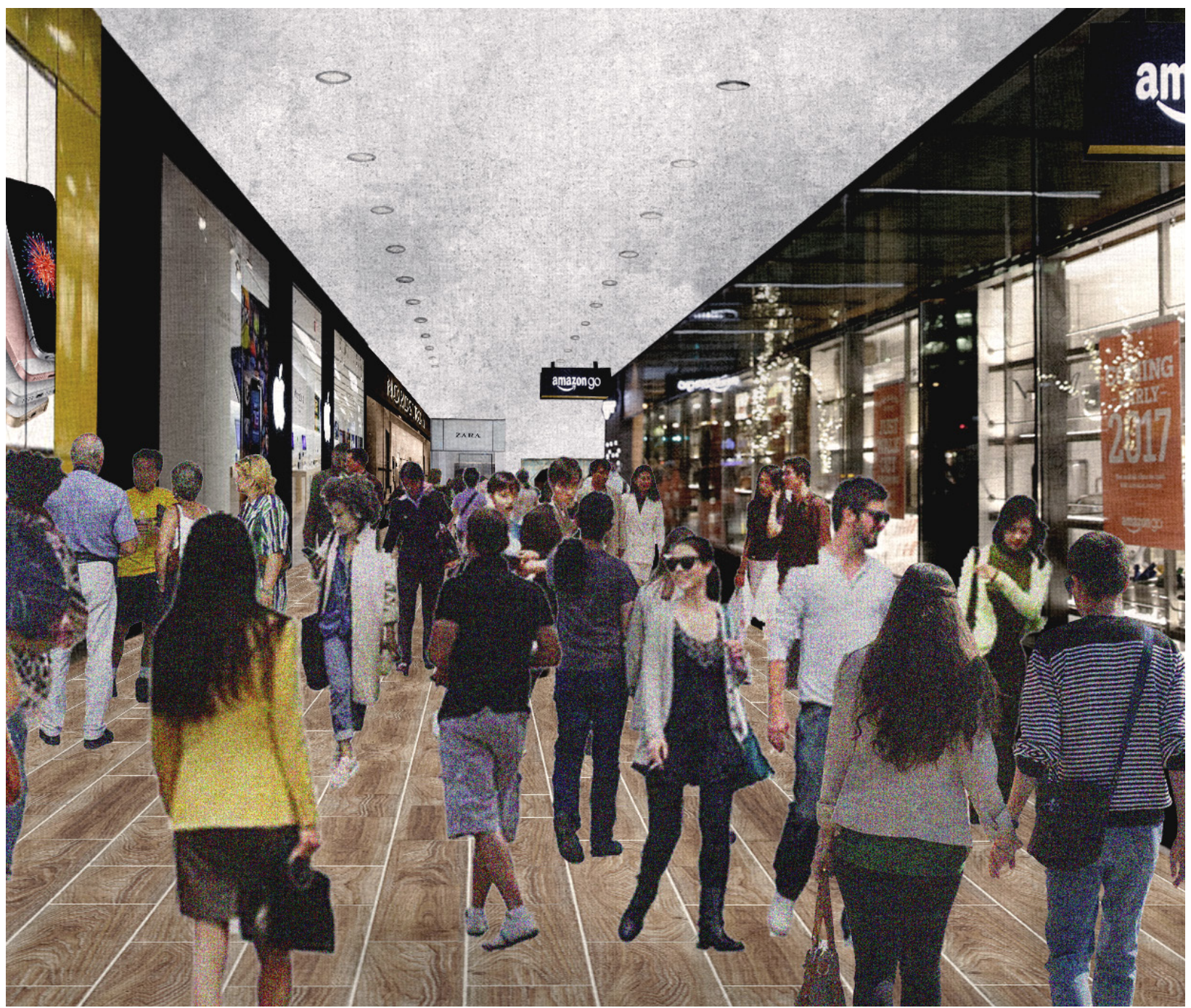

$\infty$ 
professionals, support staff, and more are all at risk of one day becoming obsolete because the machine is not only more accurate, but also cheaper. Assuming this development, I have speculated the outcome of the Eaton Centre in the year 2070 in a utopic and a dystopic state. These are described in a short story format in order to understand the new Eaton Centre and everything else that has transpired prior and afterwards.

\subsubsection{AN URBAN VILLAGE}

This project is speculating that in 2070, the city of Toronto will be on the edge of crisis with the increasing numbers and expectations of its inhabitants. What was once considered necessary to the growth of the city and essential for living in the urban core is constantly being re-evaluated. The infrastructure has drastically changed over the last couple of decades. The acceptance of mass production and the increasing rate of consumption has have shaped the new consumer lifestyle into a simple process, where the big brands have consumed the smaller manufacturers to equally supply identical products to the consumers. By 2070, the rapidly growing population compromises of millennials and seniors, who cherish their freedom and their individuality in single person households. ${ }^{27}$ Digitization of information has placed the consumers in the power position of the golden age of choice, fuelled by technology and online global markets available only a click away. ${ }^{28}$ The dynamic living standards within the urban fabric has put the integrity of built form at risk with more people favouring the high-rise mixed use typology over the other housing options, including townhouses, detached homes, and mid-rises. ${ }^{29}$

The luxury of affording a house in the suburbs or in the urban core is only available to a select few due to the automation of the work force, which has made most jobs obsolete. In reaction, the percentage of low-income households has drastically increased. ${ }^{30}$ Technology has changed the way in which we function not only at home, but also in other fields including medicine and education, where clear information and a lower margin of error prevails the disappearance of tasks once accomplished by hands. It started with the automated warehouses for drone deliveries, next came the expansion of self-driving cars, and now the once pleasurable need to shop has slowly begun to render the shopping centres defunct. As physical traffic began to drop in physical stores and sales per square foot declined, the response of most retailers was to survive the loss as long as possible, and eventually allow larger brand producers to reign over the global market. ${ }^{31}$ As mentioned before, consumption-oriented society propagandizes an ever-changing living condition, making traditional and small private helpless against brands that skilfully dominate the media-driven online platform for profit. These diminishing private businesses, 


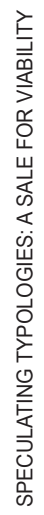

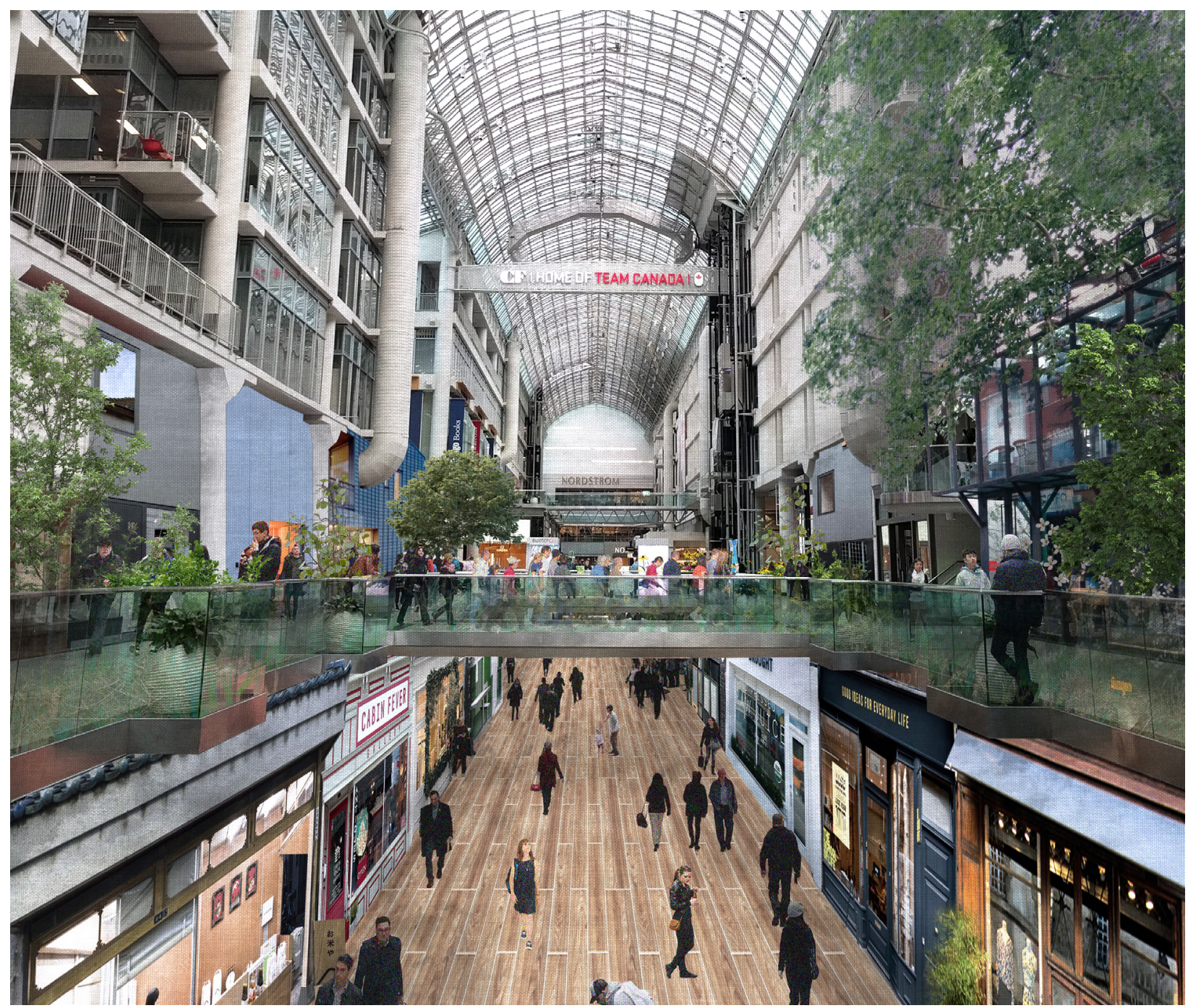


however, are the only option for some business owners to thrive, as they attempt to be different from the system that exists for automated services and online products. Small businesses can provide citizens a unique experience, harder to find amongst all the newer developments.

Years of construction has led to the shortage of space to build further. The city's inhabitants are slowly recognizing the dangers of allowing automation to run businesses that once drove the economy and pushed the people to improve and learn new skills. Now, in this future scenario, efforts are underway to adapt the unnecessary and outmoded infrastructure of the city. This included postoffices, grocery stores, banks, and churches at first. The next phase of the project tackled the shopping centres located in the urban core, seeking to reengage the citizen's individuality and the value of human input in an urban village condition while fulfilling demands for residences. Stores did not disappear, but changed in nature. Amazon, for example, set many new standards in retail through its creativity and seemingly never-ending streak of disruptive innovations to make shopping and life easier, more convenient and faster through its delivery system. ${ }^{32}$ Most necessities in life, at this time, could be obtained through online ordering and will continue to do so more elegantly in the future. From here, the hope is to conserve the good aspects of shopping and enhance them further alongside the affordable living condition necessary for the citizens of the city, and to provide an opportunity for them to join the work force and express their uniqueness.

The Eaton Centre site, serves as an adaptable structure that is able to accommodate various types of individuals and their unique businesses amongst the chaos of order and comfort occurring externally in the city fabric. The first floor still serves as a transition point for the public between the transit paths, but now also houses big box retails to attract higher number of potential shoppers with ease (figure 6.31). Apple, Amazon, Nordstrom, and Zara or their future counterparts are among the few stores located here. This level has turned into a glorified advertisement path that reinforces the trending lifestyle with potential customers. The food court is now clustered on the existing eatery level, and has expanded further by overtaking the surrounding parking structure space. The second floor is a private business level, run by entrepreneurs hoping to market their ideas (figure 6.32). Most of the inhabitants of the space from third level and up are of low-income households, consequently the available housing capabilities. The structure of the existing office program and parking lots are best suited for this new living condition due to its regulated structure layout. Units designed for these spaces have the opportunity to overlook the arcade space, with a few open between the second and third levels to serve a live/work program. The existing arcade continue to highlight the shop routes as a 


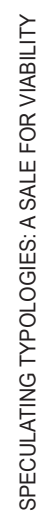

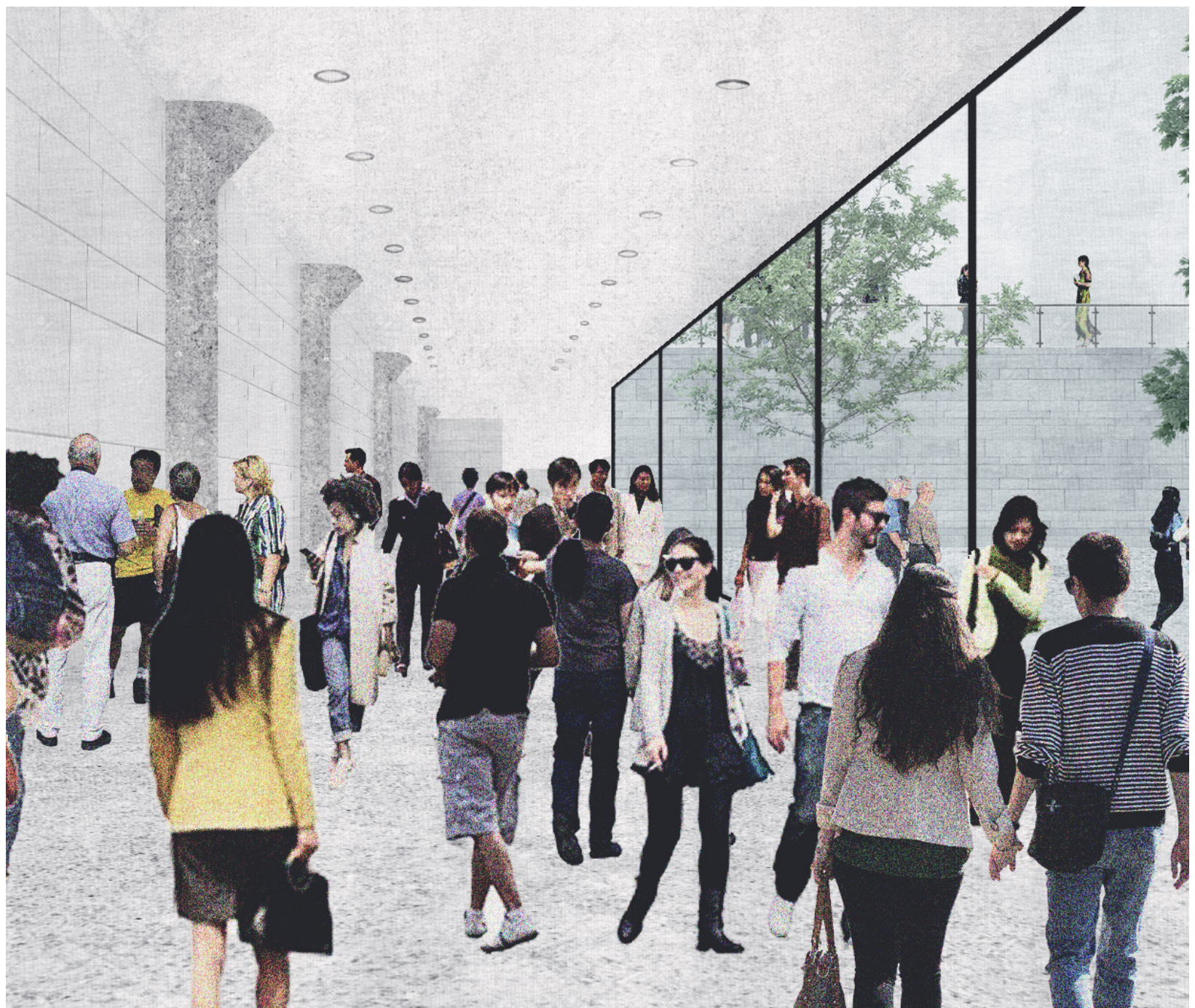


public street, and now also as a private social space for the residents on third level.

\subsubsection{CONSUMER MUSEUM}

In the year 2070, the city of Toronto, once thriving on its street level with various storefronts, has now abandoned this festive lifestyle and services the needs of its inhabitants on the digital platform. What was once considered necessary for economic growth and essential to the urban life has now transformed, leaving the spaces open for interpretation in the digitized urban fabric. The products necessary to life are now manufactured in factories, away from the city, and are advertised and distributed online for public usage. The population now is made up of a generation that was raised with these changes in technology from the beginning, who are easily able to adapt to new products and control the outcome of the consumer market. ${ }^{33}$ They are the protagonists in the golden age of choice, who constantly adjust their online consumption to keep up with the ever-changing daily lifestyle. The way in which infrastructure is organized itself has also changed, where the disappearing retail space in the city has put the continued existence of the structures that support it at risk. The spaces are left barren to possibly house the city dwellers that continue to increase in number and require comfort. ${ }^{34}$
The story of evolution is about what is left behind, the things that are discarded because it has outlived its usefulness. Humans tend to hang on to things that are absolutely necessary, and in this case the need for retail is better served online than in-store, making it easier to give up on what physically exists. The retail spaces left did not vanish easily, but rather tried to entice the consumers with showrooms that offered a comfortable, inviting environment to purchase the offered product with personal assistance. ${ }^{35}$ Every 50 years or so, commerce undergoes this kind of disruption. A century and a half ago, the growth of big cities and the rise of railroad networks made the modern department store possible. Automobiles and suburbanization came next, challenging the city based stores, and in response suburban malls were created to house discount chain stores like Home Depot, Wal-Mart, etc., to better serve the suburban shoppers. Each wave of change didn't eliminate what came before, but reshaped the landscape and redefined the consumer's expectations, often beyond recognition. ${ }^{36}$ In the year 2070, however, the traditional stores are not sufficient enough to accommodate the people who have labelled shopping as an avoidable chore.

Due to online shopping, the years of construction within the urban core to entice city dwellers into the consumer market has left behind blank retail forms from common storefronts to dead malls. The city has finally 


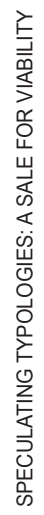

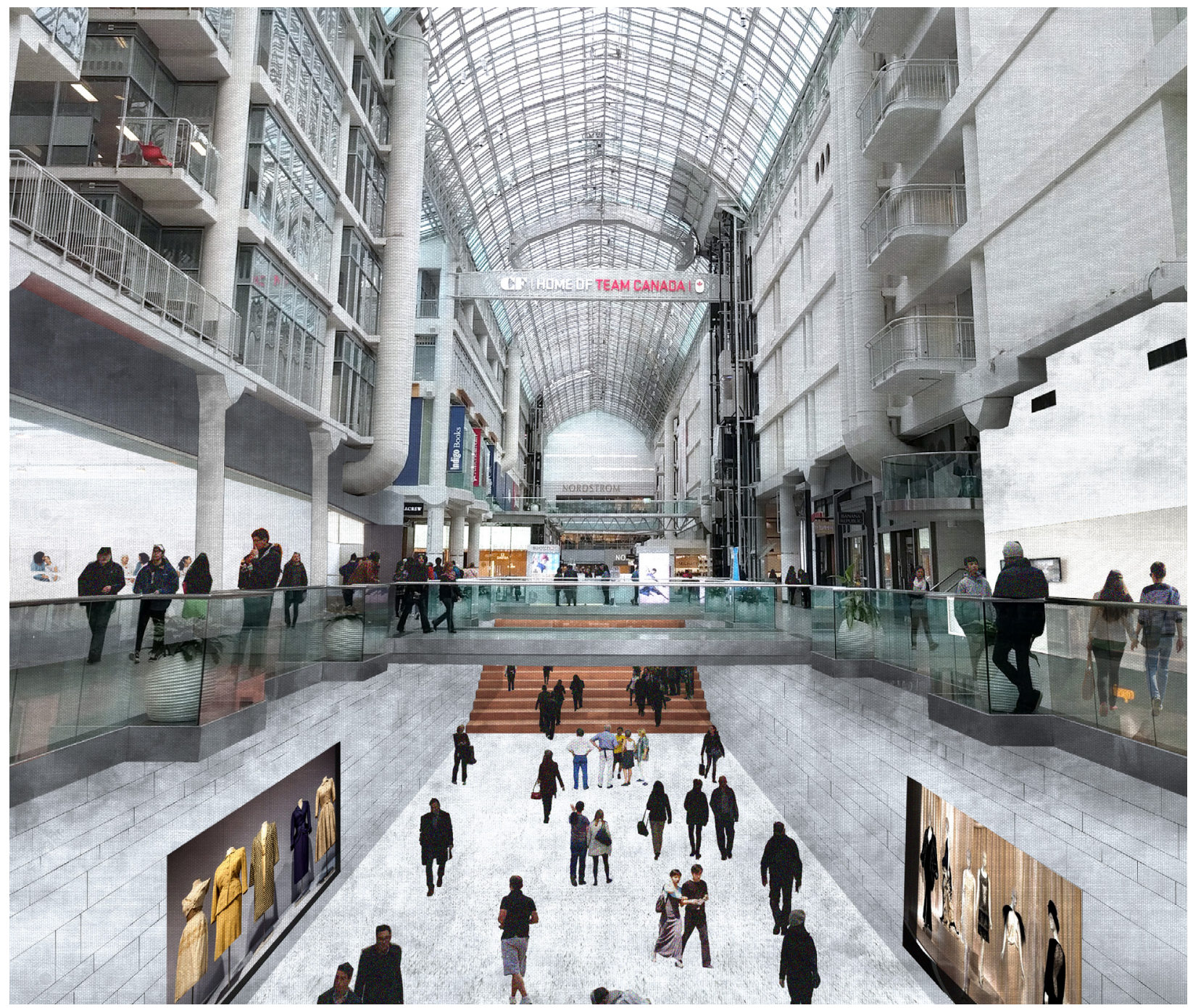


acknowledged the economic dangers from missing retail that is now better served on the digital platform. What will become of the barren structures that once thrived with a physical experience? A strategy needs to be developed to repurpose the retail framework into something equally iconic, profitable, and attractive to once again engage the city dwellers. Dead malls are flexible shells and are able to accommodate any grand program like a museum, theatre, or stadium. The Eaton Centre, as the site, serves as an adaptable structure that is able to house a new city museum that organizes different showrooms according to consumer products people once physically shopped for. The exhibits house products like cellphones, clothes, art, and books for observation. They are paying homage to the physical retail experience and retailers in hopes of answering for their decline, as it was once closely intertwined into everyone's lives.

The first floor still serves as a transition point for the public between transit paths, but is now made more solid to clearly guide the masses from one end to another to attend an undefined adaptable program (figure 3.33). The openings in-between are public zones to momentarily escape the crowdedness throughout the day, and opens to the museum on an upper level to differentiate the public programs. The existing food court now serves as cultural space, where people can convene and socialize. The second and third floors house various exhibits that were once housed by retailers, and also a number of pits in-between, in place of the existing atrium, serve as spaces for users to contemplate their museum experiences among others (figure 3.34). The existing structure is able to accommodate movable panels for quick exhibit layouts, where the existing office levels serve the museum staff and smaller private exhibitions that require discretion. The higher levels, including the office towers, are used for residential programs like affordable housing to serve the growing population of the city.

\subsection{NEAR FUTURE}

\section{5 .1 HOUSING}

Toronto by all definitions is a successful downtown. Its ability to attract and retain people and businesses and nurture an appealing cityscape makes it a vibrant city for habitation. ${ }^{37}$ Downtowns are commonly able to host a dense amount of public activities made up of commercial, institutional, recreational, and residential sectors. More importantly, each market trend affects its evolution differently, hence the way in which they progress is indefinite, but is projectable through factual study of how it is now and was before. Although Toronto conformed to the pre-1950 North American centralized city model, there was very little office and retail construction that took place from the early 1930 s to the early 1960 s. $^{38}$ Once sections 
DWELLING UNITS BY STRUCTURE TYPES

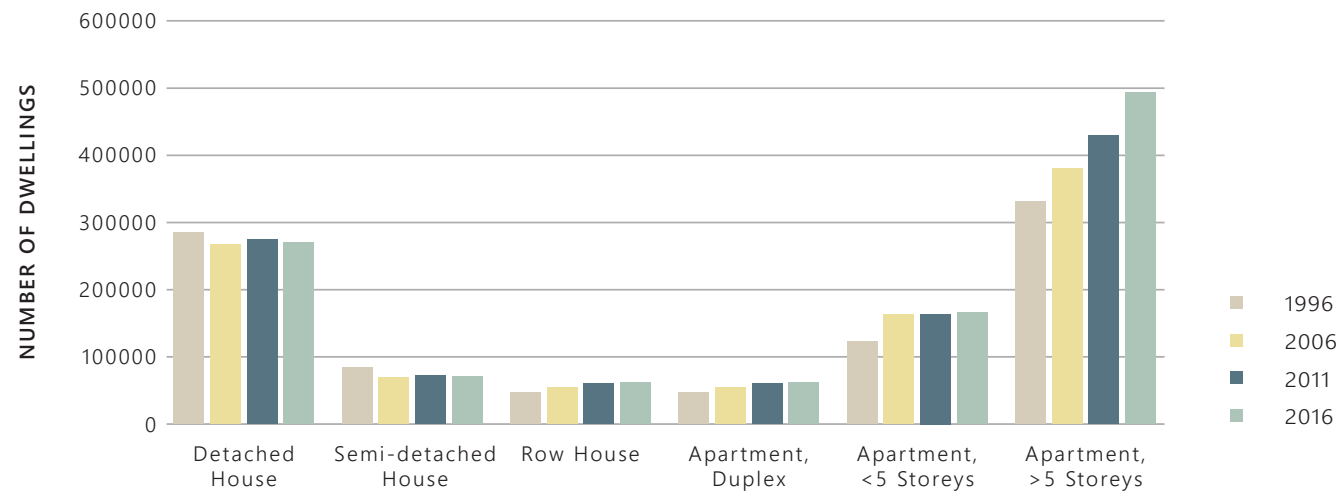

POPULATION CHANGE BY AGE GROUPS

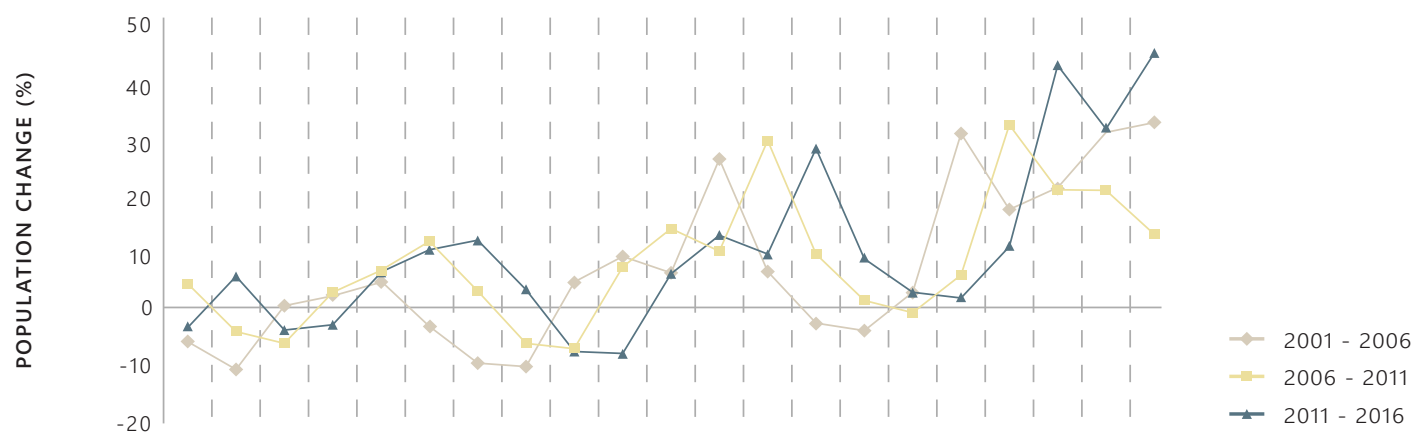

AGE

PRIVATE HOUSEHOLDS BY SIZE

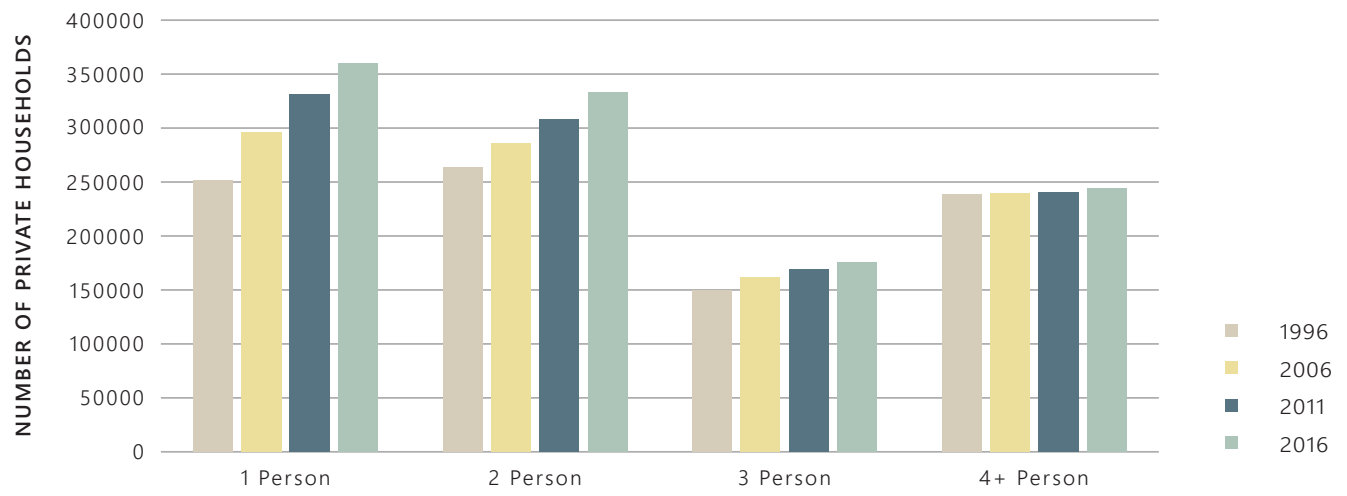


were upgraded to accommodate the increased inflow of users. Toronto began to attract the attention of residential developers, and after losing residents steadily through the 1960s, the downtown population decline levelled off in the 1970 s. $^{39}$ The problem facing the downtown core again is that of accommodation and the increasing demands of millennials and baby boomers. The ideal age to settle down and the expectations of an ideal lifestyle is no longer the same as it once was in the last century.

Housing in the downtown core is expensive, whether it is a rental or owned property. As a comparison, between 2001 and 2014 home prices increased by 133 percent while household incomes grew only 36 percent. ${ }^{40}$ In addition, the millennial's upbringing was in a technological environment, that from the start eased numerous tasks. Their free spirit to be independent fuels their lifestyle leading to a higher demand of single person homes in the downtown core, where they are close to their academic, active, and work lives. That said, the recent shift in household ownership studied in the 2016 census projects an increase in demand for single-family households to accommodate the upsizing millennials who were served for over a decade by small studio and one-bedroom condominiums. ${ }^{41}$ Between 2016 and 2026 the number of new family households with children are projected to more than double to some 37,000 net new households per year, accounting for over 20 percent of total household growth. ${ }^{42}$ According to a study conducted by the Ryerson City Building Institute, in partnership with the real estate firm Urbanation, stated that the downsizing of Baby Boomers is already in the works because of their desire to age in place and more specifically in environment of homes and communities that they have aged within thus far. ${ }^{43}$ Therefore, the market over the next decade needs to be prepared for the near future of Toronto by facing the economic realities of these demographic changes.

In terms of the construction required, the missing middle option is clearly more affordable. This form of housing is a type that exists in-between detached houses and high-rise apartments, a multi-unit cluster ${ }^{44}$ However, the current market is overflowing with condominium developments that, in the majority, is focused on creating one-bedroom units for the market. In comparison to the 41 percent twoor more-bedroom apartment units under construction right now, the 1990s produced 67 percent to support the growing families. ${ }^{45}$ The effort to decrease this gap is in development, but it is important to note that the size of these units is smaller than it was in 1990s in order to make them affordable and more plentiful. The price gap between single detached houses and condo apartments has tripled since 2007, from $\$ 200,000$ to $\$ 600,000$. $^{46}$ In addition, the millennials that do wish to upsize on average have less savings, have significant student debt and have low earning capacity. This is why the missing 


\section{NEAR FUTURE}

RESIDENCE

BABY BOOMERS ENTERING RETIREMENT

MILLENNIAL GENERATION SEEKING-FAMILY ORIENTED HOUSING

YOUNG PROFESSIONALS AND STUDENTS DOWNSIZING

$20 \%$ INCREASE IN NUMBER OF BIRTHS Between $2000-2016$

$20 \%$ projected household growth Between $2016-2026$

$89 \%$ DECREASE FOR LOW-RISE HOUSING AVAILABILITY IN 2016

3 X price gap between single-detached HOUSES AND CONDO APARTMENTS SINCE 2007

\section{RETAIL}

GLOBALLY, WE-COMMERCE IS HEADED TOWARDS $15 \%$ to $20 \%$ of total sales

1990 S embraced onLine shopping, E-COMMERCE

EVERy 50 years or so, RetaILING undergoes DISRUPTION

2017, E-COMMERCE ACCOUNTED FOR NEARLY $3.4 \%$ of total RETAIL SAlES in CANADA

E-COMMERCE WILl ACCOUNT for $10 \%$ of CANADIAN RETAIL SALES By 2020 
middle developments encompassing of townhouses, mid-rise apartments, and duplexes is more obtainable for the public, which as a result are located on smaller lots while still providing a layout suitable for both families and single-person household. The competition between downsizing seniors and upsizing millennials will not be resolved anytime soon from this particular projection, however the accommodations can be constructed that will enable both groups to enjoy urban living.

\subsubsection{RETAIL}

Change in retail, as discussed before, is constant throughout many periods of history; it is in very nature to develop, to improve, and to deliver. One of the problems facing the shopping culture now is decreased interest in the physical experience. Physical stores are not dying, but the products sold by them are increasingly available online. In addition, the shopping malls hosting these stores are becoming less usable, especially in United States to their quantities. One thing is clear, shopping is not dying, but a transformation of its experience needs to take place. Consumers are in the power position, as 2017 is the golden age of choice, convenience and demand for value, all facilitated by mobile devices making the global bazaar just a tap away. ${ }^{47}$ Globally, e-commerce has made the shopping more accessible and simpler, where products bought are delivered the following day with a better deal and more options. The e-commerce sector has grown by 39.5 percent in Canada between 2012 and 2015, according to Statistics Canada, while in-store sales only grew by 14.2 percent. ${ }^{48}$ Convenience provided technology is project to decimate the workforce in the future because not only is it more competitive, but it can potentially be outsourced to anywhere around the world.

The idea of display windows and presenting products in spotlight has worked in the past, and moving forward was improved with showrooms, product demonstrations, and more to increase in-store foot traffic. Furthermore, the spread of discount chains like Wal-Mart and big-box stores like Home Depot in the 1960s and 1970s began to redefine consumer expectations and reshape the retail landscape. ${ }^{49}$ The brick and mortar stores are now once again undergoing transformations by digitizing their products based on customer convenience and rolling out new features, but are strengthening their physical experience for possible buyers. By understanding how the present stores profit from their design, the future of retail can be directed. On the other hand, a bevy of internetbased retailers in the 1990s, like Amazon, embraced what they call online shopping or e-commerce, and the platform is growing exponentially. ${ }^{50}$ Amazon has surely set new standards for the shopping experience with its creative stocks and seamless service to not only make the checkout experience more convenient but more enjoyable. 
Between 2010 and 2016, Amazon's sales in North America quintupled from $\$ 16$ billion to $\$ 80$ billion. ${ }^{51}$ In addition, their drone delivery system aims to further refine their customer services in the future. Their online services did experiment with multiple strategies to refine their current state, which is why its base is now strong enough to serve as an alternate retail experience. This especially includes millennials who are more likely to spend money on an experience and activities in-person rather than physical goods.

This resulted in a shift from physical retail; some of the solutions to avoid the declining interest in physical retail are to improve the characteristics that made it unique in the first place. By investing in elements like the showrooms and display windows, the physical locations are not pushing the product forward, but rather enticing the consumers with all of the amenities housed inside the store. ${ }^{52}$ Alongside, demonstrations of products, a store can still remain viable for many consumers who still prefer an authentic retail experience. Larger retailers like Nordstrom are also experimenting by housing pop-up retailers to further enhance their interior environment. Now the retailers are not only competing with one another, but also with entrepreneurs who develop and distribute new products online. ${ }^{53}$ Pop-up retail serves these entrepreneurs as an outlet to reach out to their consumers in the physical realm. By allowing them to advertise and sell in larger brand named stores, the two retail worlds are colliding and cooperating with one another to further the retail experience. A person can still make several trips to a store before completing a purchase and end up buying a completely different product. The labyrinth characteristic of retail still exists to further lengthen the consumers' experience. However, in my opinion, popup stores are the ideal option to support the future of retail, not only in terms of the variety it provides but also customization, value and foundation for entrepreneurs who seek independence in this technological age. Physical retail is not dying, but rather needs to be refreshed for the consumers by means of quicker transformations.

\subsection{PROGRAM EXPLORATION}

Using selective obsolescence as the foundation, this proposal speculates on the near future use of urban shopping centres in new ways, the next evolutionary step in the retail typology. The current trend of online shopping will not overtake the physical retail experience anytime soon, however its effects in the long term among the variety, accessibility, and pricing will surely be noticeable. Speculating forward into the uncertainty of how the city and its people will coexist, the proposed program considers how future dwellers will shop, commune, and reside within the urban core, especially within a shopping centre. Housing and retail typologies explored in the 
previous section are distributed strategically to house the required programs within the existing structure and floor plates, after the removal of partitions that once defined the interior storefronts. The new program again plays an important role among the city dwellers, and future direction of retail and residential design as a strategic model designed to accommodate the near future trends.

The program is divided into eight new blocks, three highrise towers and one elongated retail form. Individual neighbourhood blocks located alongside the retail form various living and work conditions, including co-housing, micro apartments, live/work units, townhouses, courtyard apartments and WeWork. The three high-rise towers house educational and office programs alongside a number of commercial programs to increase engagement amongst the tenants. Lastly, the retail form is located centrally, where the mall arcade once existed, and houses numerous pop-up shipping container shops, that vary in sizes and organization to highlight a different retail experience in each of the form's sections. There are eight main access points located throughout the master plan, six already existing in the current mall layout and two more created by opening Shuter Street towards Toronto City Hall. Each path doubles as an outdoor space, the entries to individual neighbourhoods, and are slightly ramped to accommodate for the gradation change on site.
The existing façade plays a prominent role along the site's border. For that reason, a complete removal of the façade is avoided for specific neighbourhoods and is integrated as a design component. By setting up a guideline for these neighbourhood blocks in terms of sizing, the existing façade coexists with the new program and provides a certain level of privacy off the bordering street. The spaces in-between these two façades is then used privately by the tenants as an outdoor space. In addition, the new program has the ability to showcase itself onto the bordering streets by projecting itself through the existing glazing.

Each neighbourhood block drawn during the exploration was selected and laid out according to an intended public/ private interaction. Programs like micro apartments, live/ work units and WeWork are located along the major street -Yonge street- to welcome the users, while co-housing, townhouses, and courtyard apartments are located along James Street to increase tenant privacy. In addition, the scale at which these blocks stand varies depending on the available space. In the case of micro housing block four, a grid was overlaid on top of the existing structure to define a set of rules onto which the units inside would be organized. From a range of ten separate micro layouts for studios, the residences were organized along the edge of the form to allow for an open central component that enables social interaction between future neighbours. Each unit is also designed to have a Juliet balcony overlooking the outdoor 


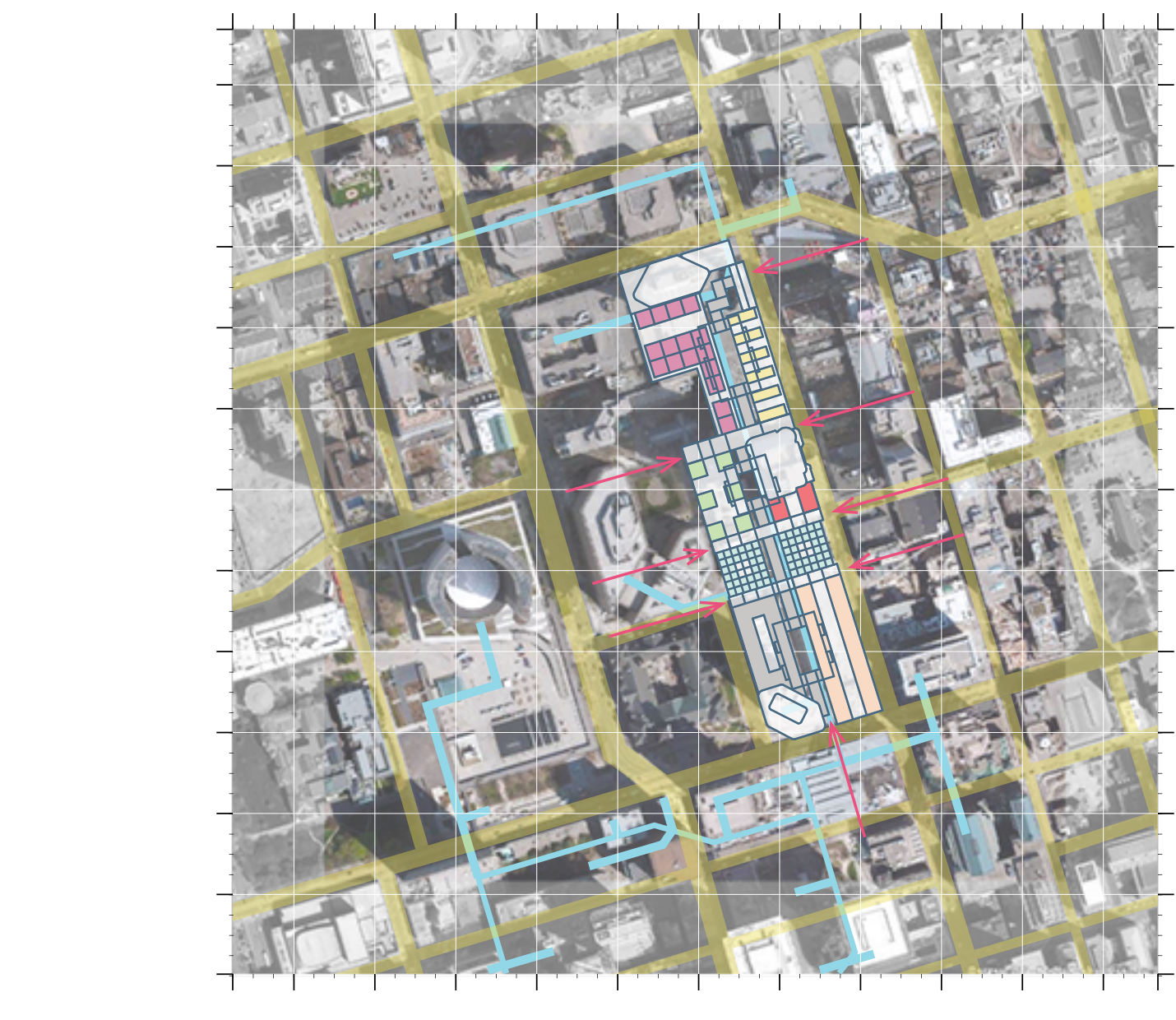


transition spaces, and smaller studio units have the option to add an outdoor balcony. Spaces that encourage social interaction are also laid out at every level to not only connect the separate levels, but also to entice the tenants to use the provided facilities through exploration. The comfort found in micro living units encourages a transient lifestyle that advocates exploration, interaction, and a certain level of living sensibility that is often found in closely-knit neighbourhoods. A large atrium space is also placed in the hollowed centre to serve as a circulation core and a space for social gatherings at different levels. The natural lighting and glass enclosure allows the tenants from different levels to gather and connect during certain hours and events to boost a neighbourly environment.

The elongated retail form in the centre was inspired from the current enclosed mall typology, where an enclosure houses various stores safely away from outdoor noises and environment. Rectilinear in shape, the roofs of the form are angled and punctured to accommodate the skylights and green roofs through the transition. Its minimum height is eight metres and is nine metres in width, and can accommodate up to three to four storeys of shipping container levels in some areas. The shopping experience envisioned here is condensed to entice higher level of potential shoppers, which is beneficial for the retailers since they have just begun to set ground for their businesses. Each section is fully glazed and has a fixed entrance at both ends. These entrances are to build up users' expectations prior to exploration and provide after hour security. The retailers located adjacent block four are promoting their clothing businesses in a threestorey layout. This form of layout concentrates retail and circulation in two halves, and offers gathering spaces for socialization above the circulation. Each of the levels has a deck structure, extruded from the shipping container framework, to allow shoppers to branch out and explore the surroundings. A few food vendors are placed at the higher levels to entice the users to explore and purchase the available products. 


\subsection{PROJECT DOCUMENTS}

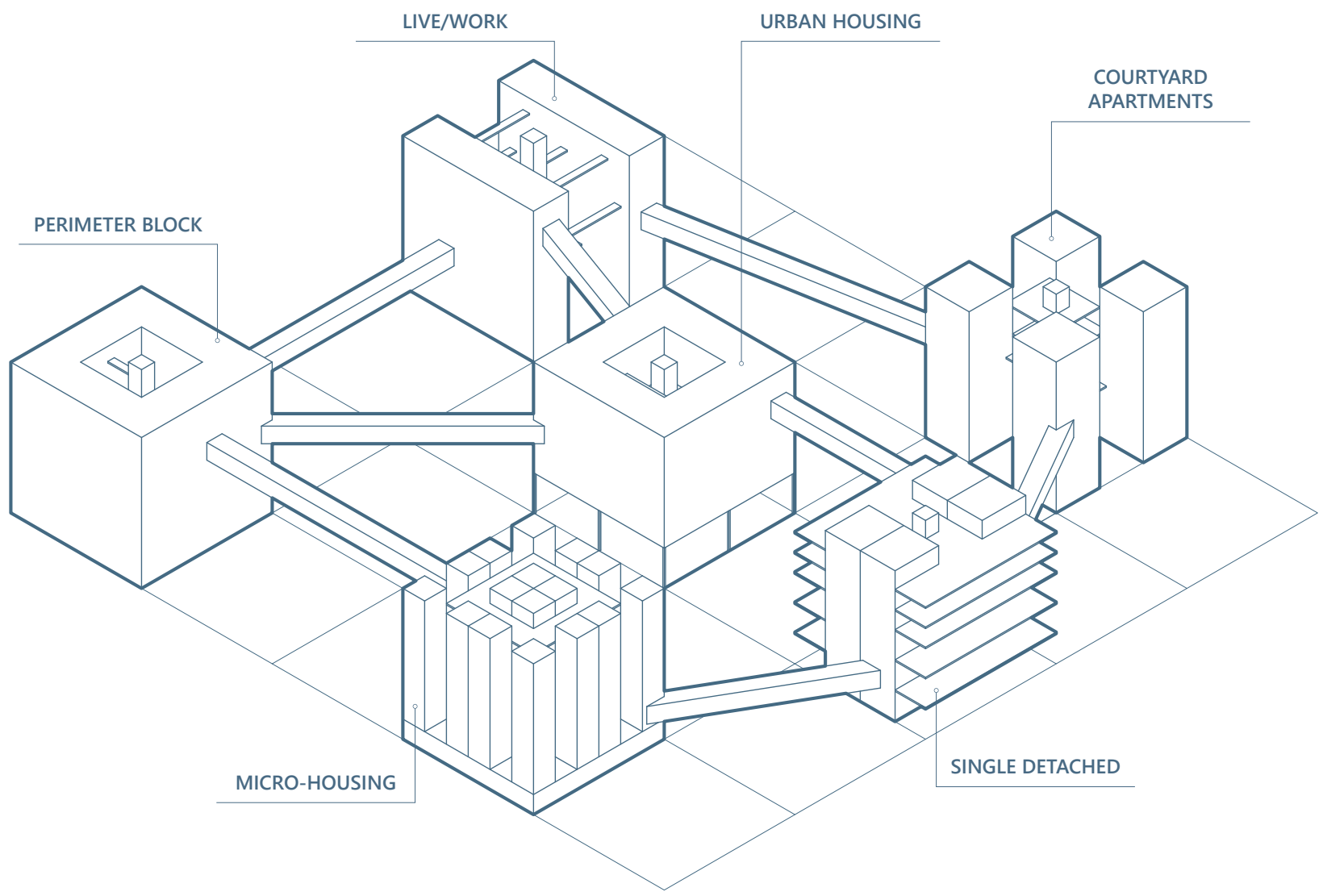




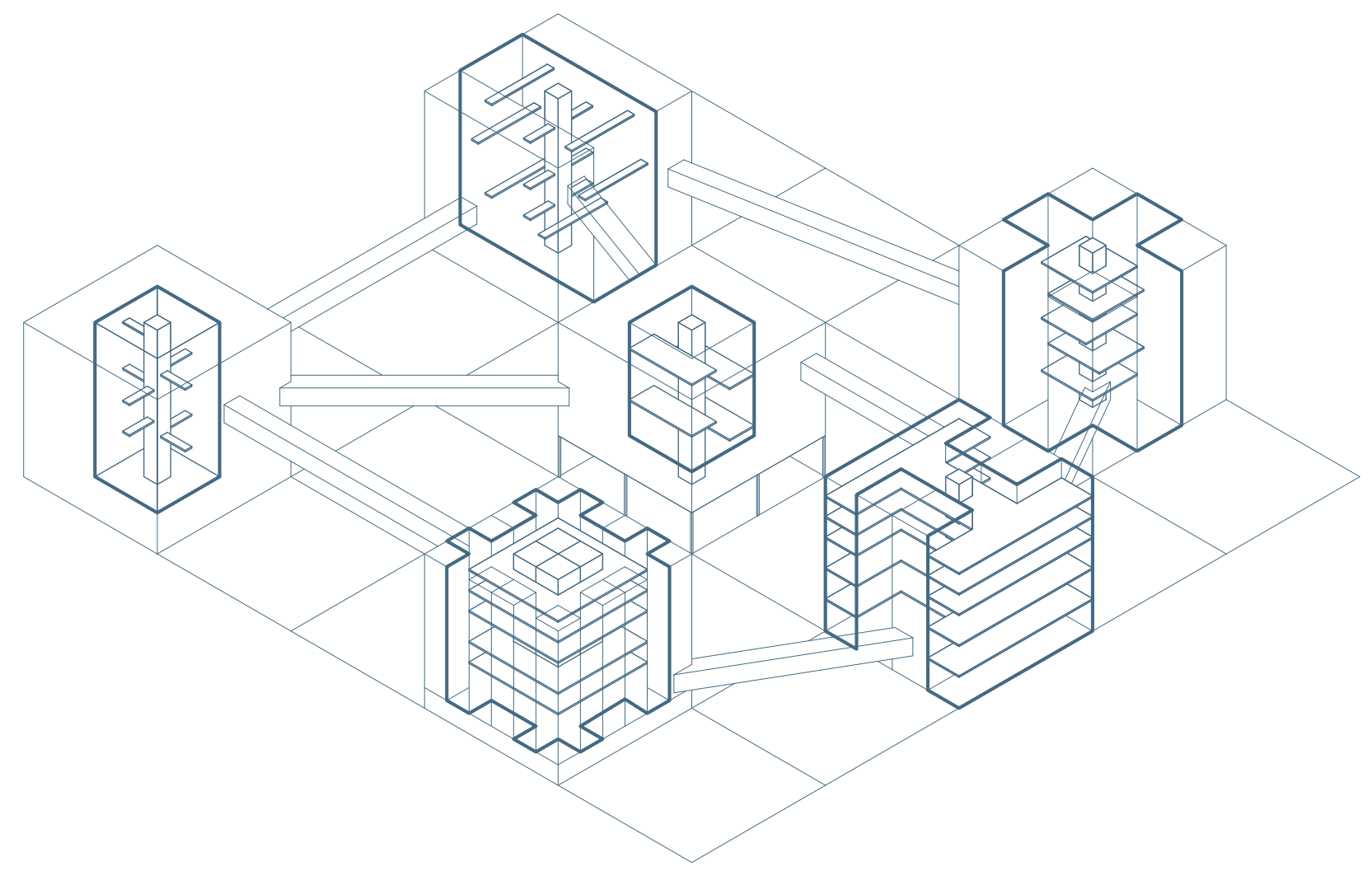

Fig.6.39 Internal circulation core for the residential neighbourhoods 


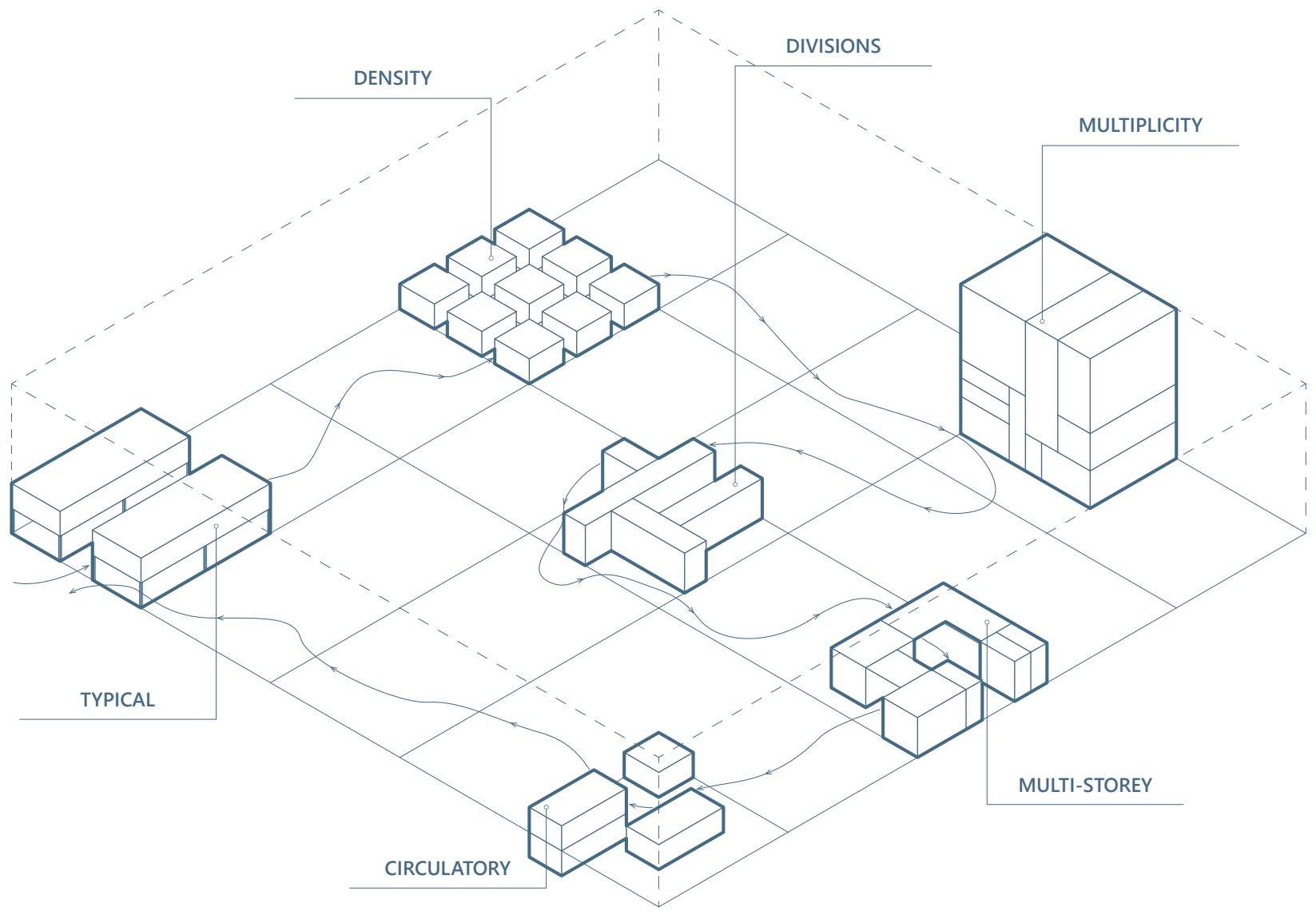




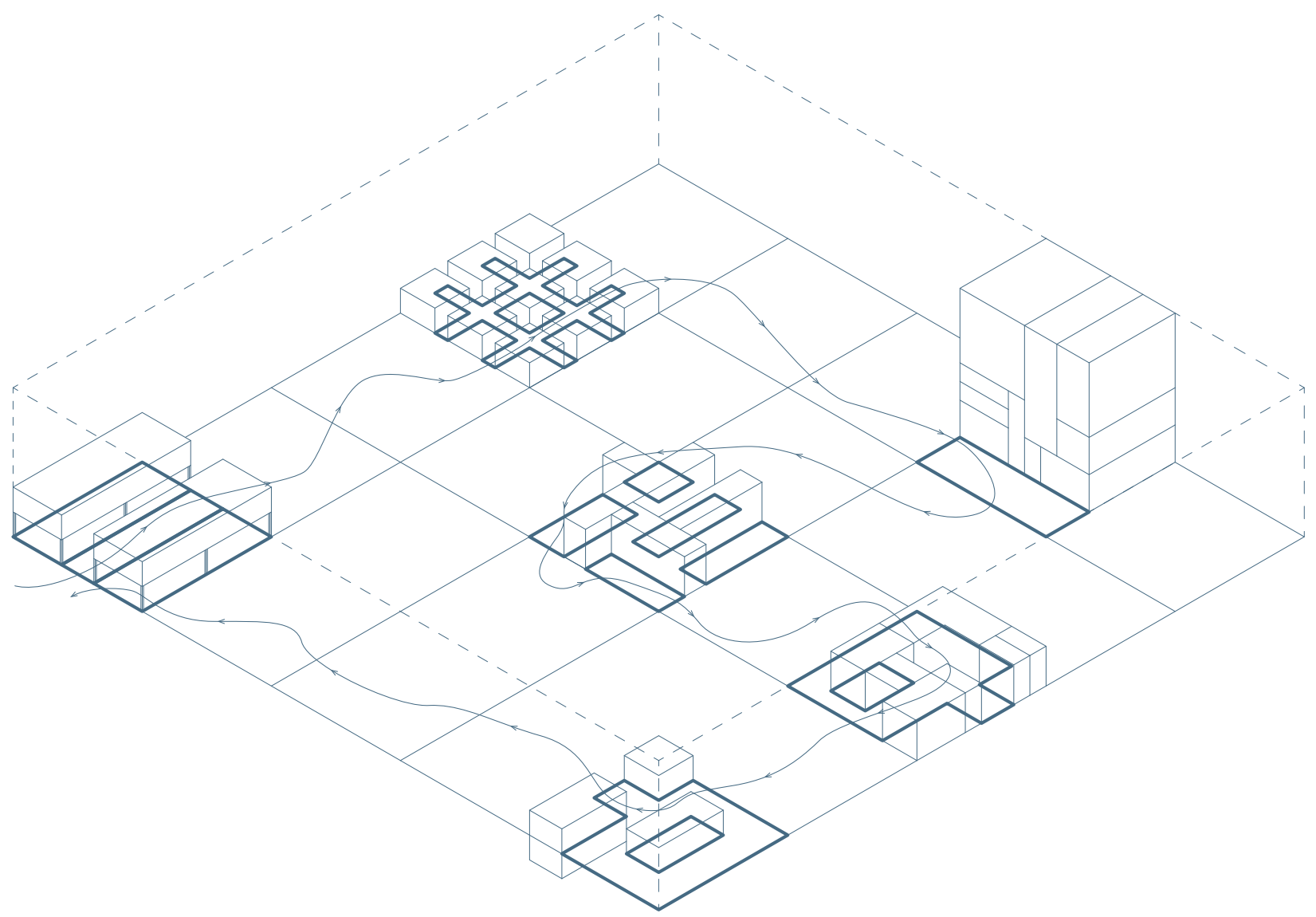




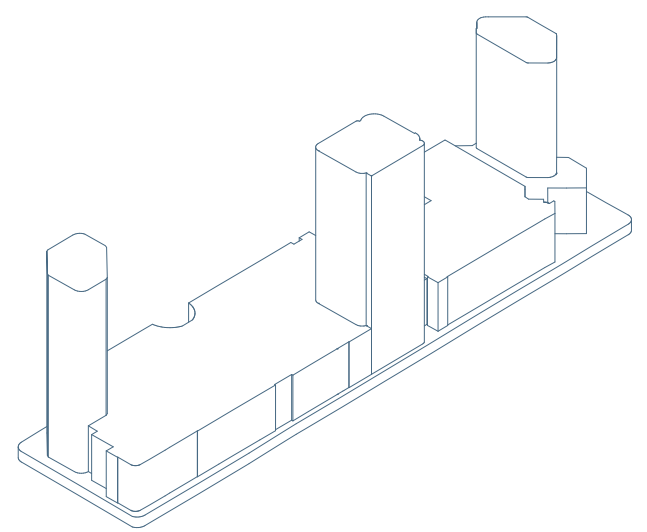

\section{EXISTING FORM}

Consideration of existing framework and street access

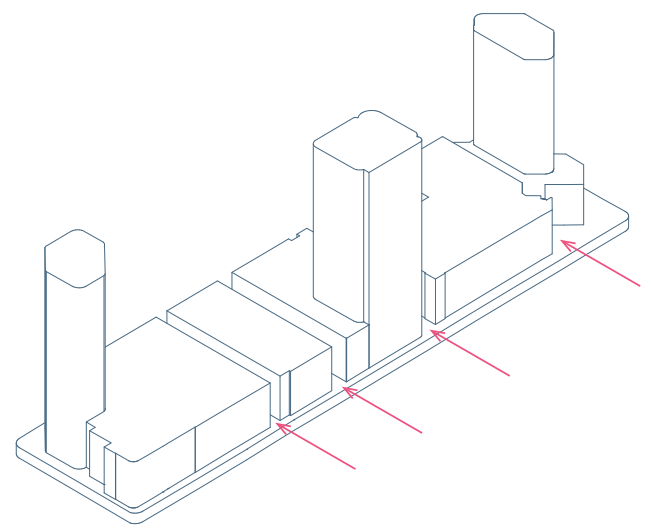

\section{ENTRY POINTS}

Opening the existing entryways, and creating a path from Shuter Street

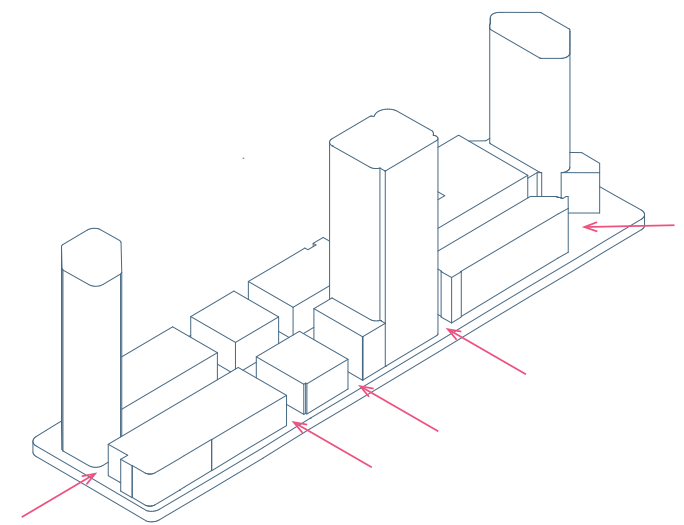

\section{CENTRAL CIRCULATION}

Removal of central arcade, mezzanines, and floor plates 


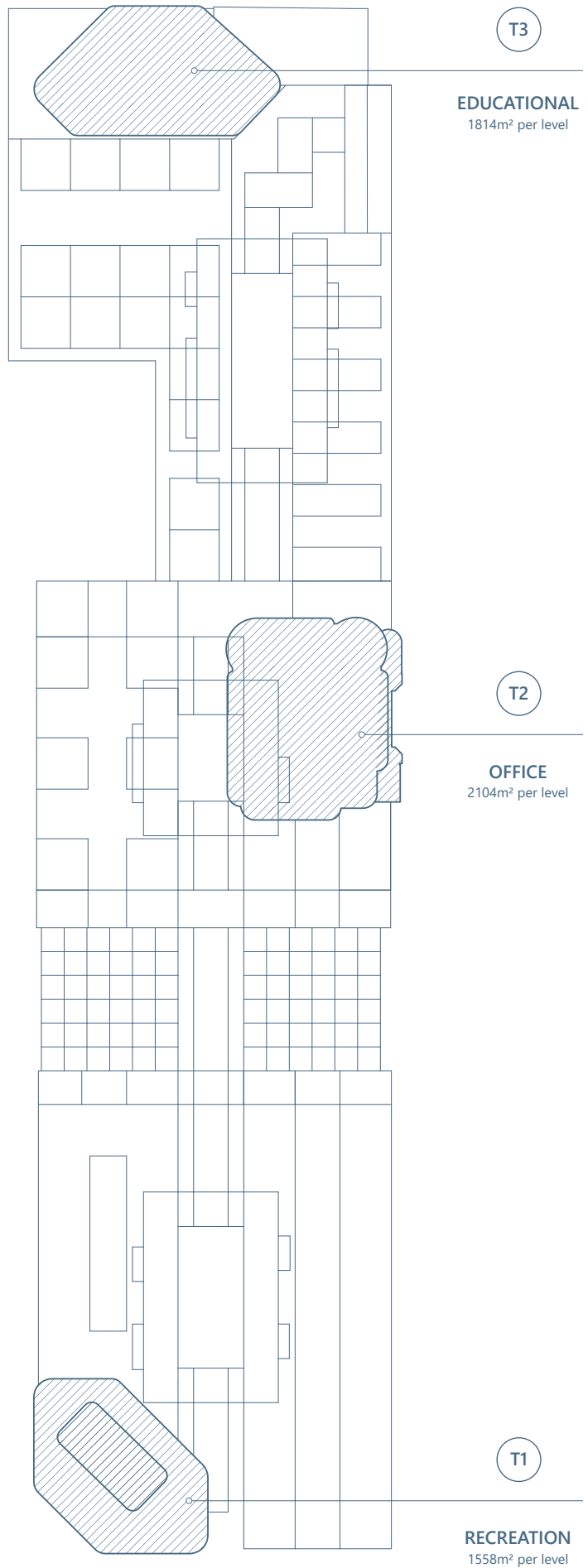

Fig.6.43 Master plan tower programs 


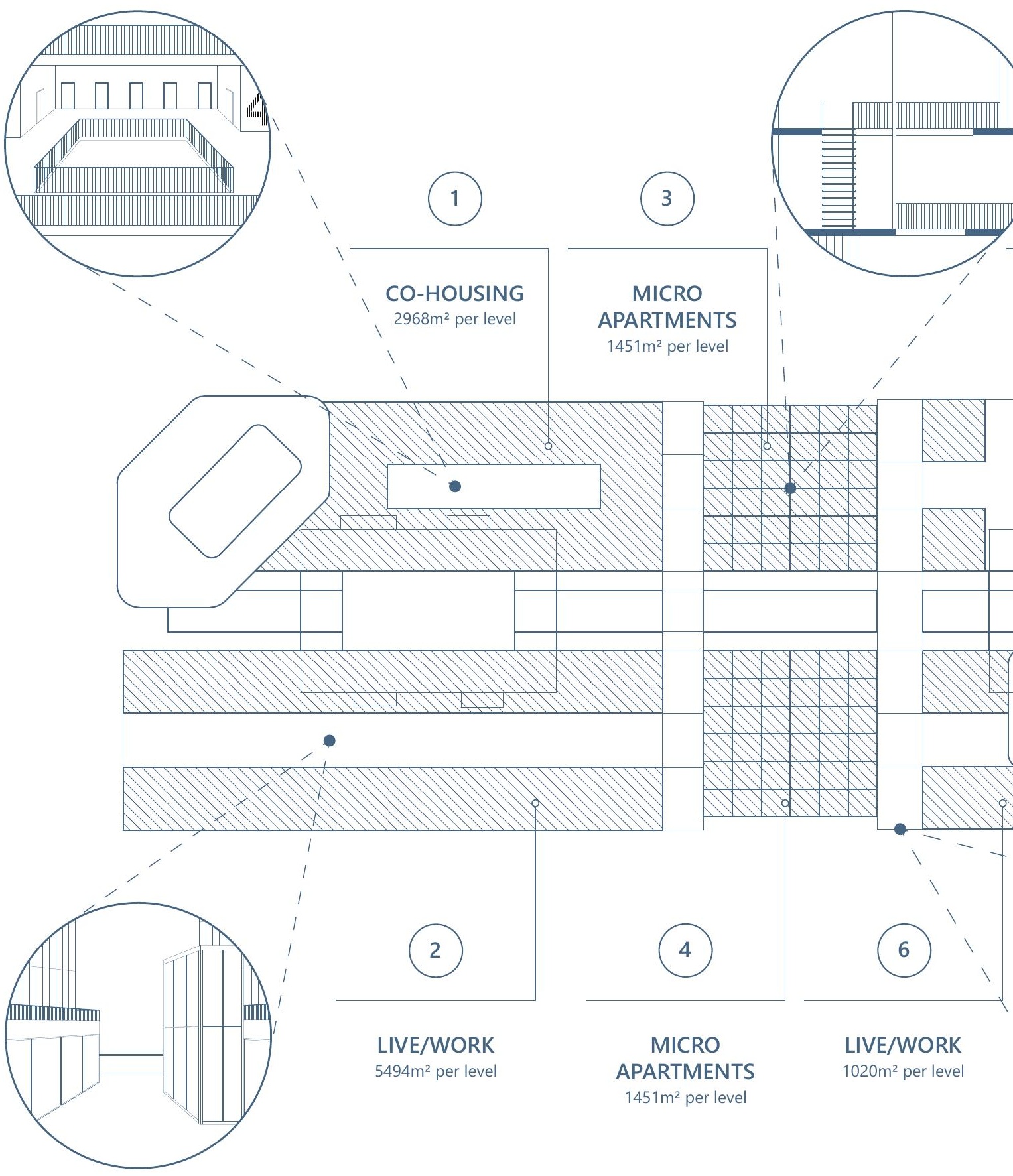




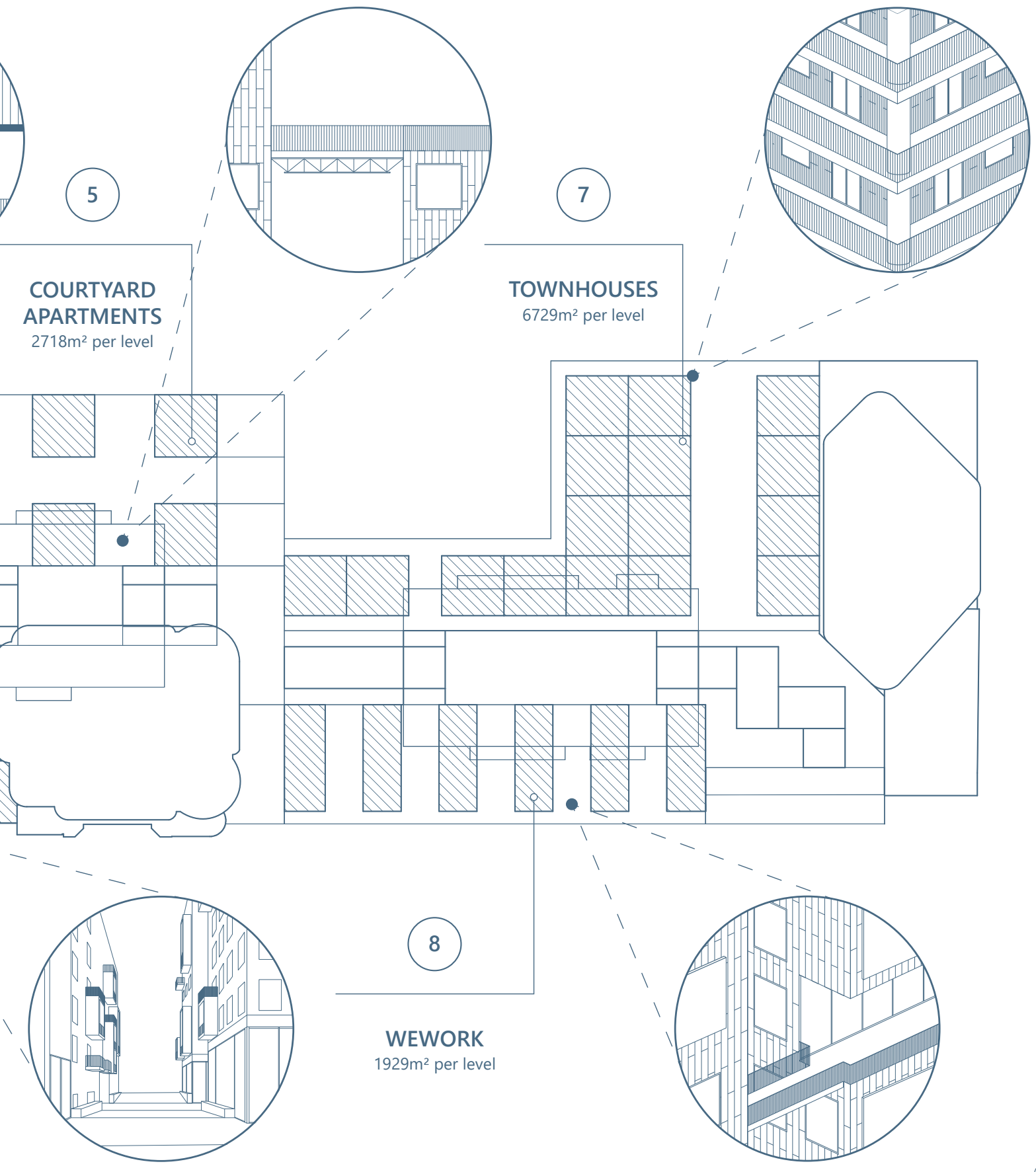



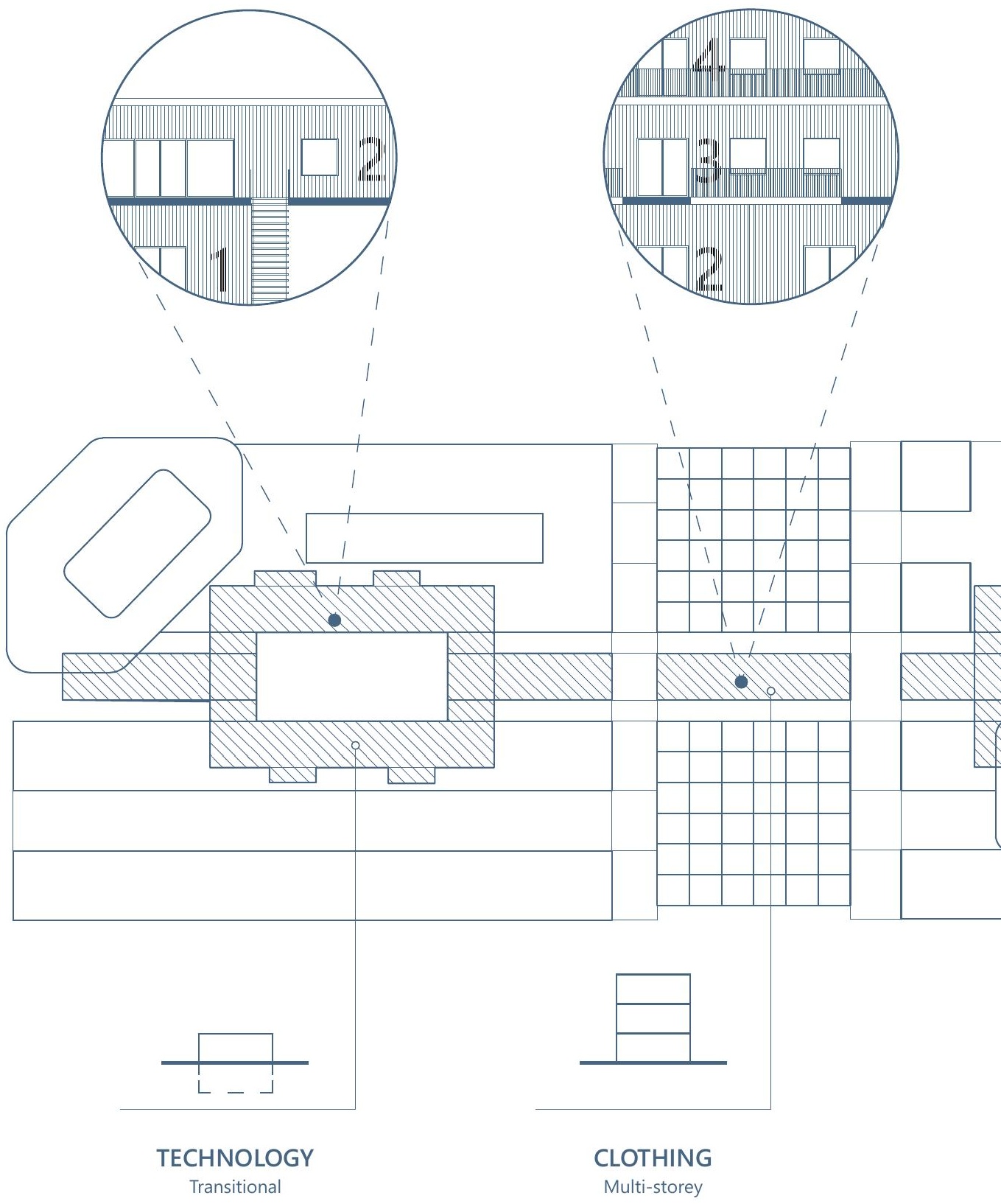


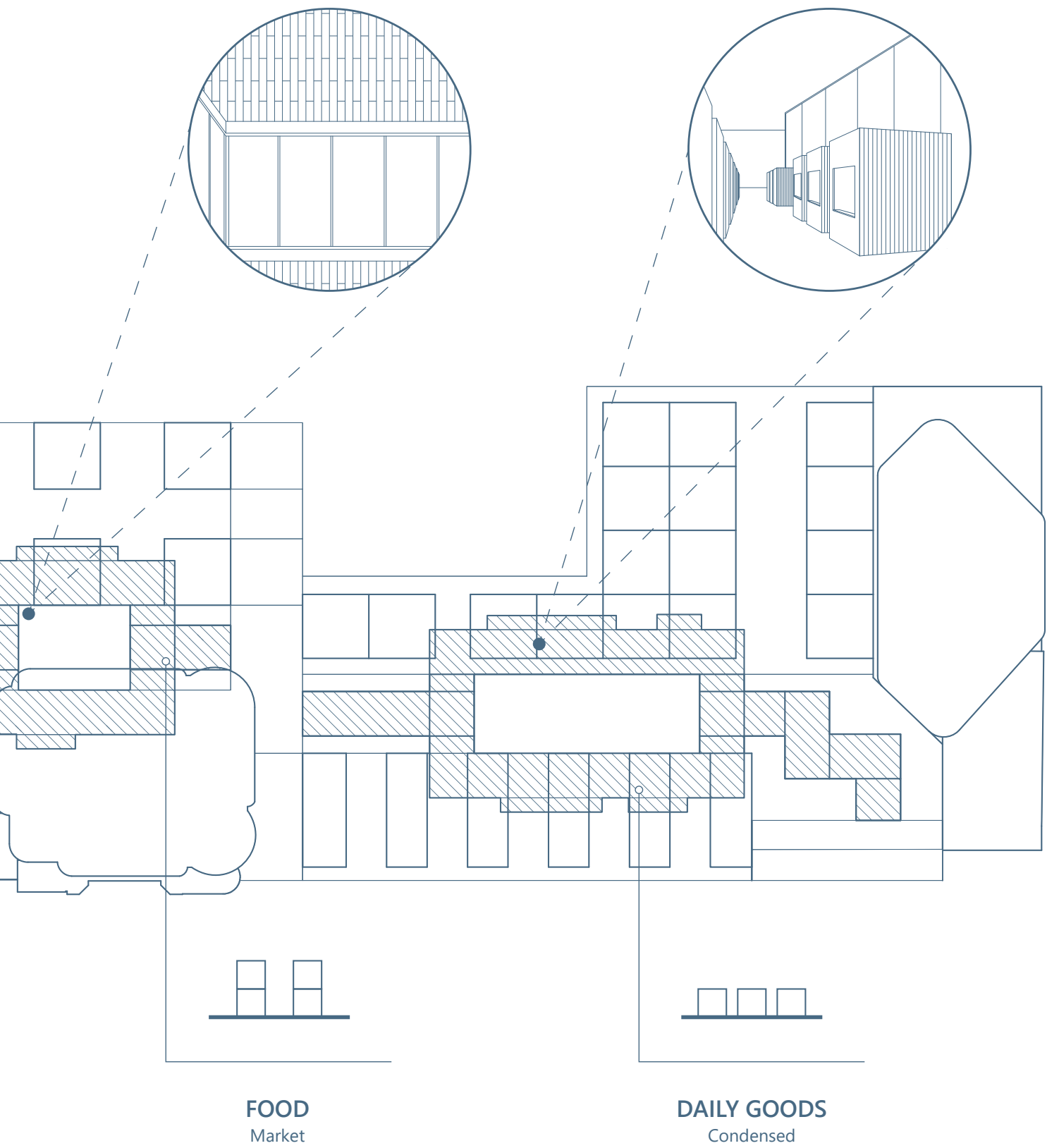




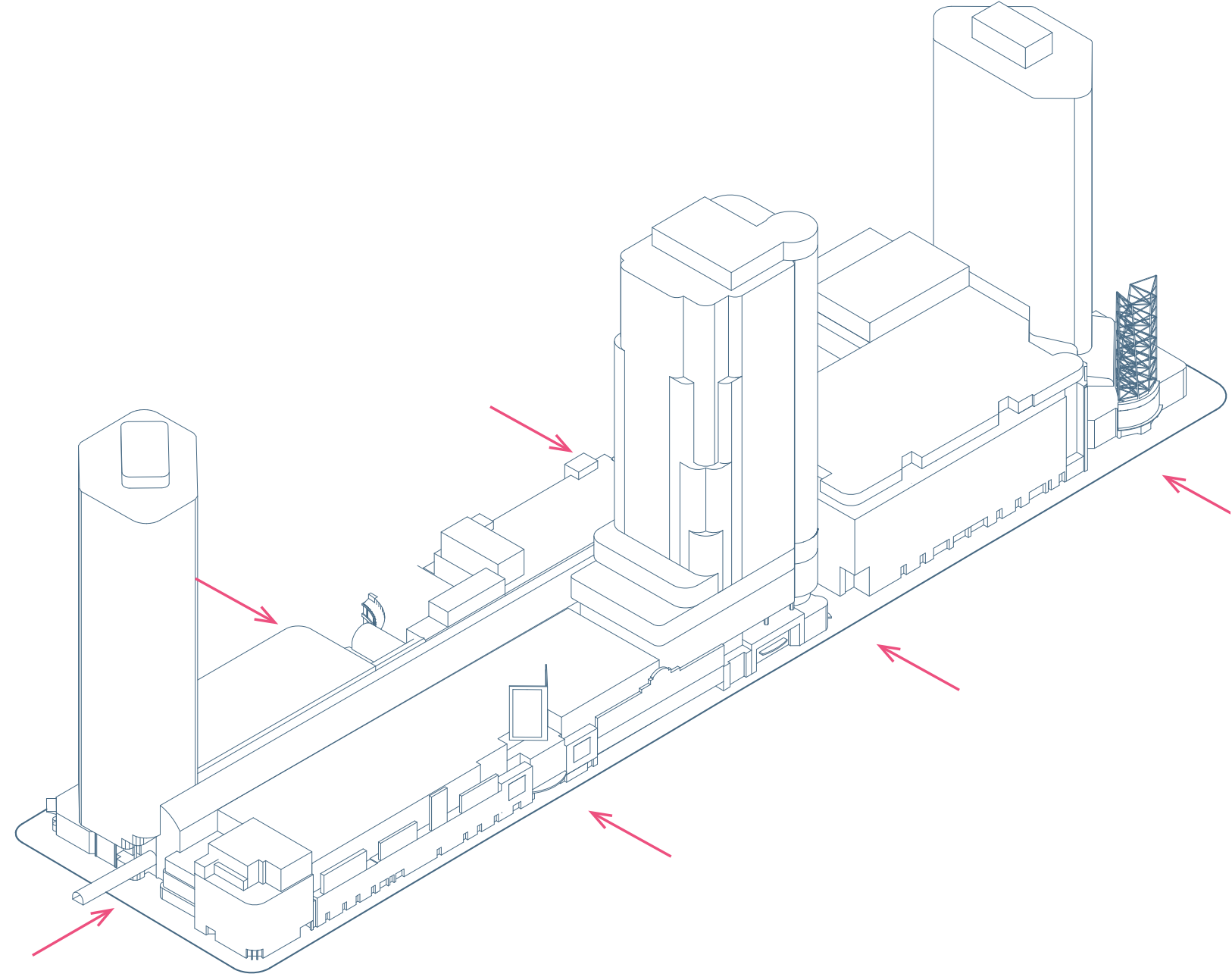

$\frac{10}{5}$

Fig.6.46 Existing massing 


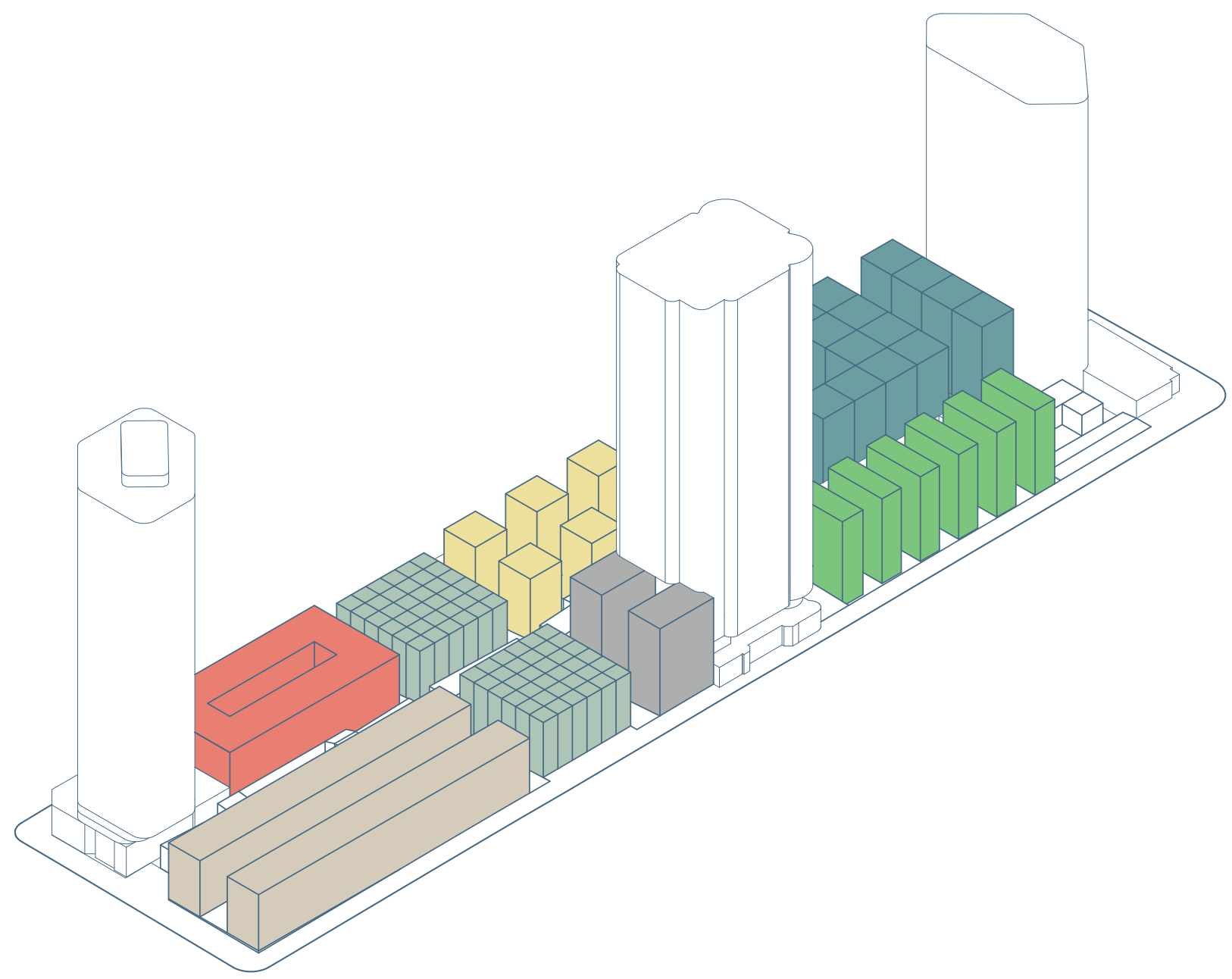

Fig.6.47 Near future neighbourhood intervention 


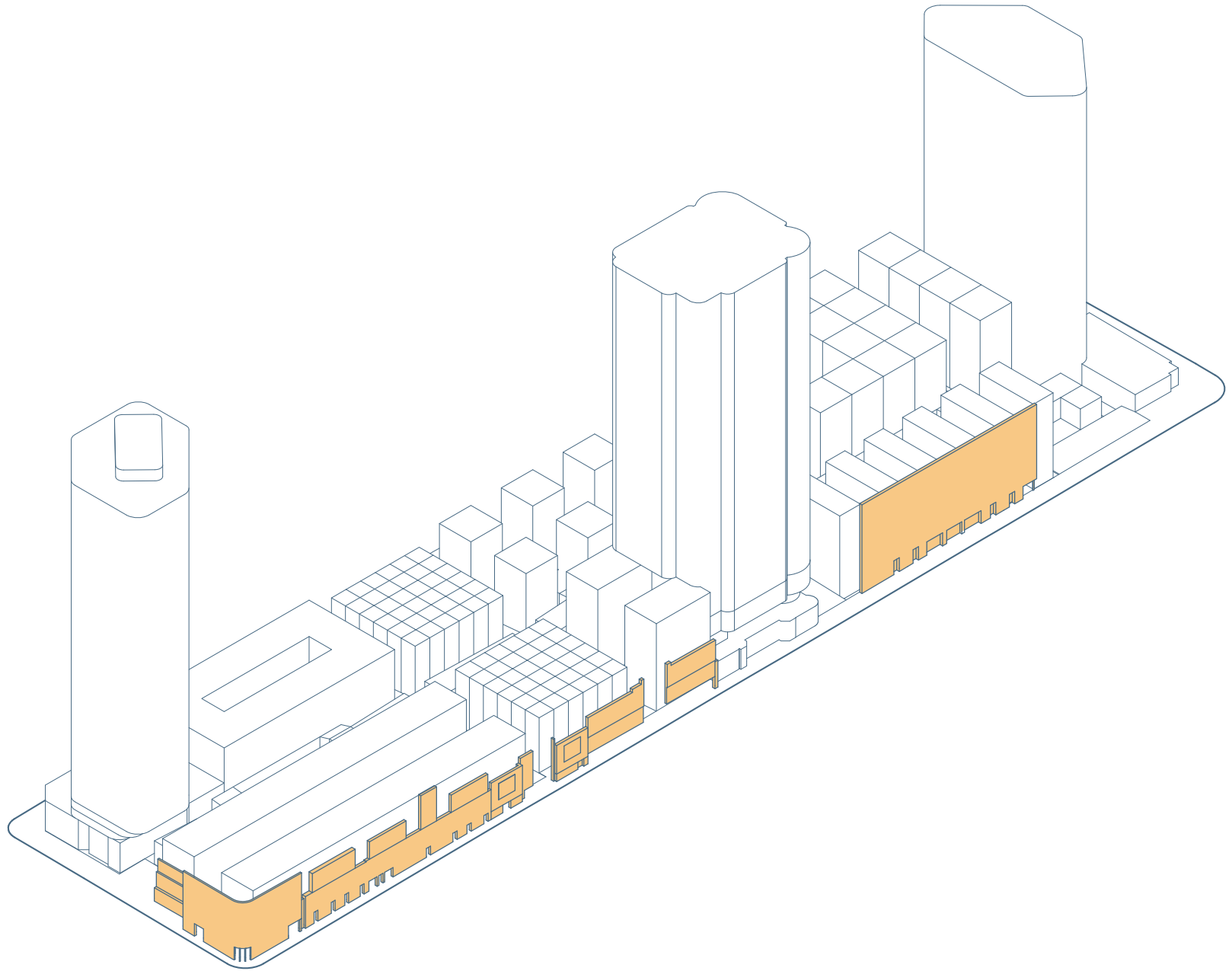




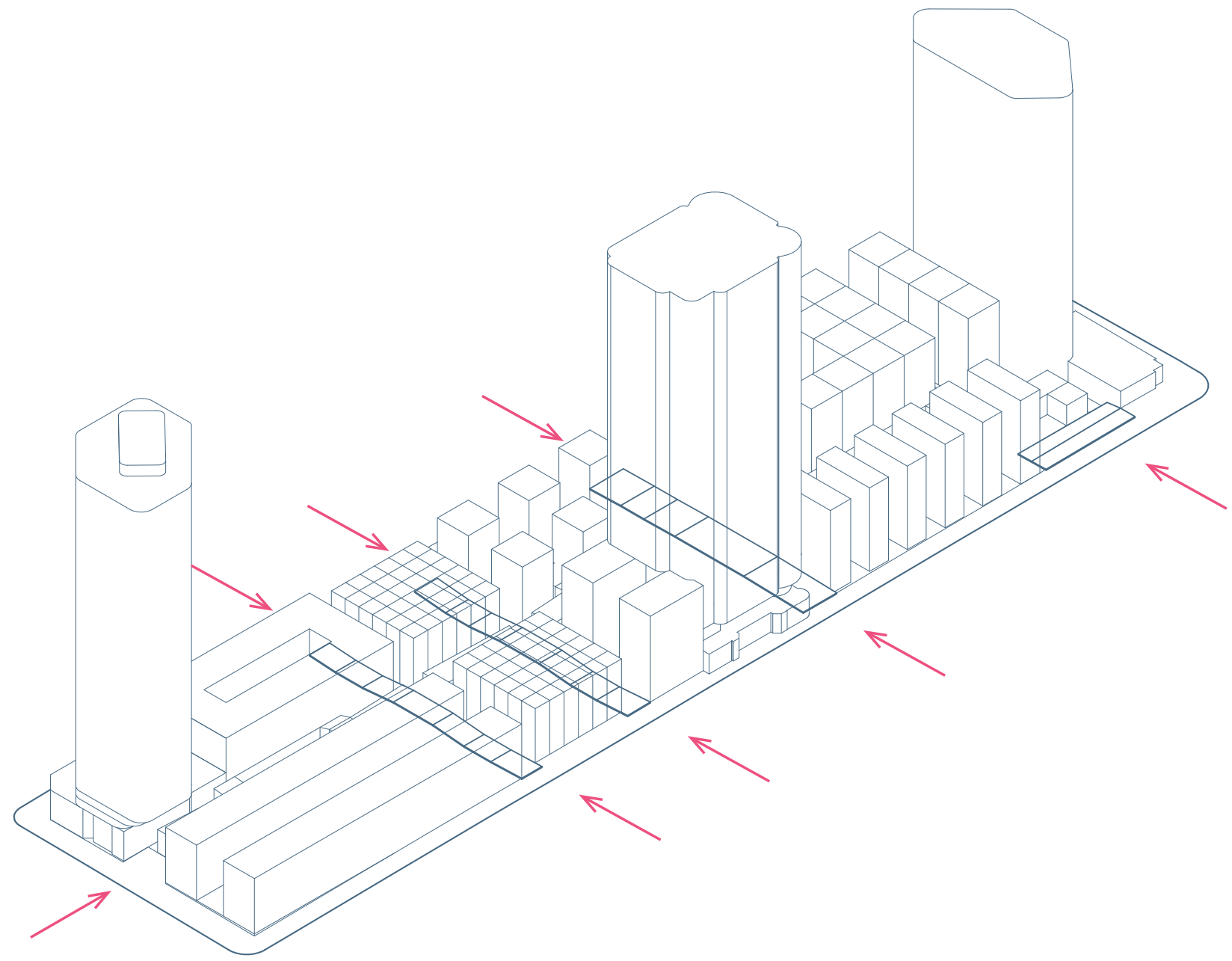




$$
2
$$




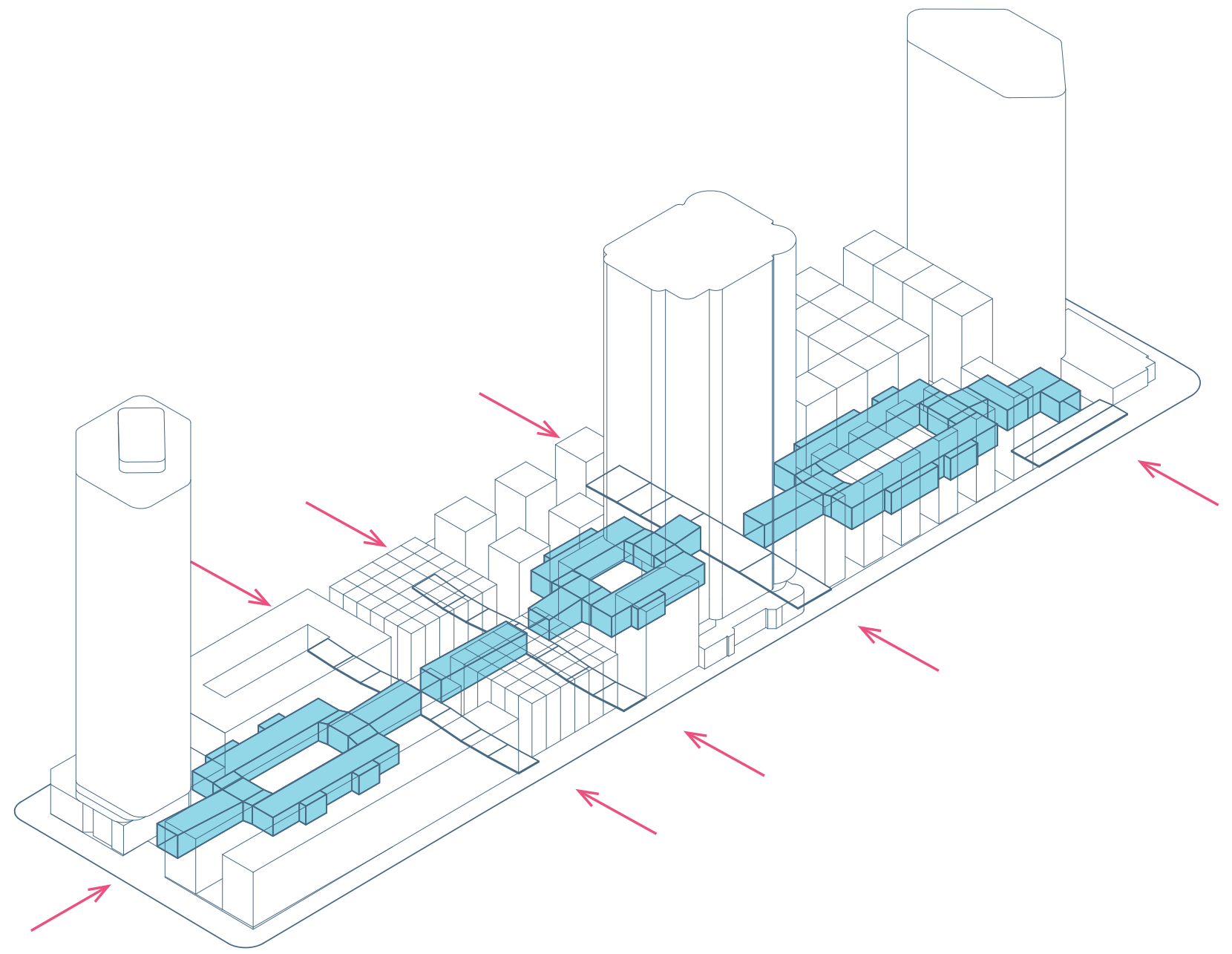




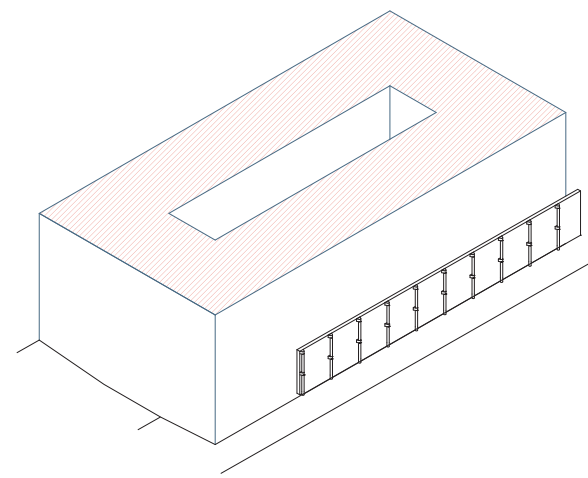

\section{BLOCK 1: CO-HOUSING}

Area: $75.7 \mathrm{~m} \times 39.2 \mathrm{~m}$

Max depth: $14 \mathrm{~m}$

Max height: $25 \mathrm{~m}$

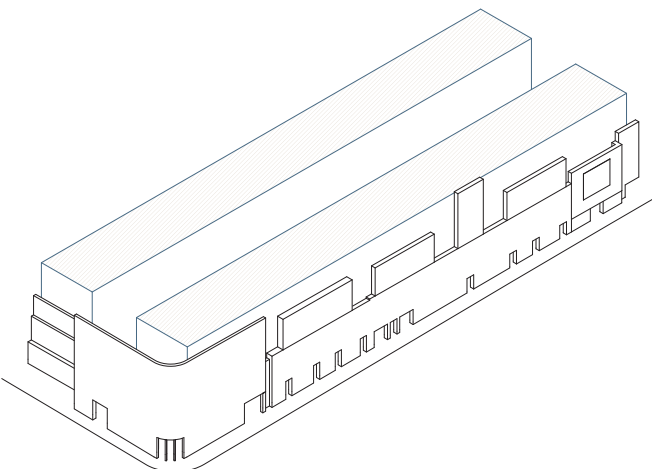

\section{BLOCK 2: LIVE/WORK}

Area: $125 \mathrm{~m} \times 43 \mathrm{~m}$

Max depth: $14 \mathrm{~m}$

Max height: $21.7 \mathrm{~m}$

\section{BLOCK 3: MICRO APARTMENTS}

Area: $39 \mathrm{~m} \times 37.2 \mathrm{~m}$

Max depth: $6.5 \mathrm{~m}$

Max height: $25 \mathrm{~m}$

\section{BLOCK 4: MICRO APARTMENTS}

Area: $39 \mathrm{~m} \times 42.2 \mathrm{~m}$

Max depth: $6.5 \mathrm{~m}$

Max height: $21.7 \mathrm{~m}$ 


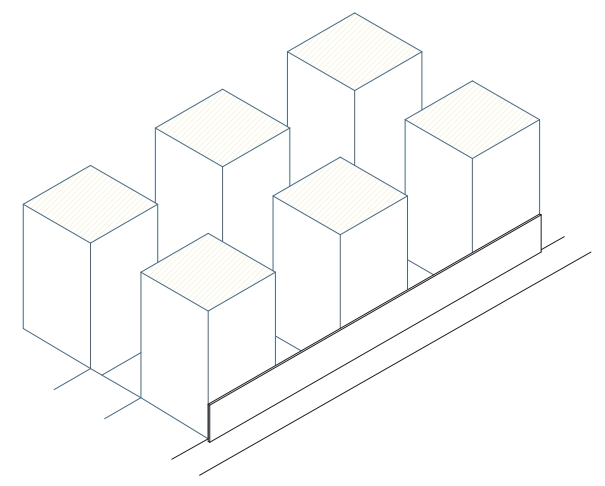

BLOCK 5: COURTYARD APARTMENTS

Area: $69 \mathrm{~m} \times 39.4 \mathrm{~m}$

Max depth: $14 \mathrm{~m}$

Max height: $25 \mathrm{~m}$

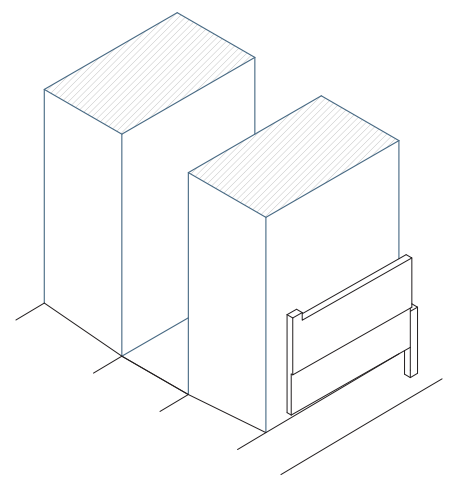

\section{BLOCK 6: LIVE/WORK}

Area: $24 \mathrm{~m} \times 42.5 \mathrm{~m}$

Max depth: $14 \mathrm{~m}$

Max height: $32.7 \mathrm{~m}$

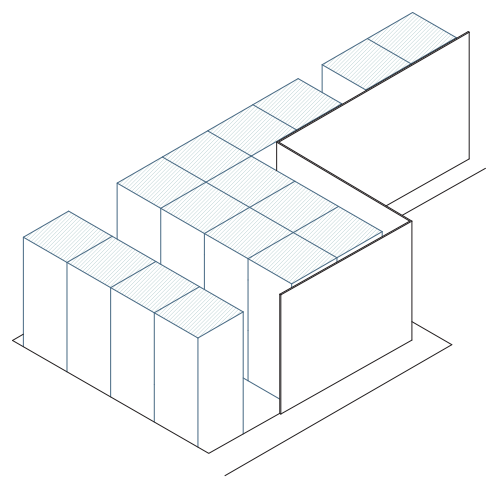

BLOCK 7: TOWNHOUSES

Area: $120.46 \mathrm{~m} \times 60.26 \mathrm{~m}$

Max depth: $14 \mathrm{~m}$

Max height: $32.7 \mathrm{~m}$

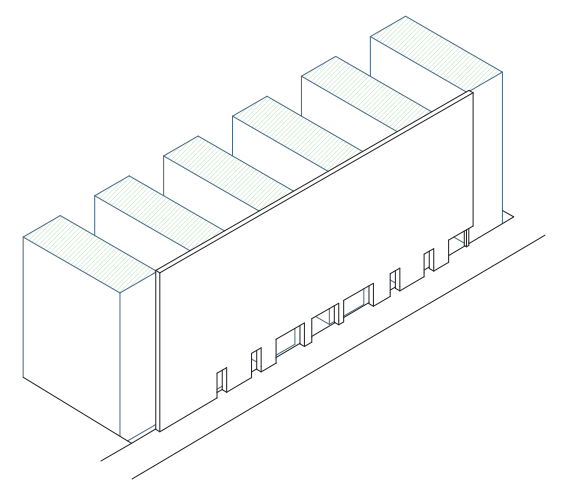

BLOCK 8: WEWORK

Area: $76.9 \mathrm{~m} \times 25.1 \mathrm{~m}$

Max depth: $8.5 \mathrm{~m}$

Max height: $32.7 \mathrm{~m}$ 
BLOCK 3/4- MICRO APARTMENT OPTIONS

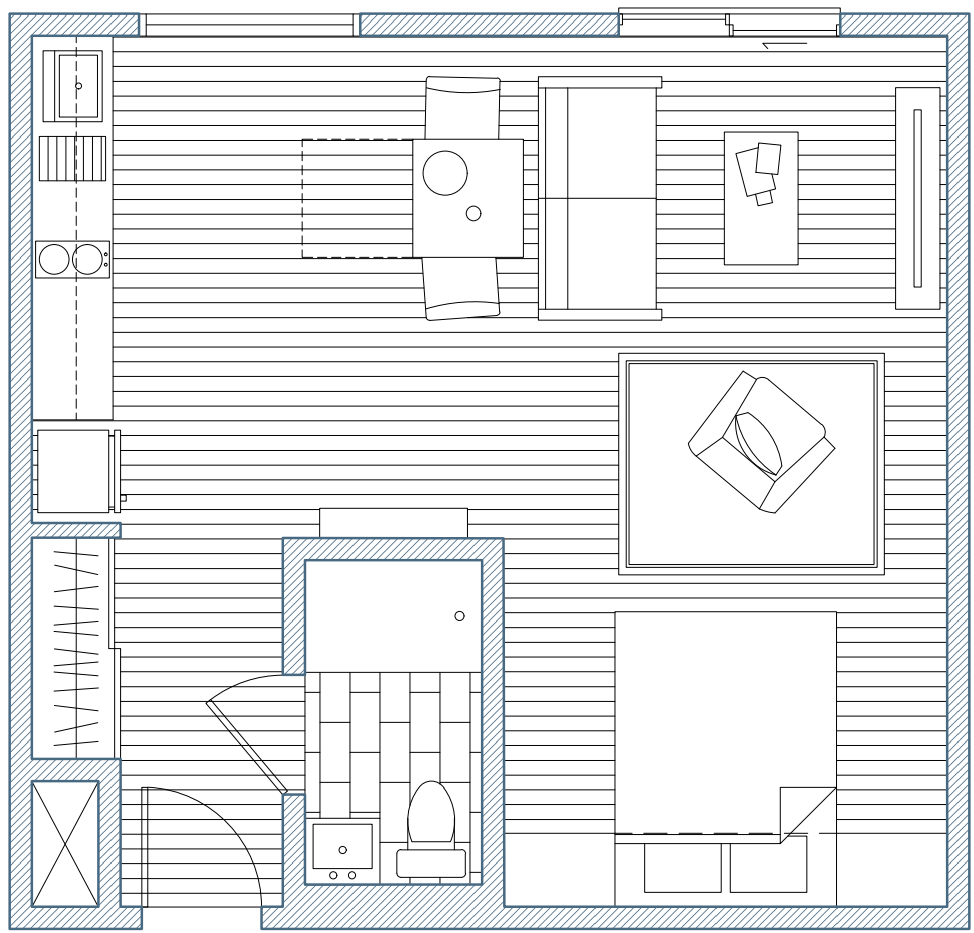

UNIT TYPE 1

Area: $40.30 \mathrm{~m}^{2}$ 


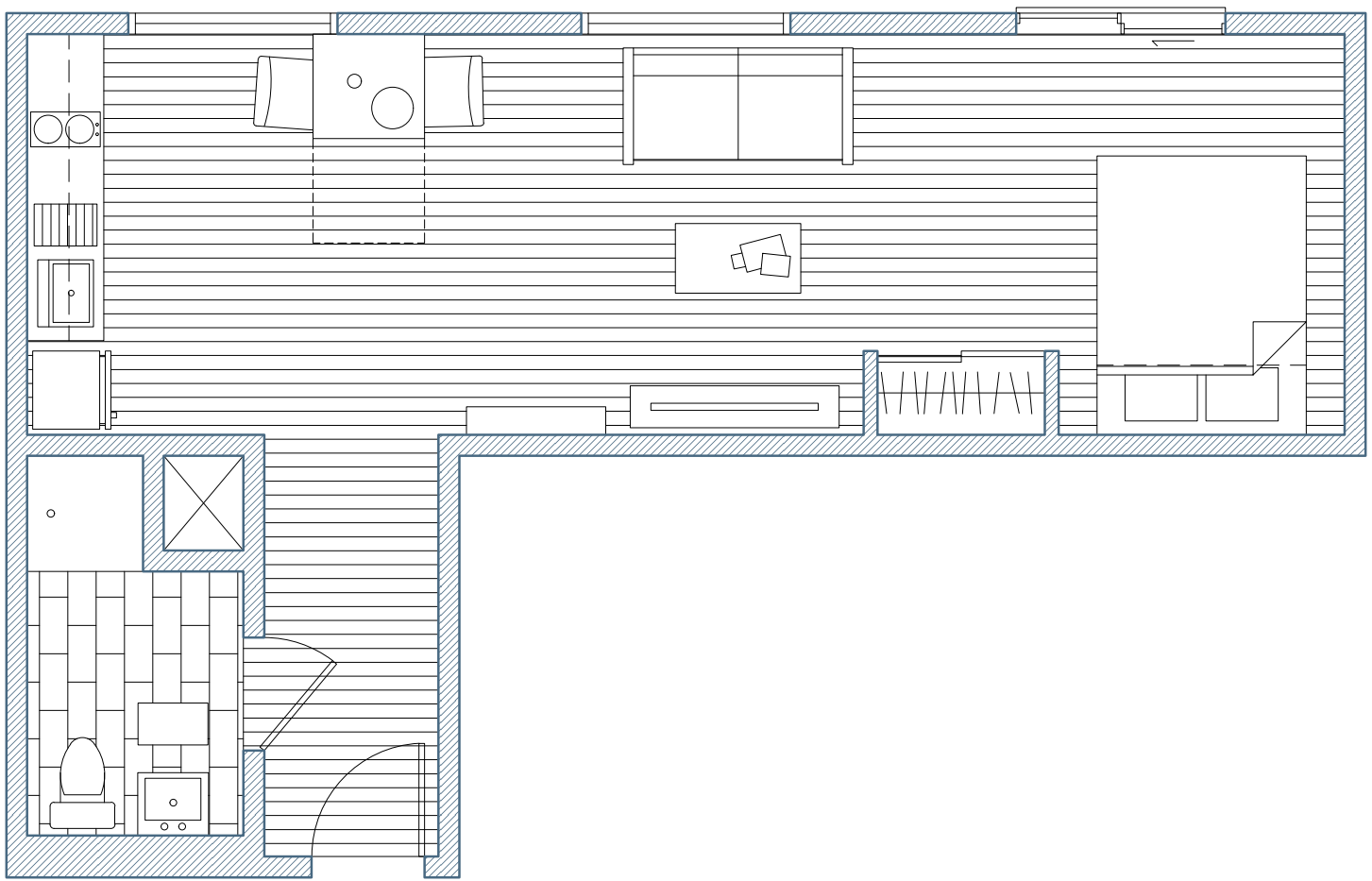

UNIT TYPE 2

Area: $40.8 \mathrm{~m}^{2}$ 


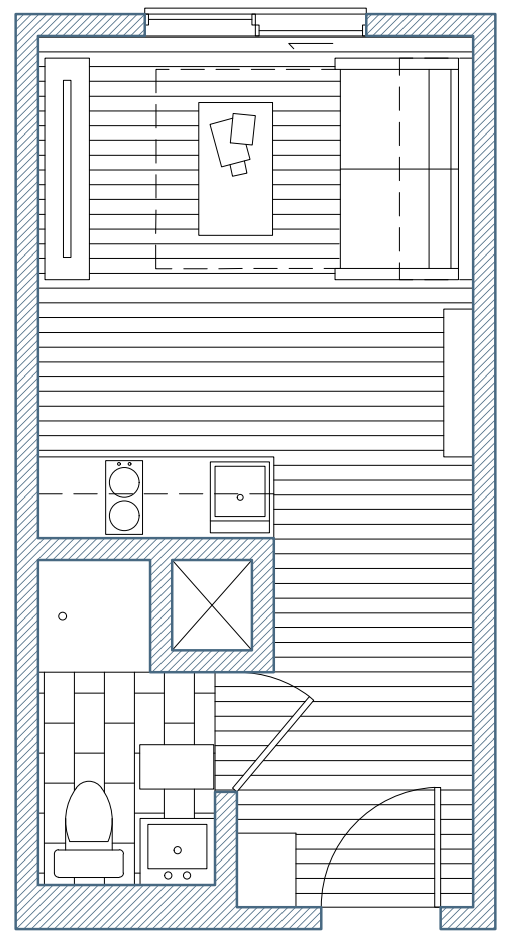

UNIT TYPE 3

Area: $20.2 \mathrm{~m}^{2}$ 


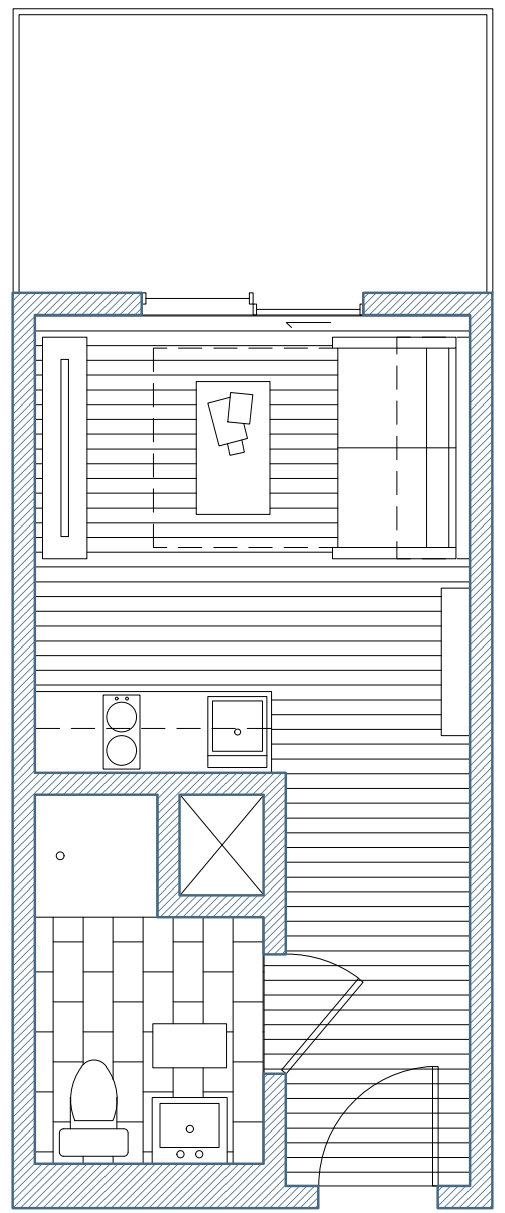

UNIT TYPE 4

Area: $26.4 \mathrm{~m}^{2}$ 


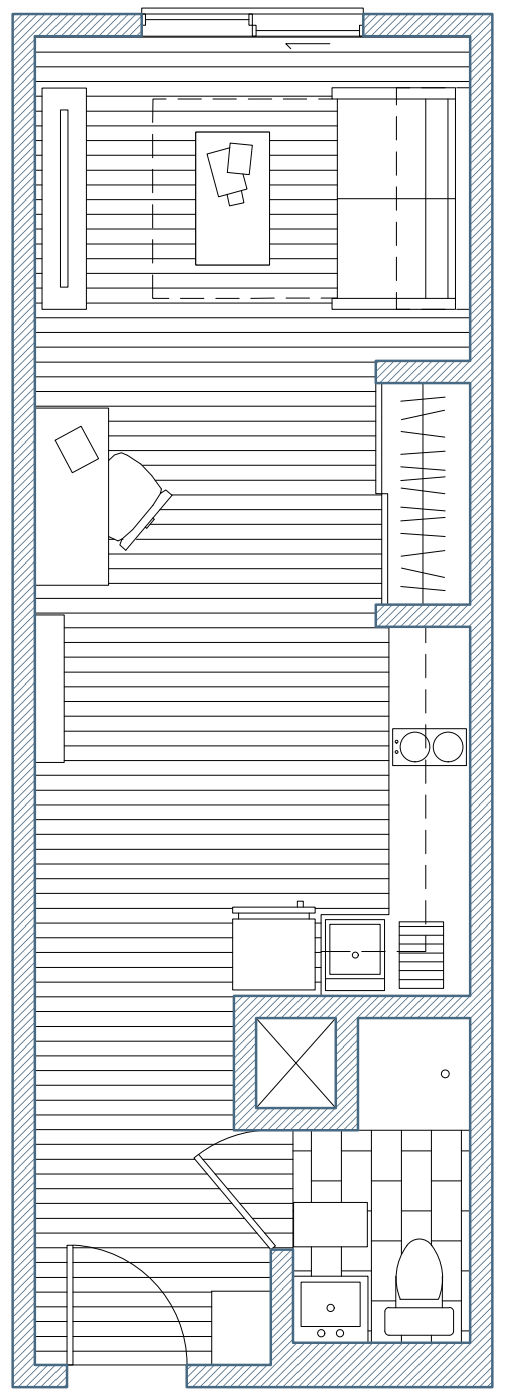

UNIT TYPE 5

Area: $30.2 \mathrm{~m}^{2}$ 

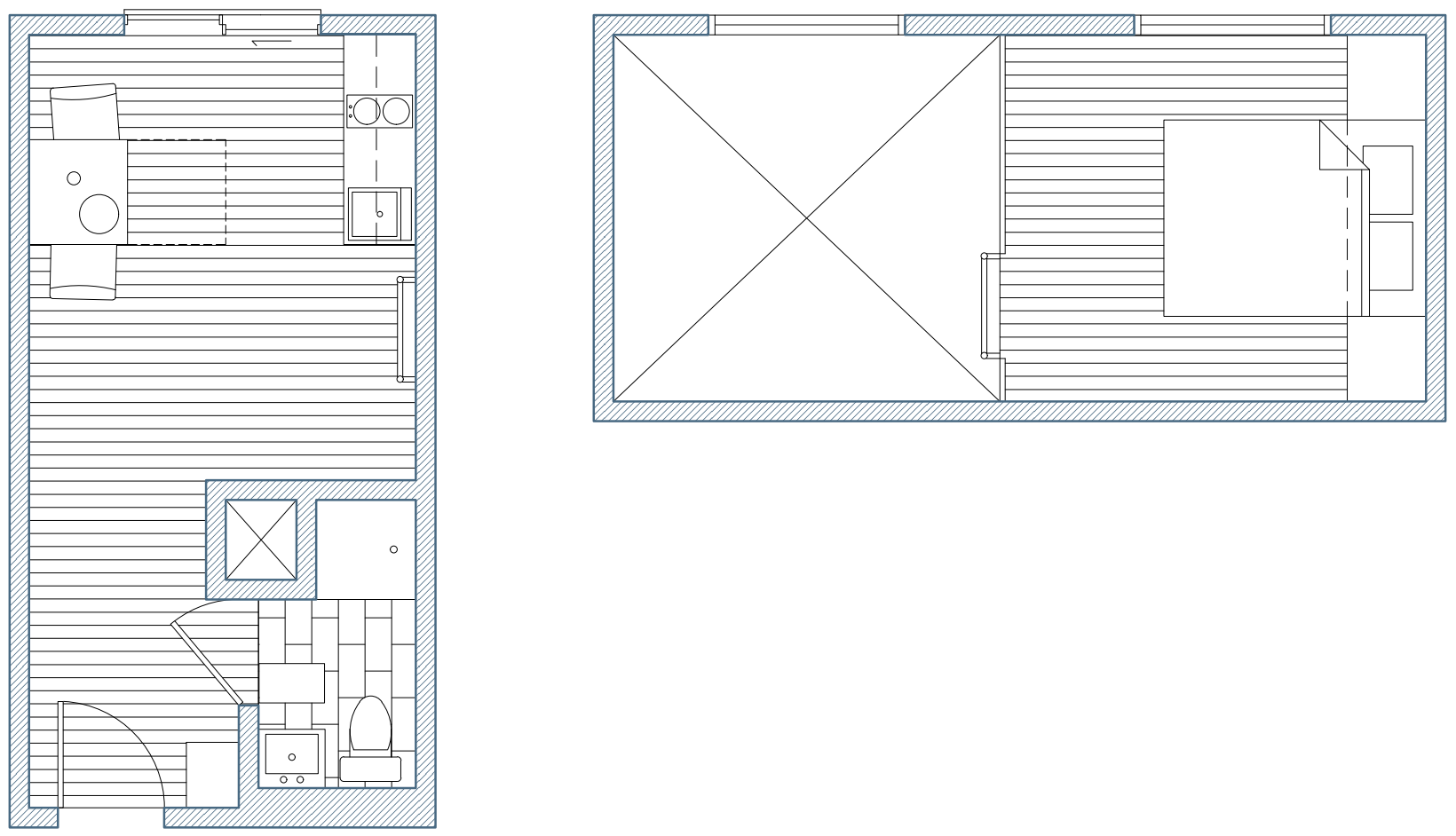

\section{UNIT TYPE 6}

LEVEL 1

Area: $30.2 \mathrm{~m}^{2}$

LEVEL 2 

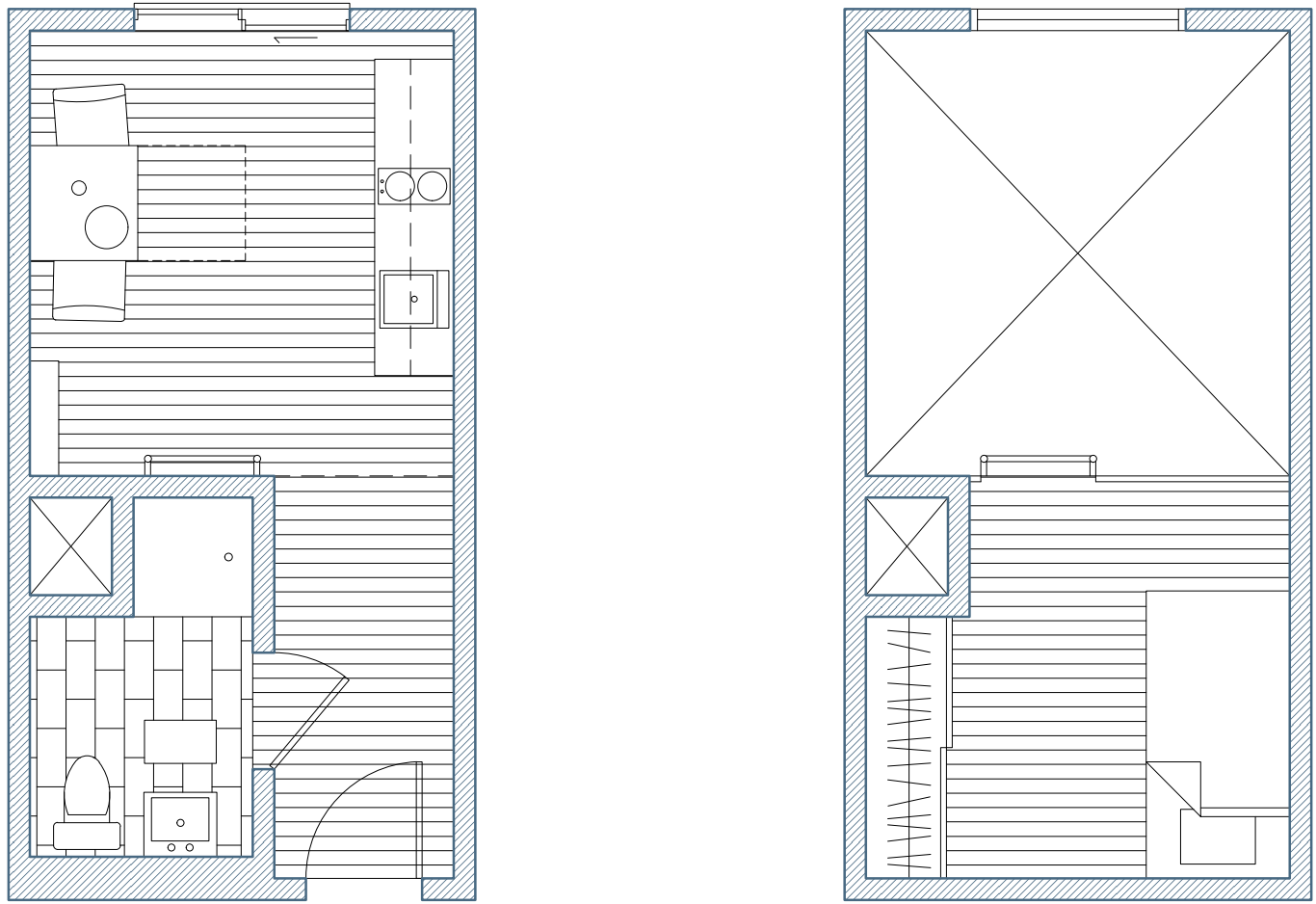

UNIT TYPE 7

LEVEL1

Area: $30.2 \mathrm{~m}^{2}$

LEVEL 2 


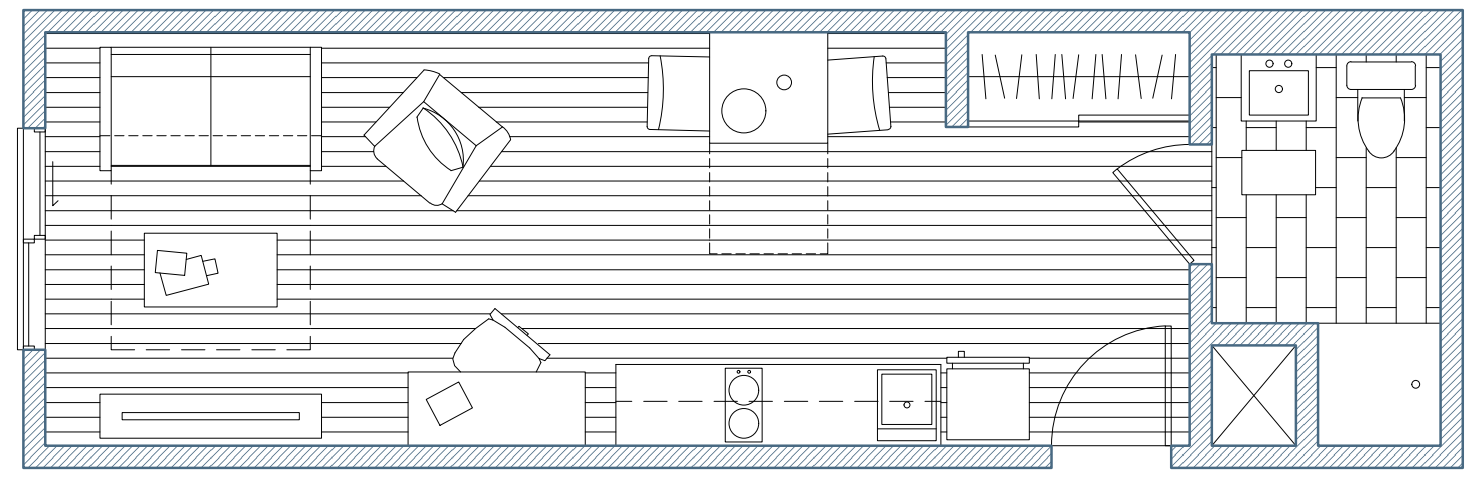

\section{UNIT TYPE 8}

Area: $30.2 \mathrm{~m}^{2}$ 


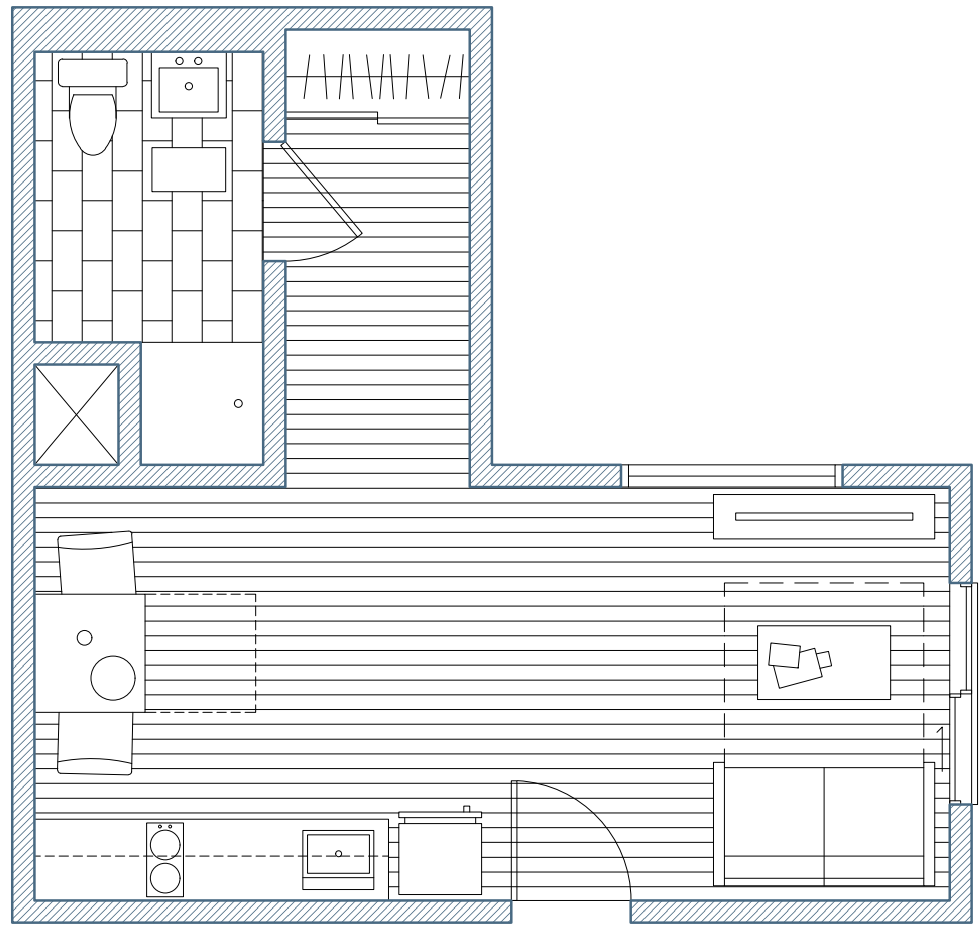

UNIT TYPE $\mathbf{9}$

Area: $30.2 \mathrm{~m}^{2}$ 

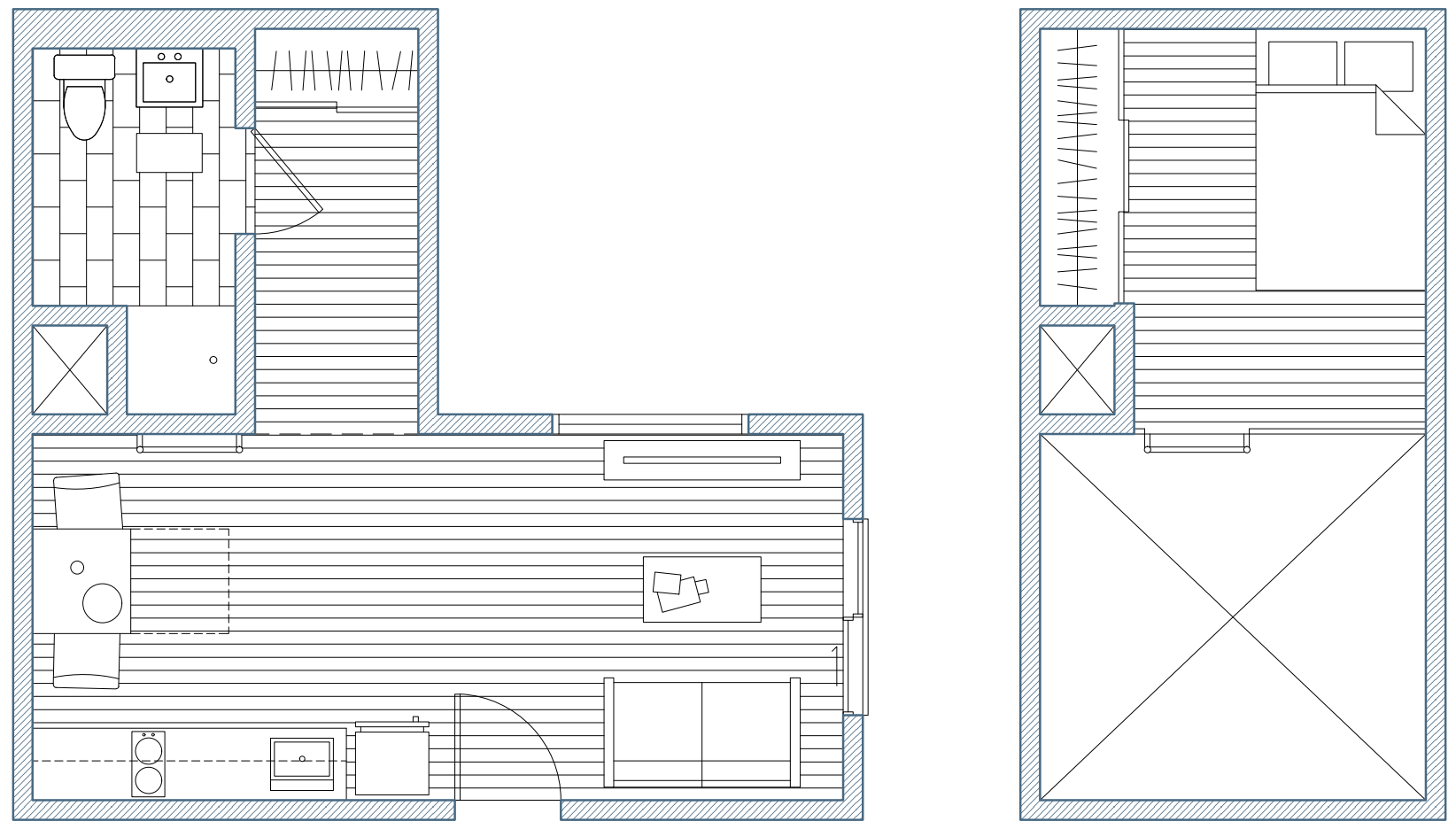

UNIT TYPE 10

LEVEL 1

LEVEL 2

Area: $40.3 \mathrm{~m}^{2}$ 
BLOCK 4-PLANS
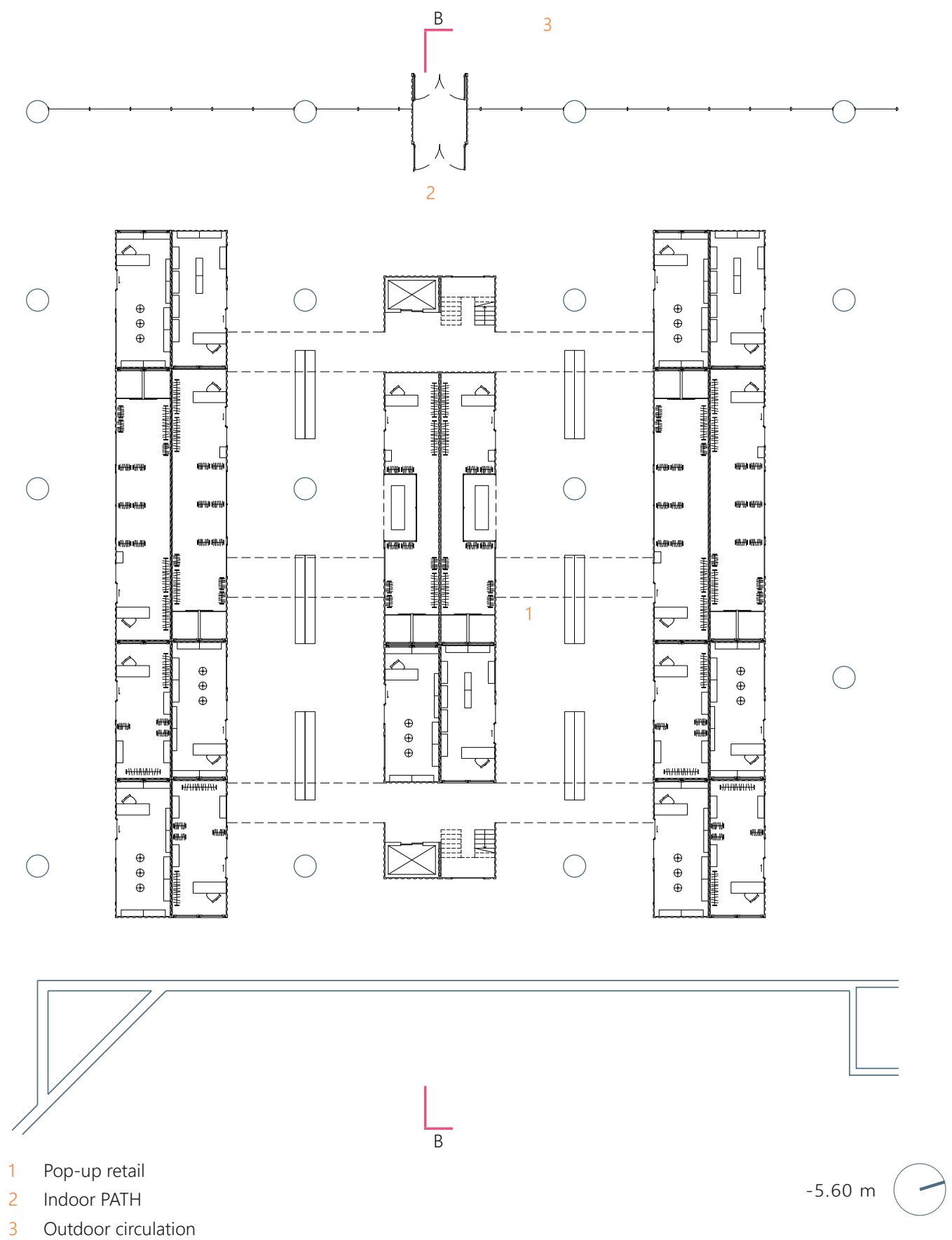
B
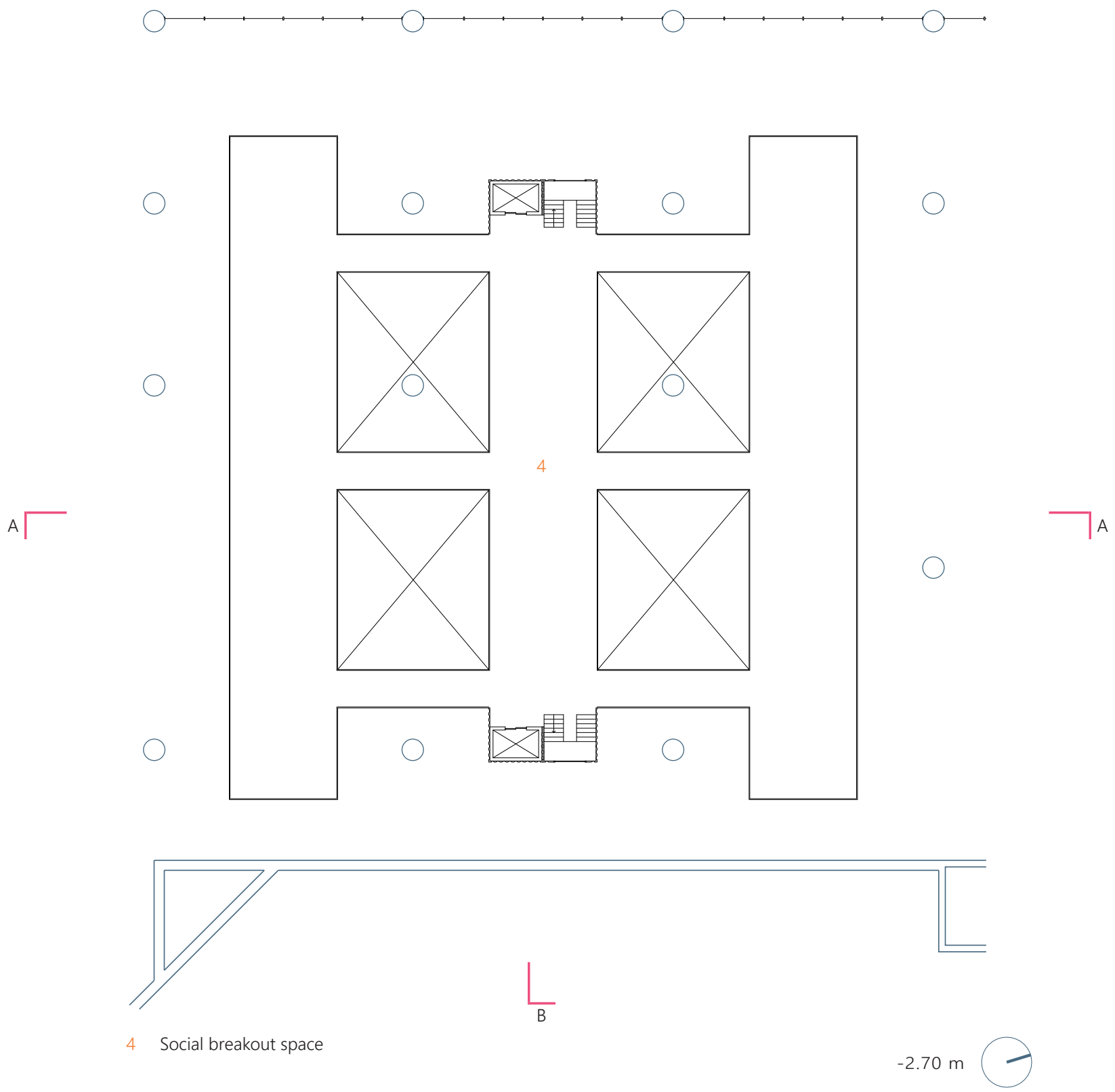

Fig.6.64 Block 4: Proposed level 1-1 


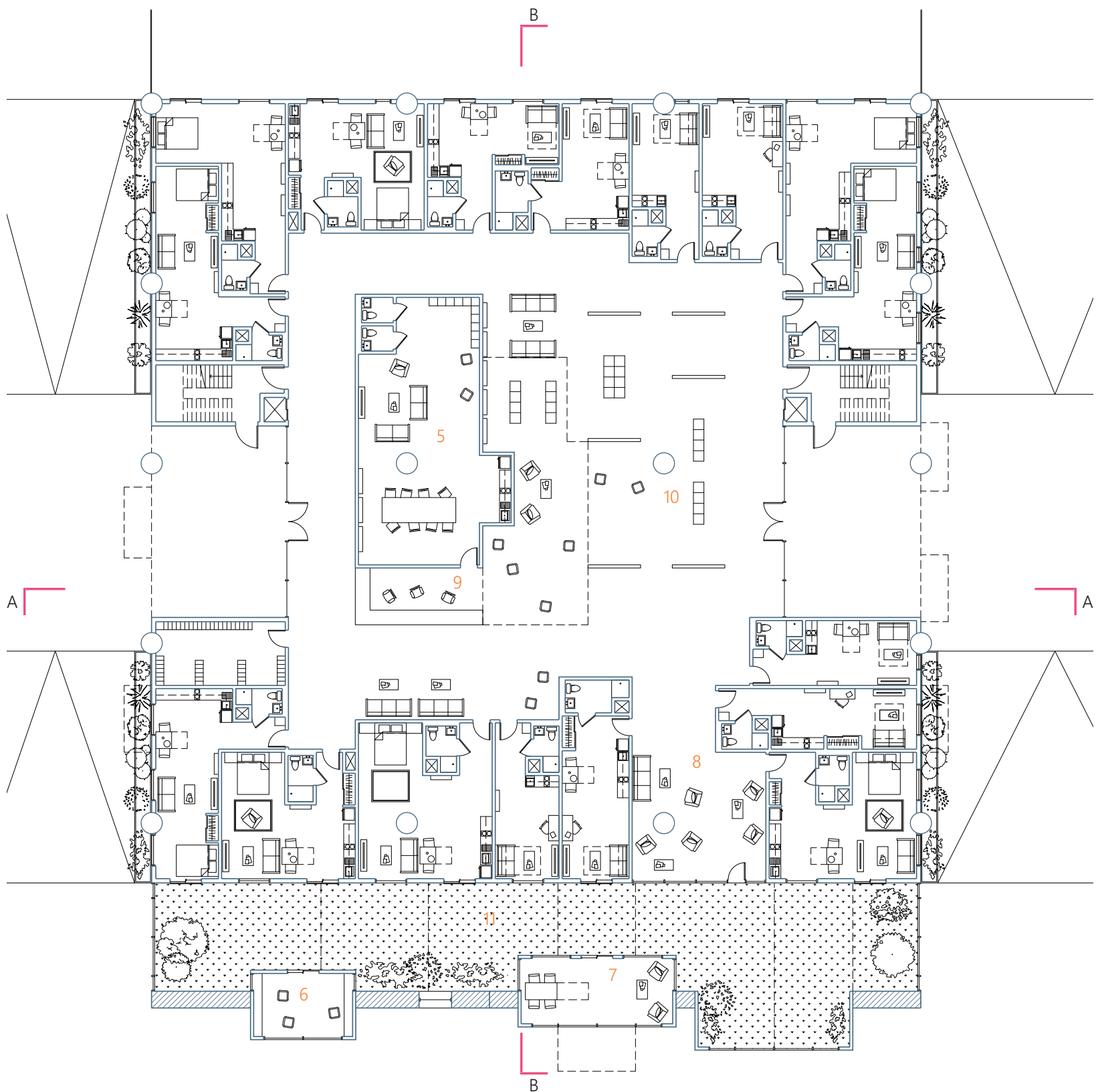

Administration

Play space

Work space

Hangout space
9 Reception

10 Event space

11 Private outdoor space

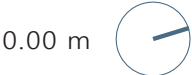




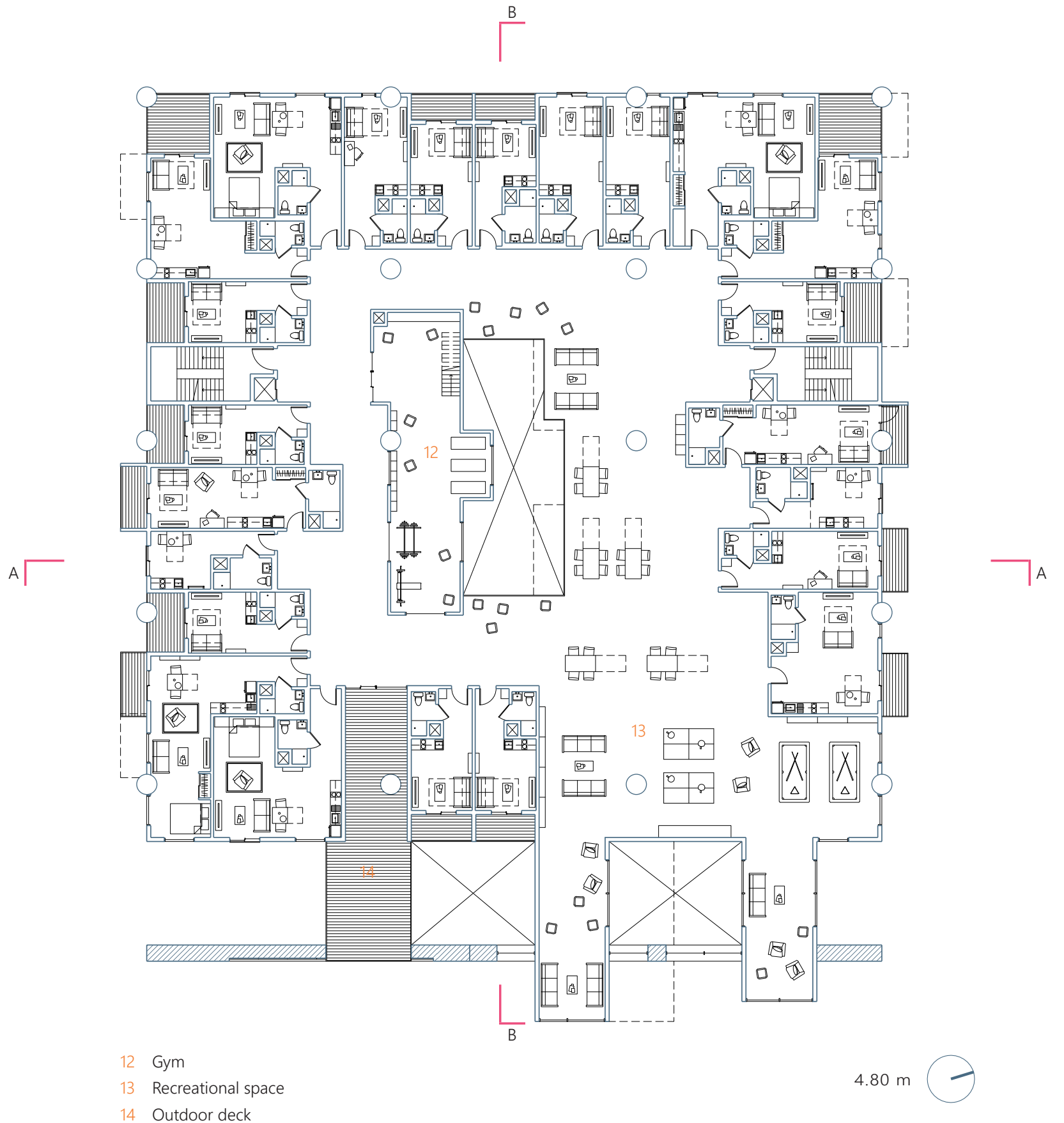

Fig.6.66 Block 4: Proposed level 3 


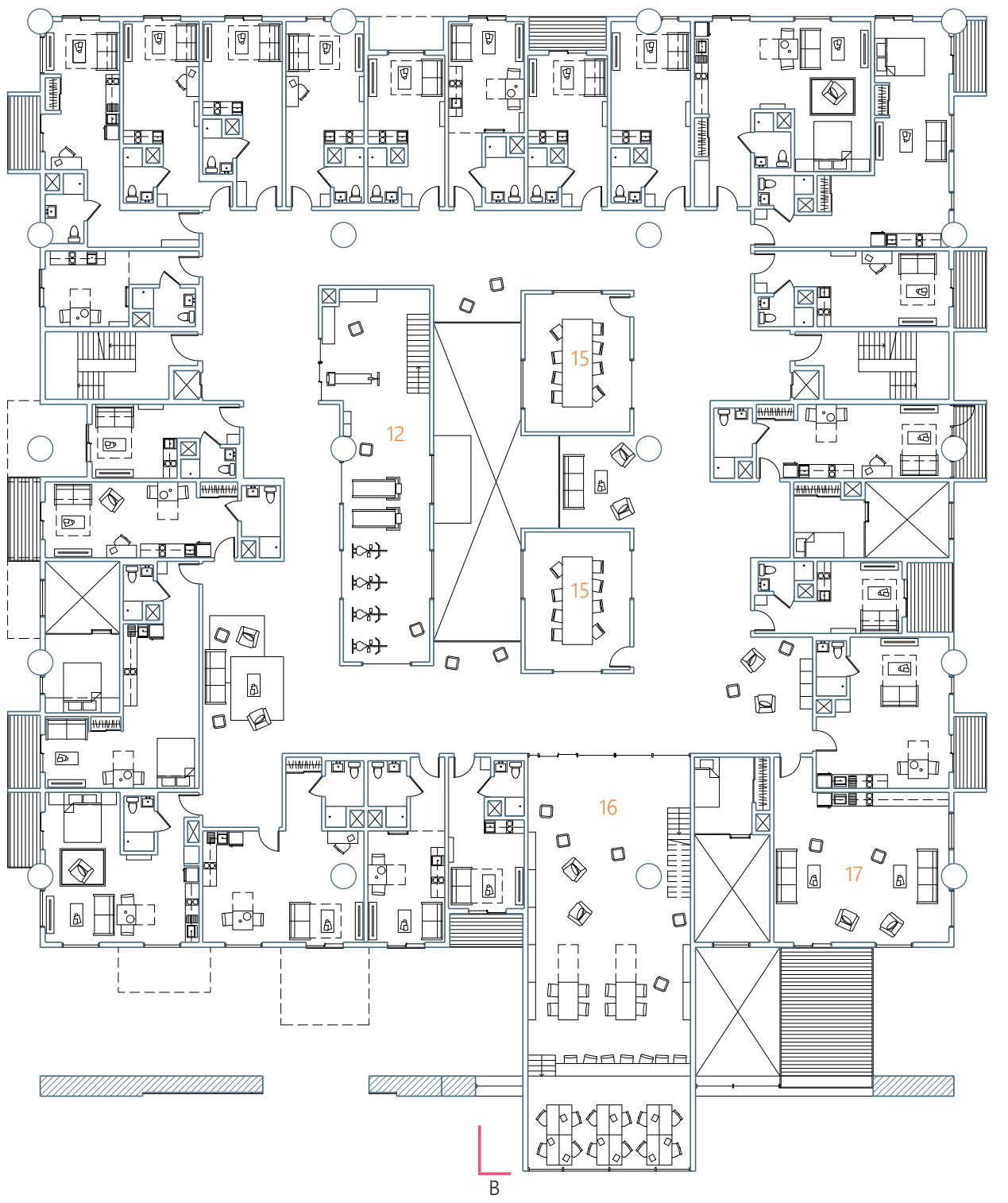

15 Study space

16 Library

$8.00 \mathrm{~m}$

17 Party room 


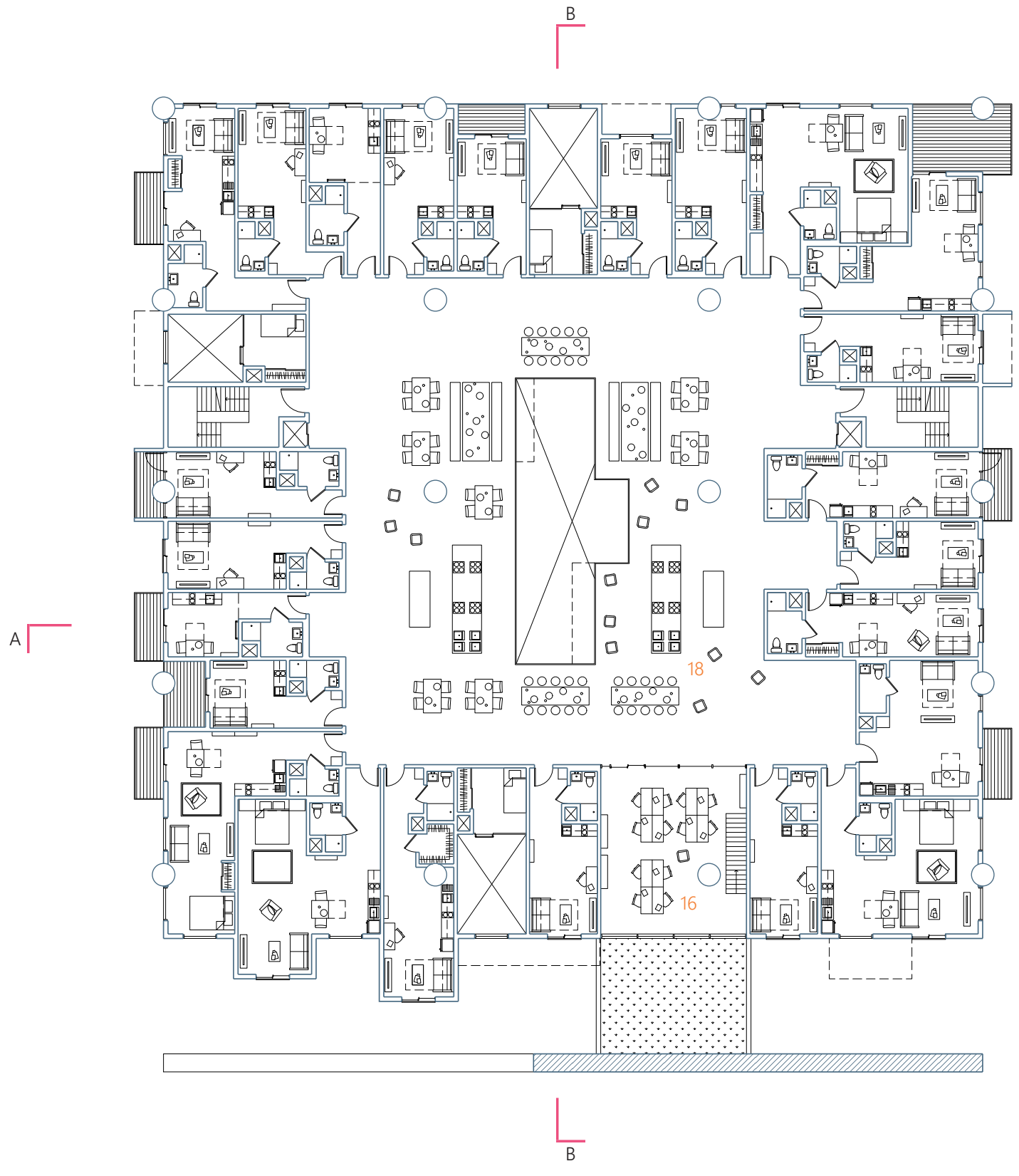

18 Communal kitchen

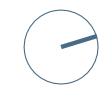



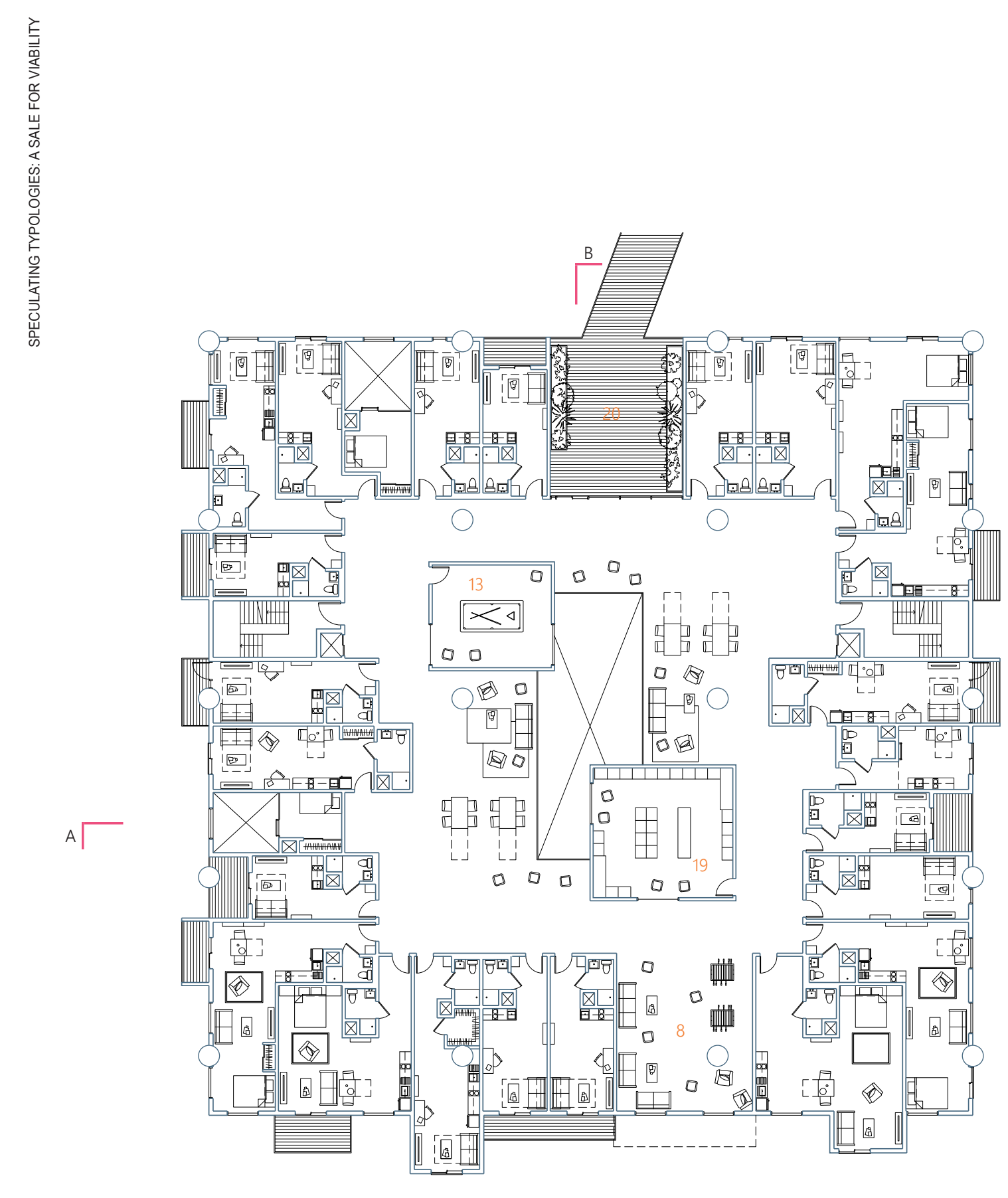


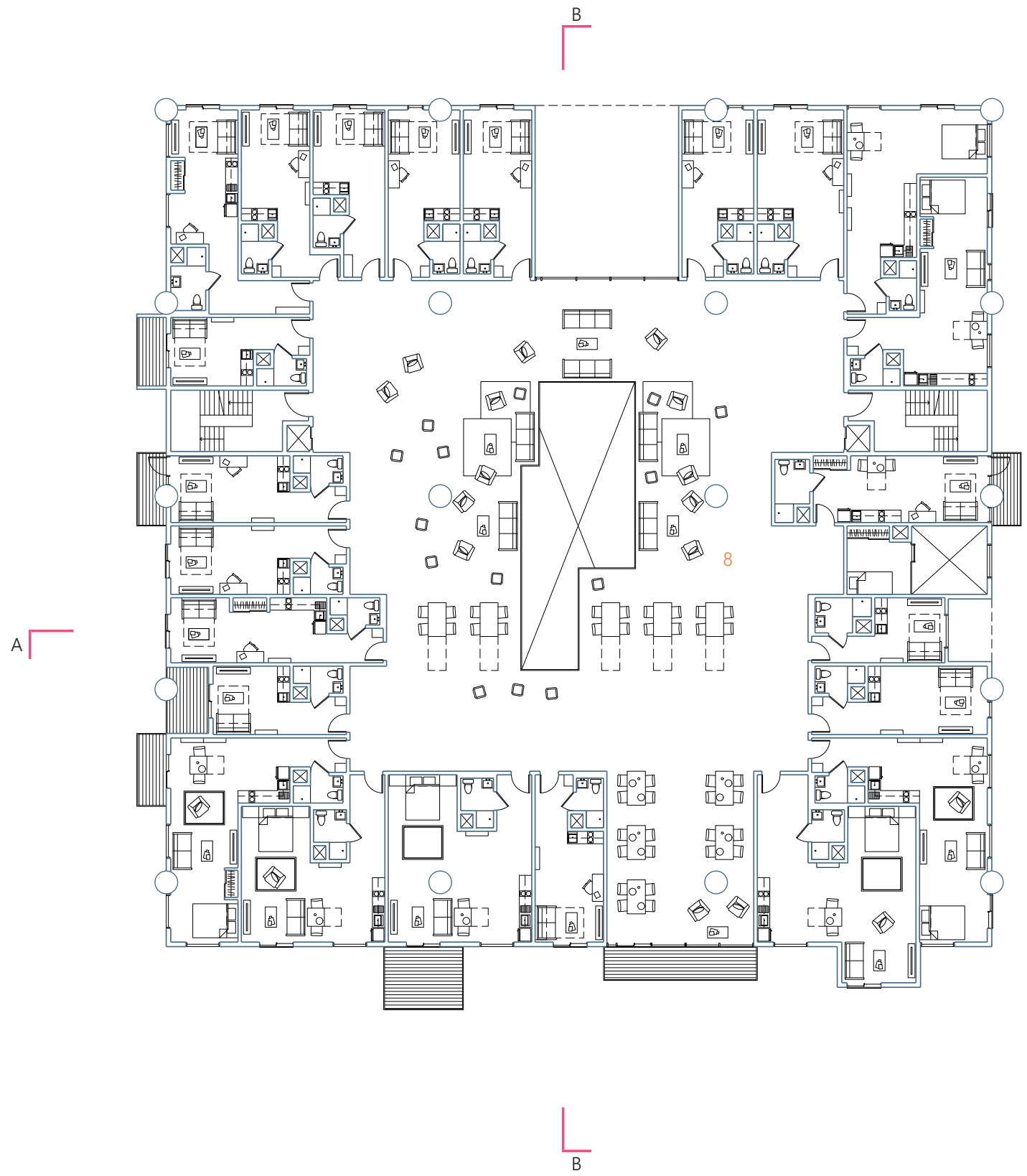

$18.30 \mathrm{~m}$

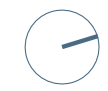



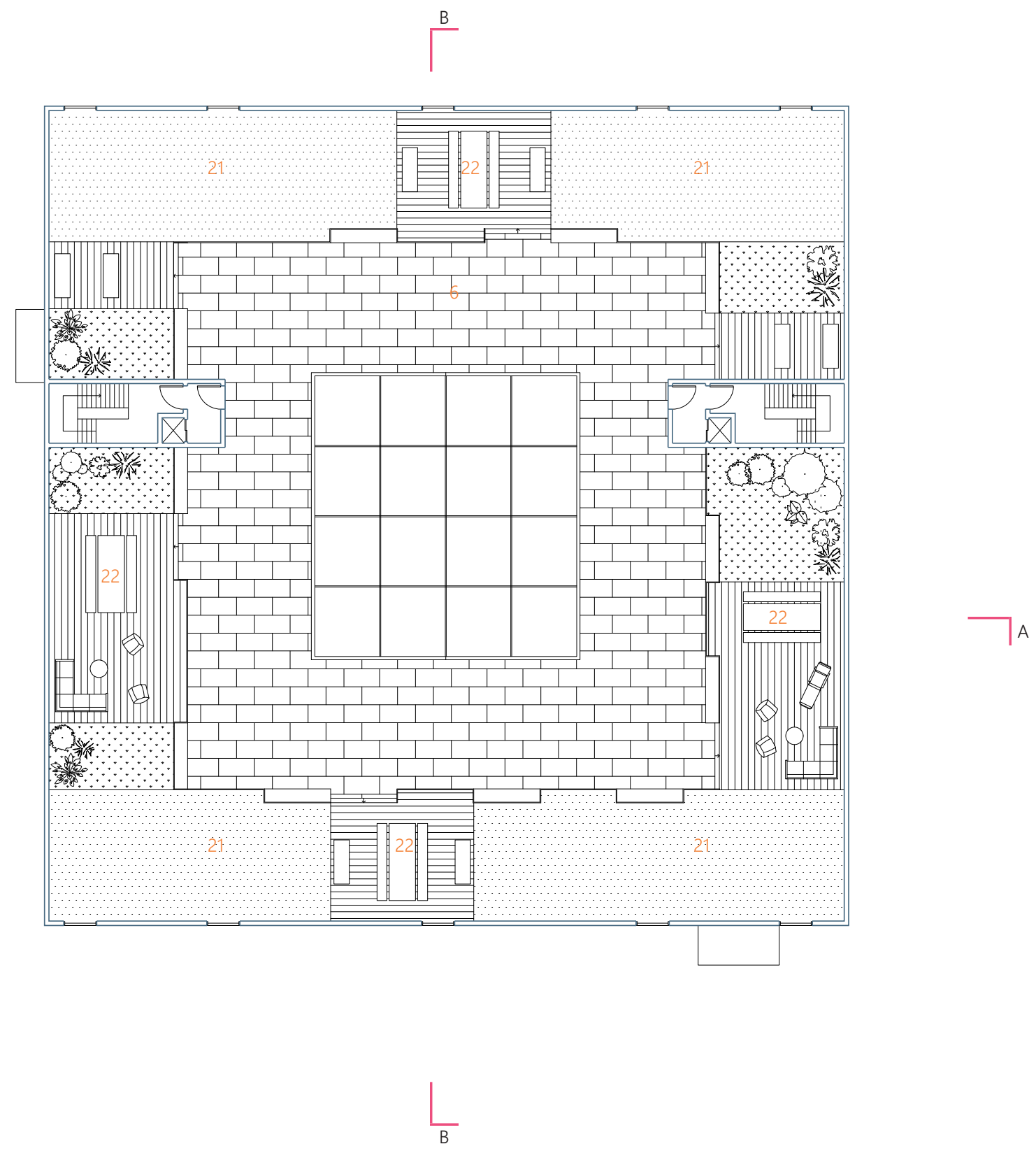

21 Roof garden

22 Social deck

$21.70 \mathrm{~m} \longrightarrow$ 


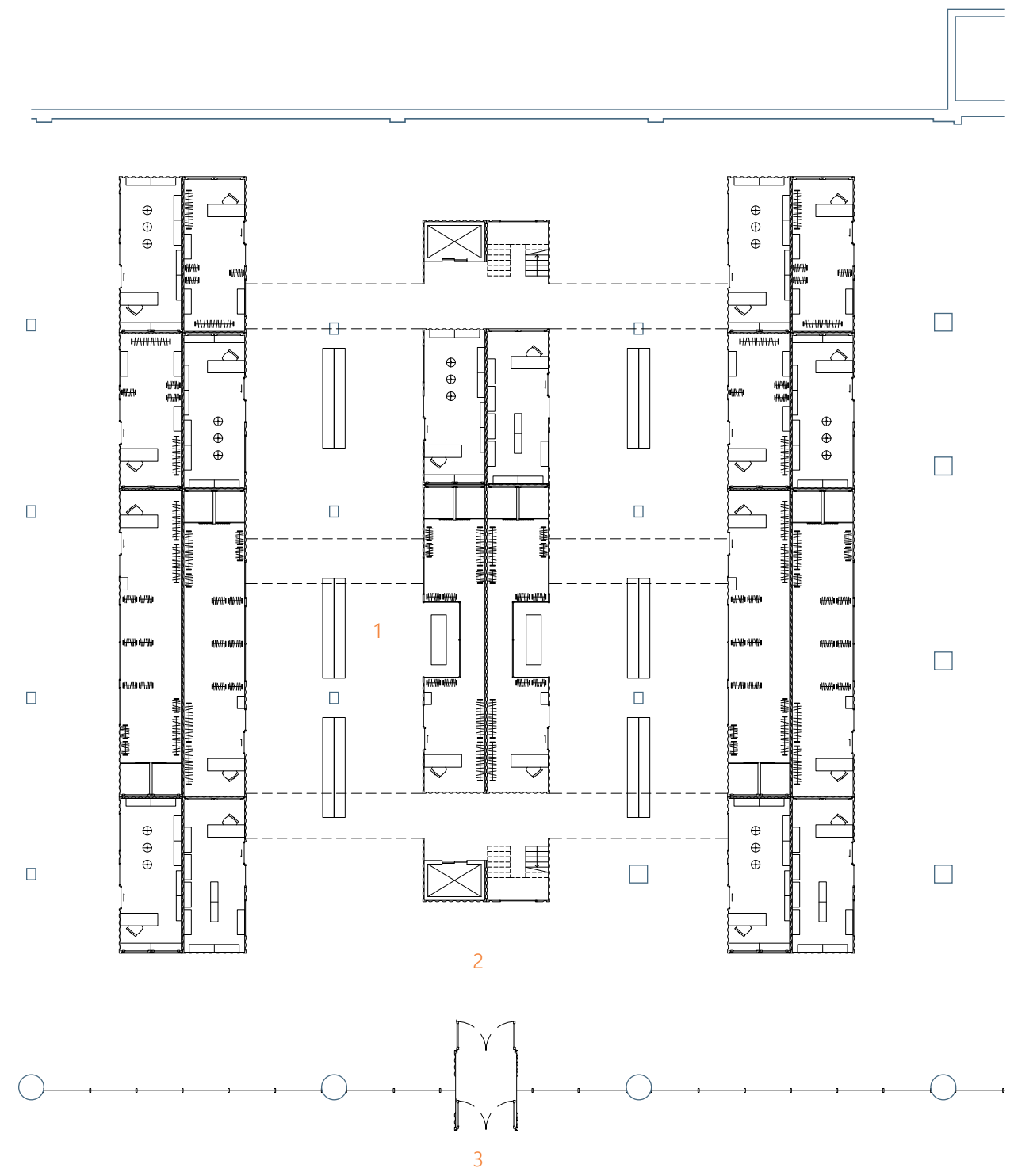

$-5.60 \mathrm{~m} \bigcirc$

Fig.6.72 Block 3: Proposed level 1 

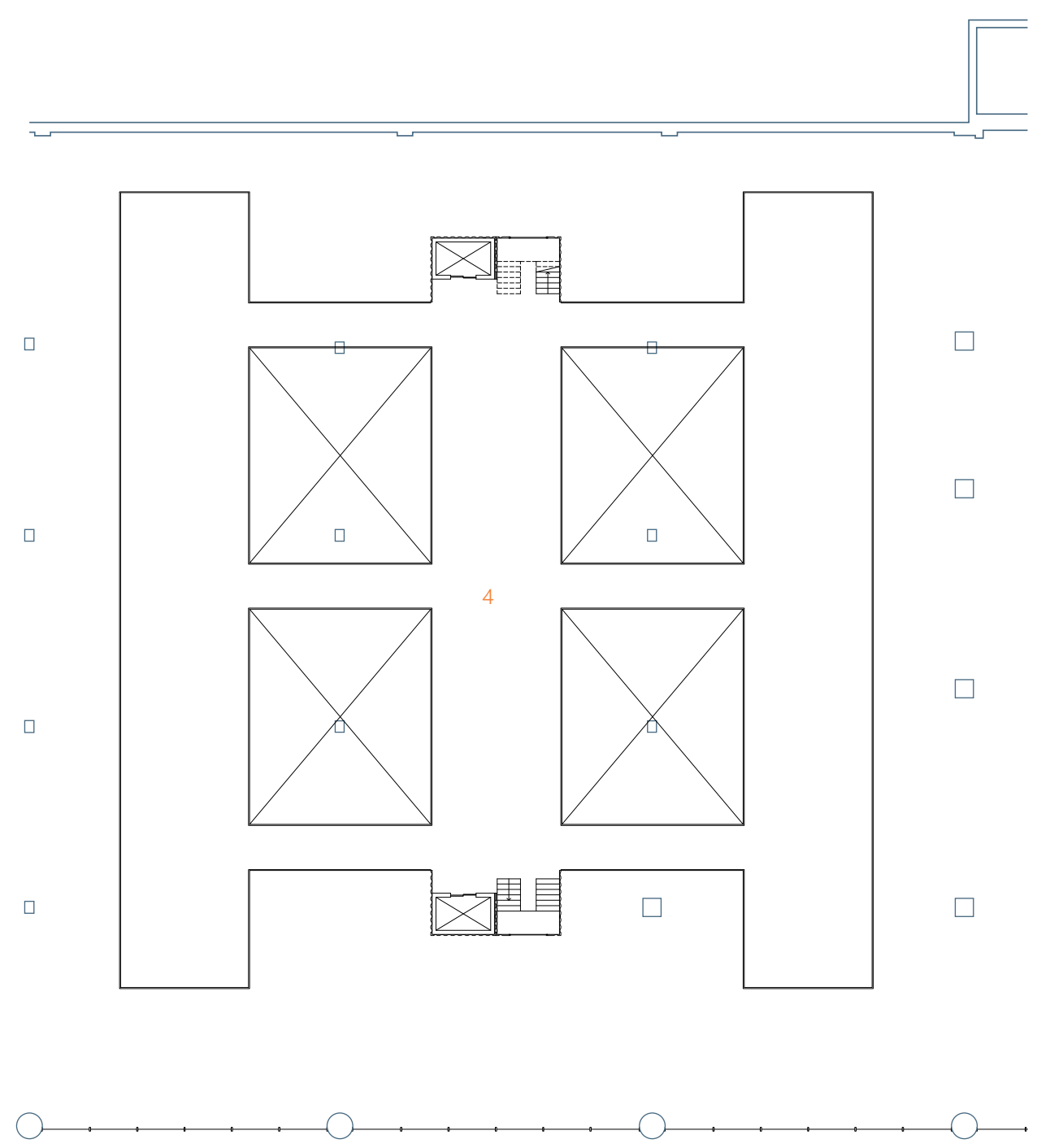

$-2.70 \mathrm{~m} \longrightarrow$ 

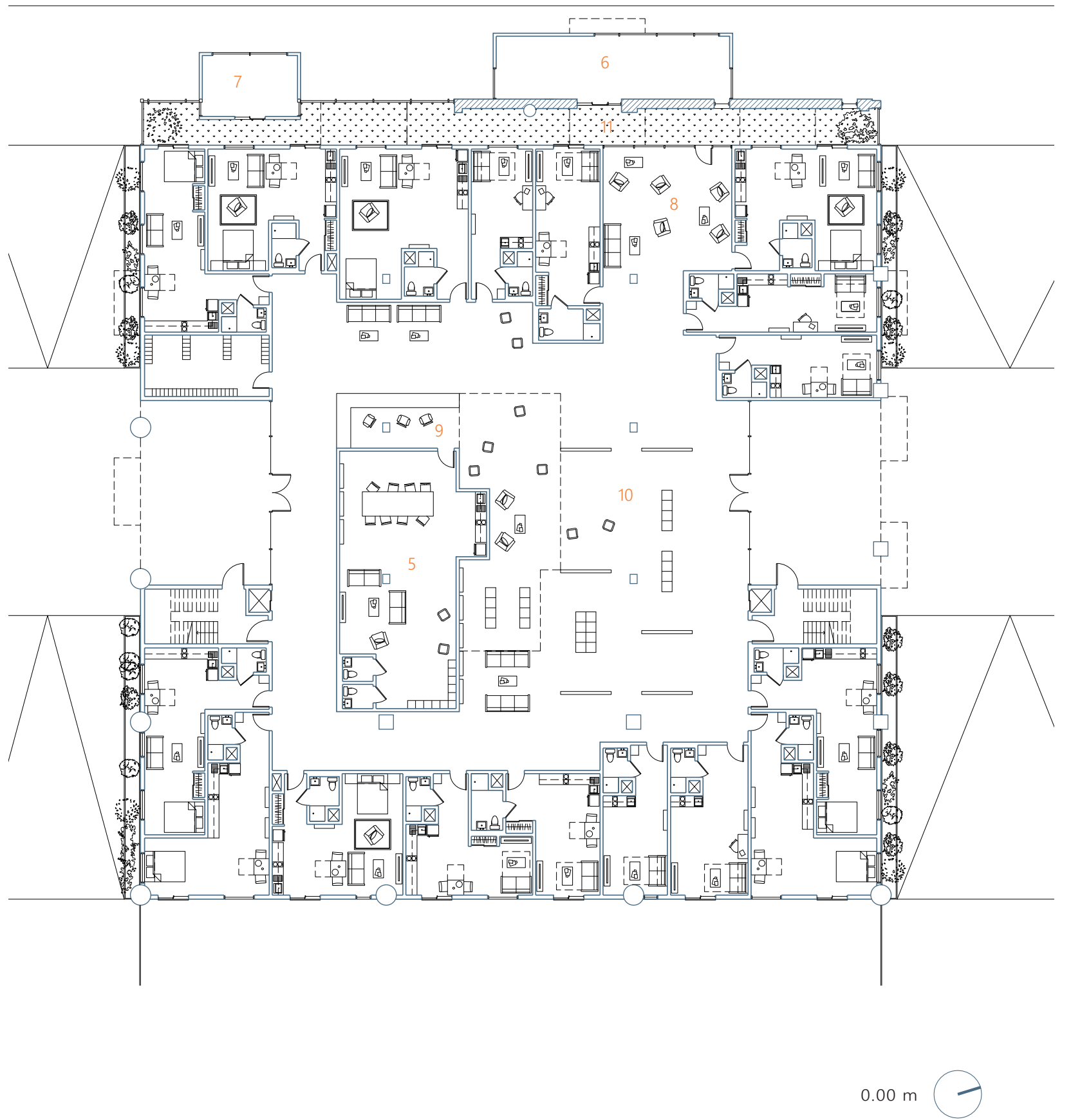


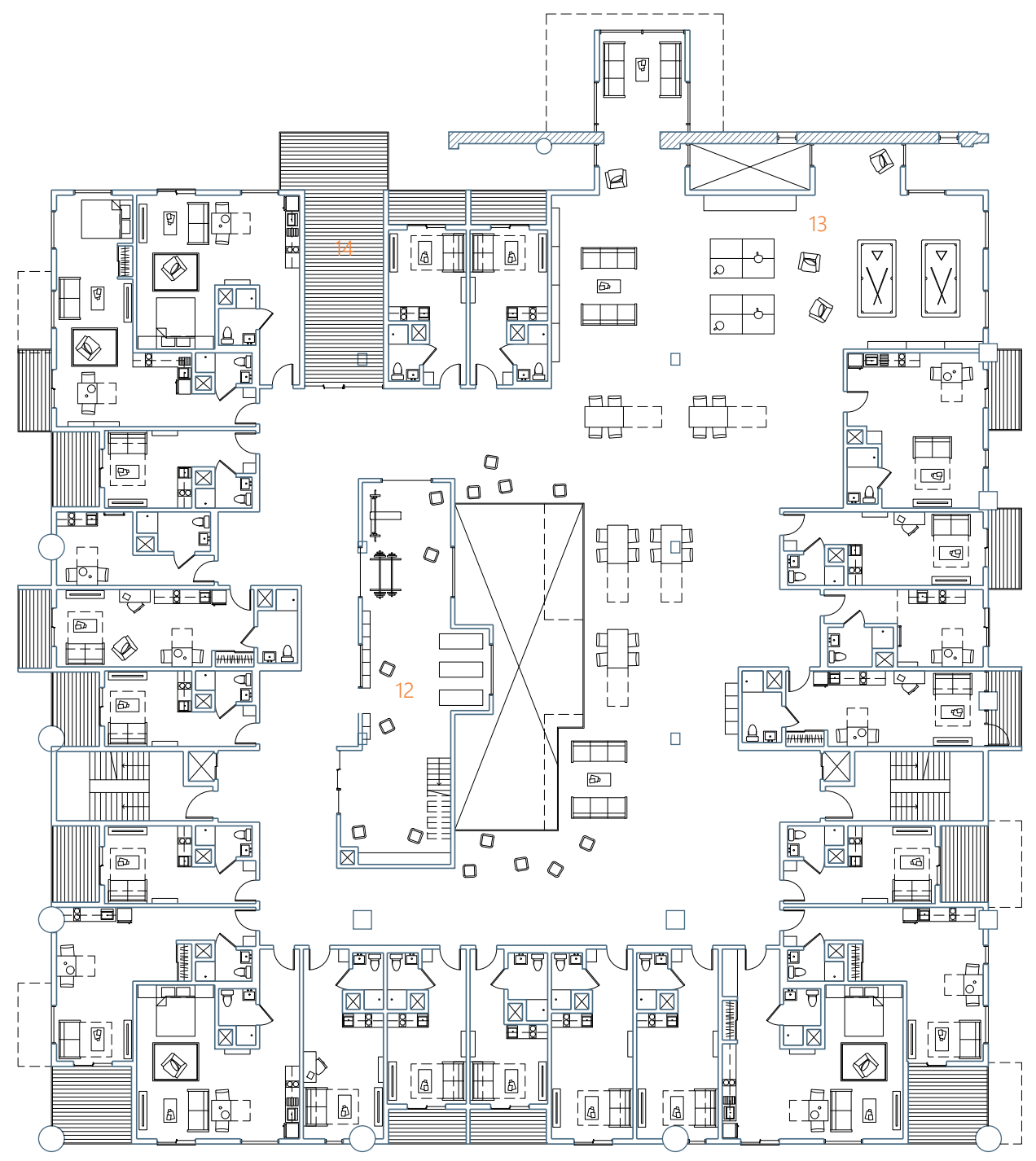

$4.80 \mathrm{~m}$ 


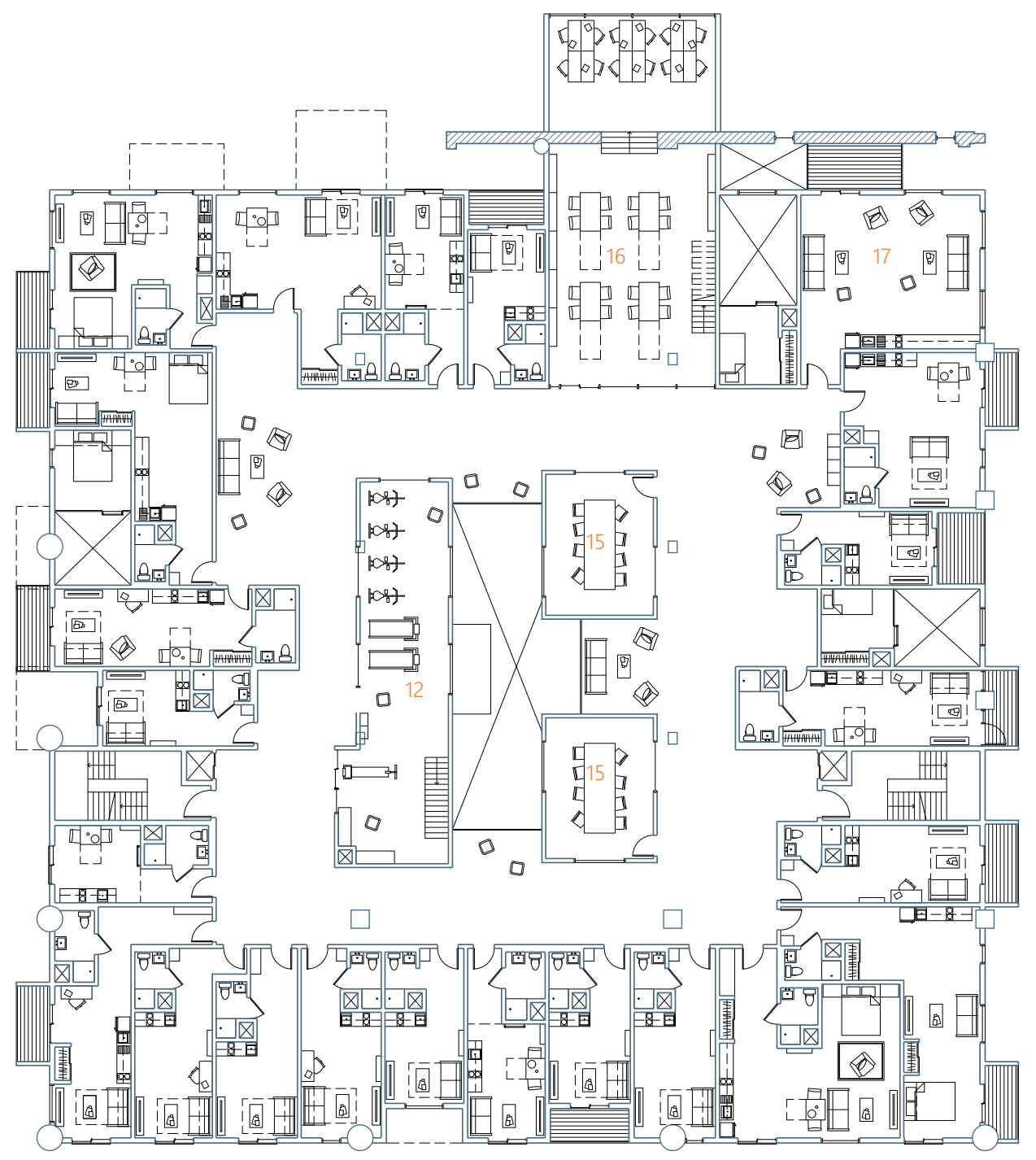

$8.00 \mathrm{~m}$

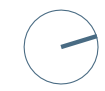




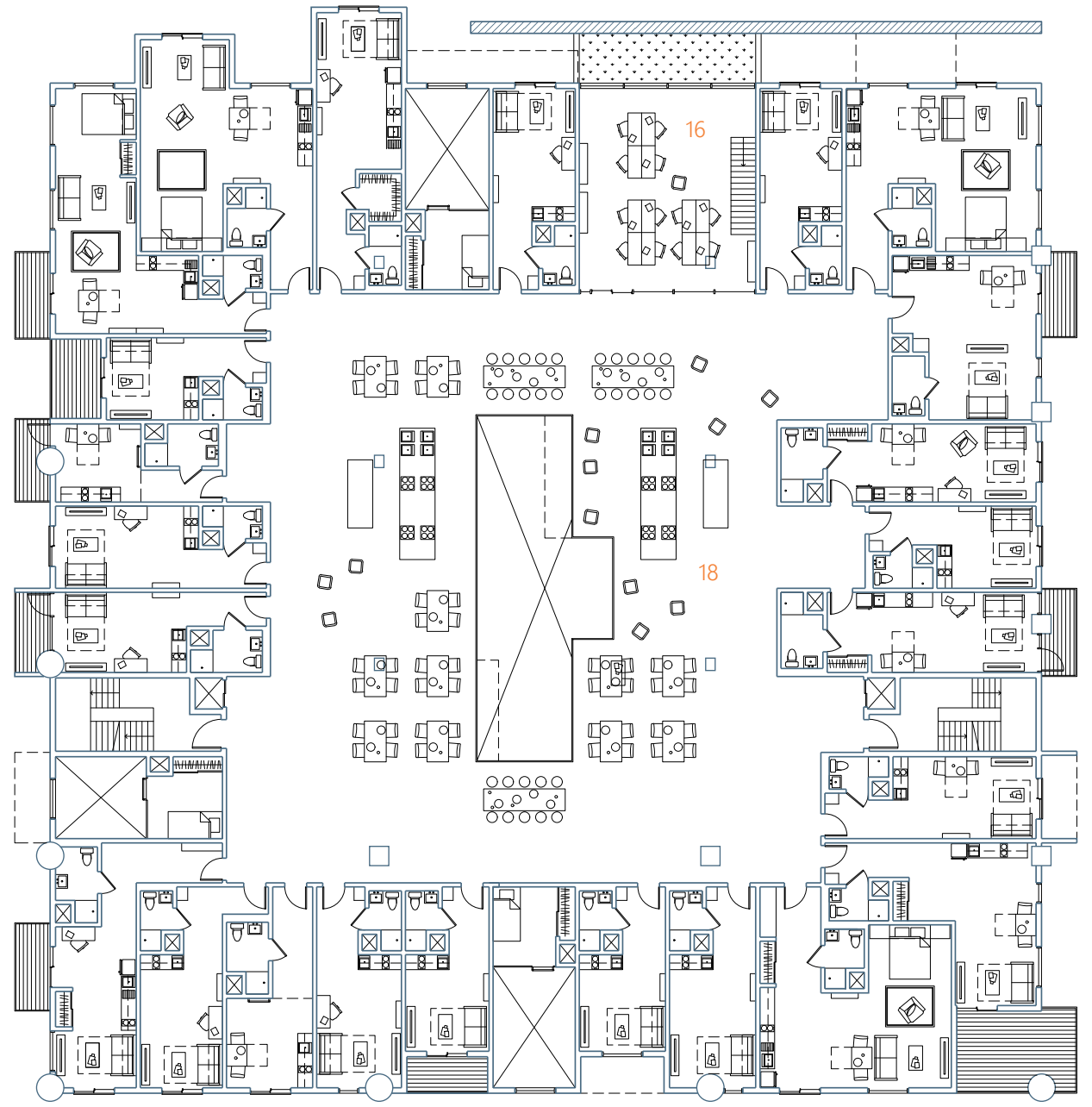




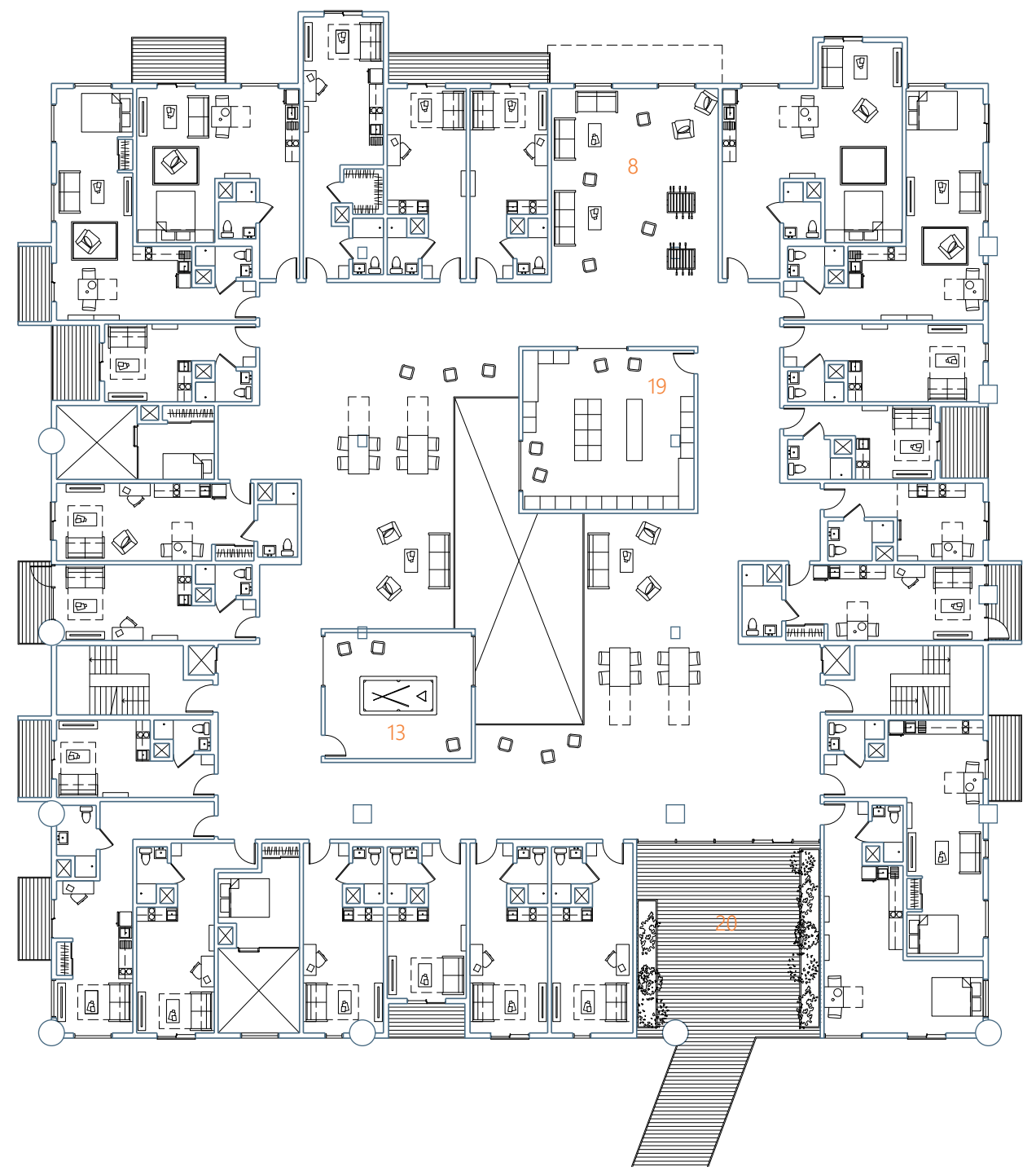

$14.60 \mathrm{~m}$

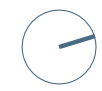




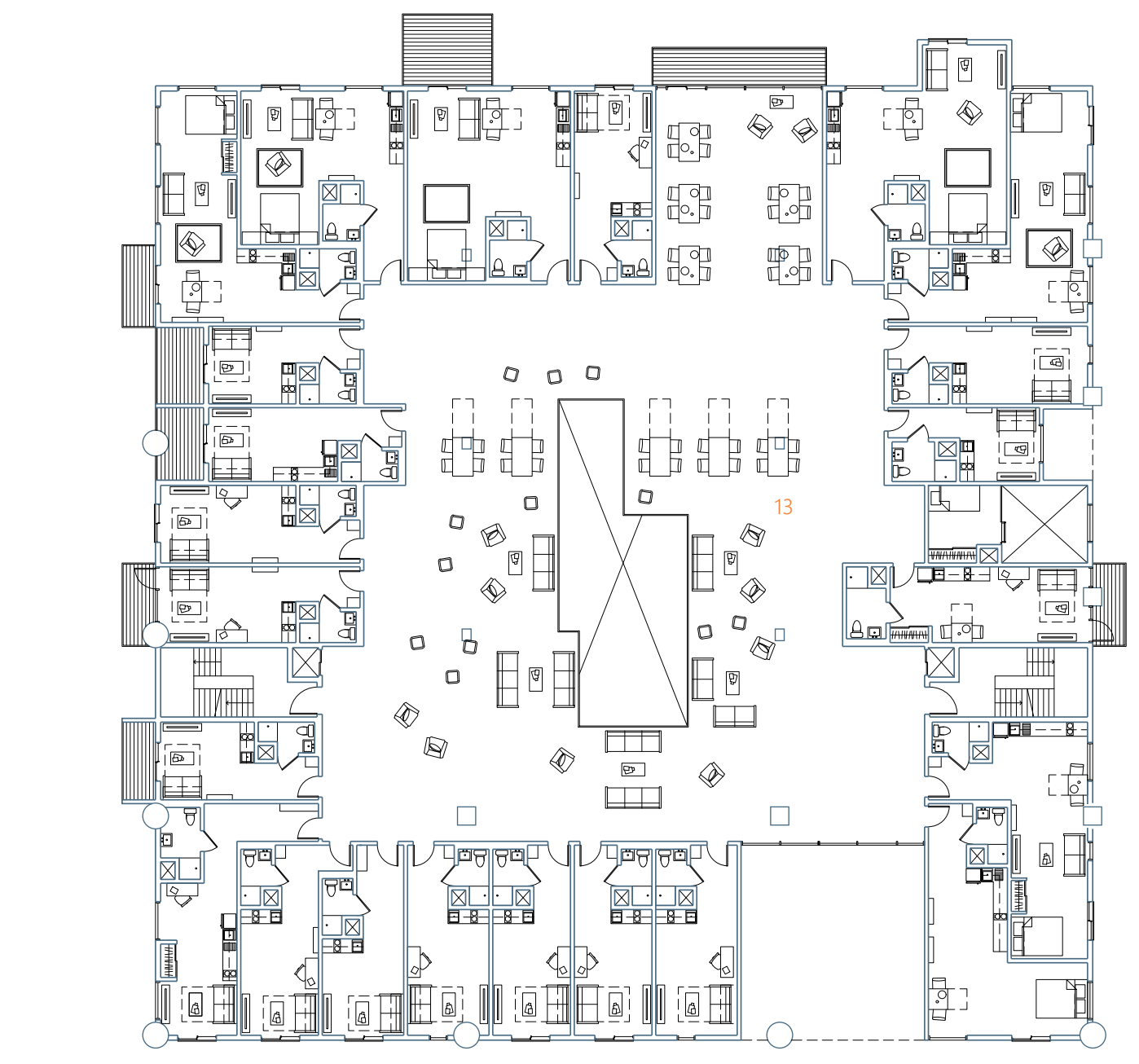

$17.70 \mathrm{~m}$

ఠ) 


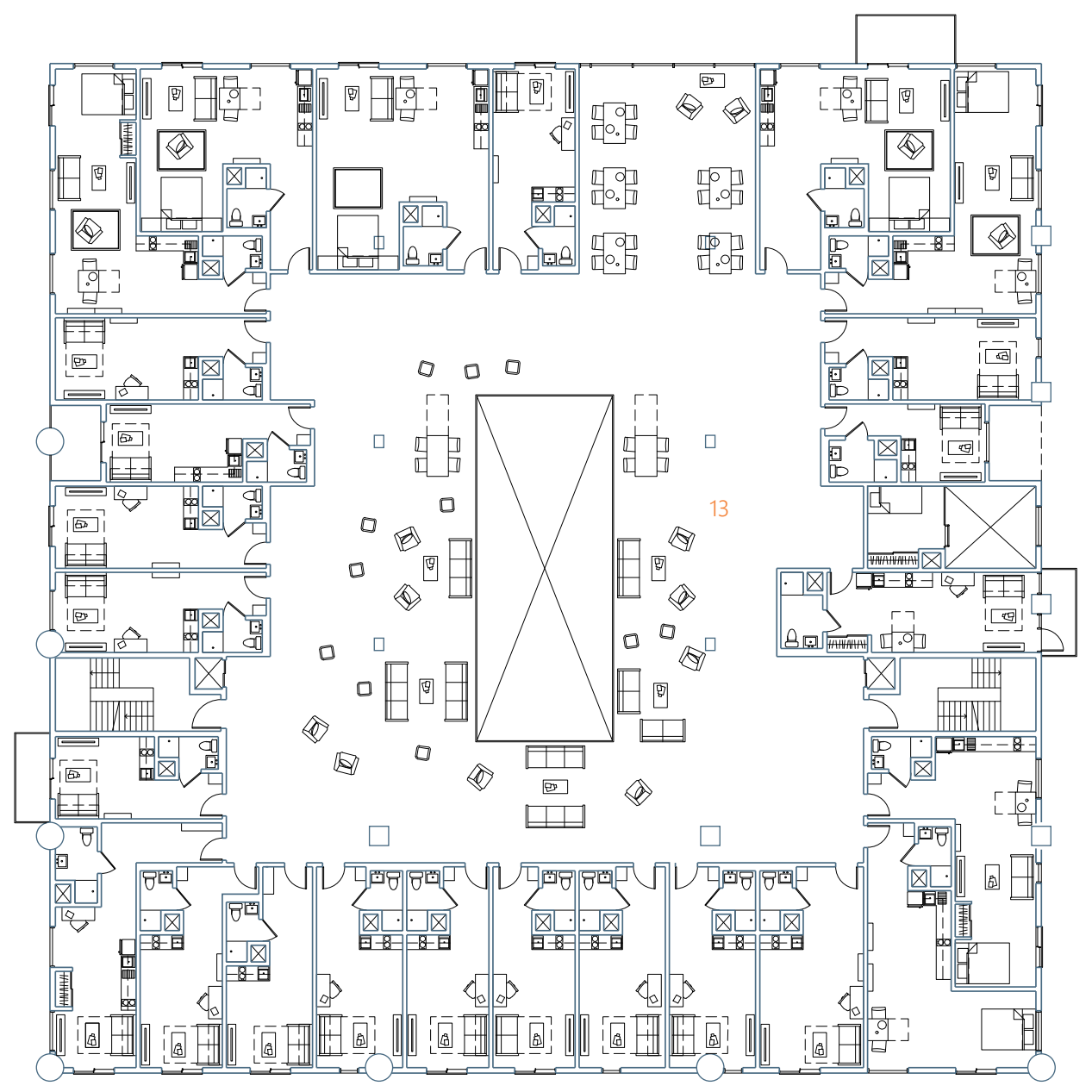




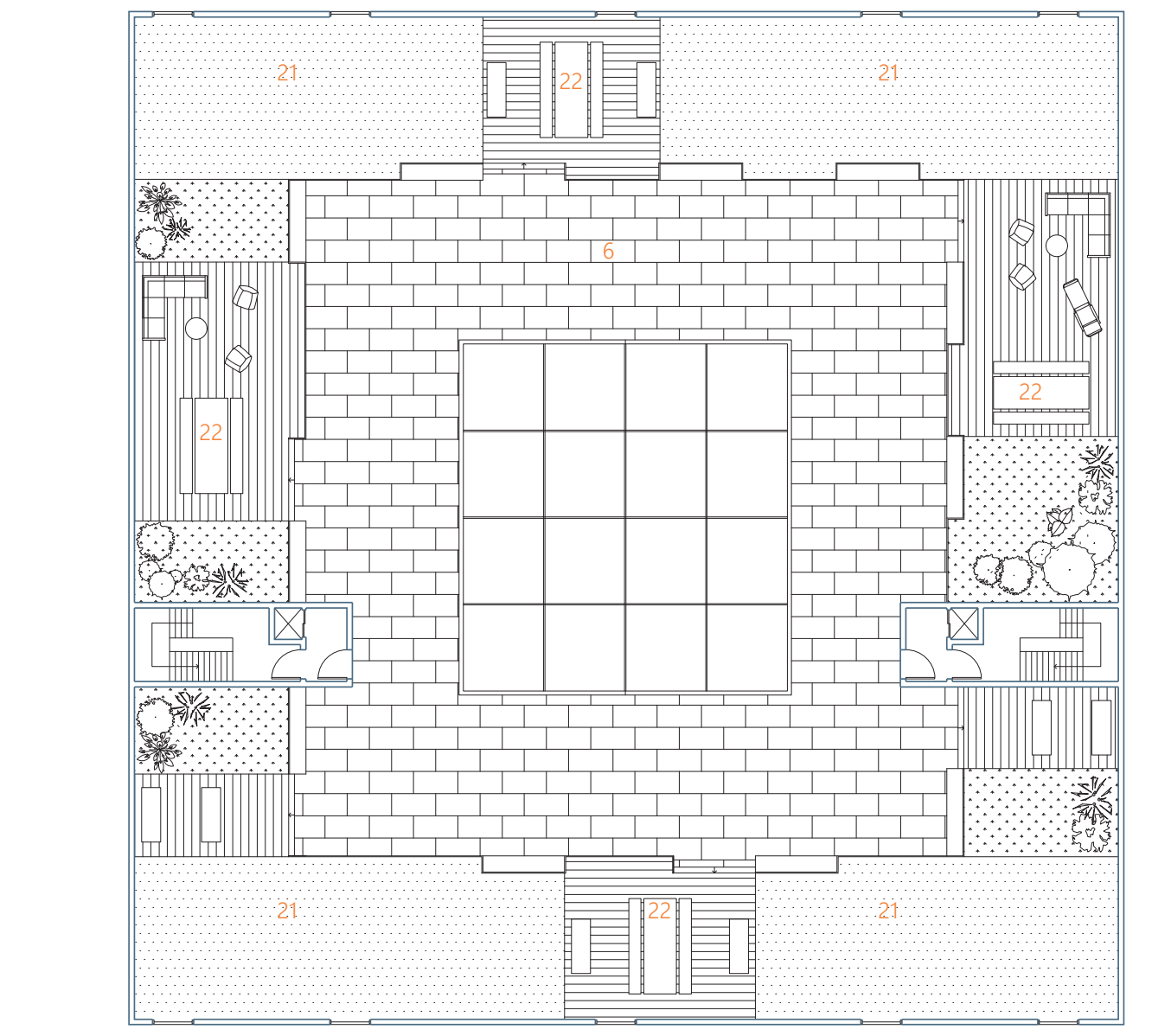

$25.00 \mathrm{~m}$ 


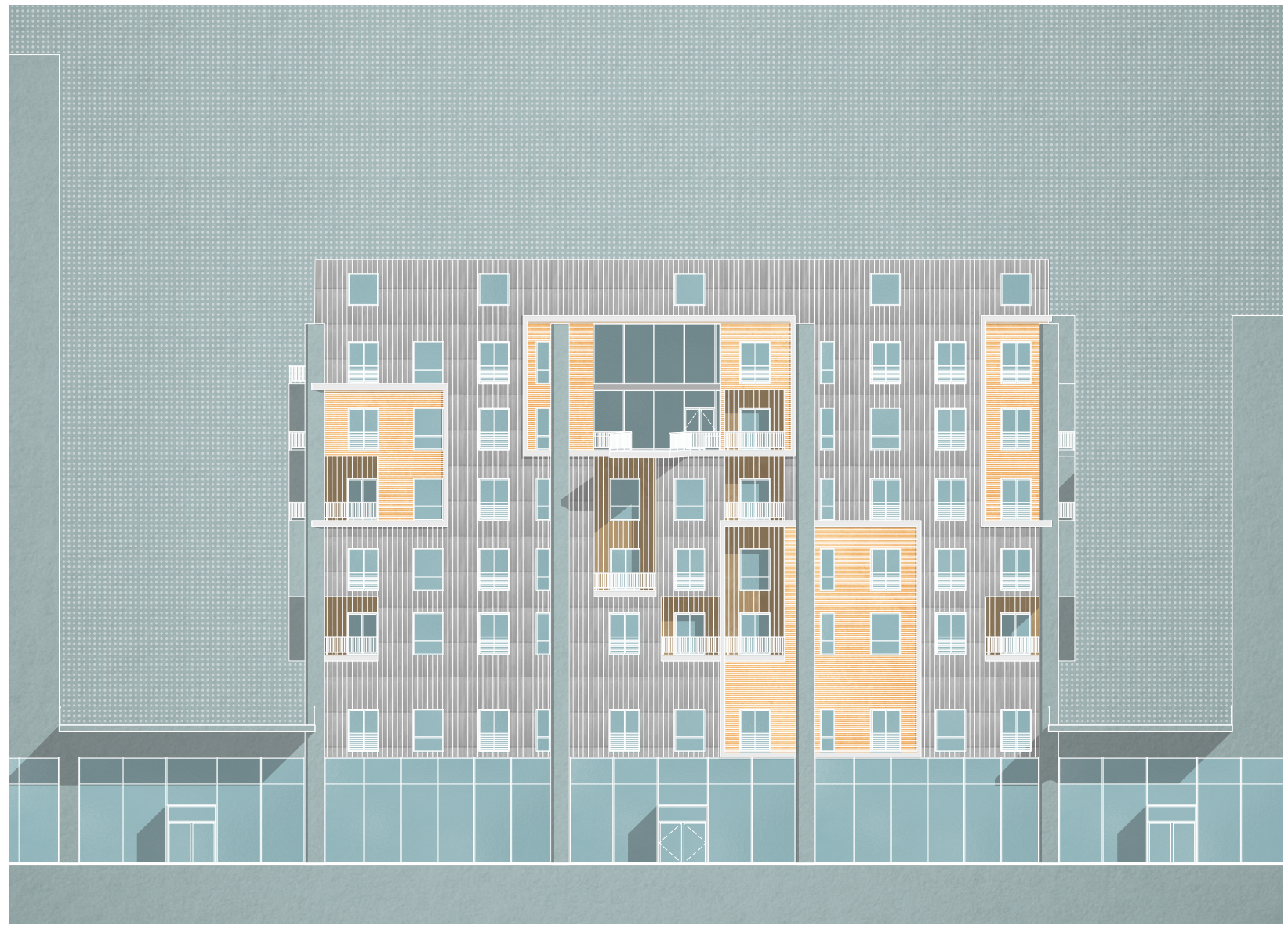




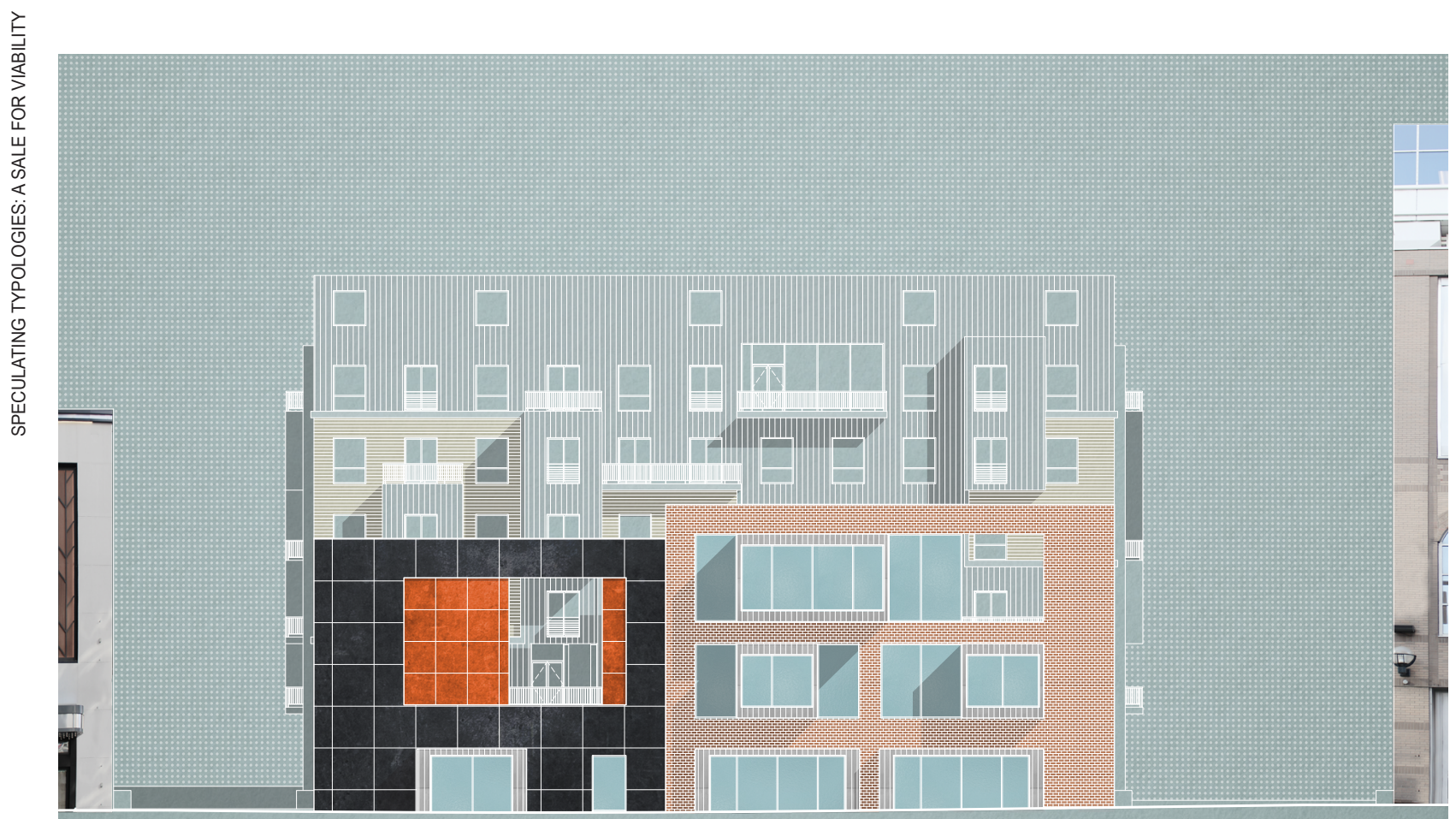

6.83

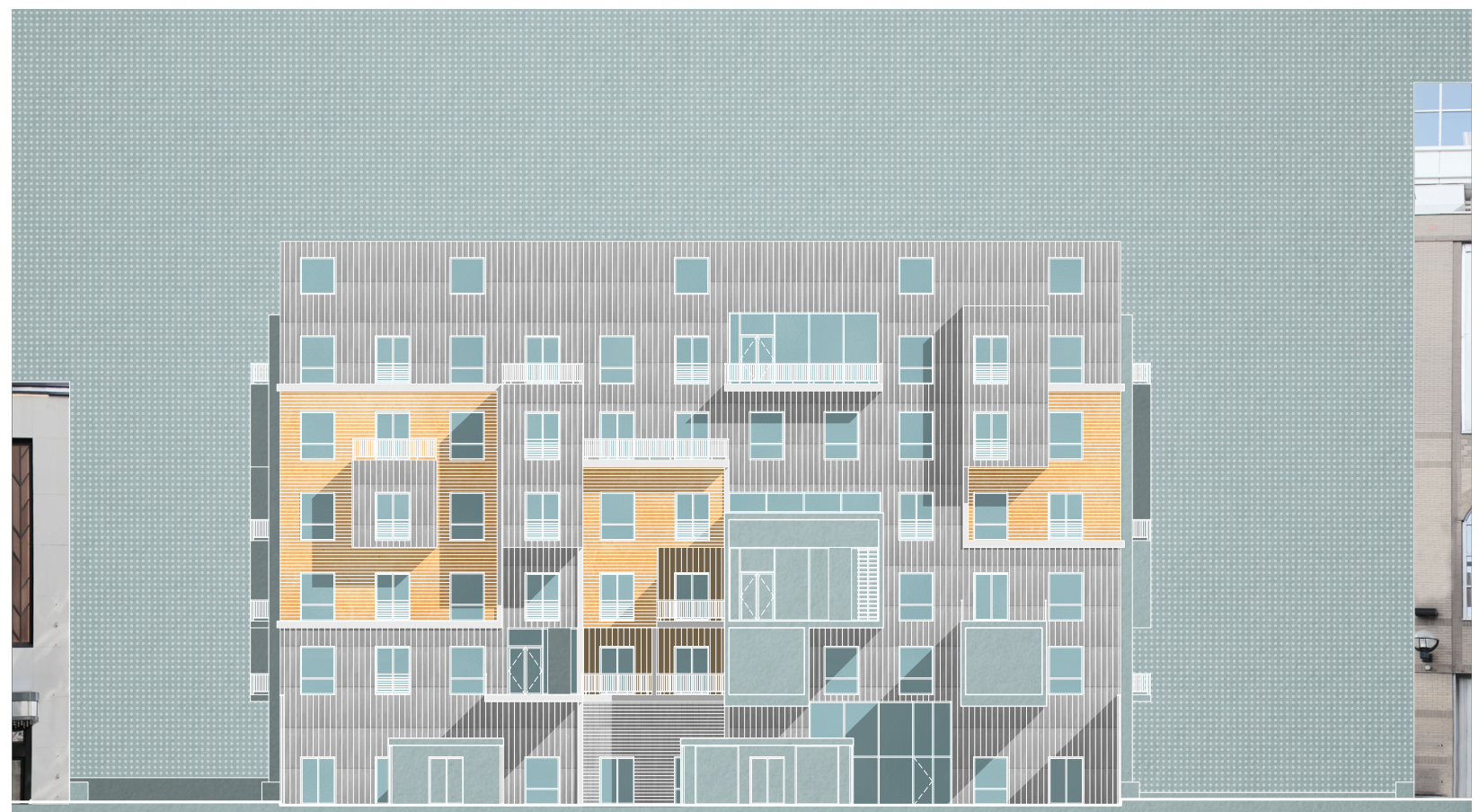

m 6.84

เ

ケ

Fig.6.83 Block 4: East street elevation, Fig.6.84 Block 4: East elevation beyond the existing façade 


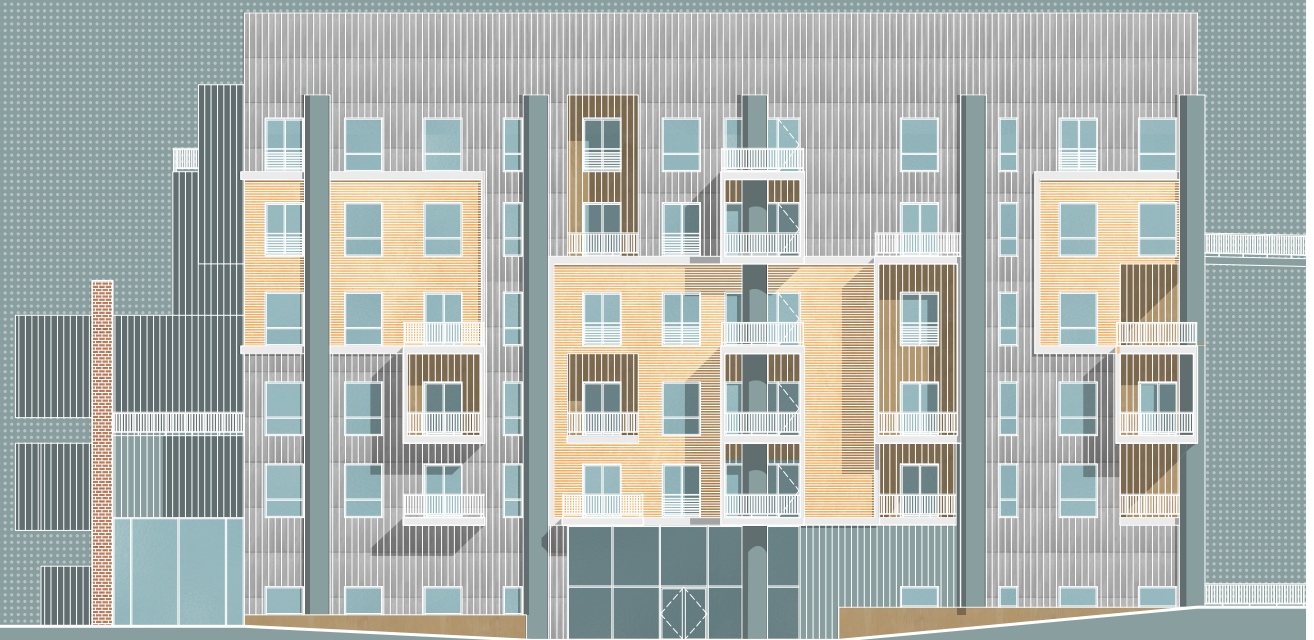

6.85

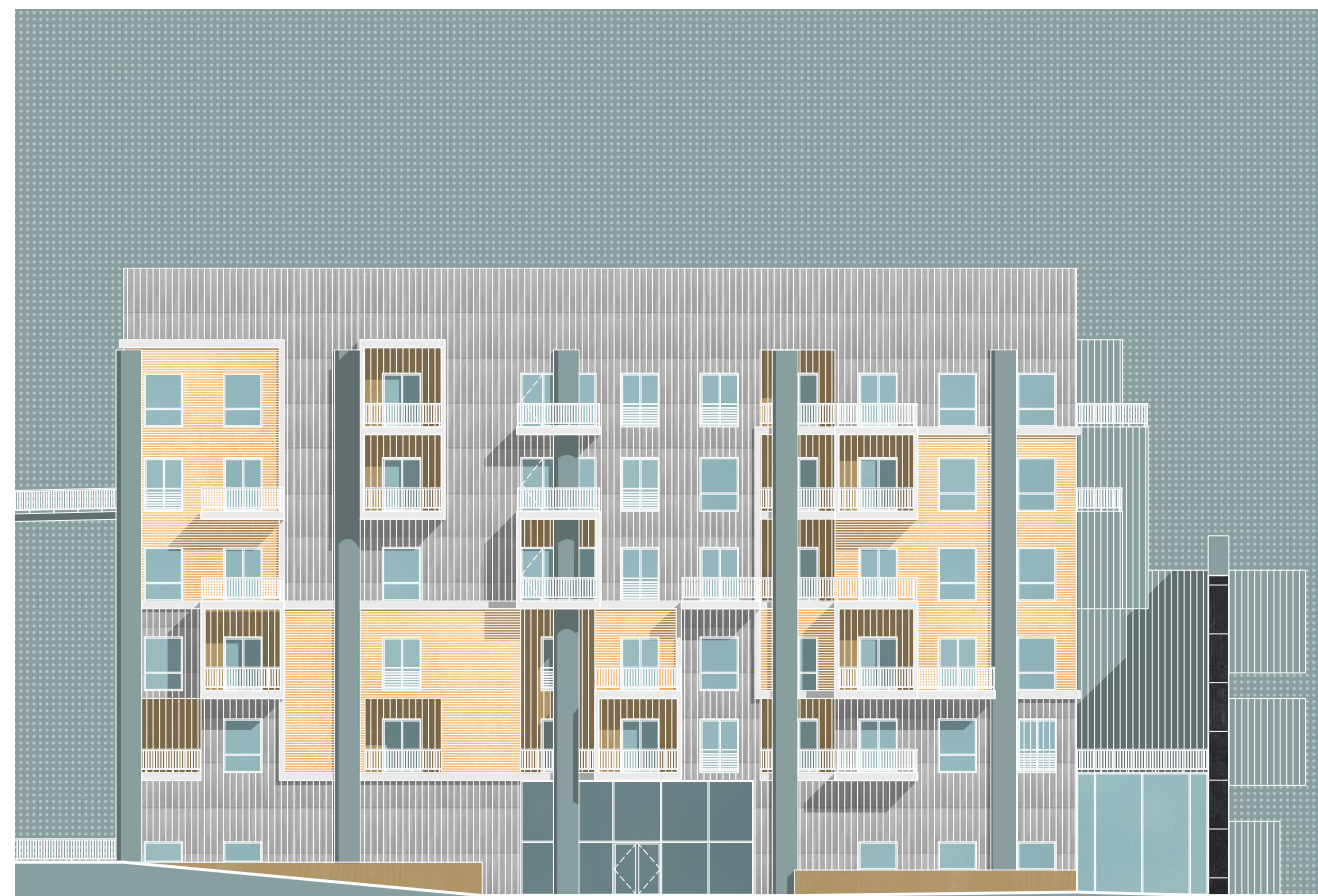




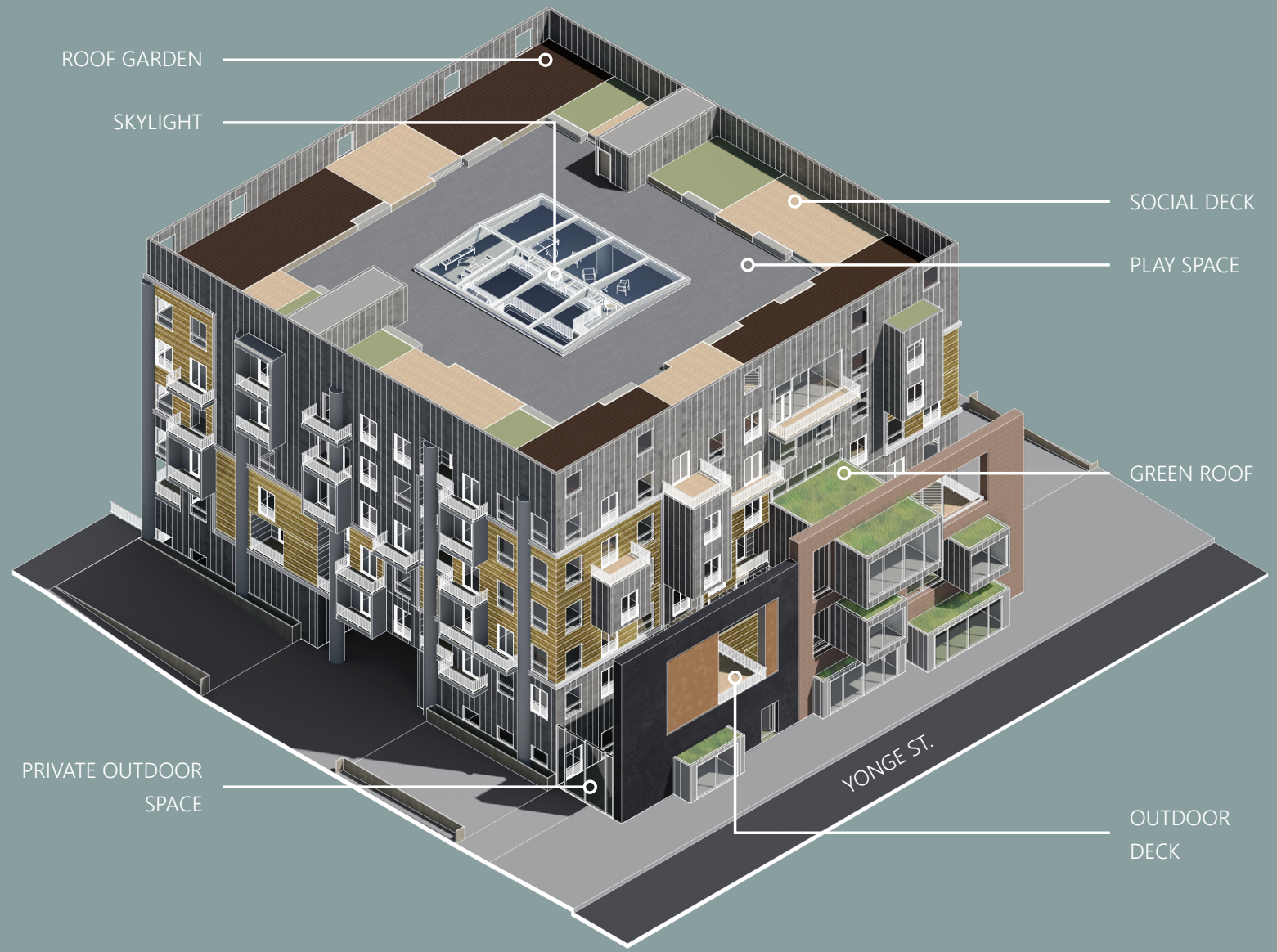




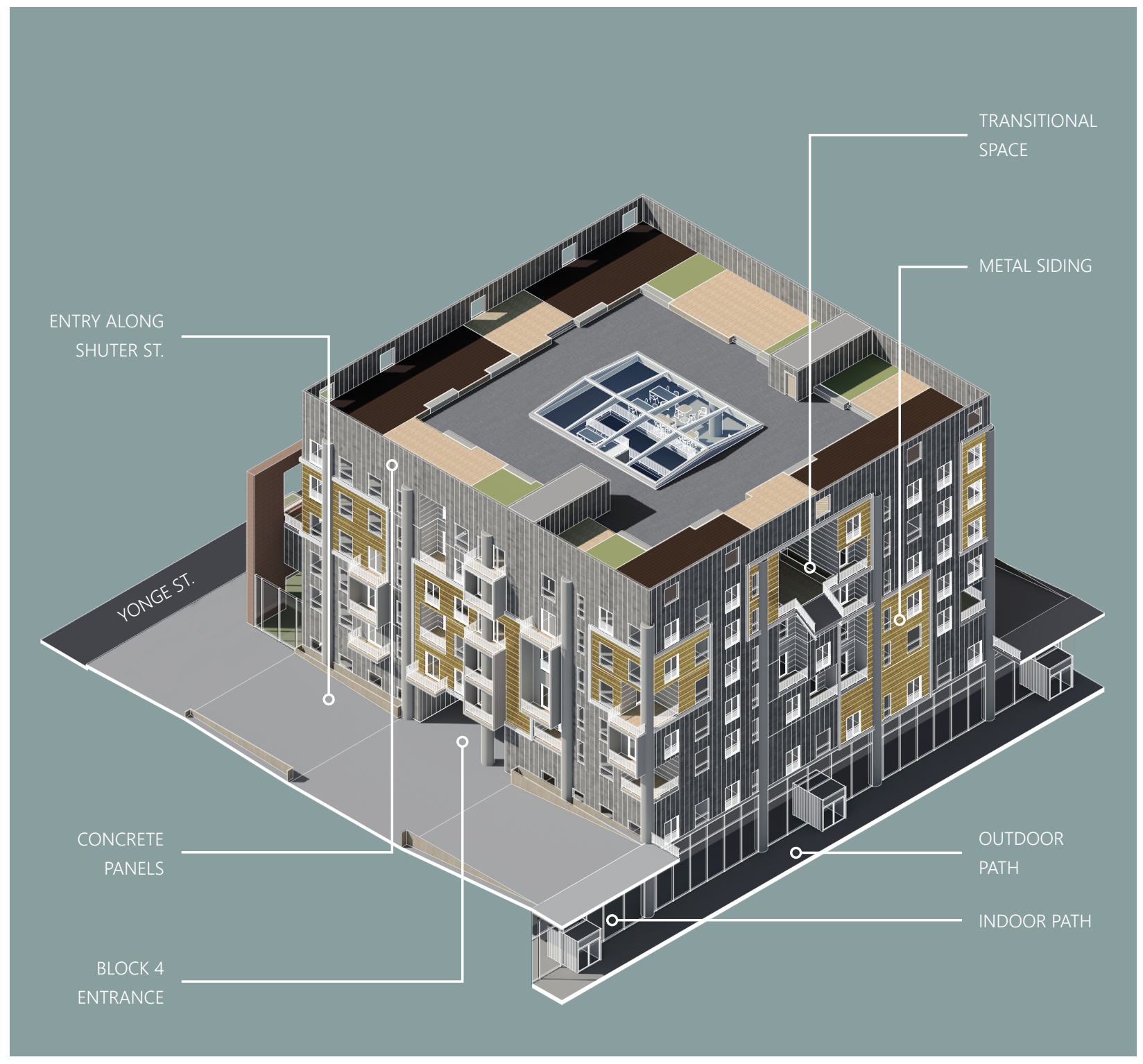




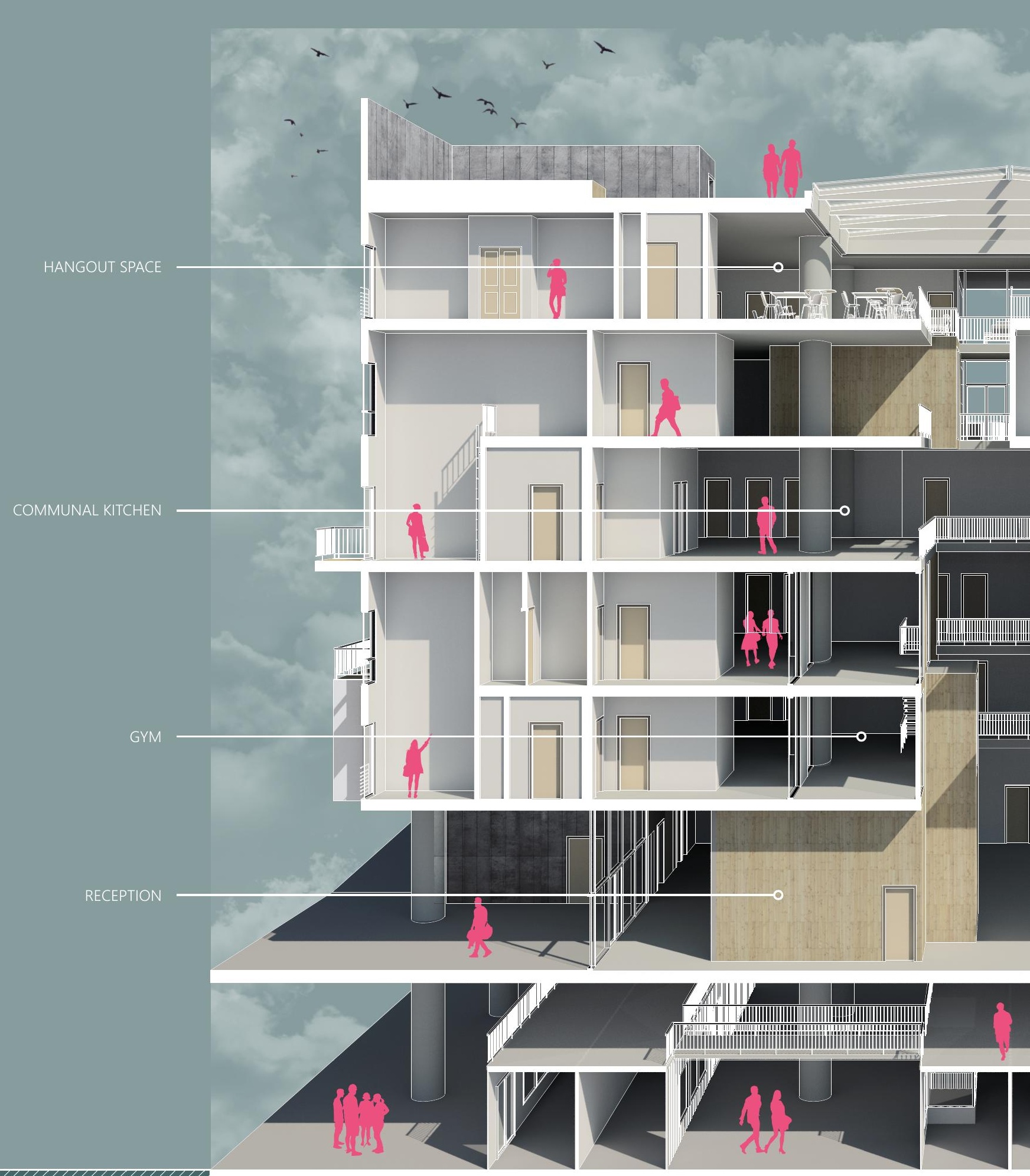




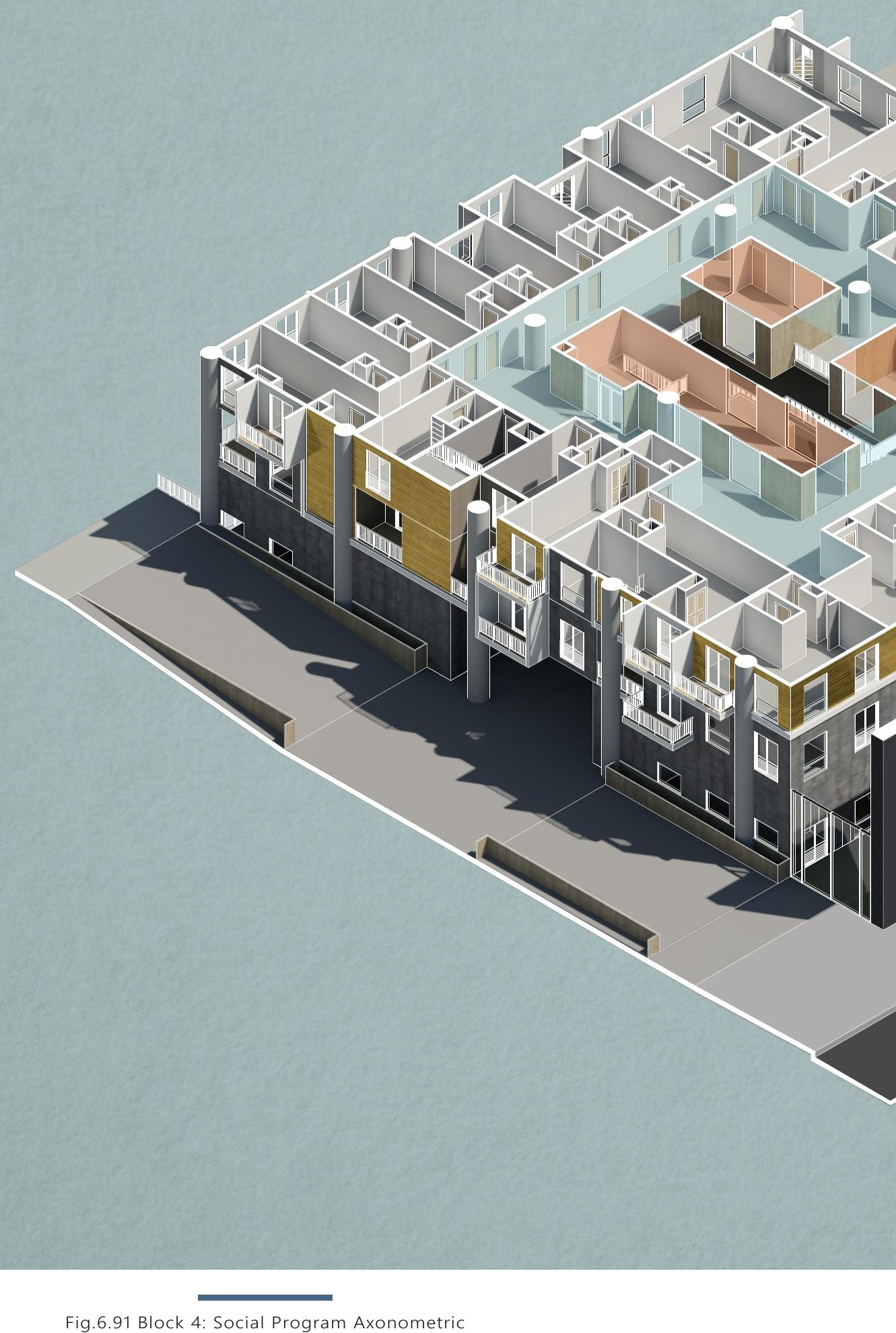




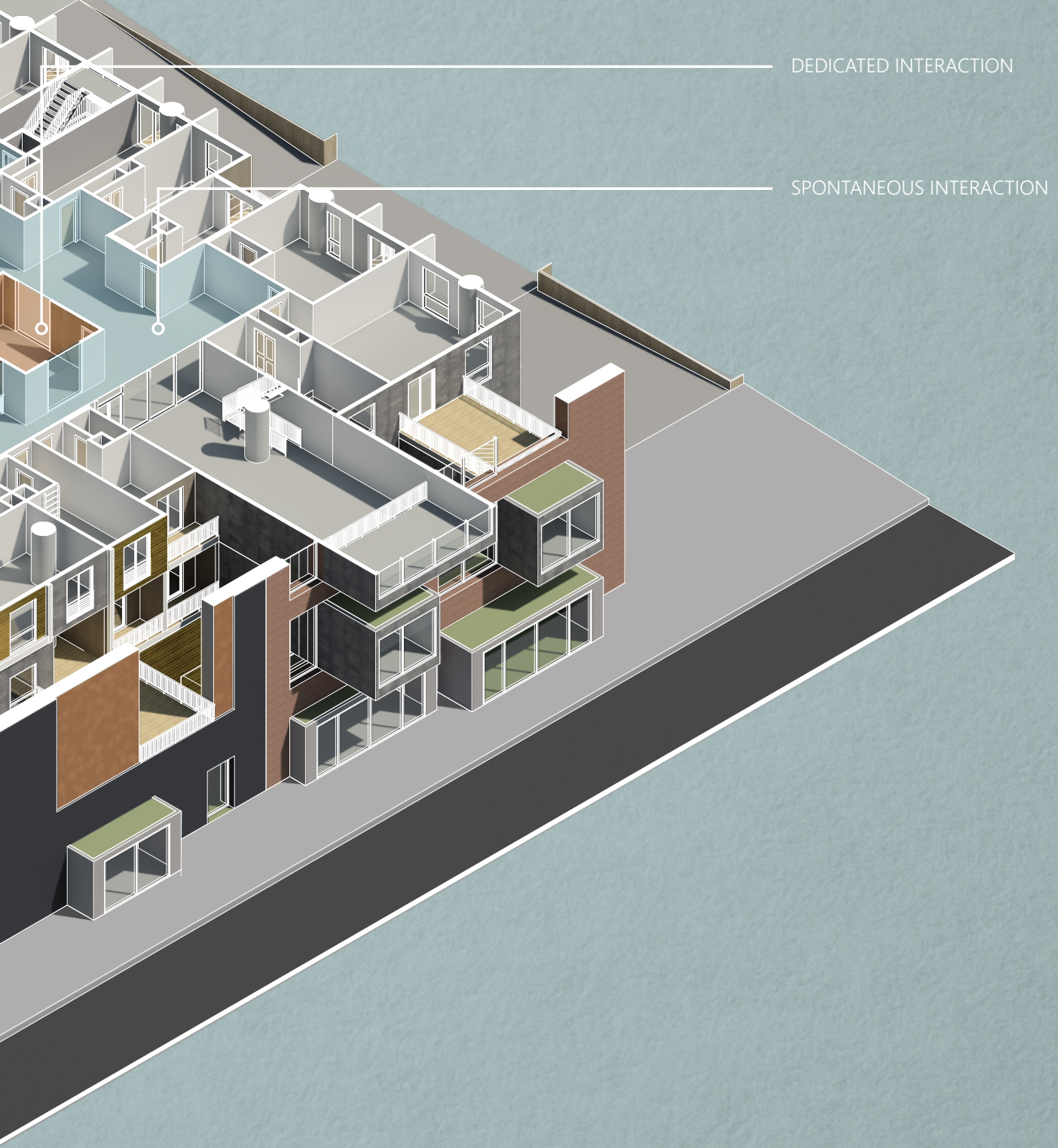



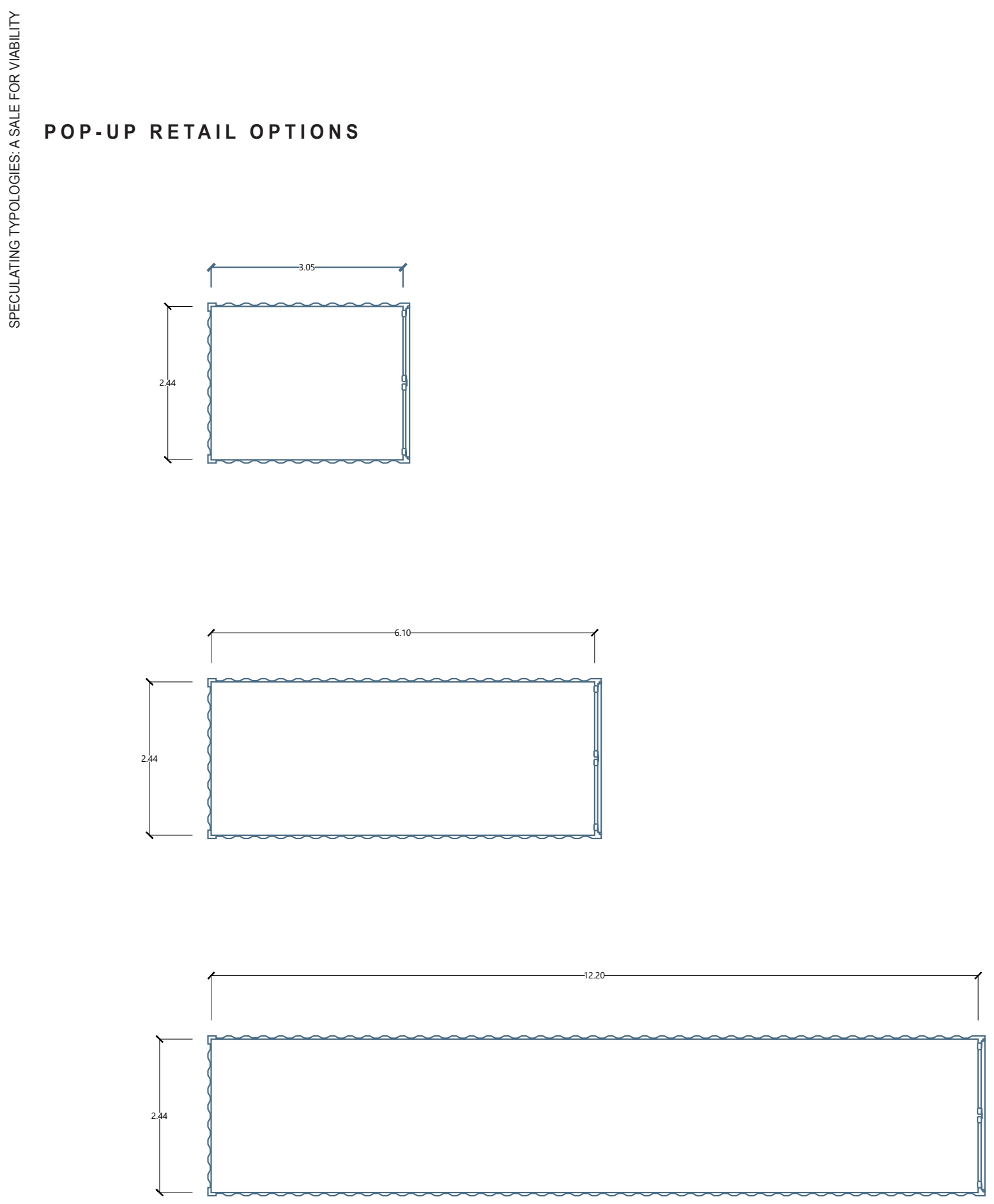

$n$
6
5

Fig.6.92 Available shipping container options 

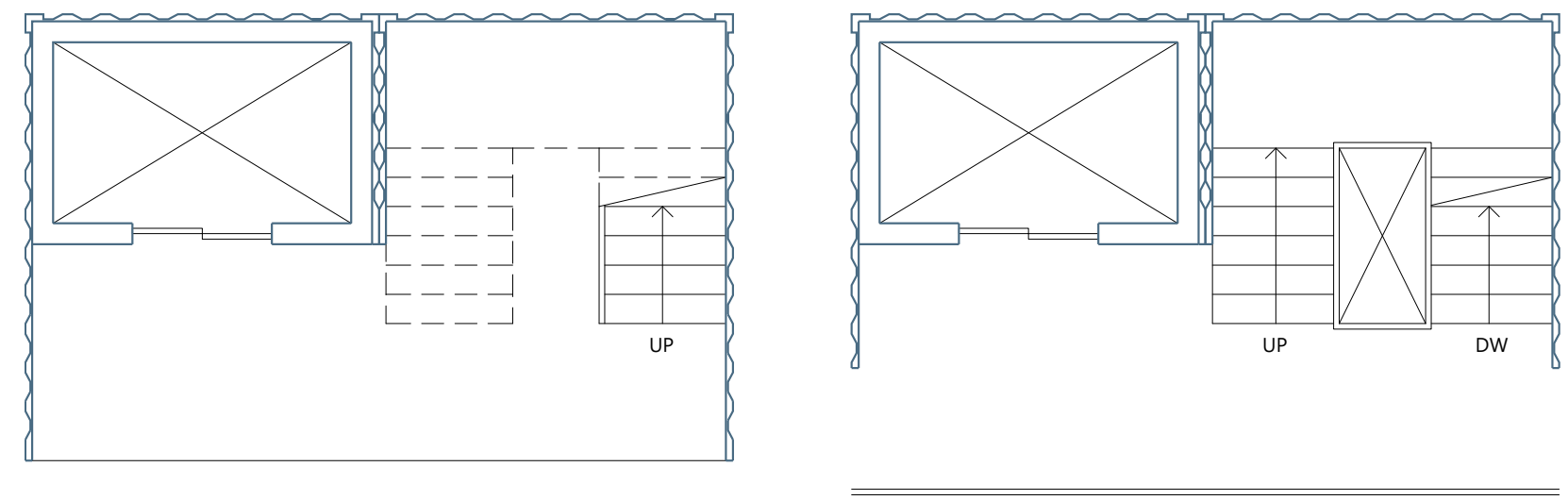

\section{CIRCULATION CORE}

LEVEL 1

Area: $15.9 \mathrm{~m}^{2}$

LEVEL 2

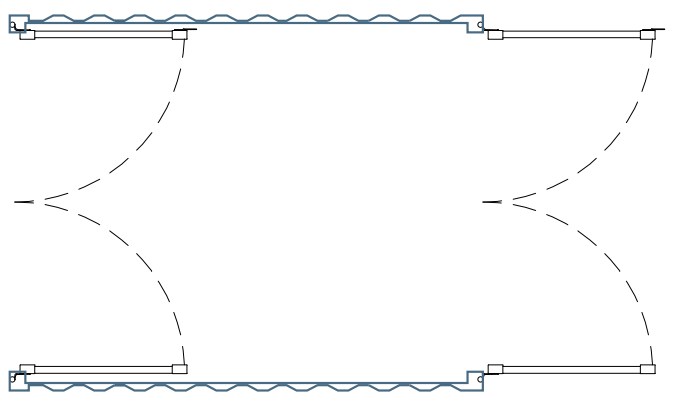

EN T R Y

Area: $7.4 \mathrm{~m}^{2}$ 

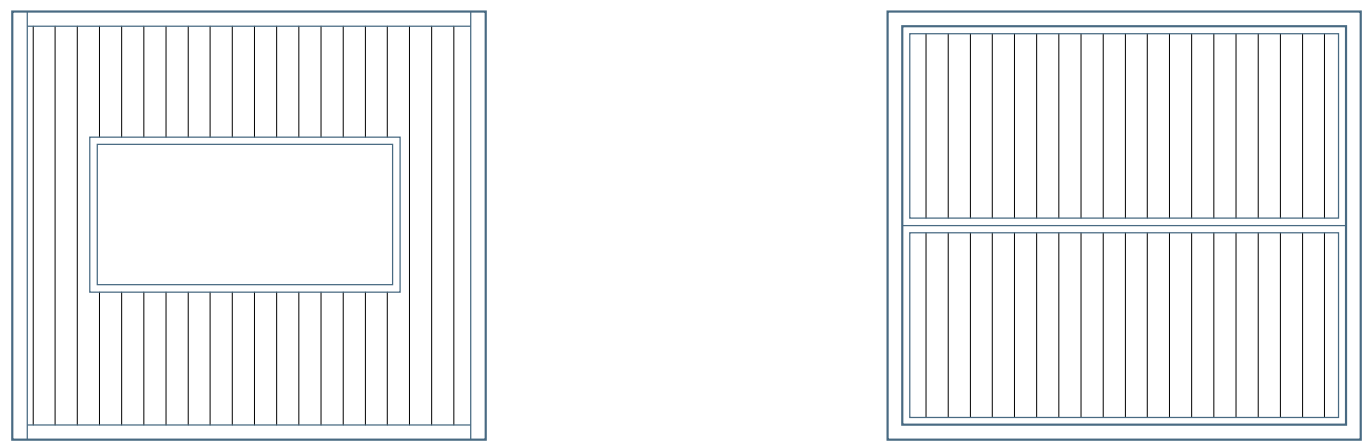

ELEVATION
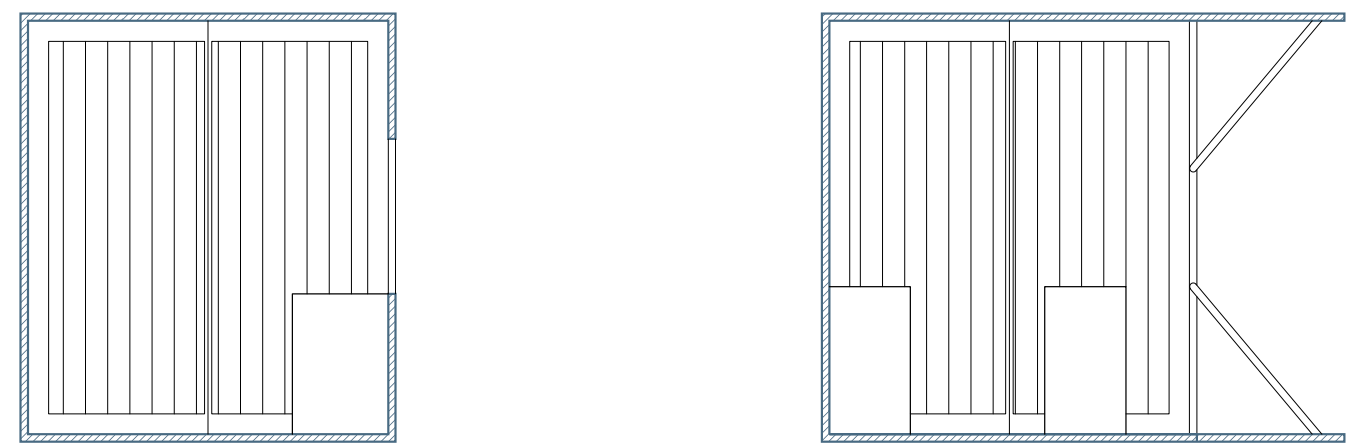

\section{SECTION}
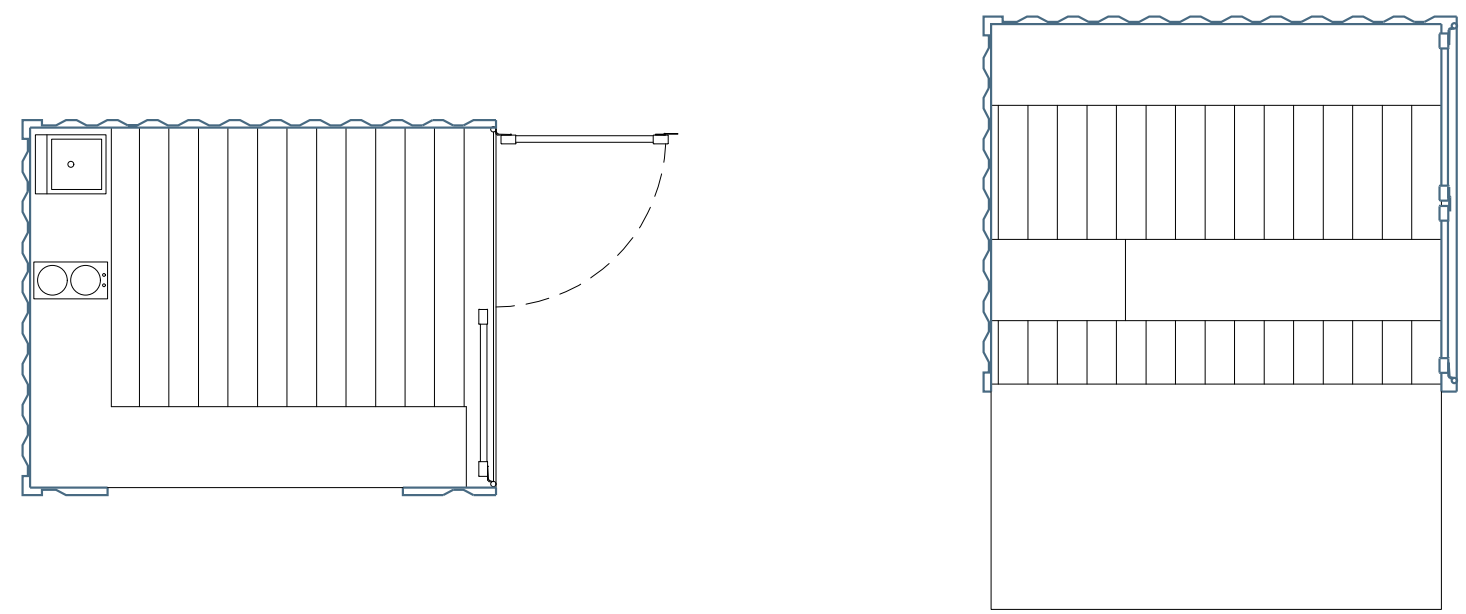

\section{PLAN}

(ก) Area: $7.4 \mathrm{~m}^{2}$ 


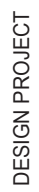

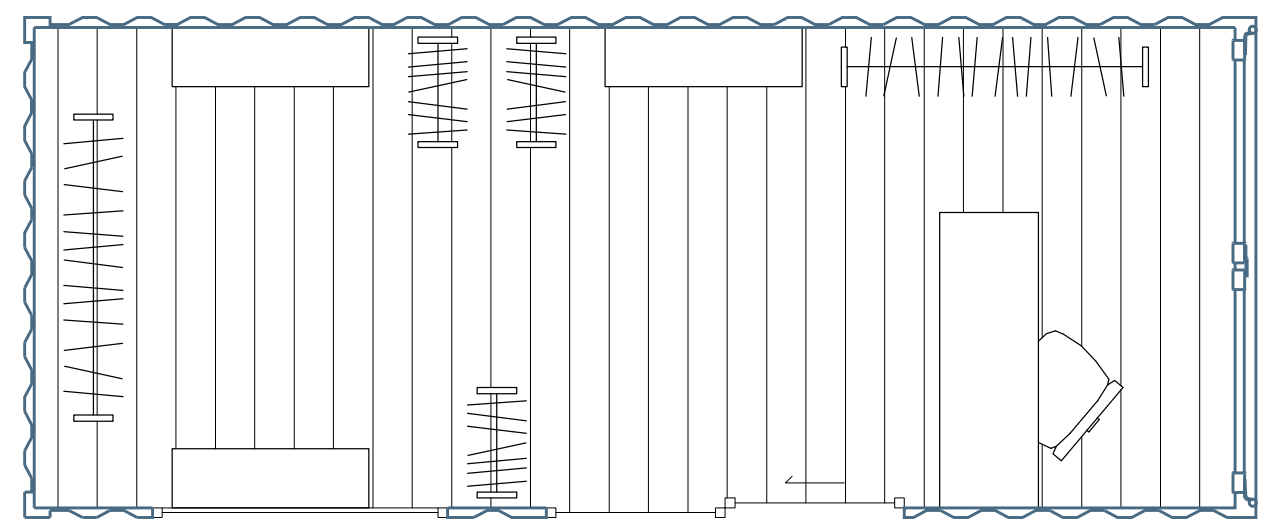

CLOTHING SHOP

Area: $14.9 \mathrm{~m}^{2}$

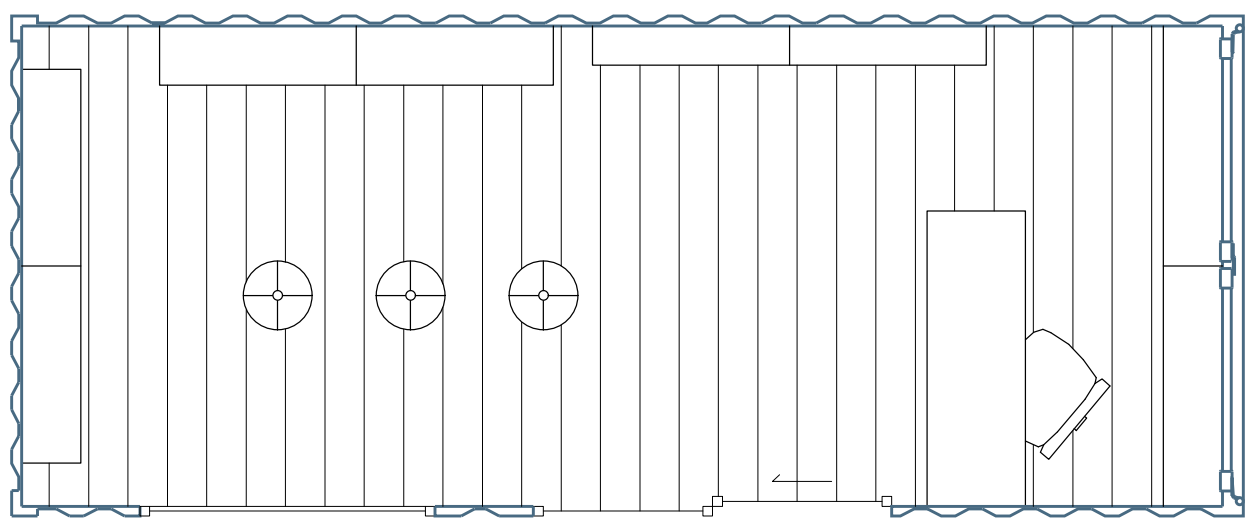

BOOK STORE

Area: $14.9 \mathrm{~m}^{2}$

Fig.6.96 Pop-up medium size shop option 1

$\bullet$
$\stackrel{0}{=}$ 


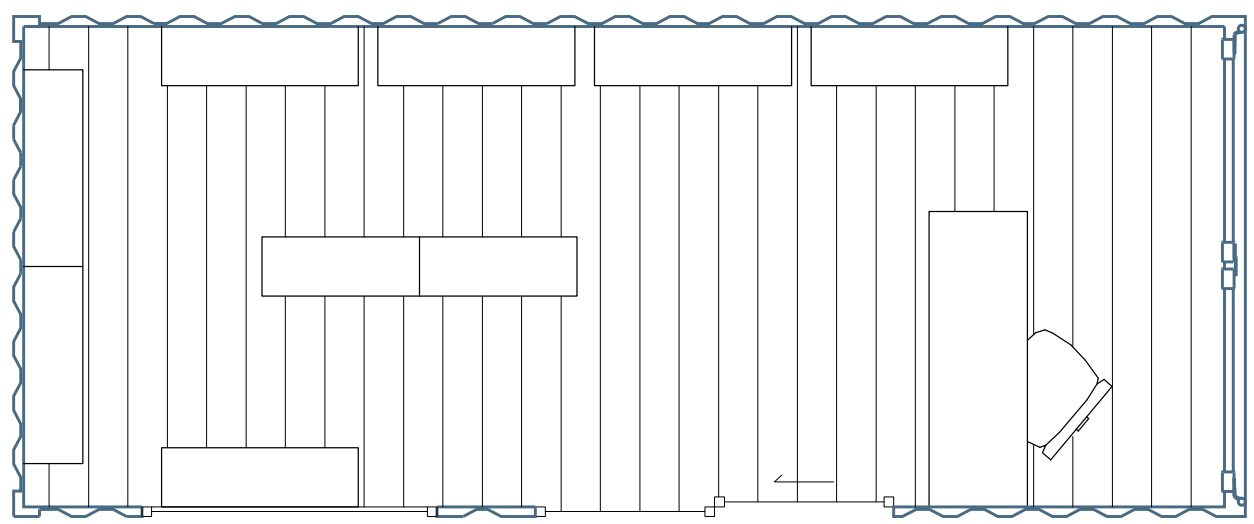

JEWELLERY SHOP

Area: $14.9 \mathrm{~m}^{2}$

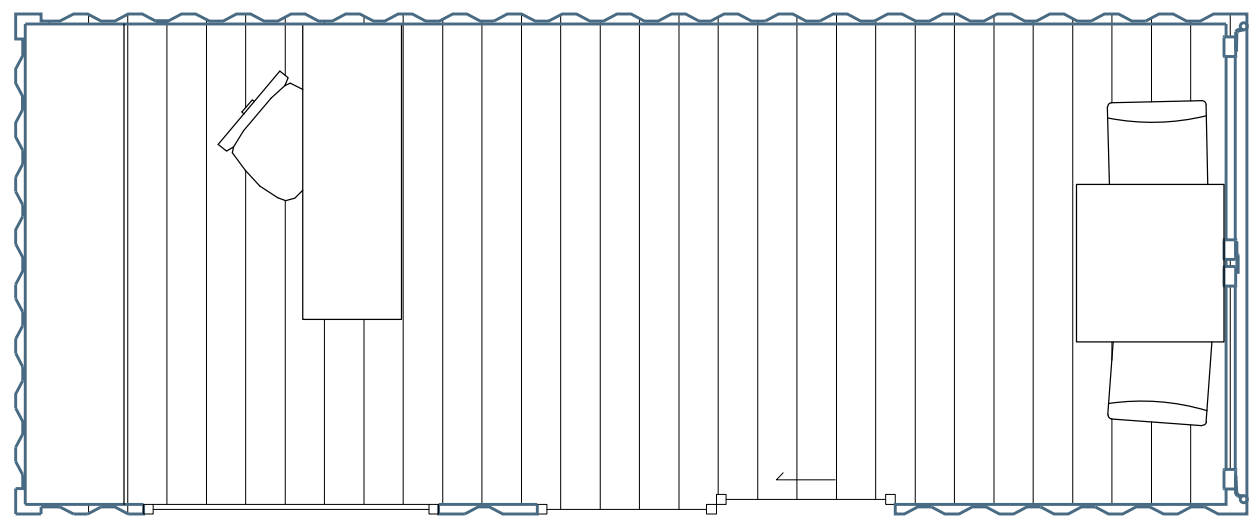

BOOK CAFE



Area: $14.9 \mathrm{~m}^{2}$

0 


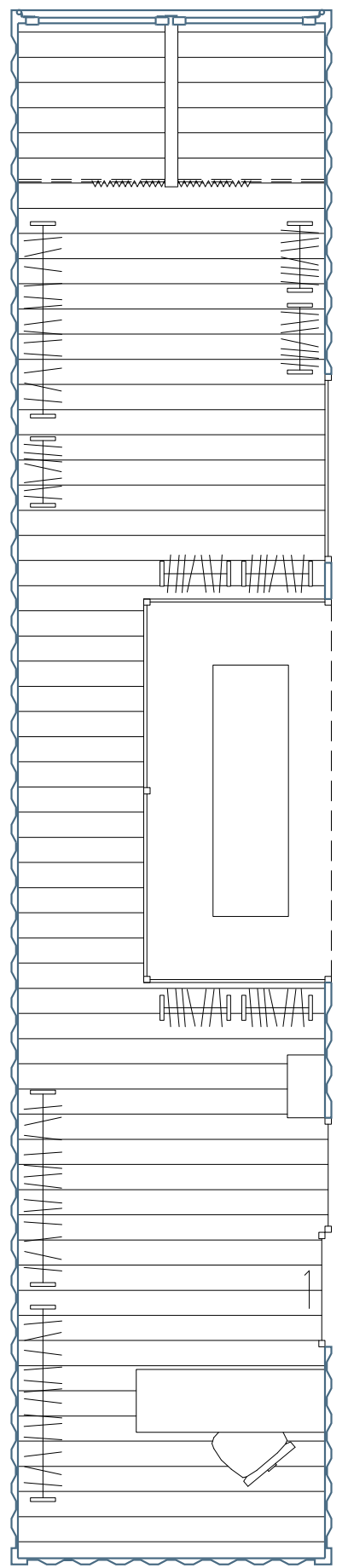

CLOTHING SHOP

Area: $29.8 \mathrm{~m}^{2}$

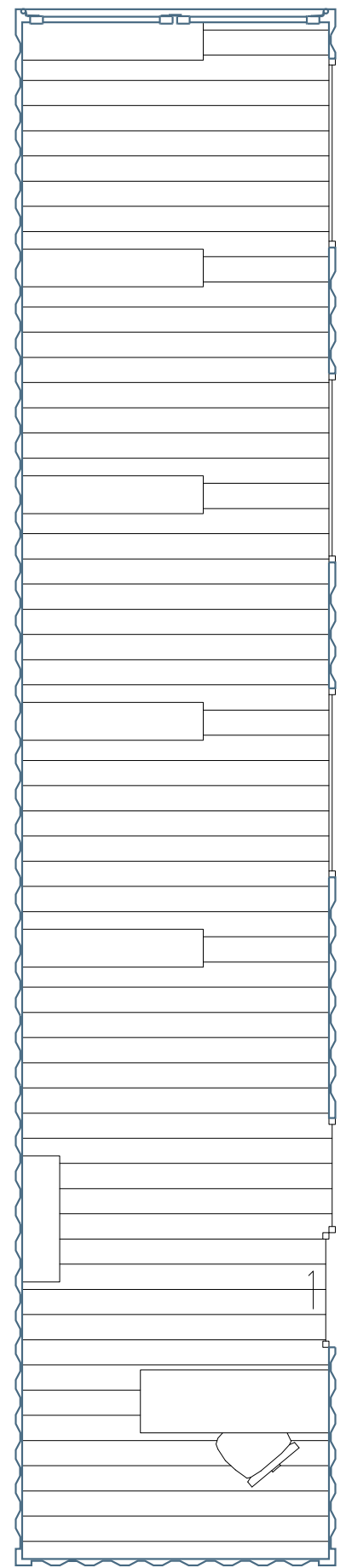

G A L LERY

Area: $29.8 \mathrm{~m}^{2}$

$\infty$

Fig.6.98 Pop-up large size shop option 1 

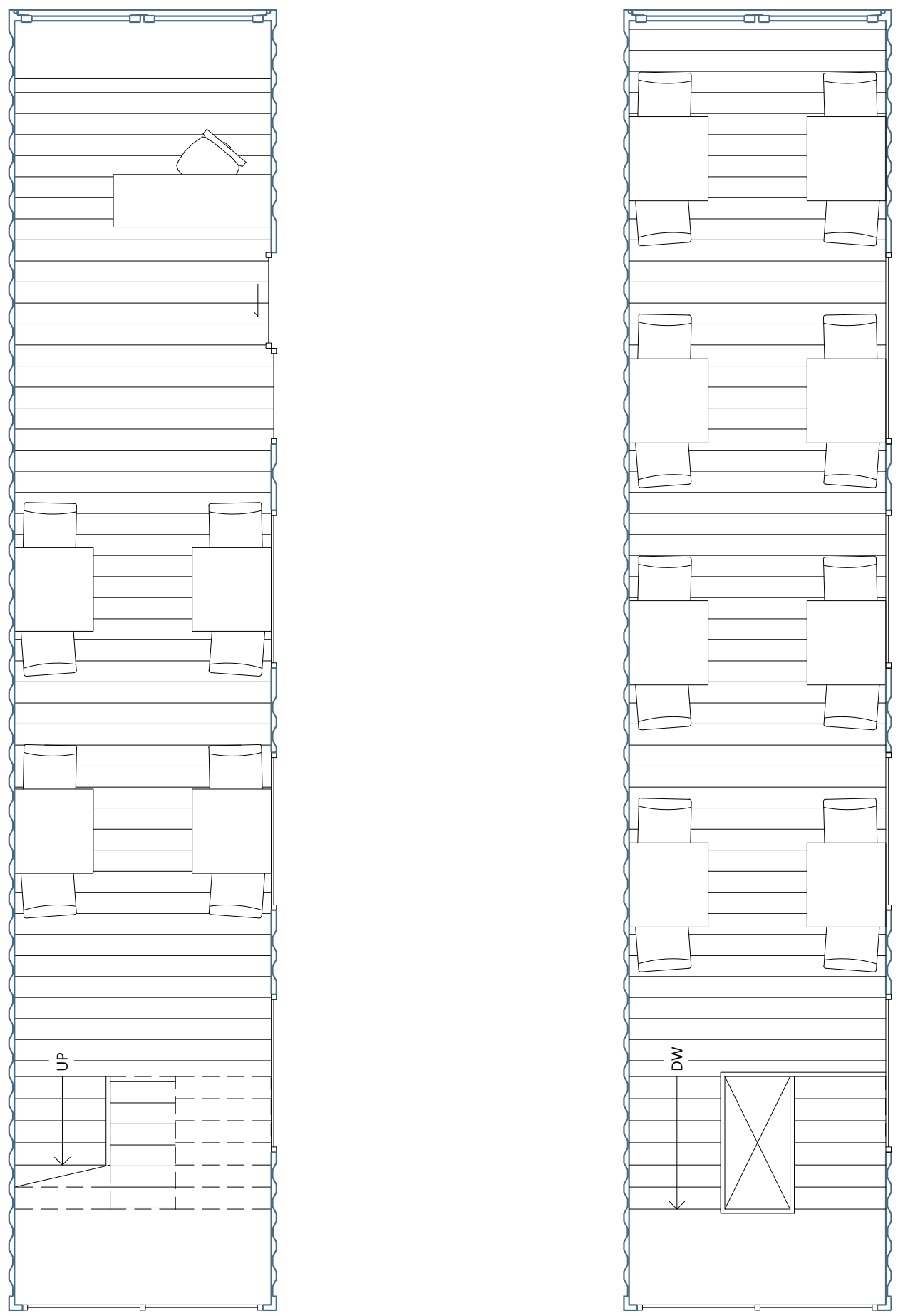

\section{A F E}

LEVEL 1

の Area: $59.5 \mathrm{~m}^{2}$

LEVEL 2

Area: $59.5 \mathrm{~m}^{2}$

-

Fig.6.99 Pop-up large size shop option 2 


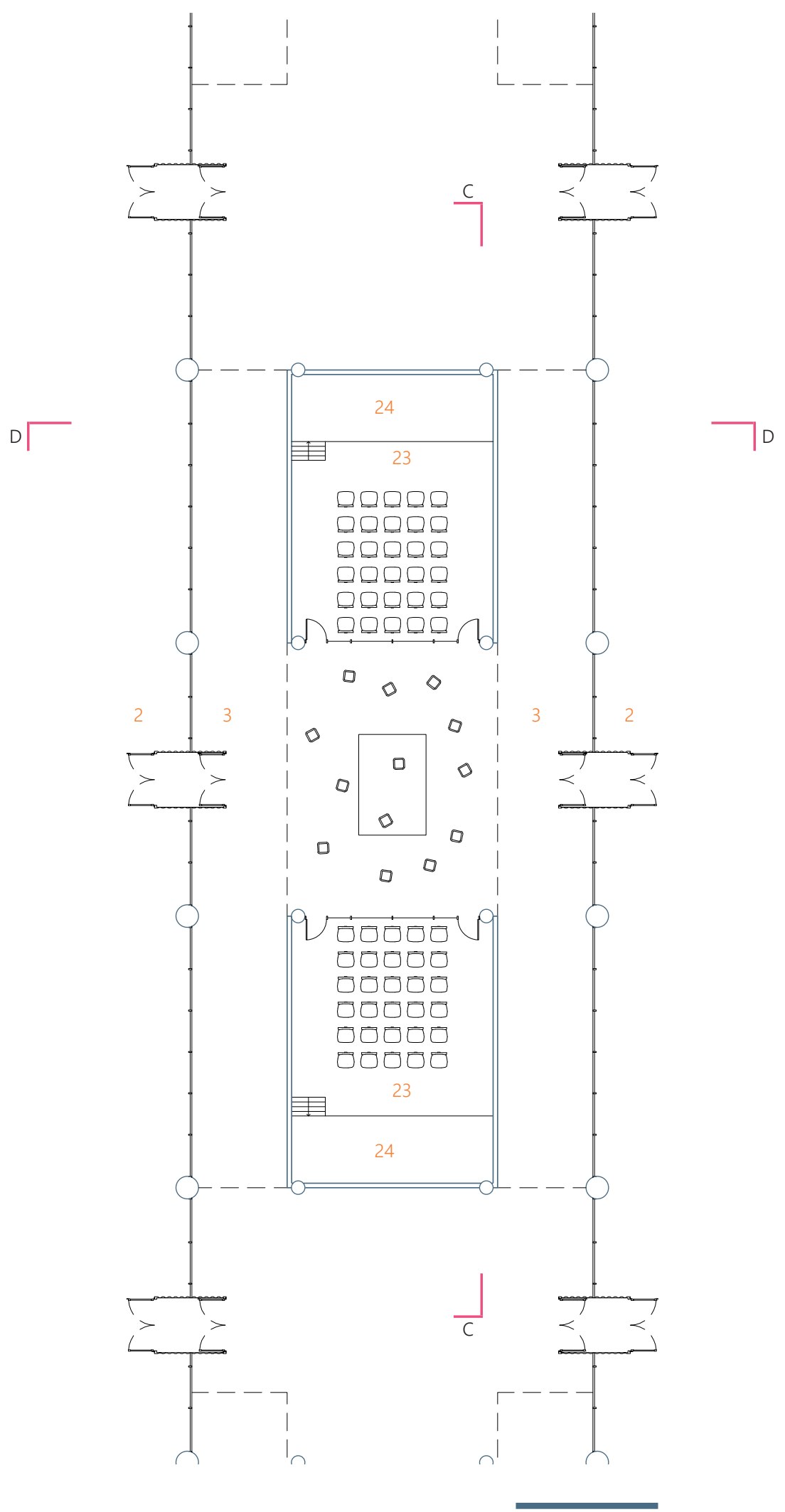

23 Flex Space

24 Storage below stage

Fig.6.100 Retail Block 3-4: Proposed level 1 

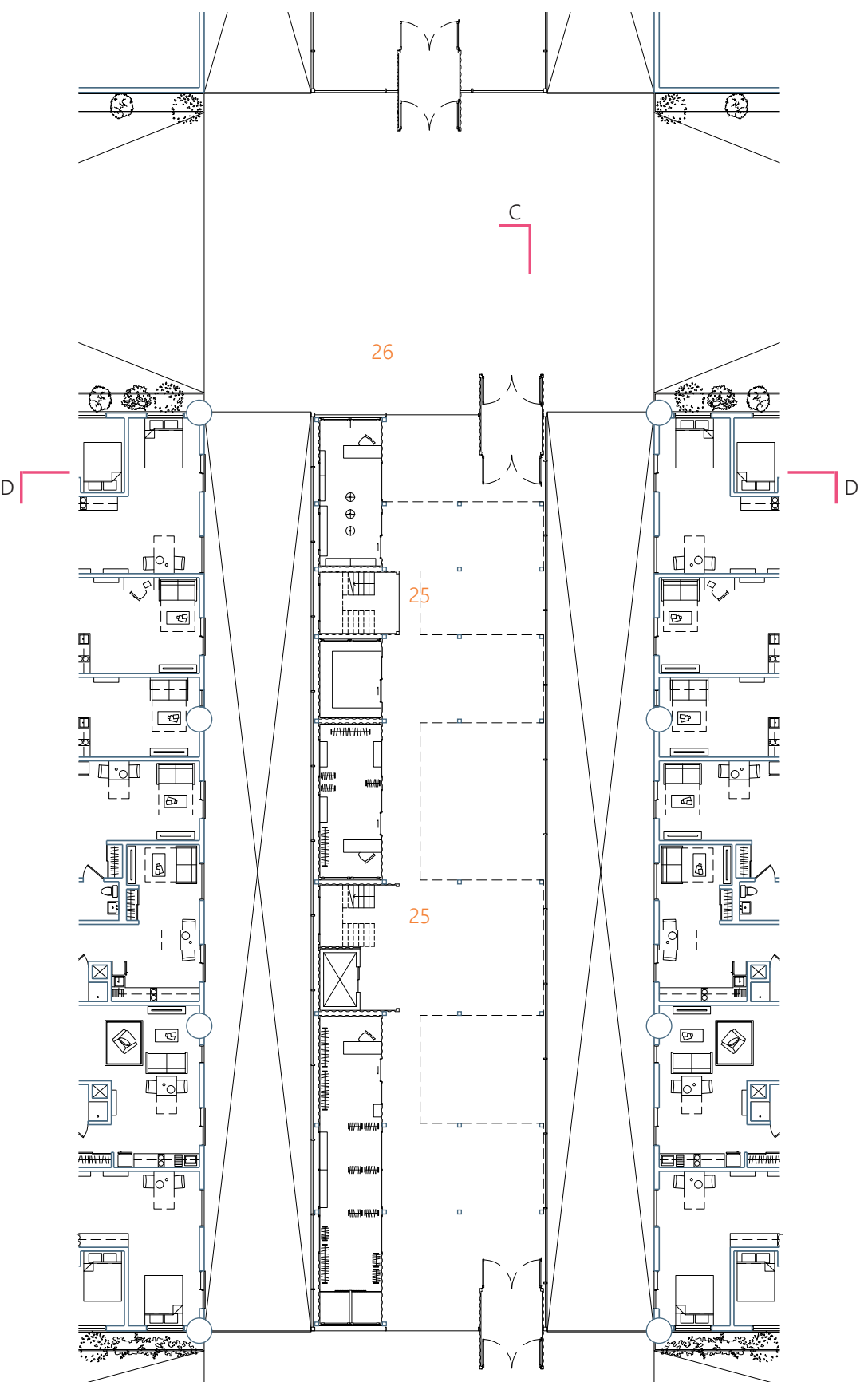

25 Circulation zone

26 Outdoor path

26

$\frac{1}{c}$

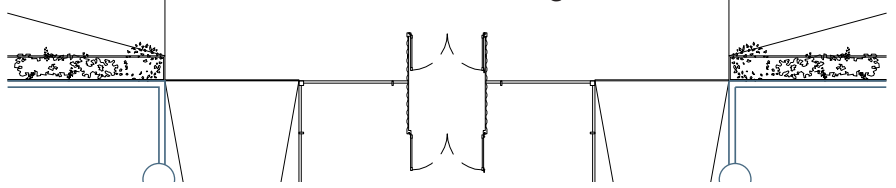

$1.30 \mathrm{~m}$

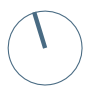



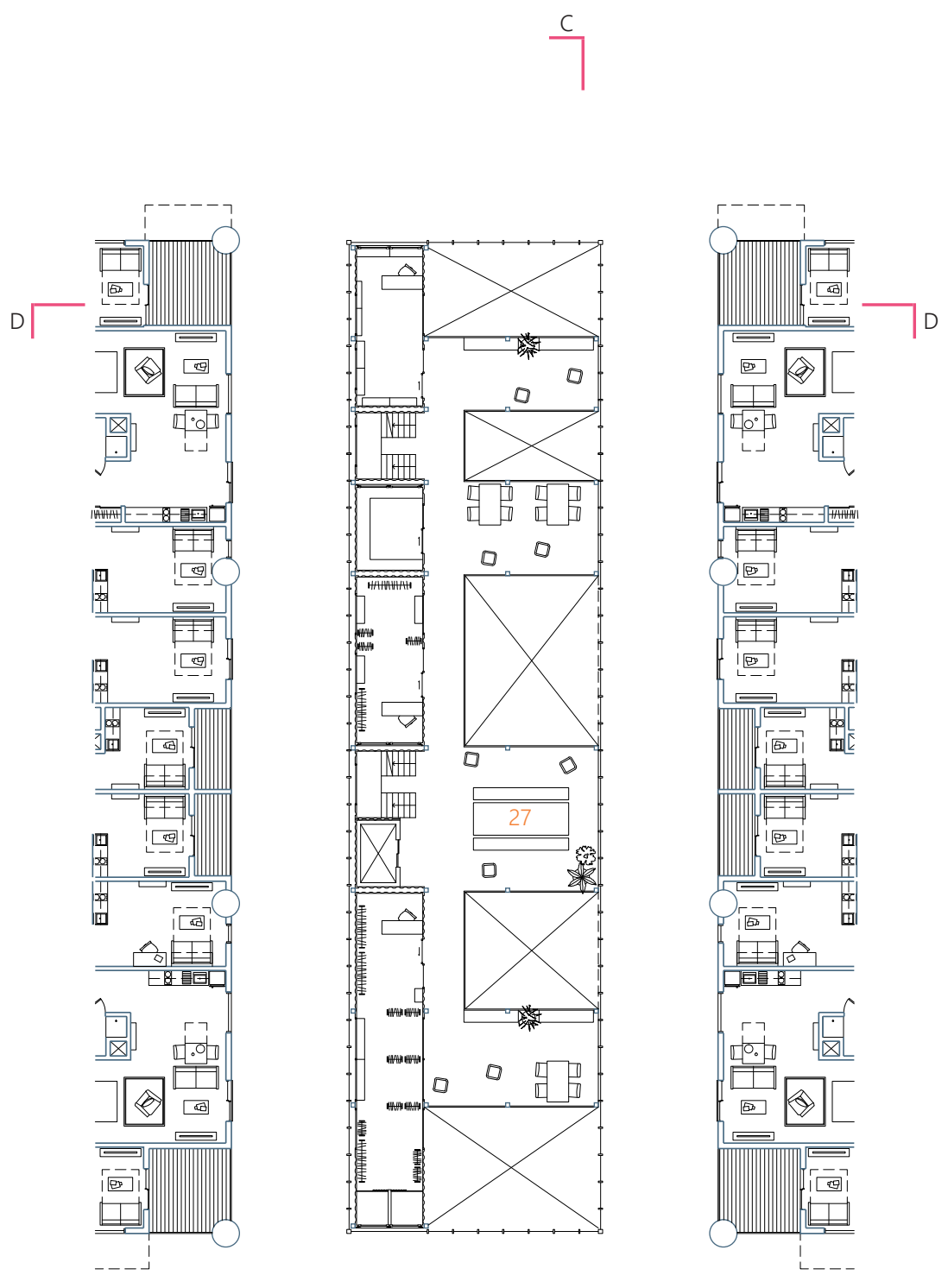

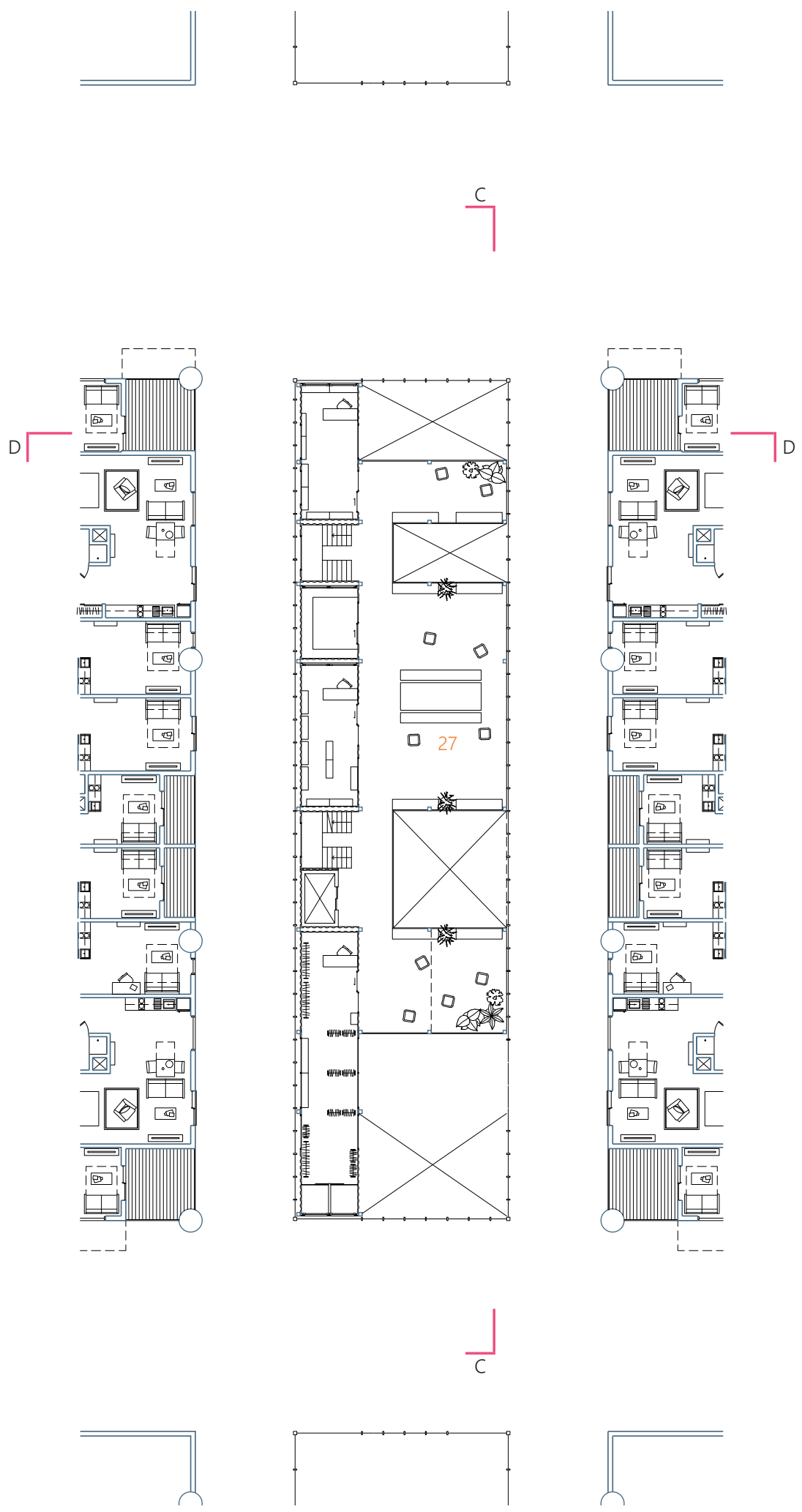

$$
\frac{1}{C}
$$

Fig.6.103 Retail Block 3-4: Proposed level 4 

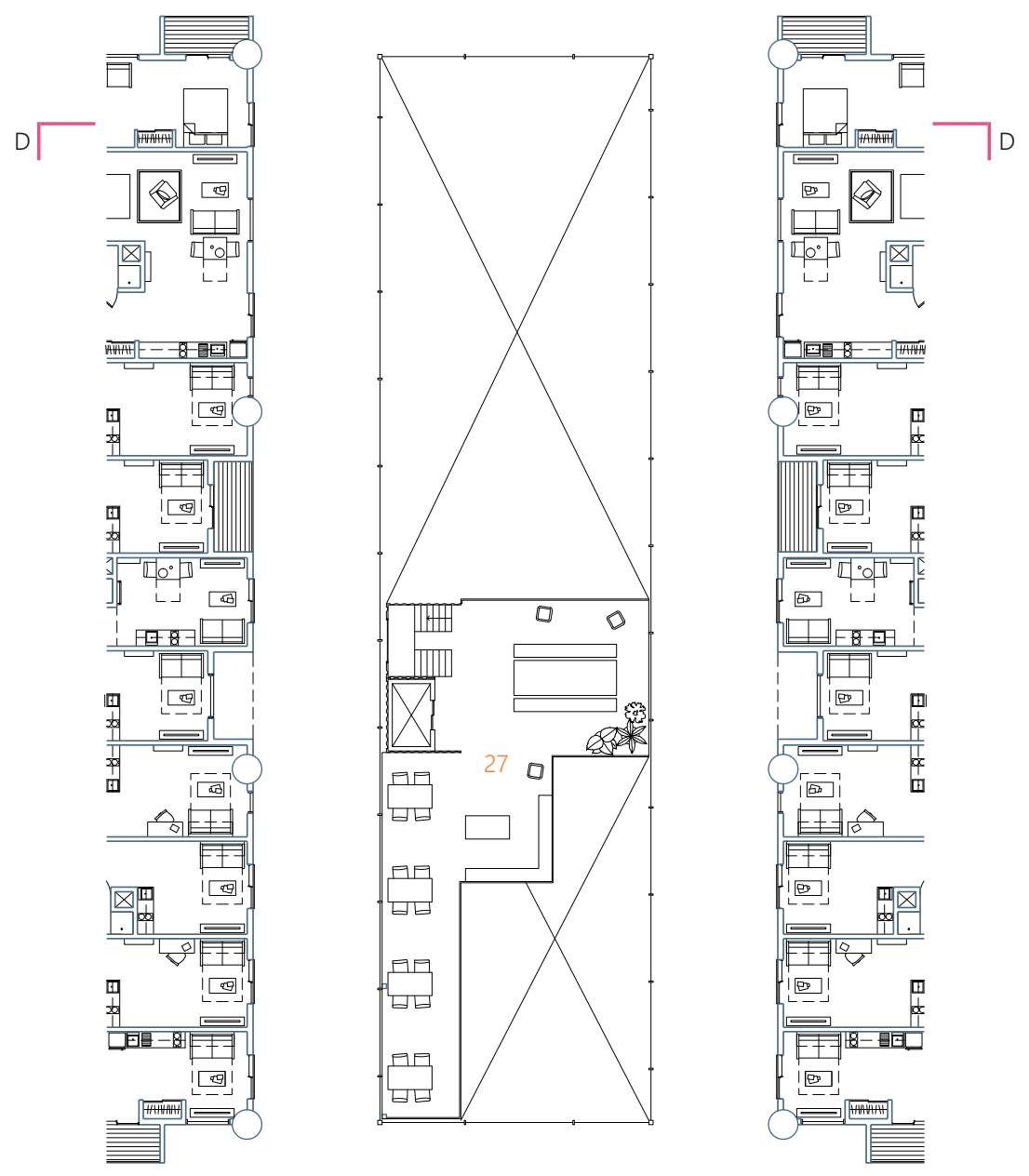

$$
\frac{1}{C}
$$
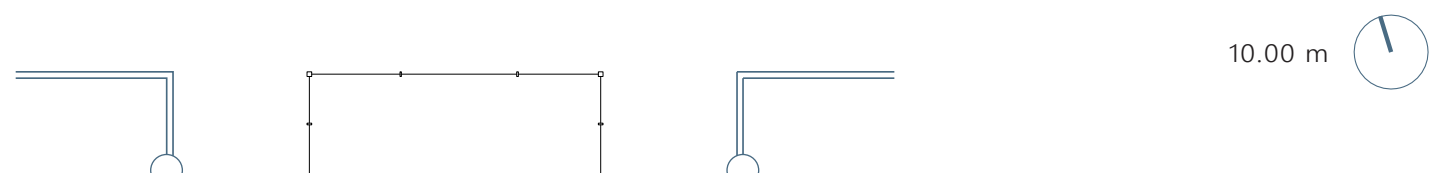

Fig.6.104 Retail Block 3-4: Proposed level 5 


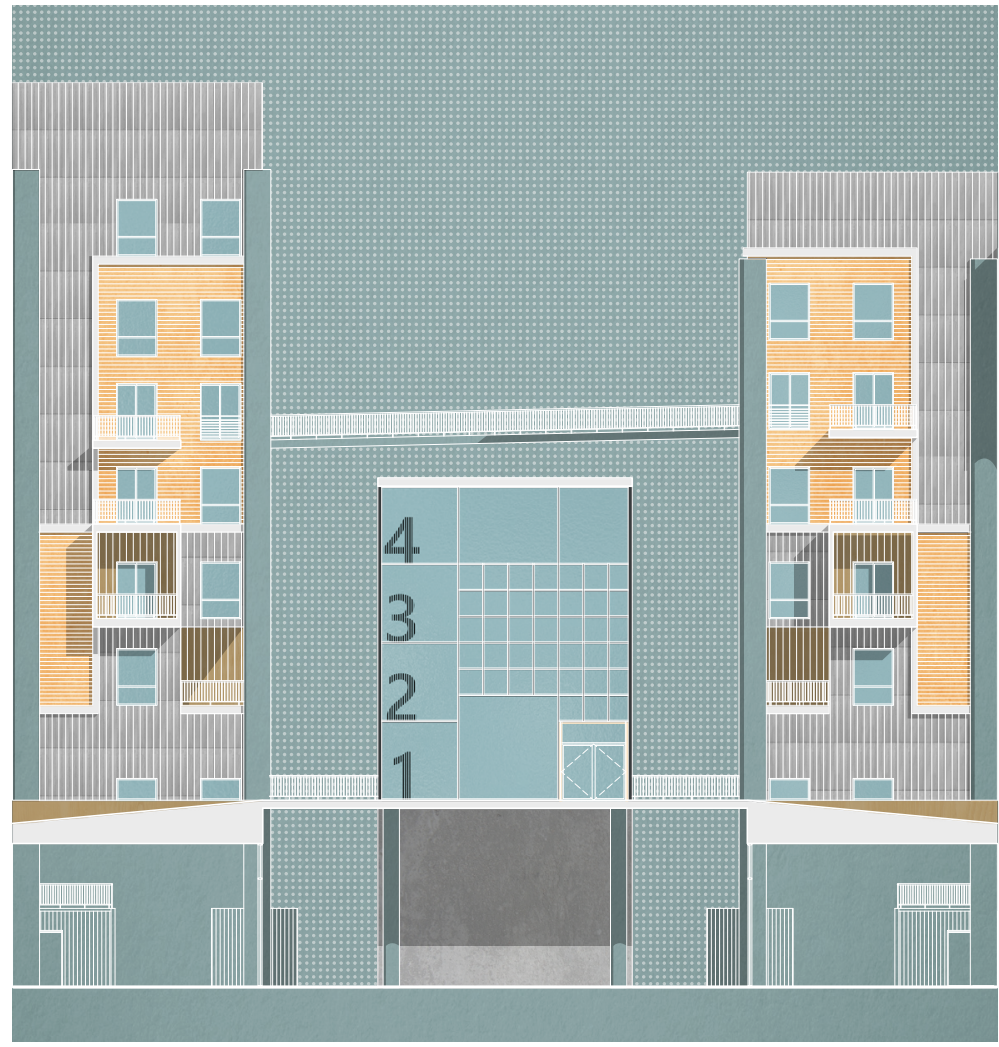

6.105

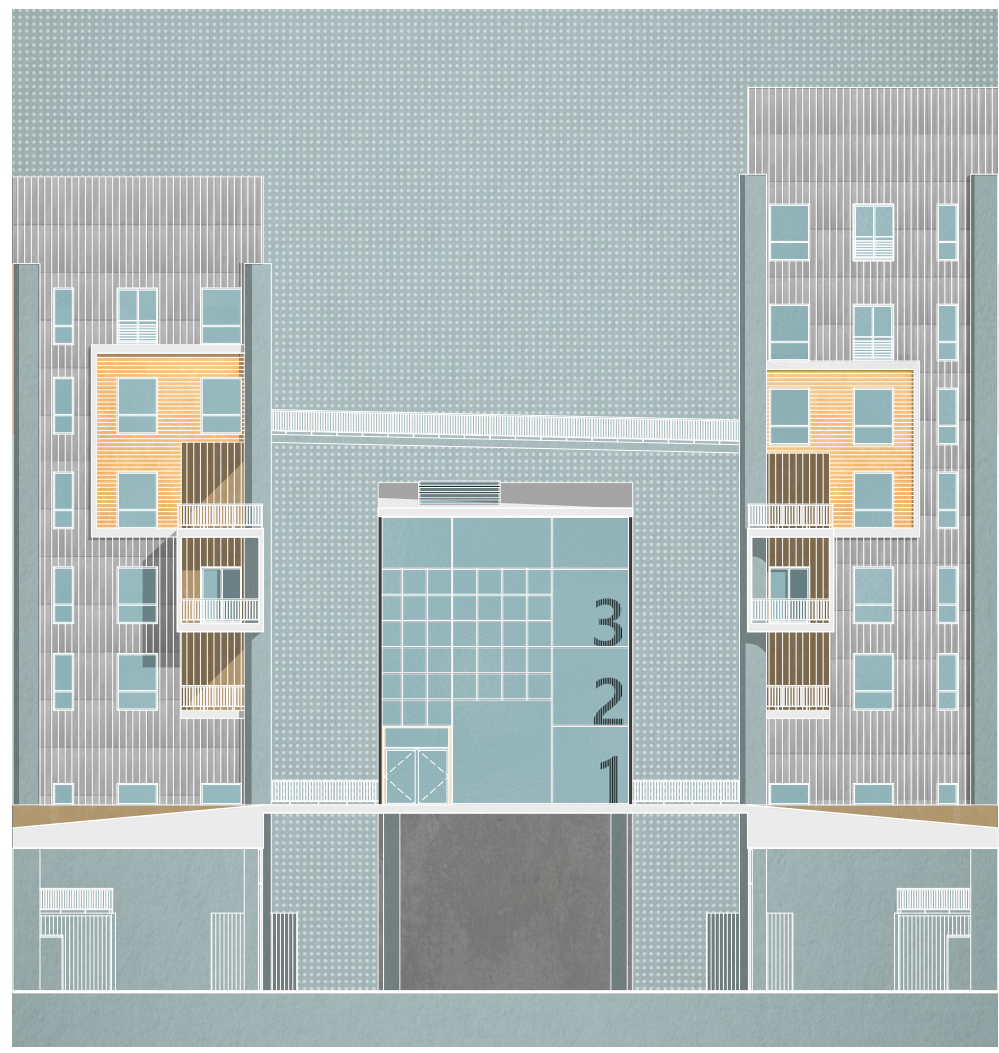

( 6.106

$N$

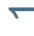

Fig.6.105 Retail Block 3-4: South elevation, Fig.6.106 Retail Block 3-4: North elevation 

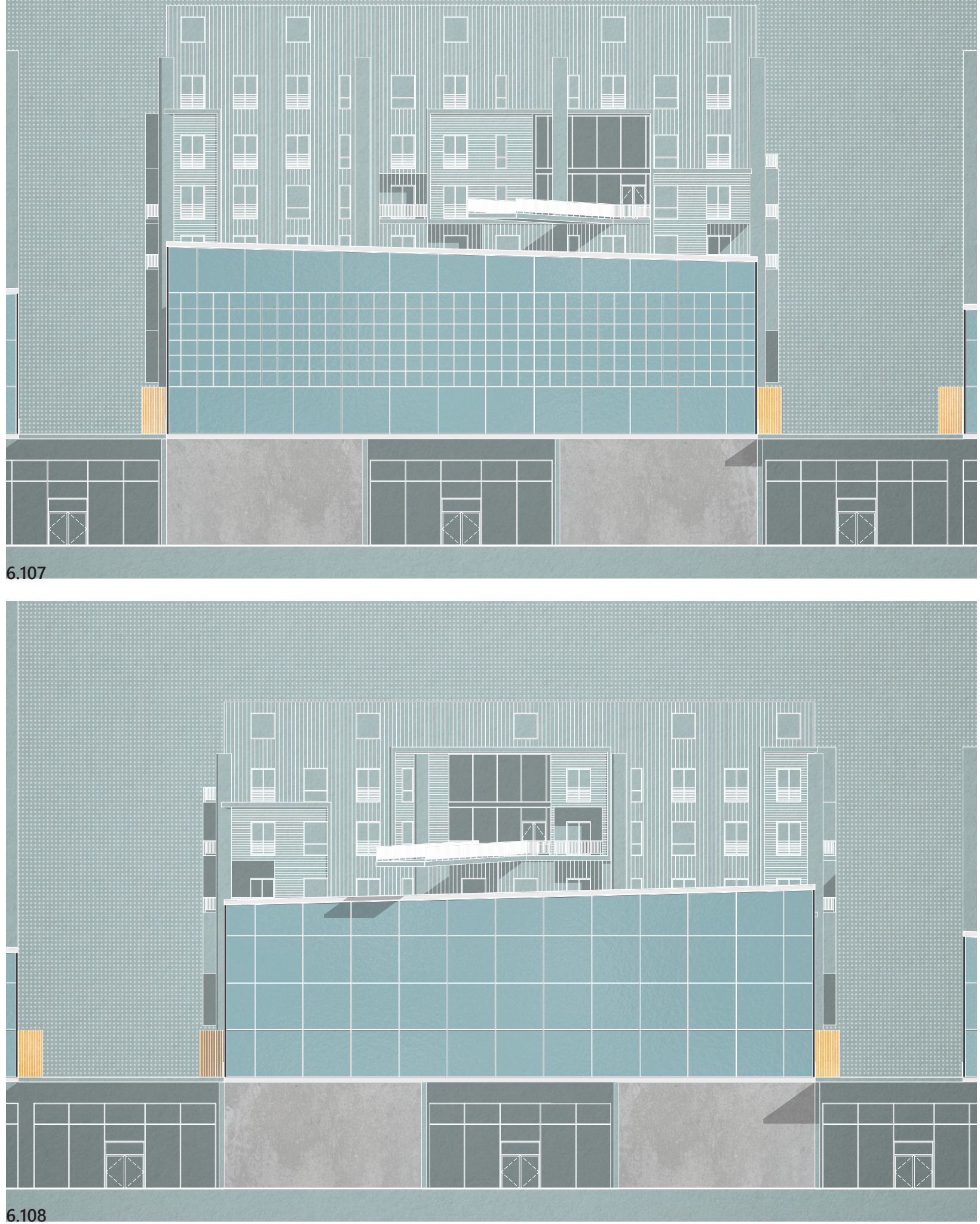

Fig.6.107 Retail Block 3-4: West elevation, Fig.6.108 Retail Block 3-4: East elevation 


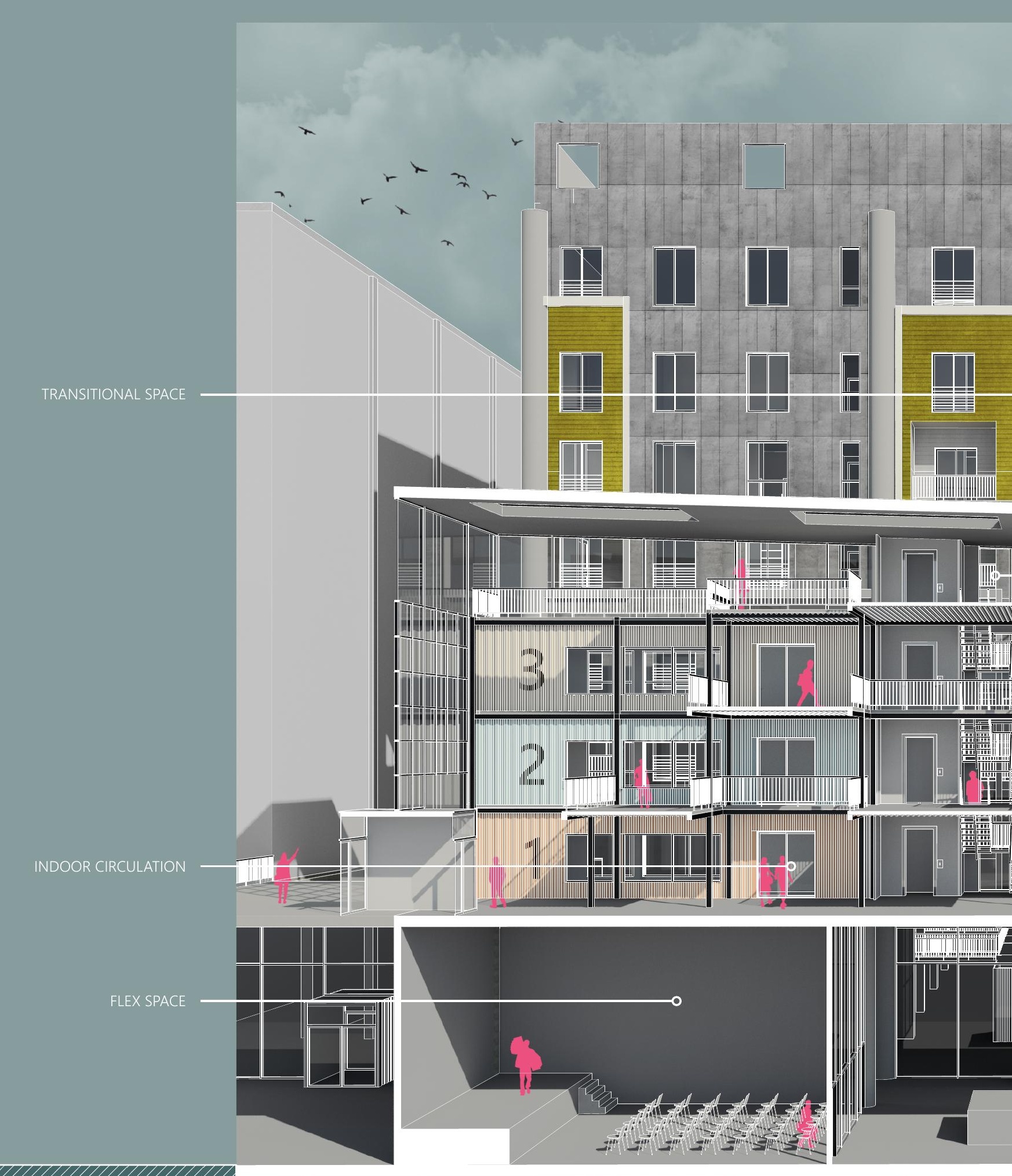



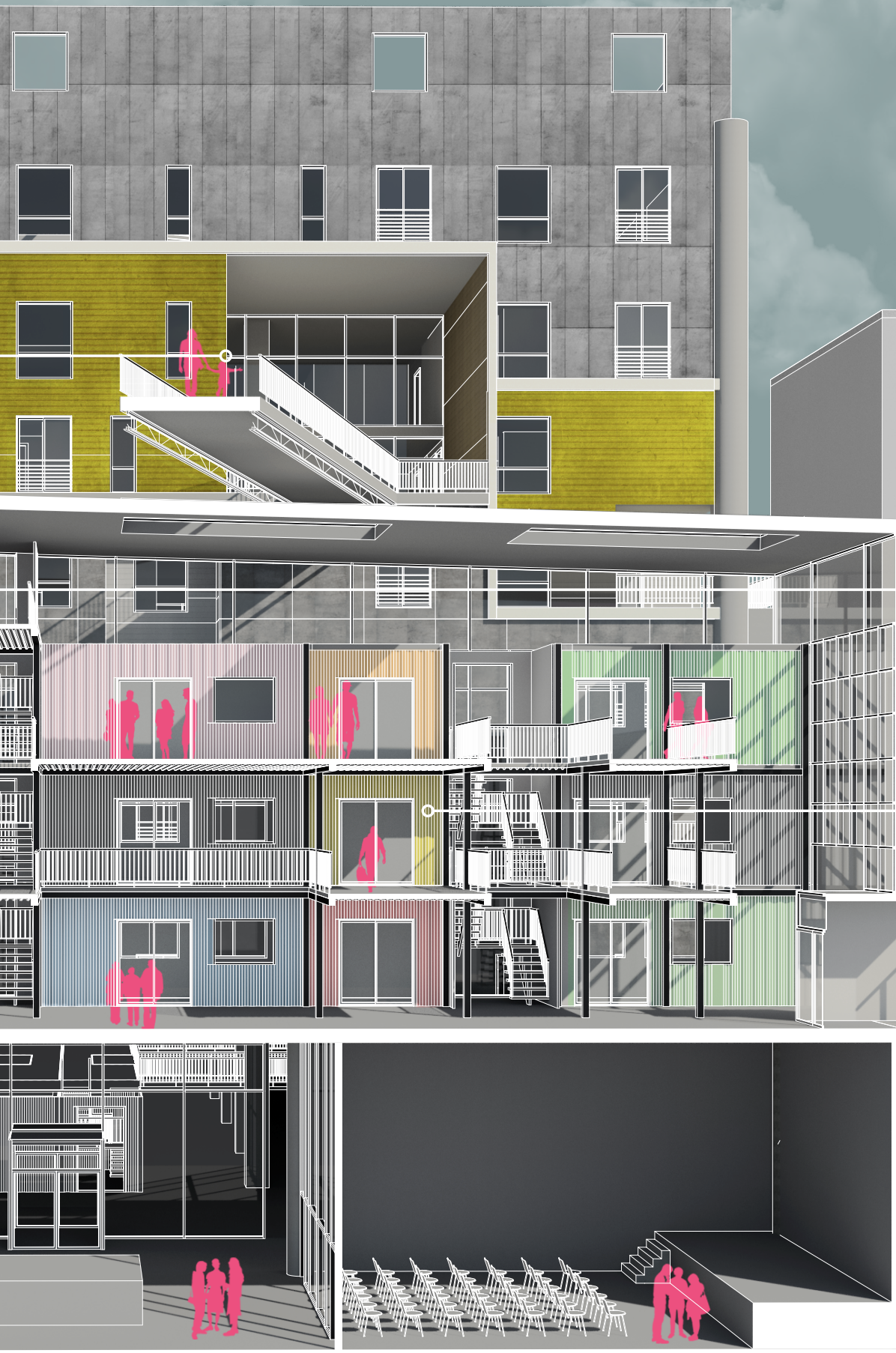

CIRCULATION CORE

SOCIAL SPACE
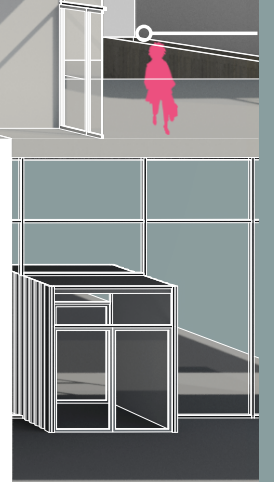


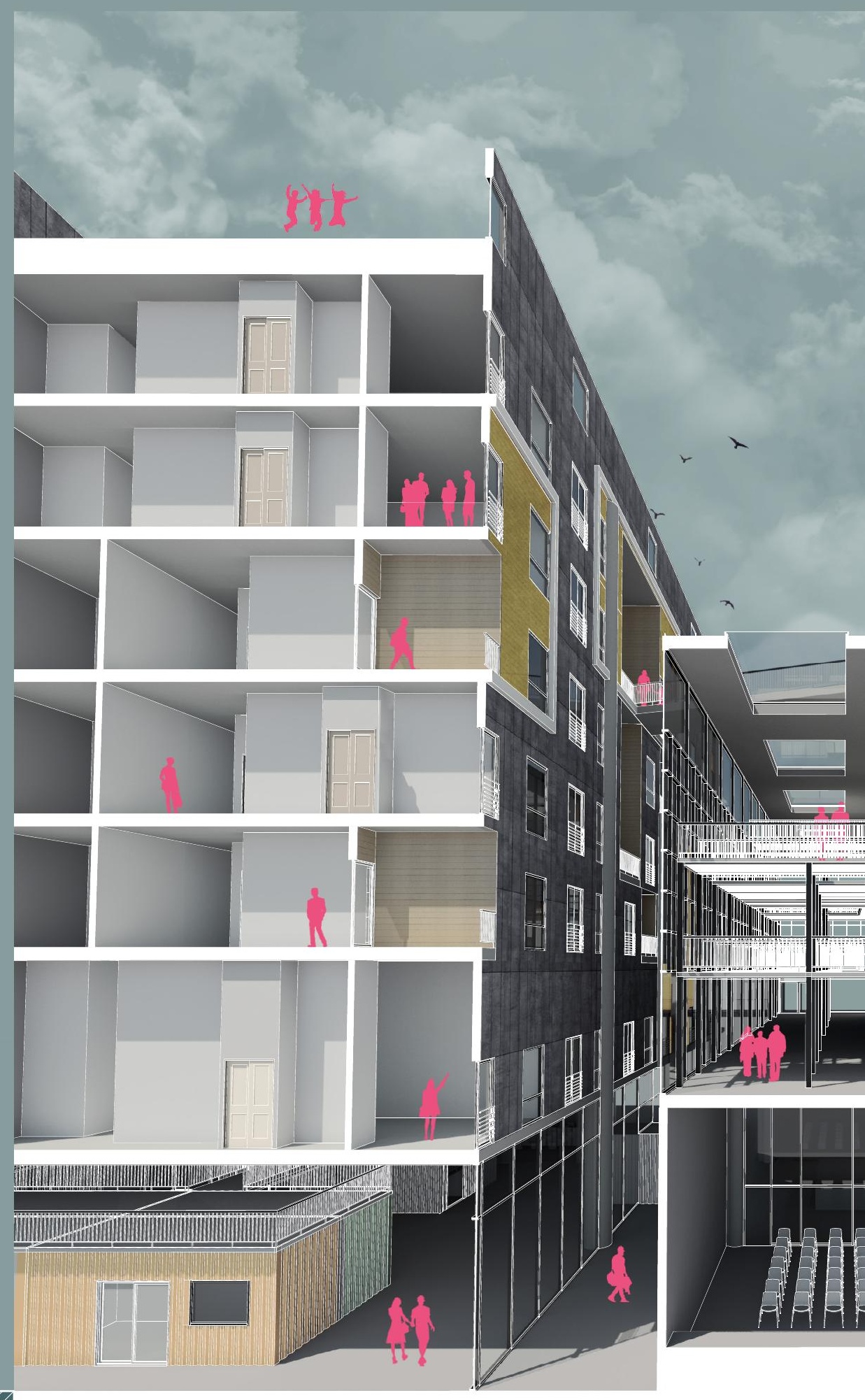

a

N

Fig.6.110 Retail Block 3-4 Section D-D 


\section{TRANSITIONAL SPACE}

PATH RETAIL

OUTDOOR CIRCULATION 


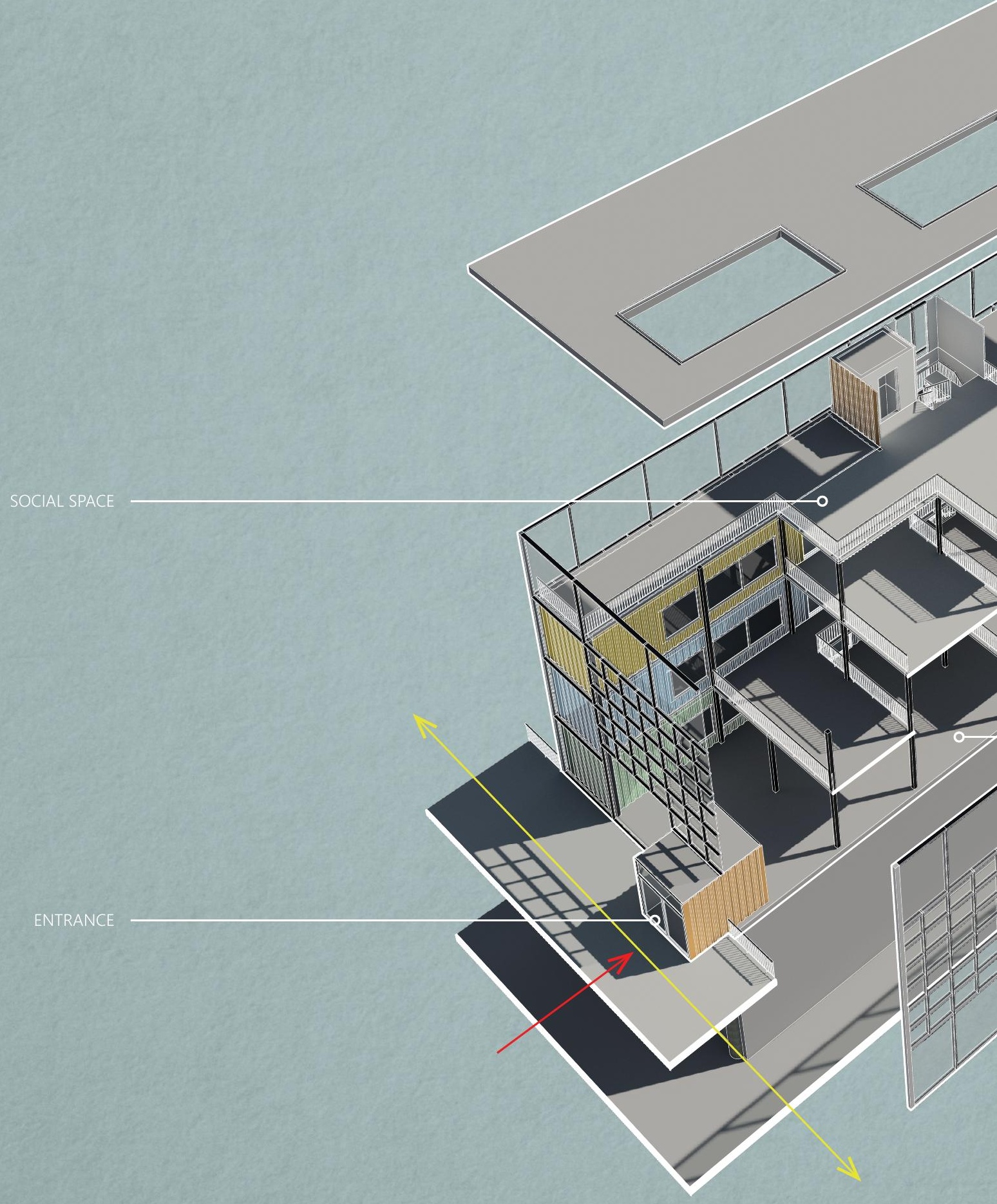




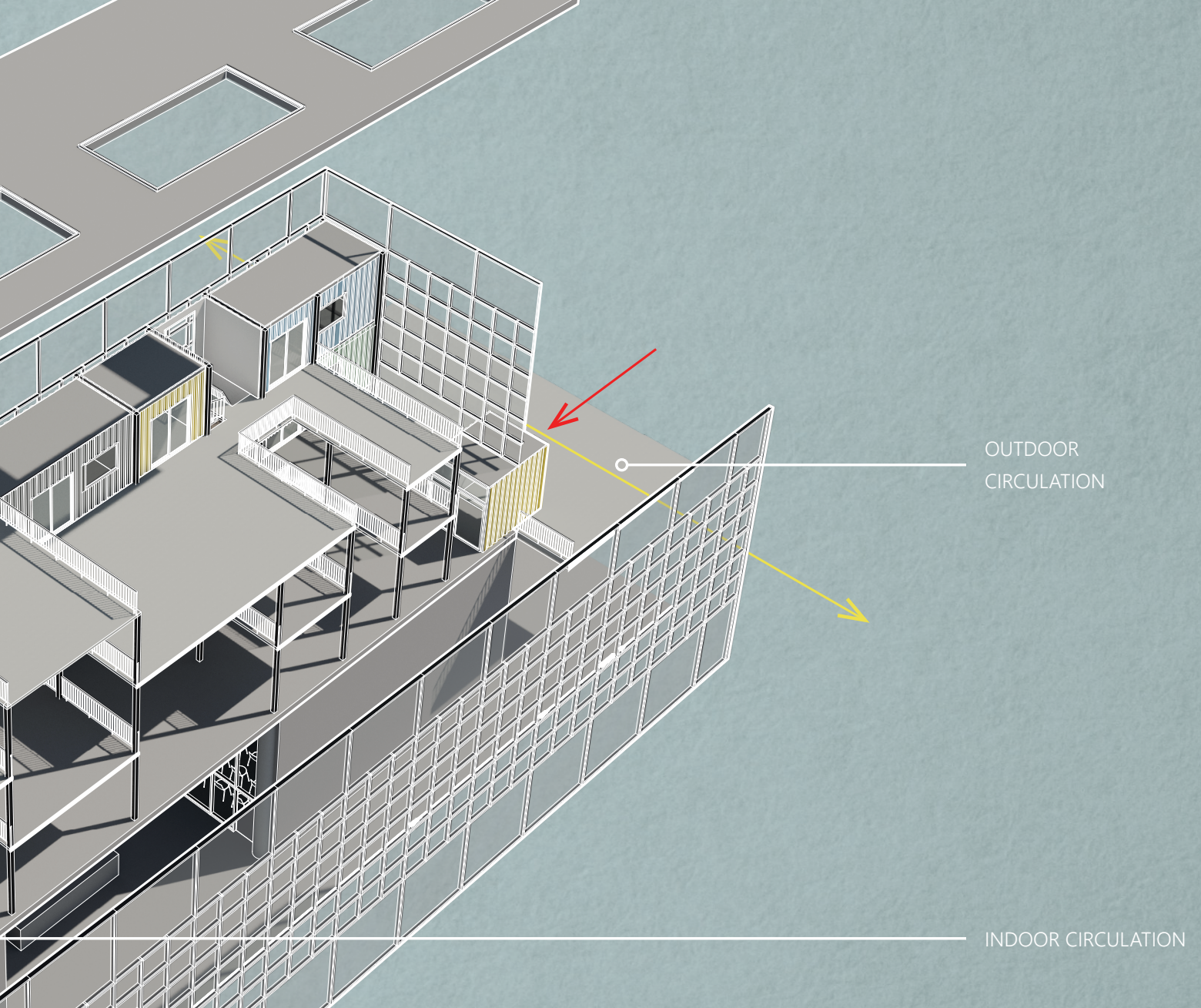




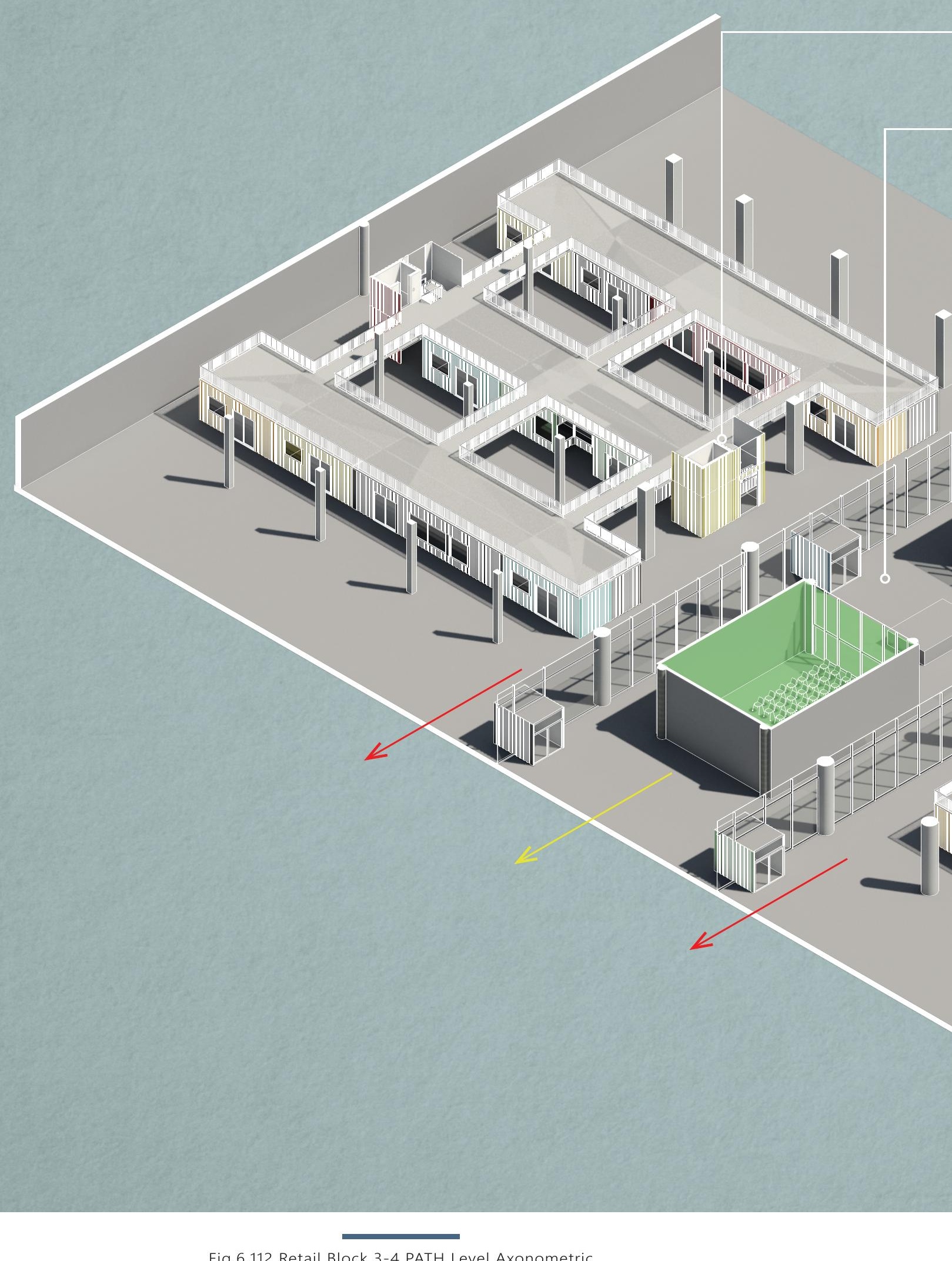

Fig.6.112 Retail Block 3-4 PATH Level Axonometric 


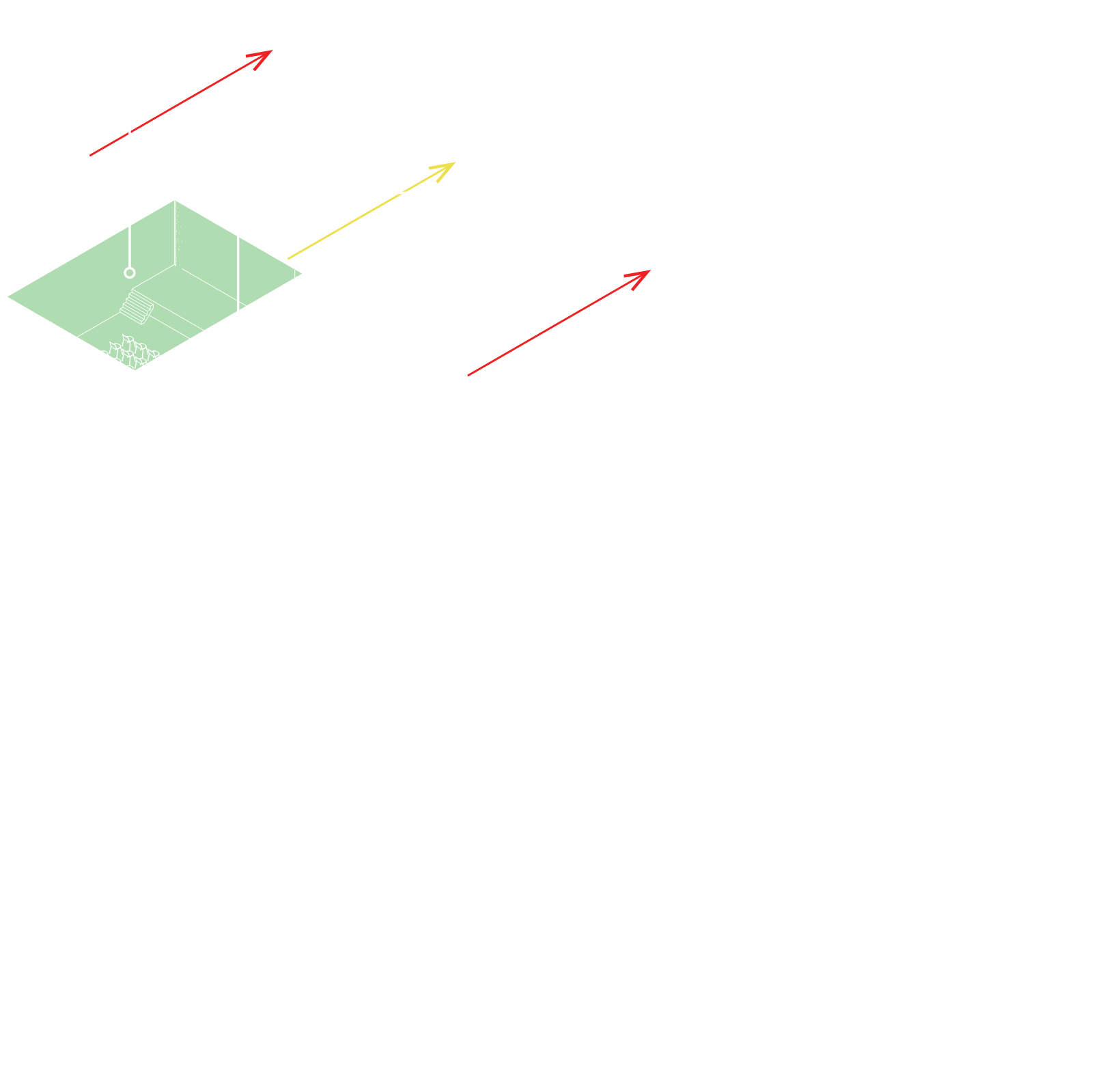




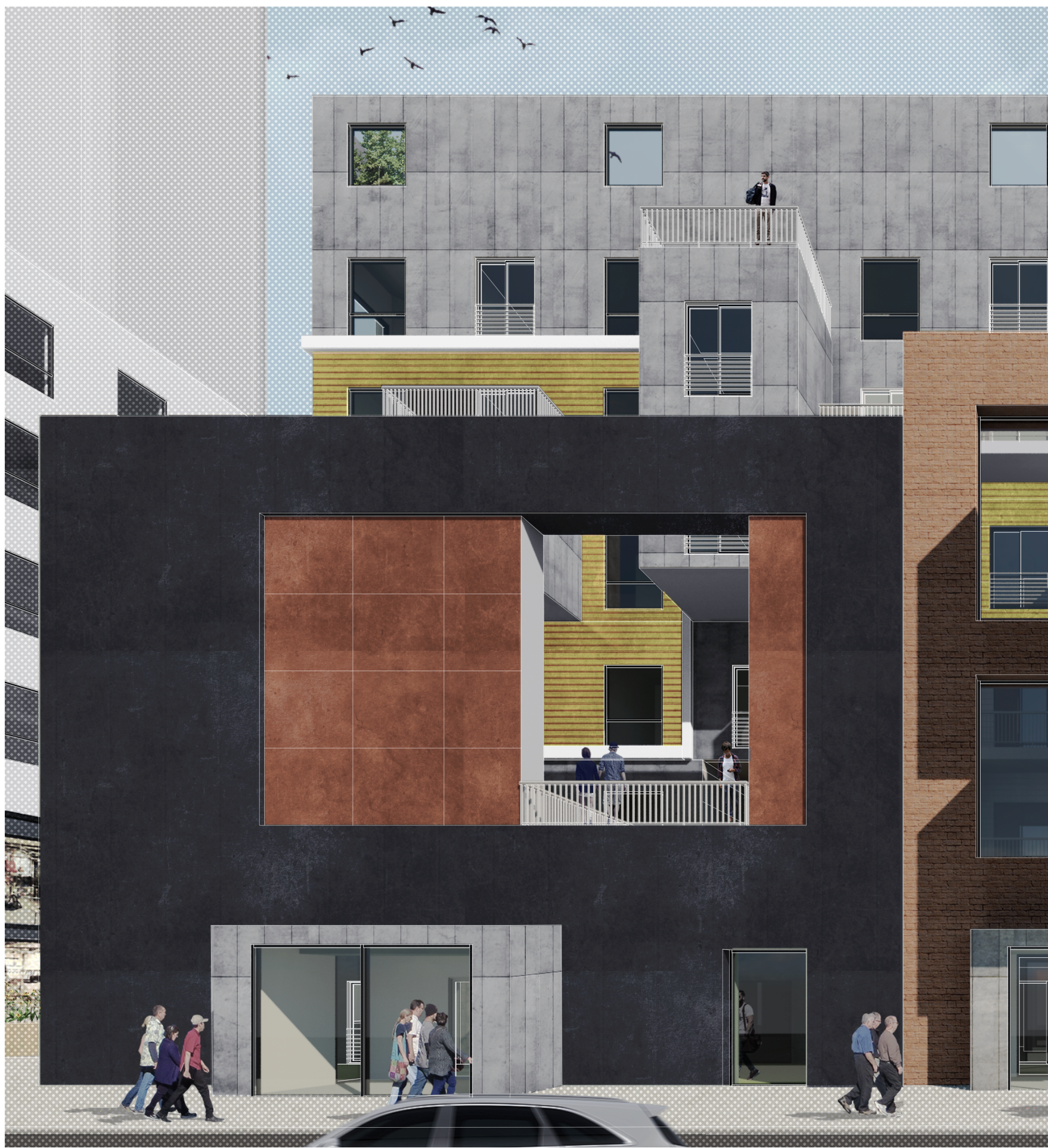




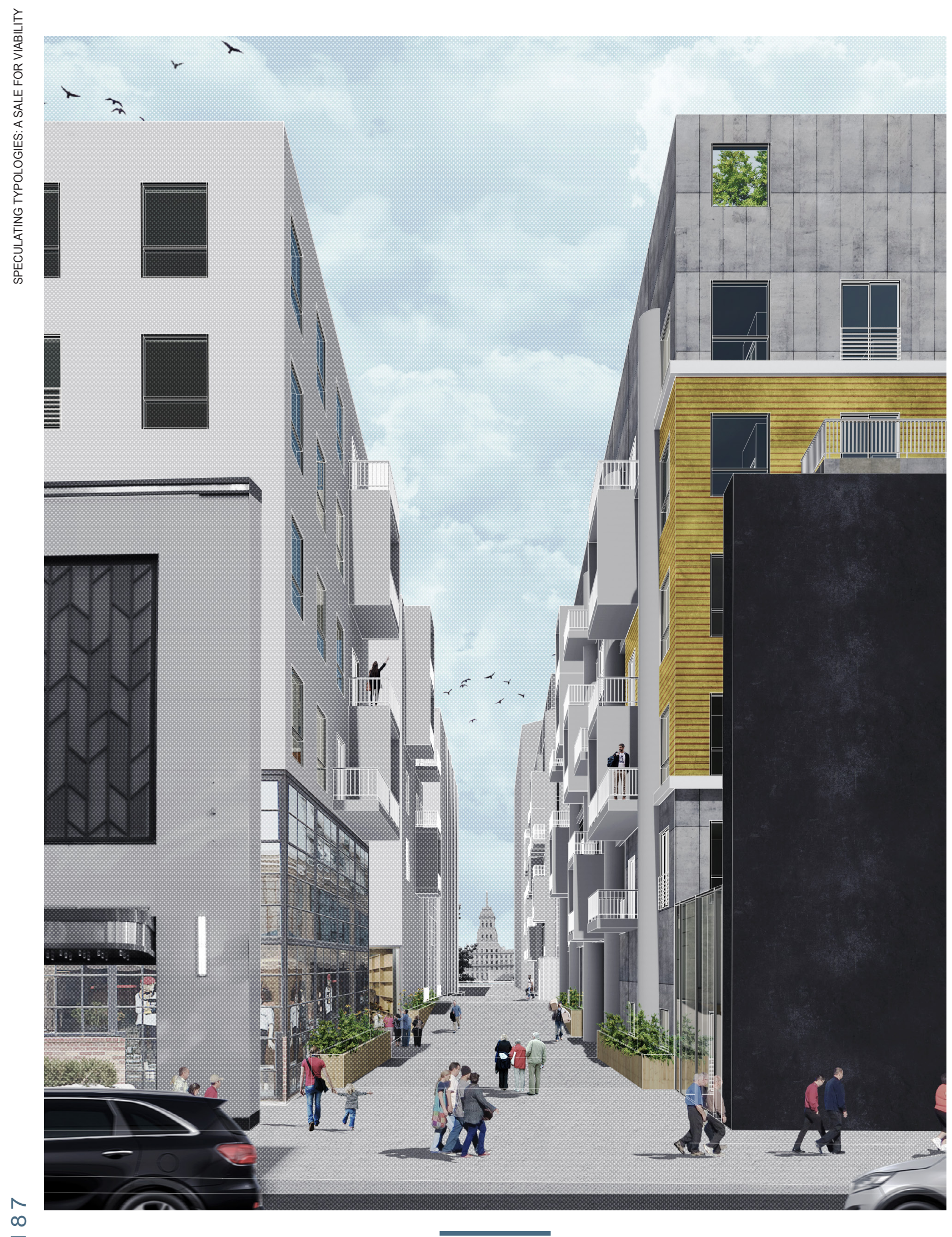

Fig.6.114 Block 4 South Entry 


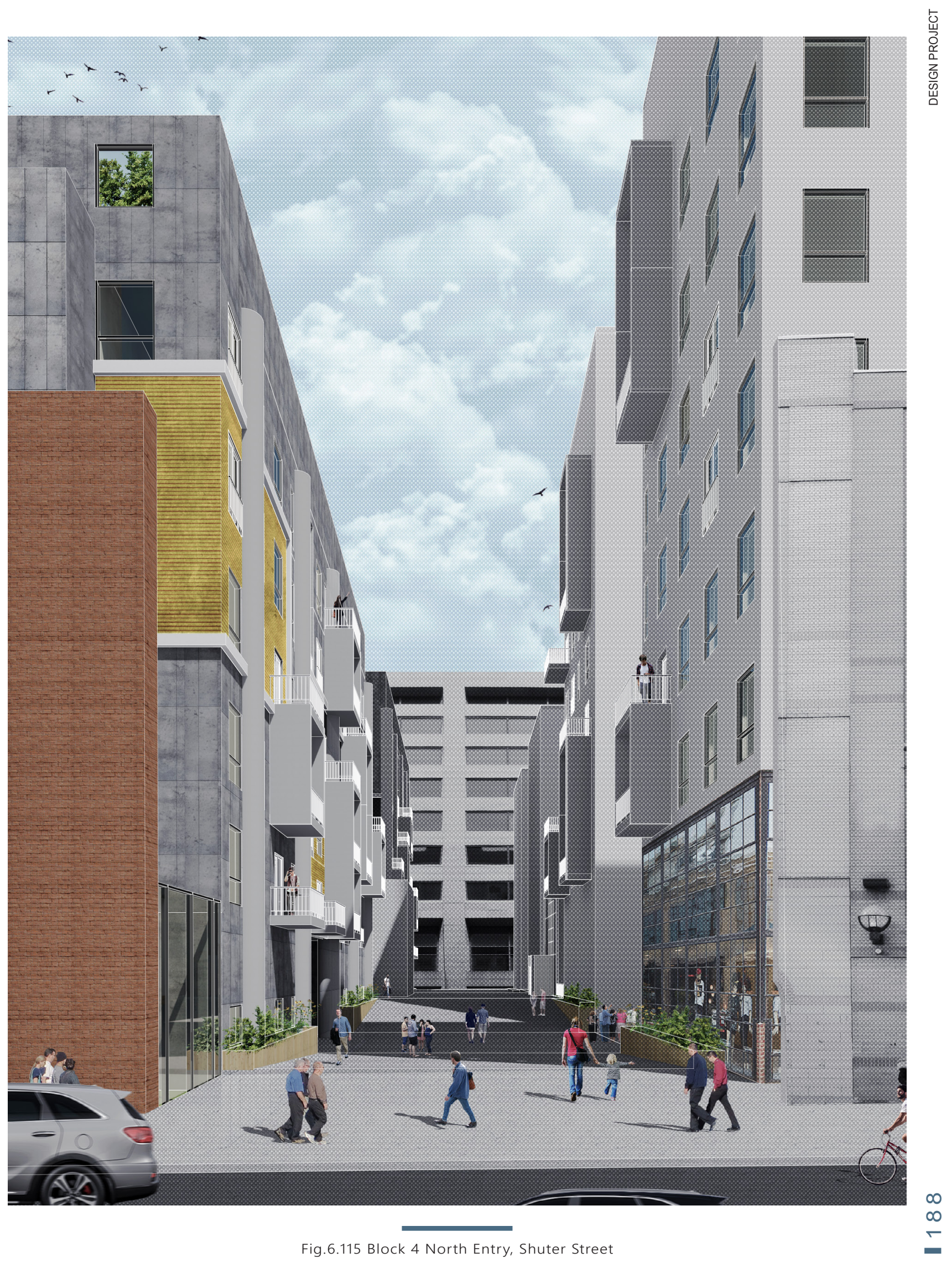




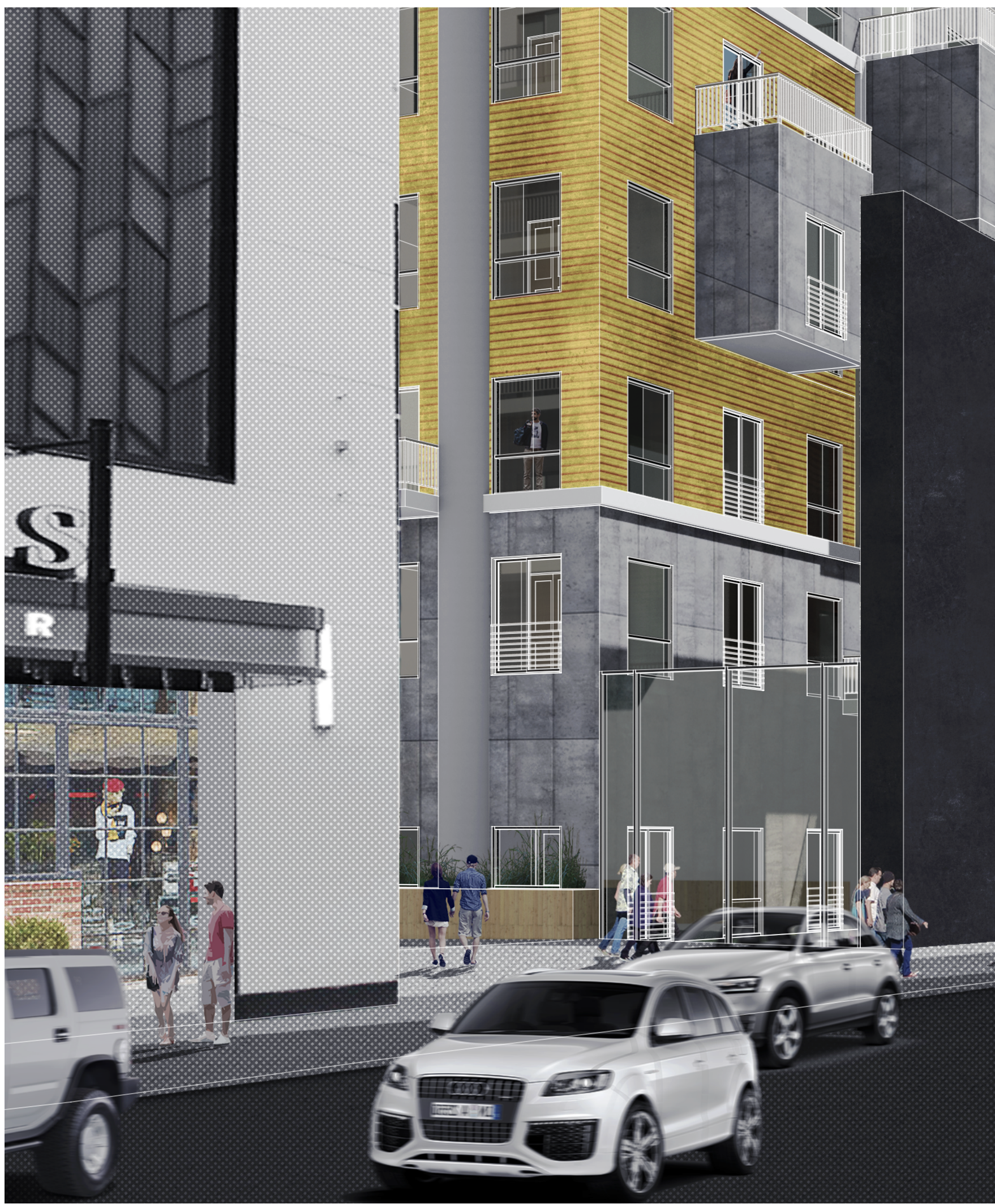




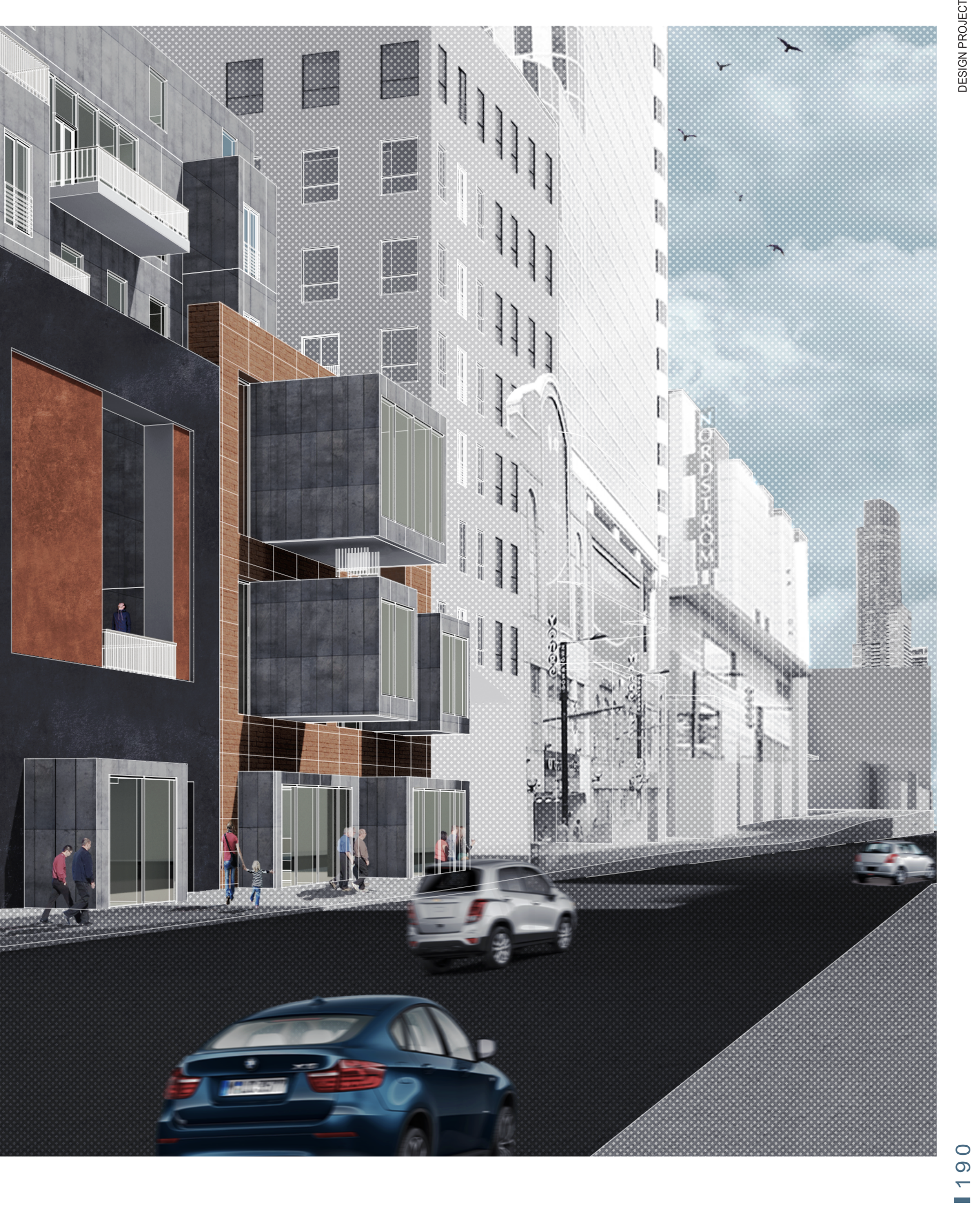




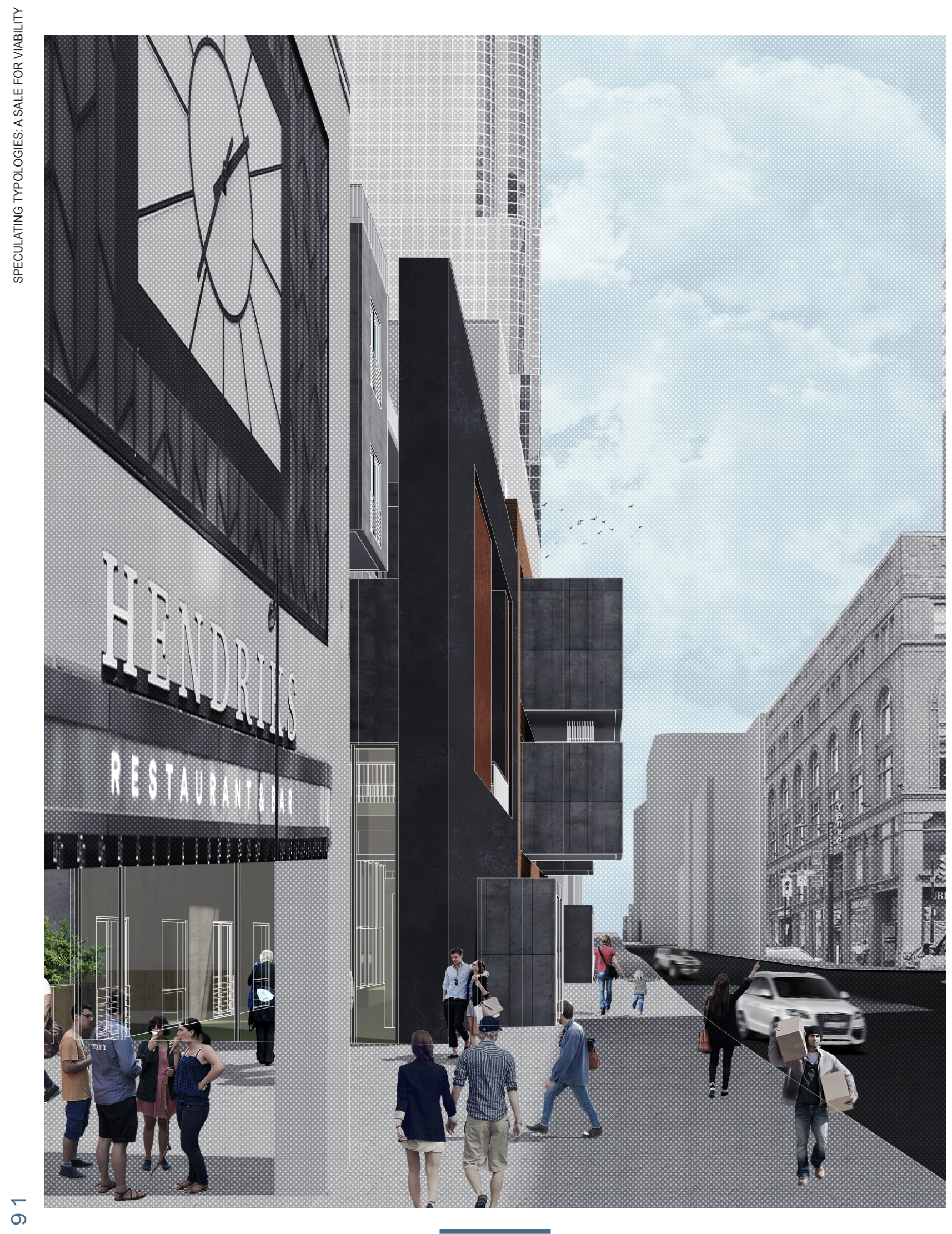

$\stackrel{2}{2}$

Fig.6.117 Approach to Block 4 Micro apartment neighbourhood on Yonge Street 


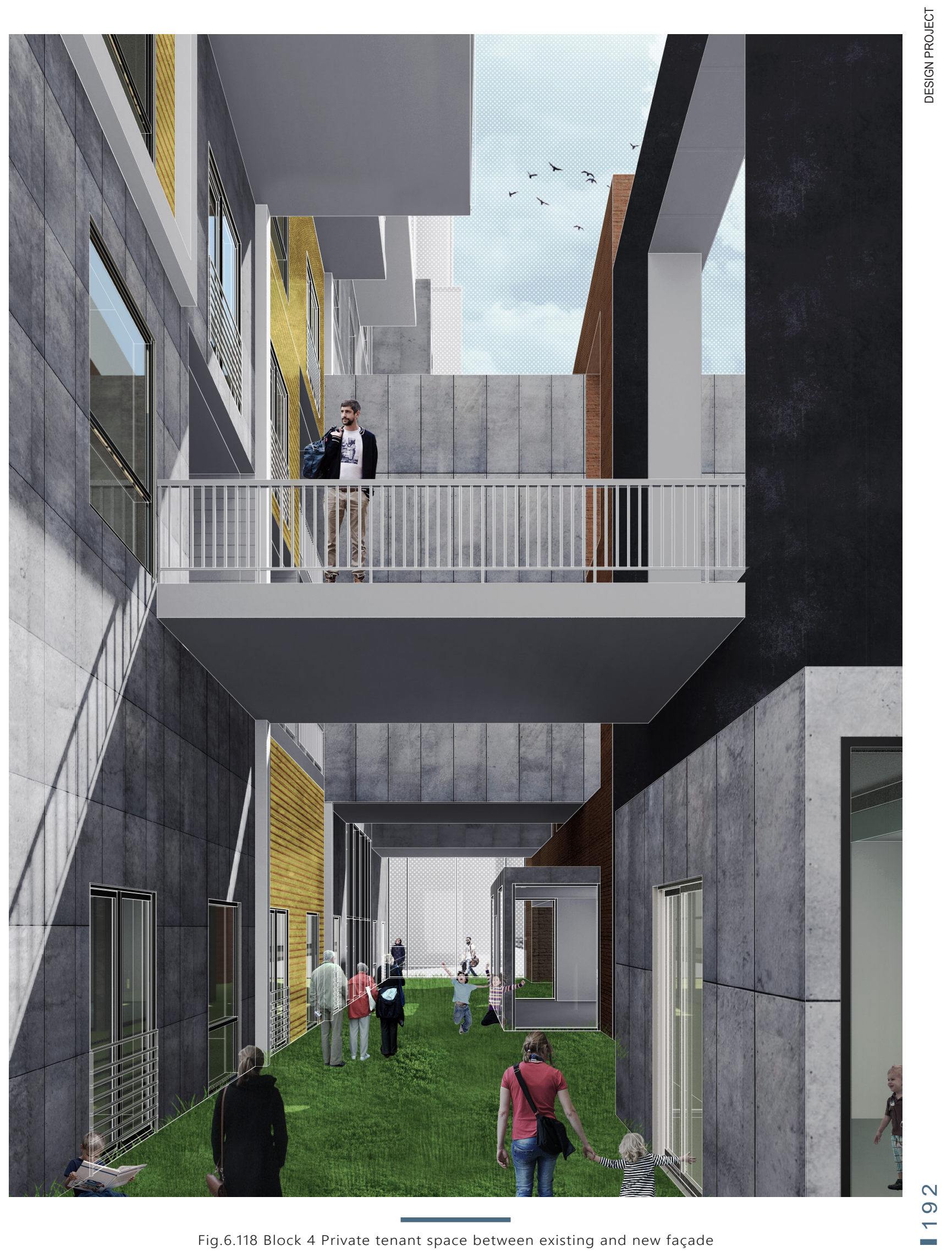




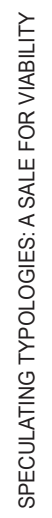

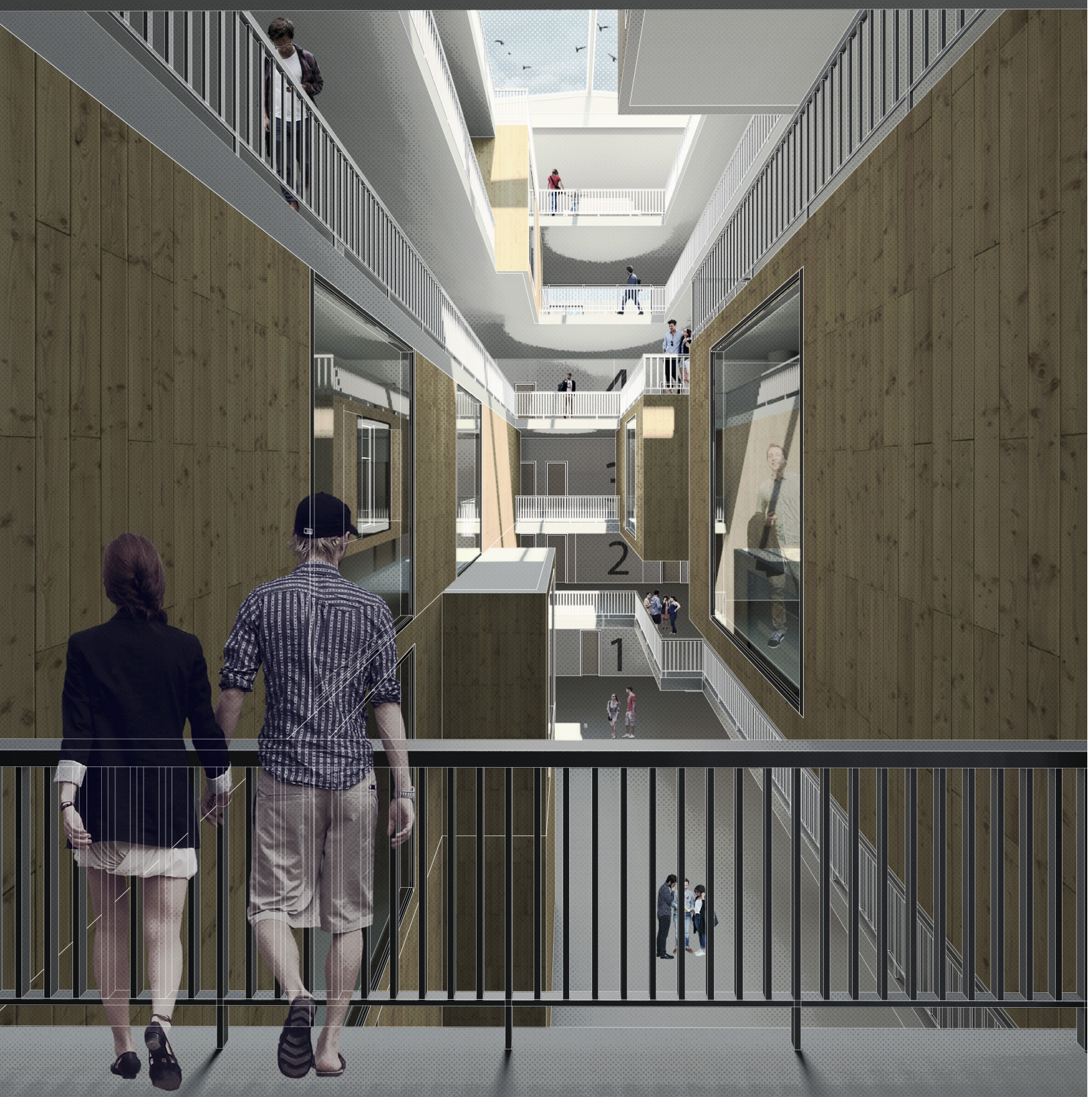



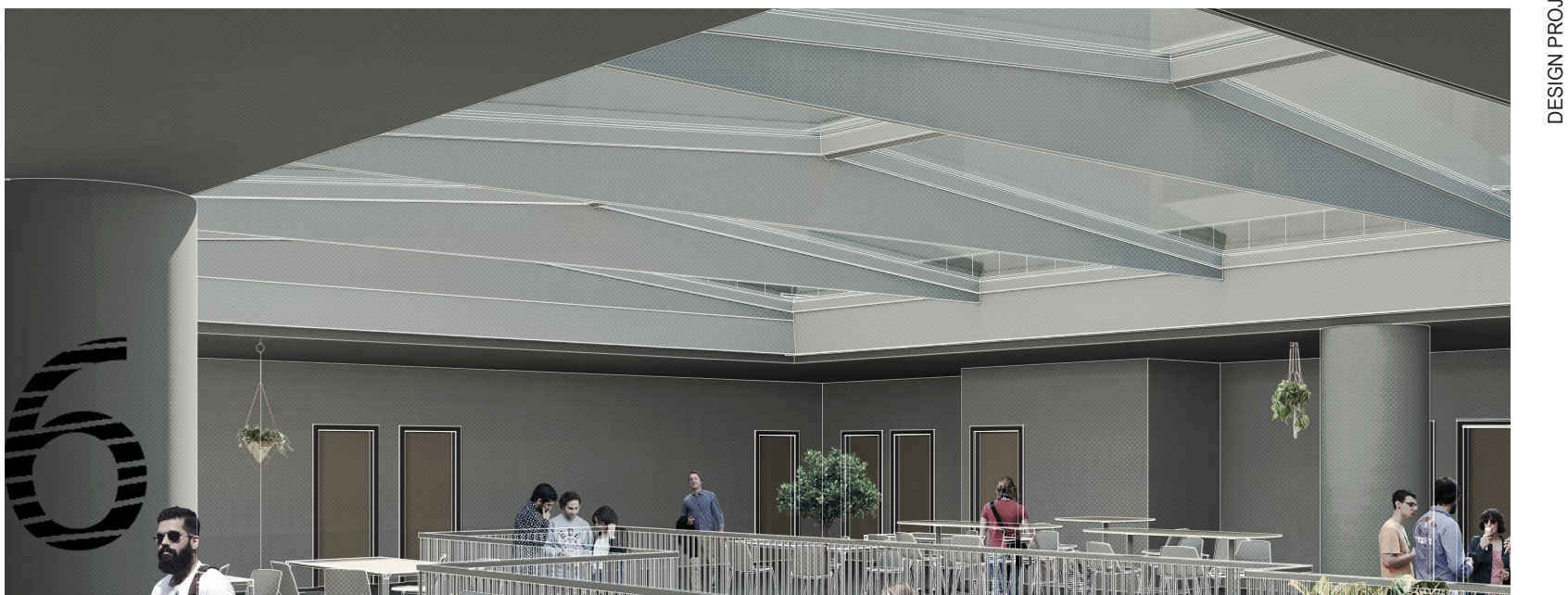
dit
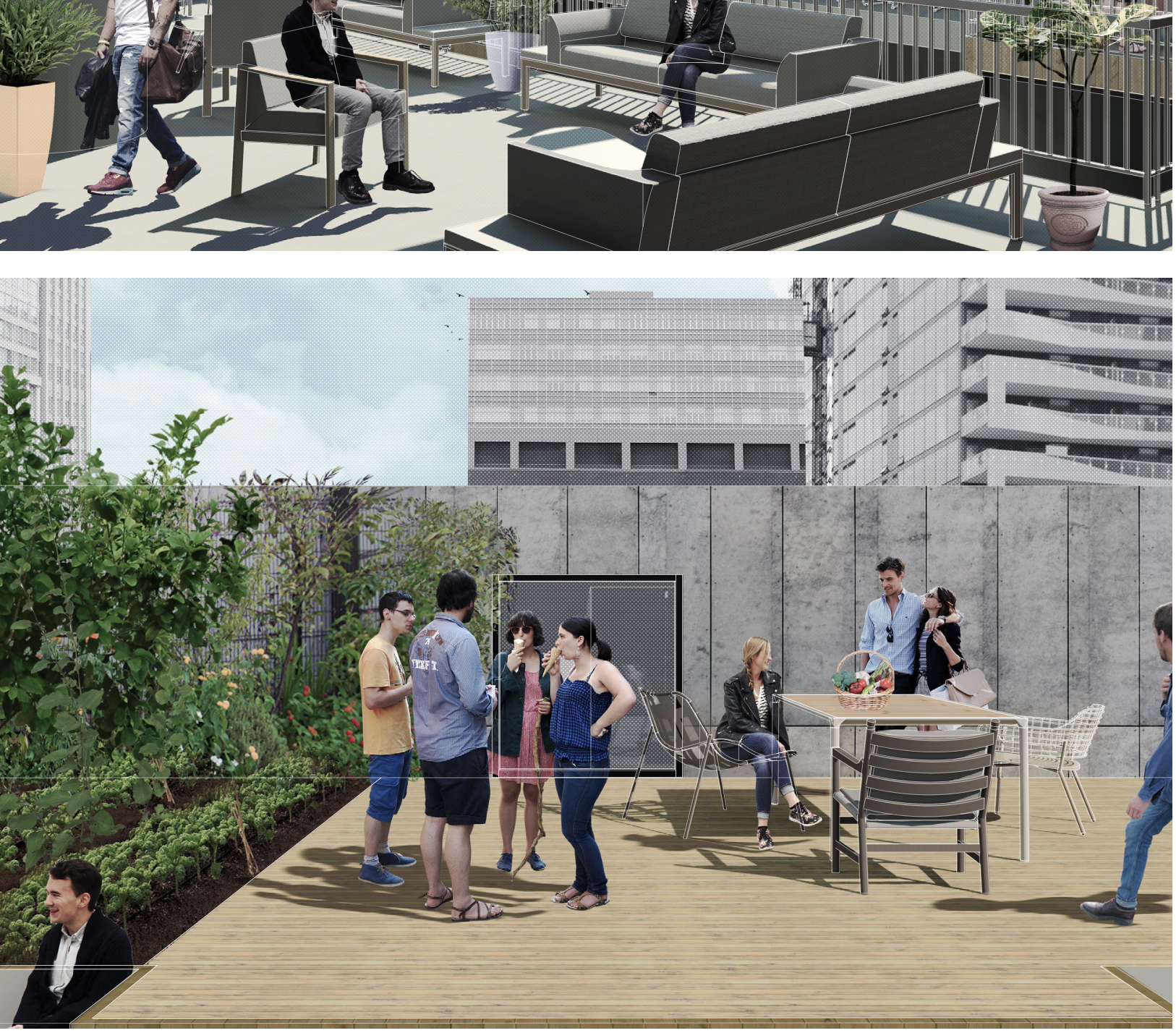


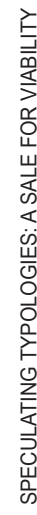

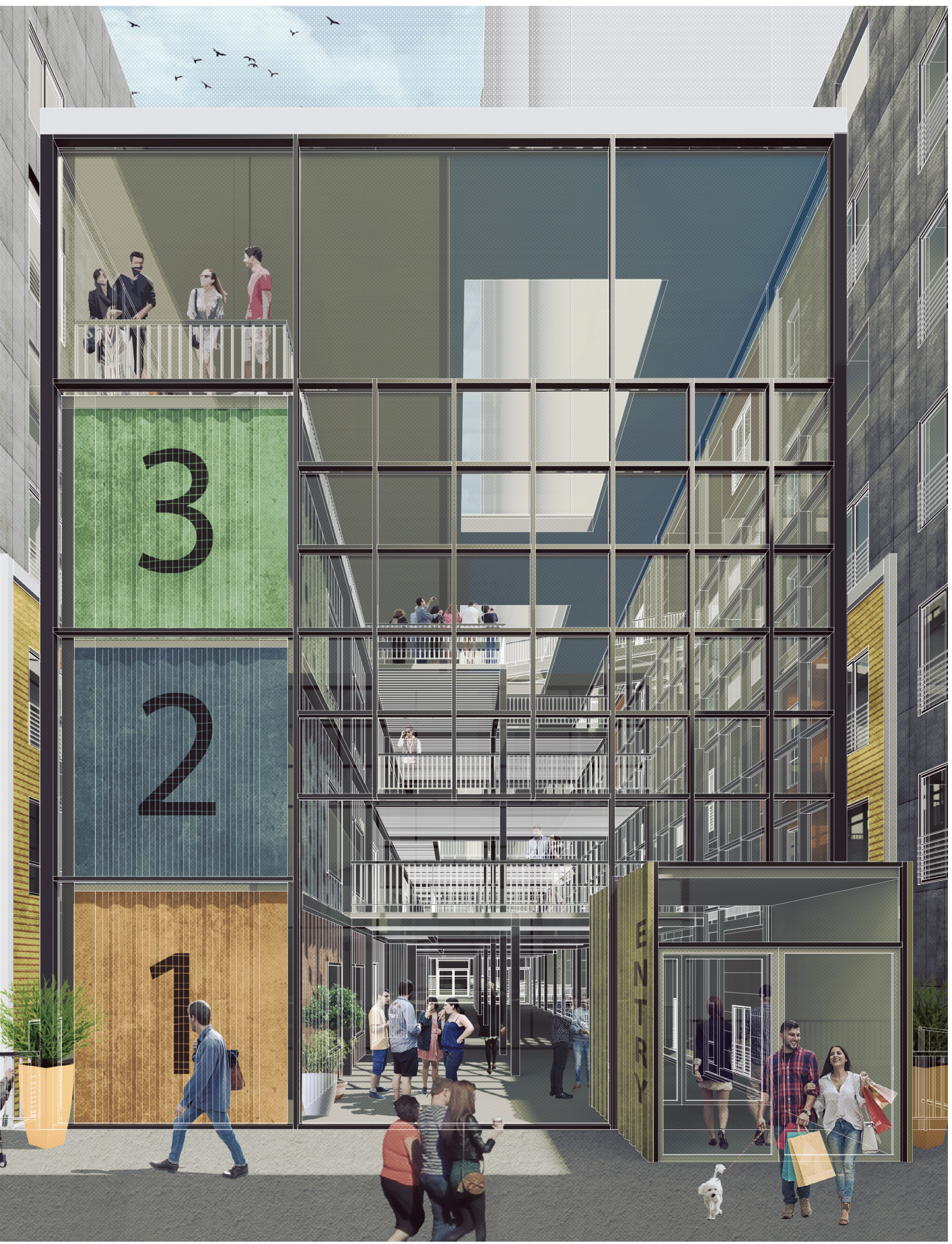

20

-

Fig.6.121 Block 3-4 Retail South Entrance 

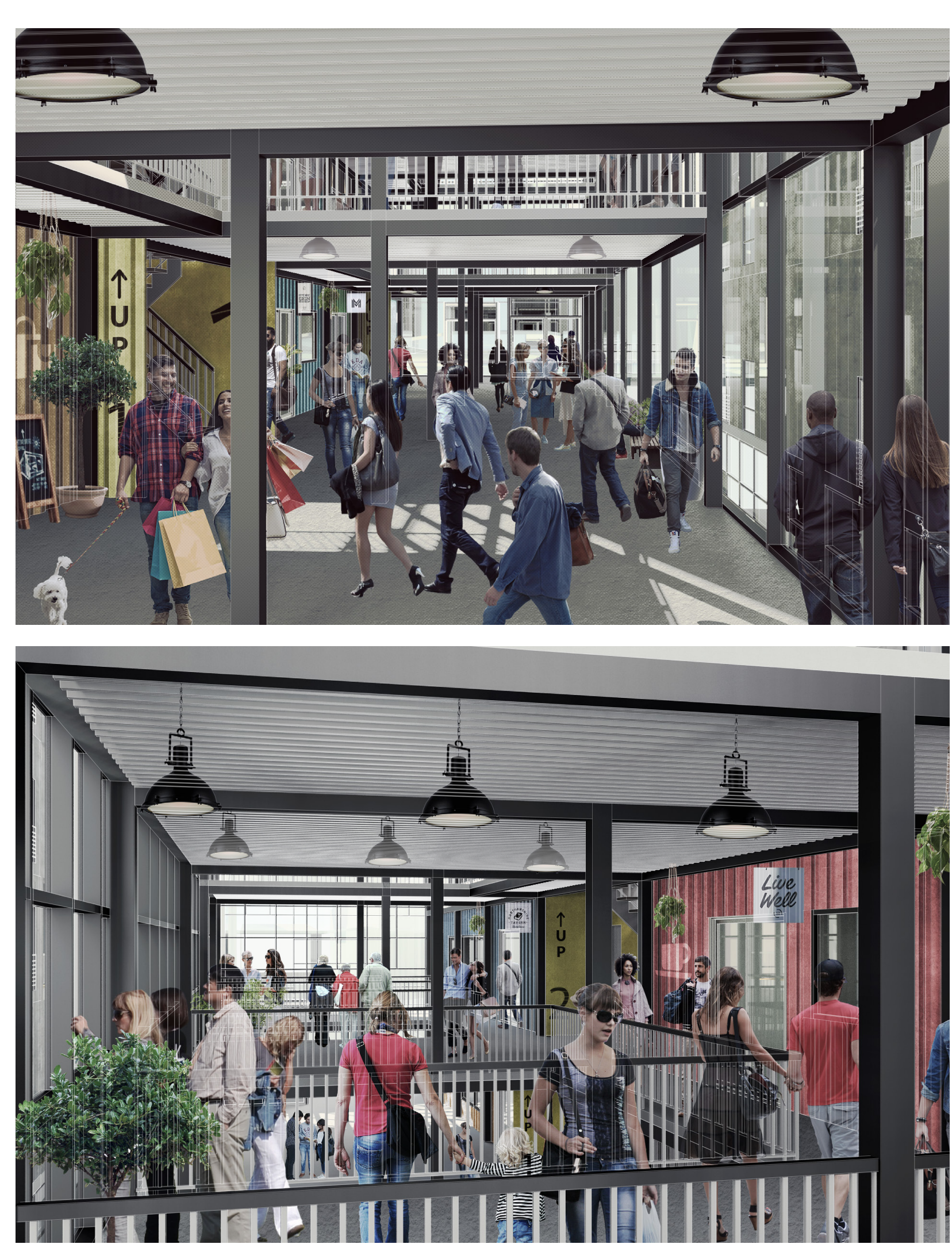

Fig.6.122 Block 3-4 Retail Level 2 View, Fig.6.123 Block3-4 Retail Level 3 View 


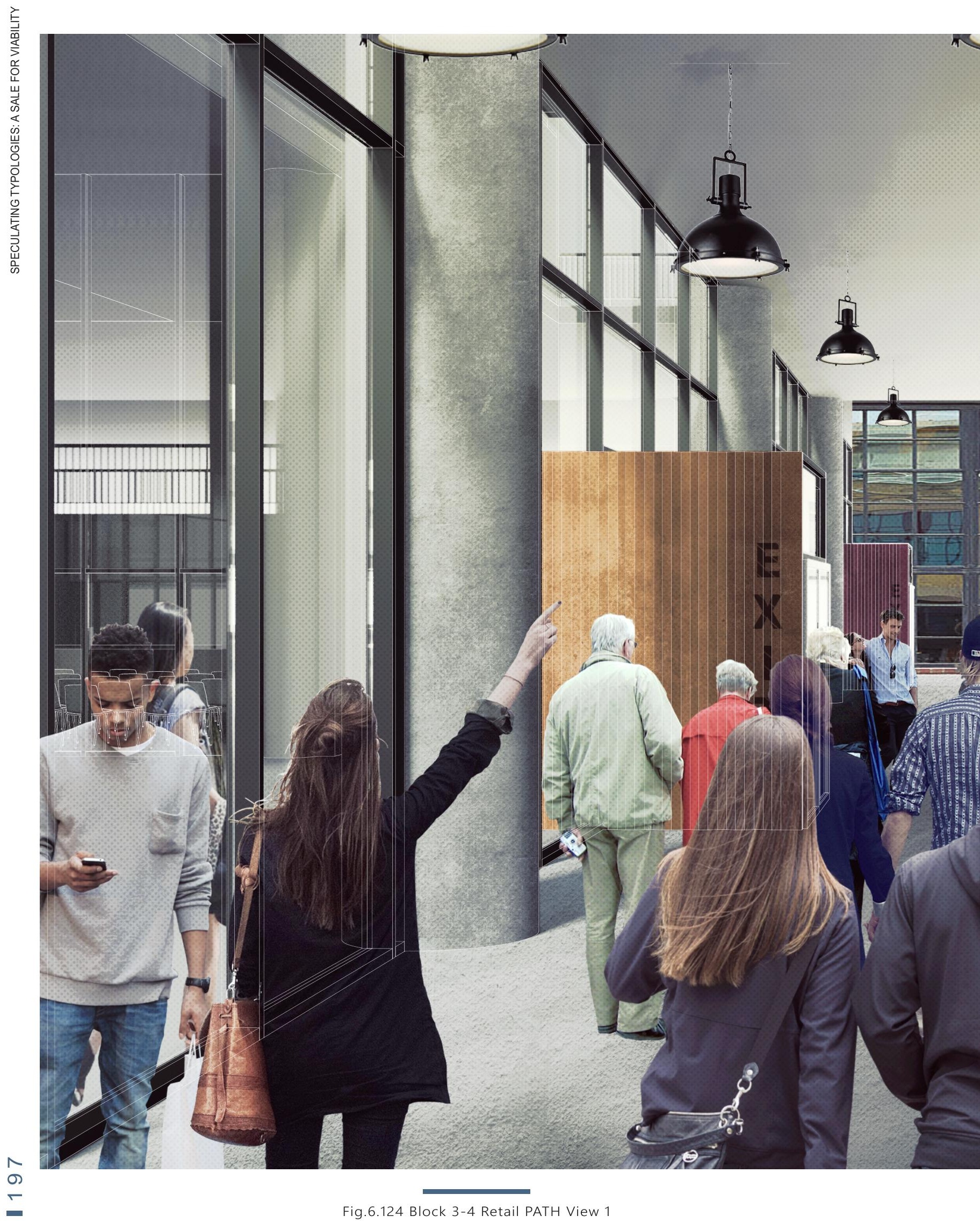




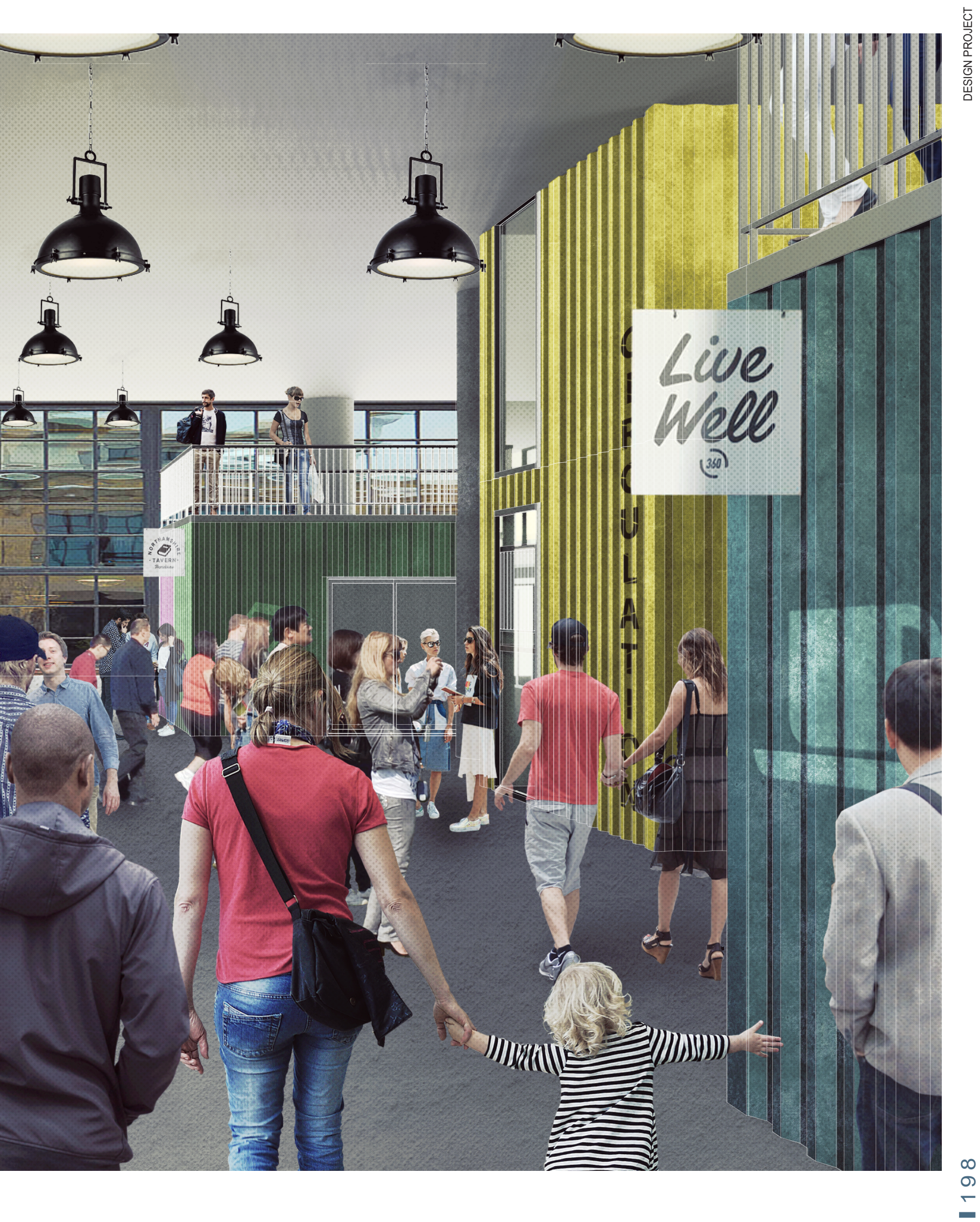



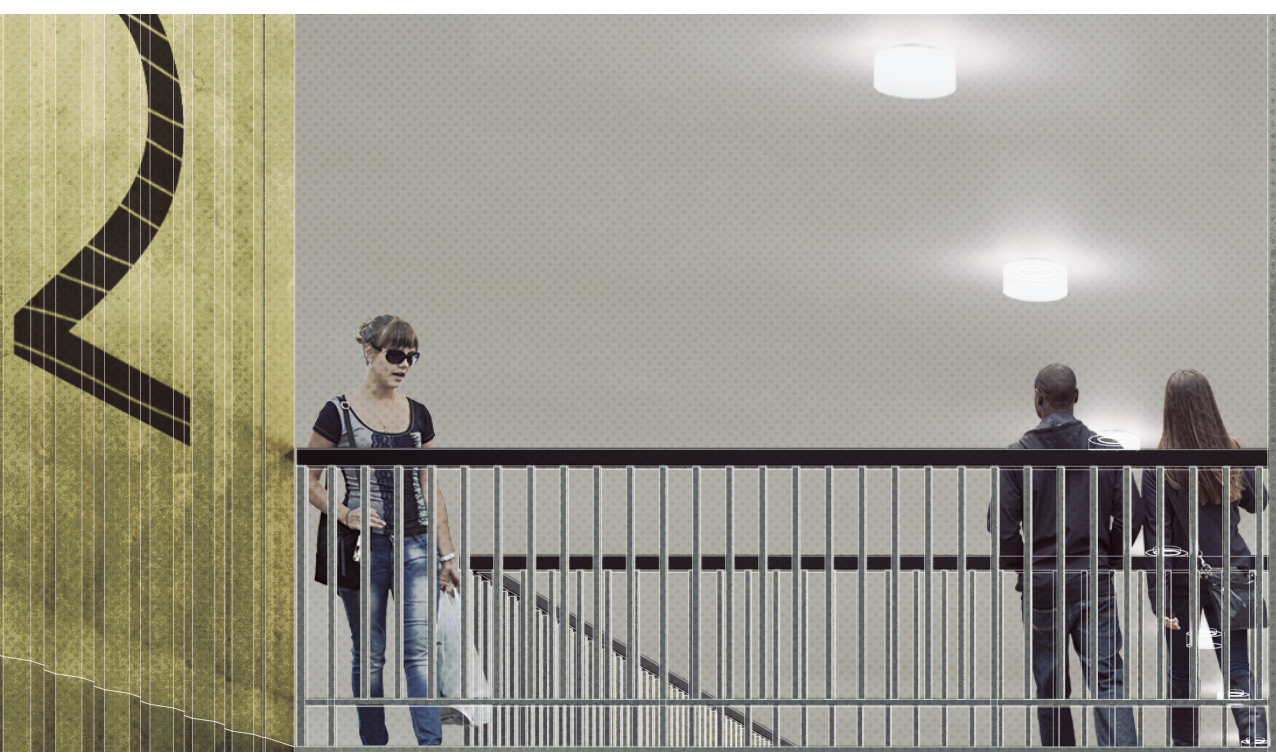

C

L.

A

T

I

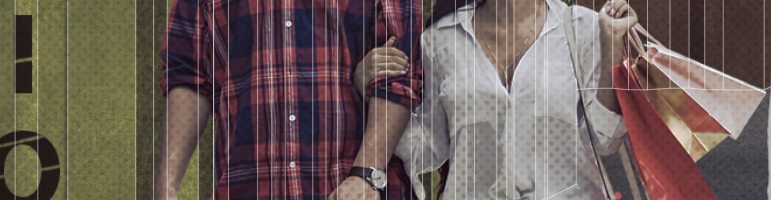

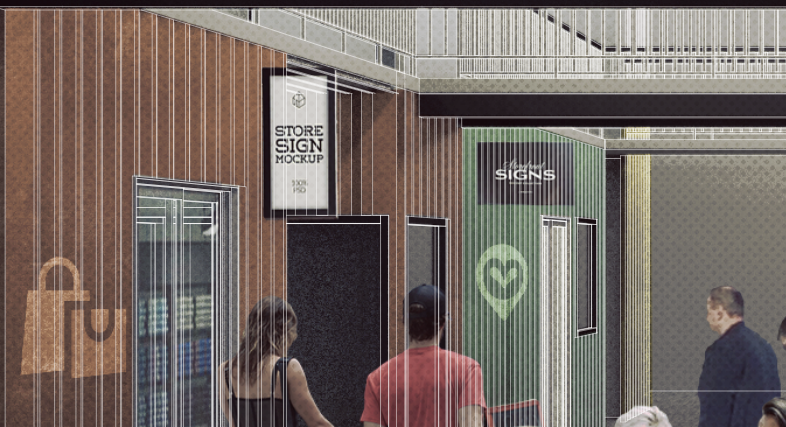

a
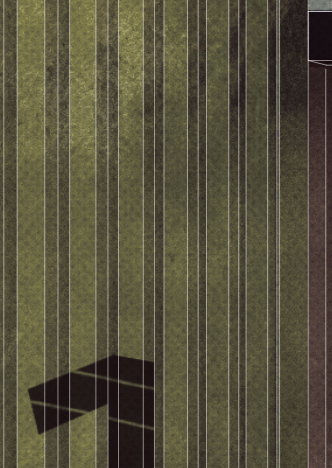

0

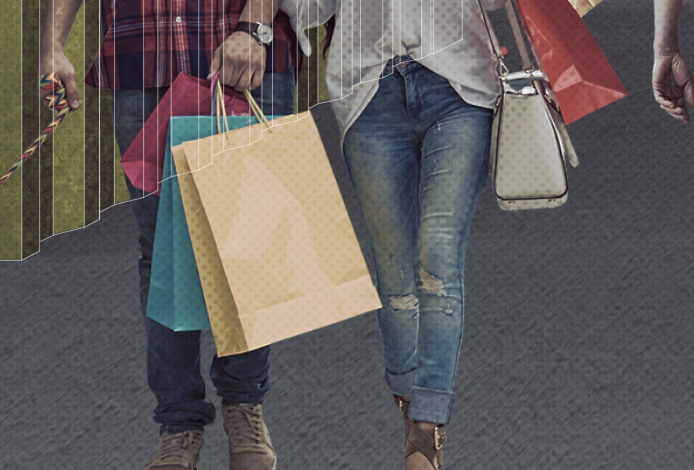

N
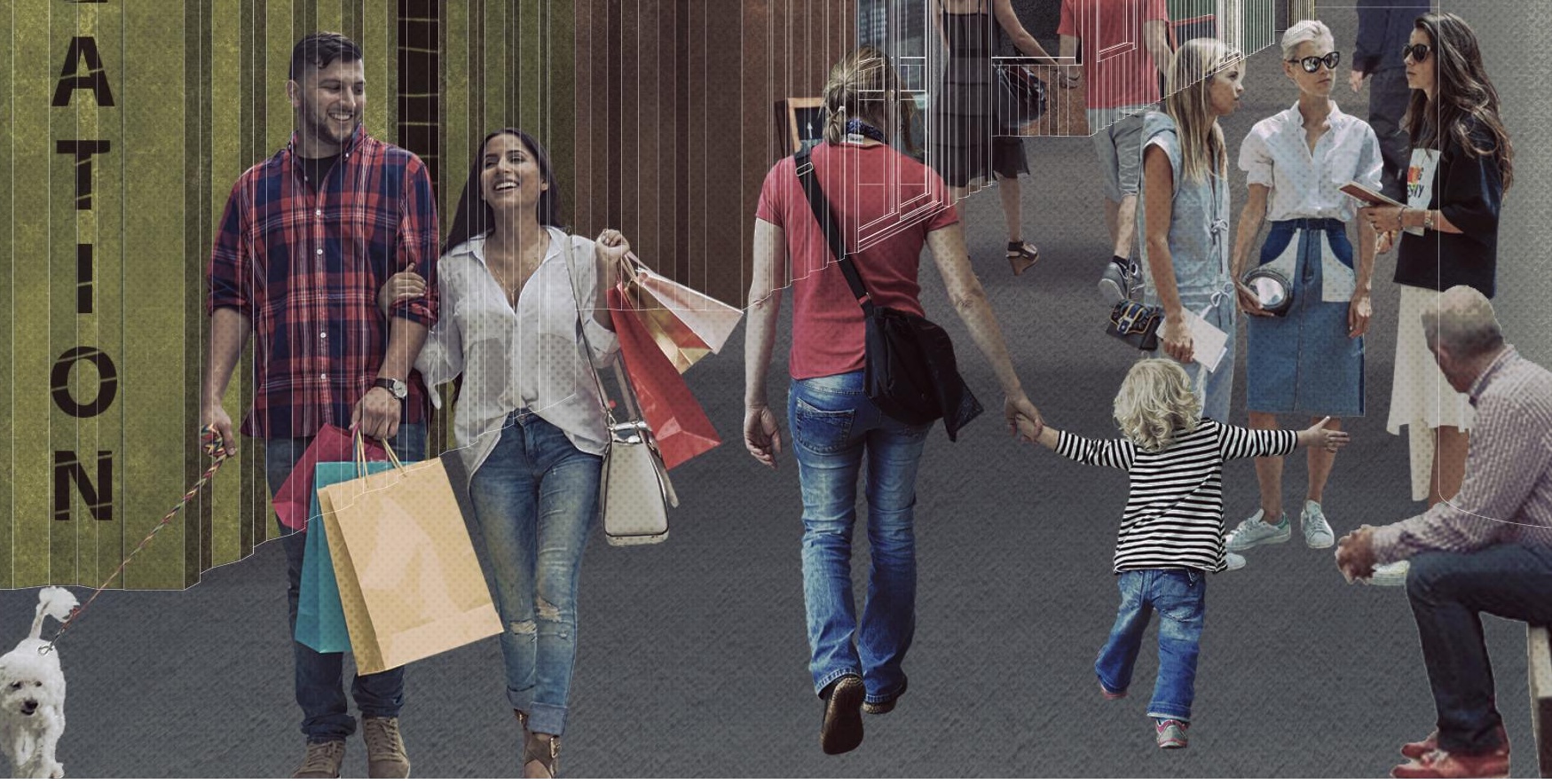

.

Fig.6.125 Block 3-4 Retail PATH View 2 

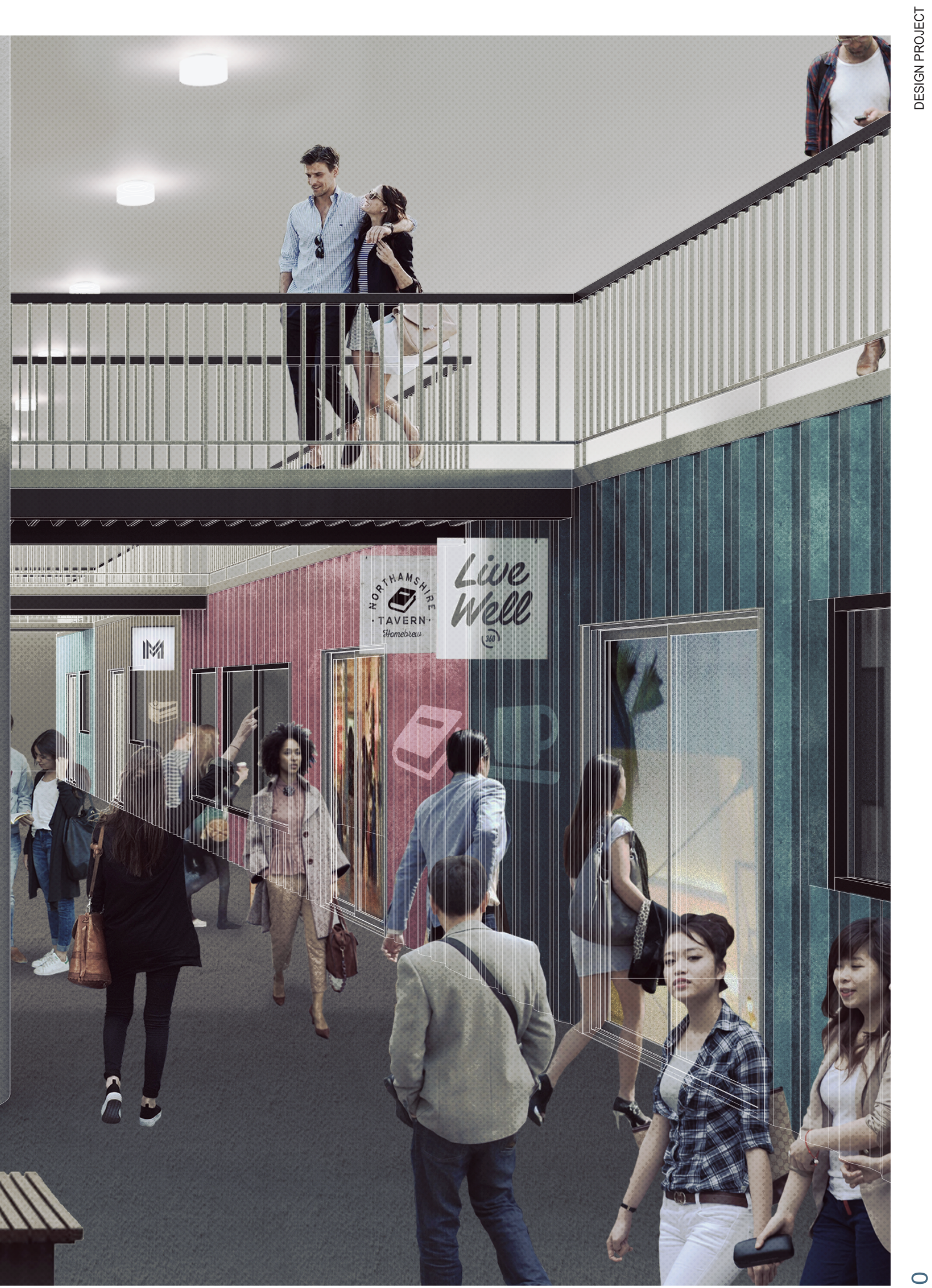

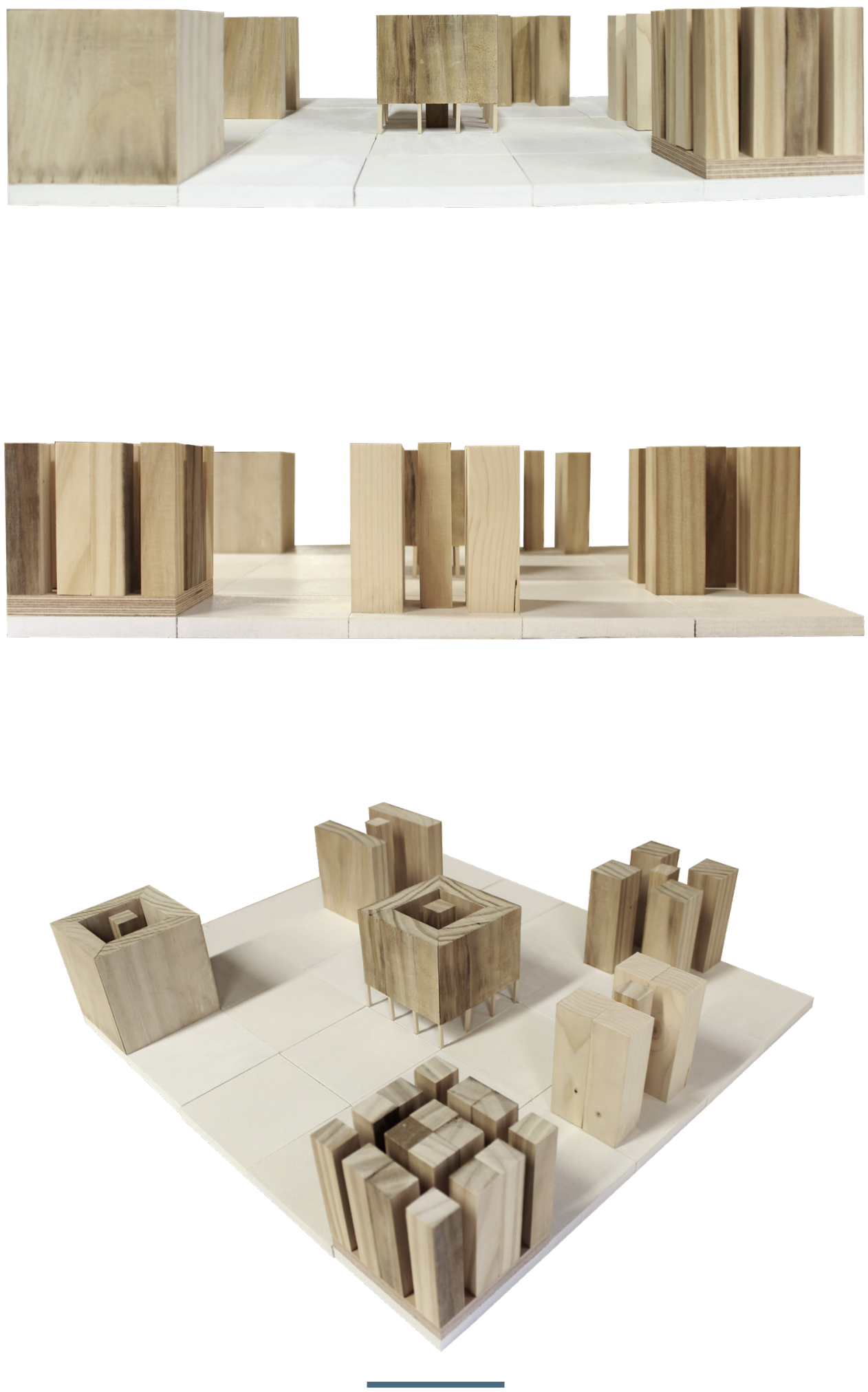

Fig.6.126 Residential typology exploration model 

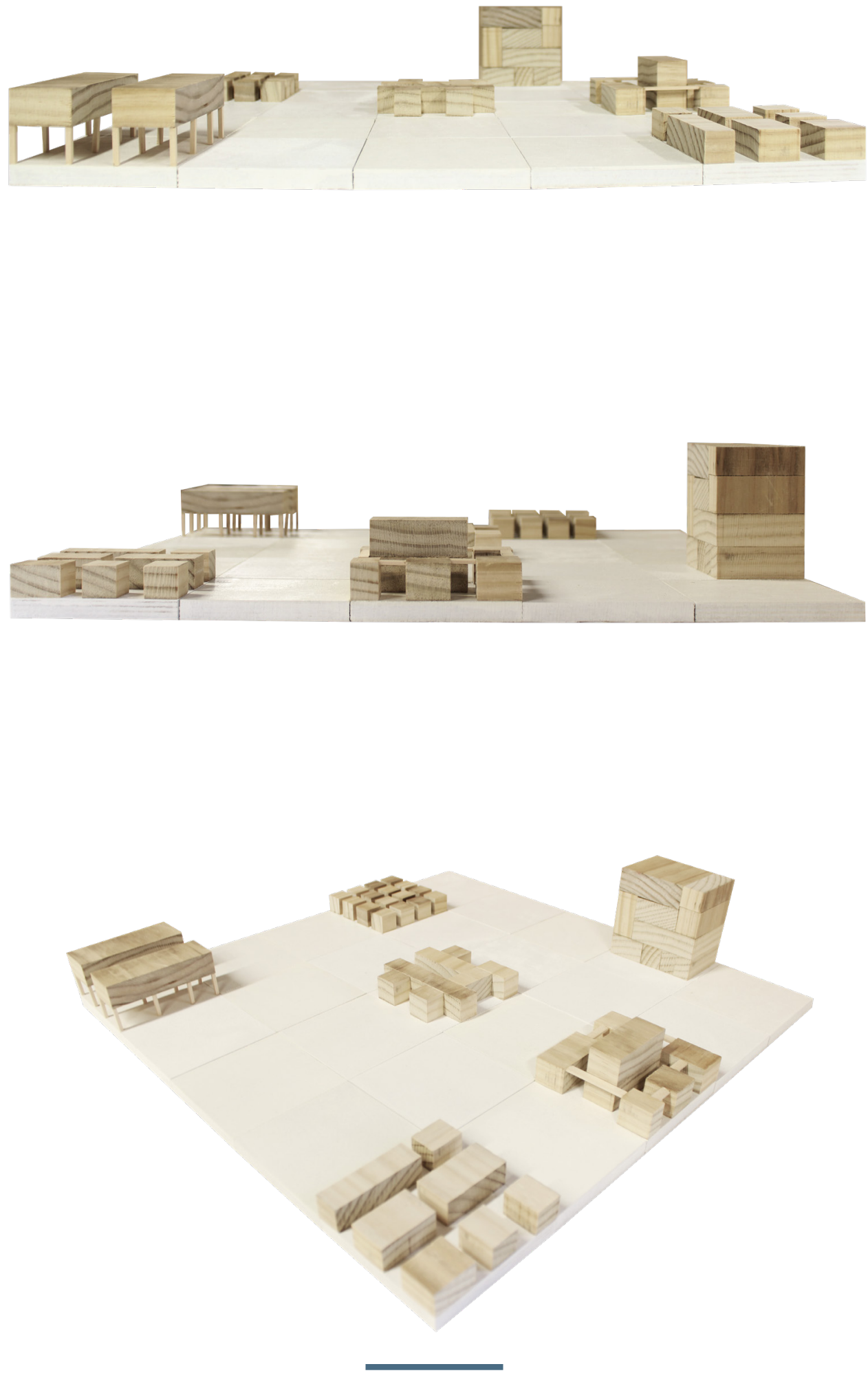

Fig.6.127 Retail typology exploration model 


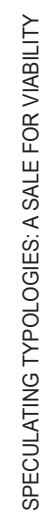

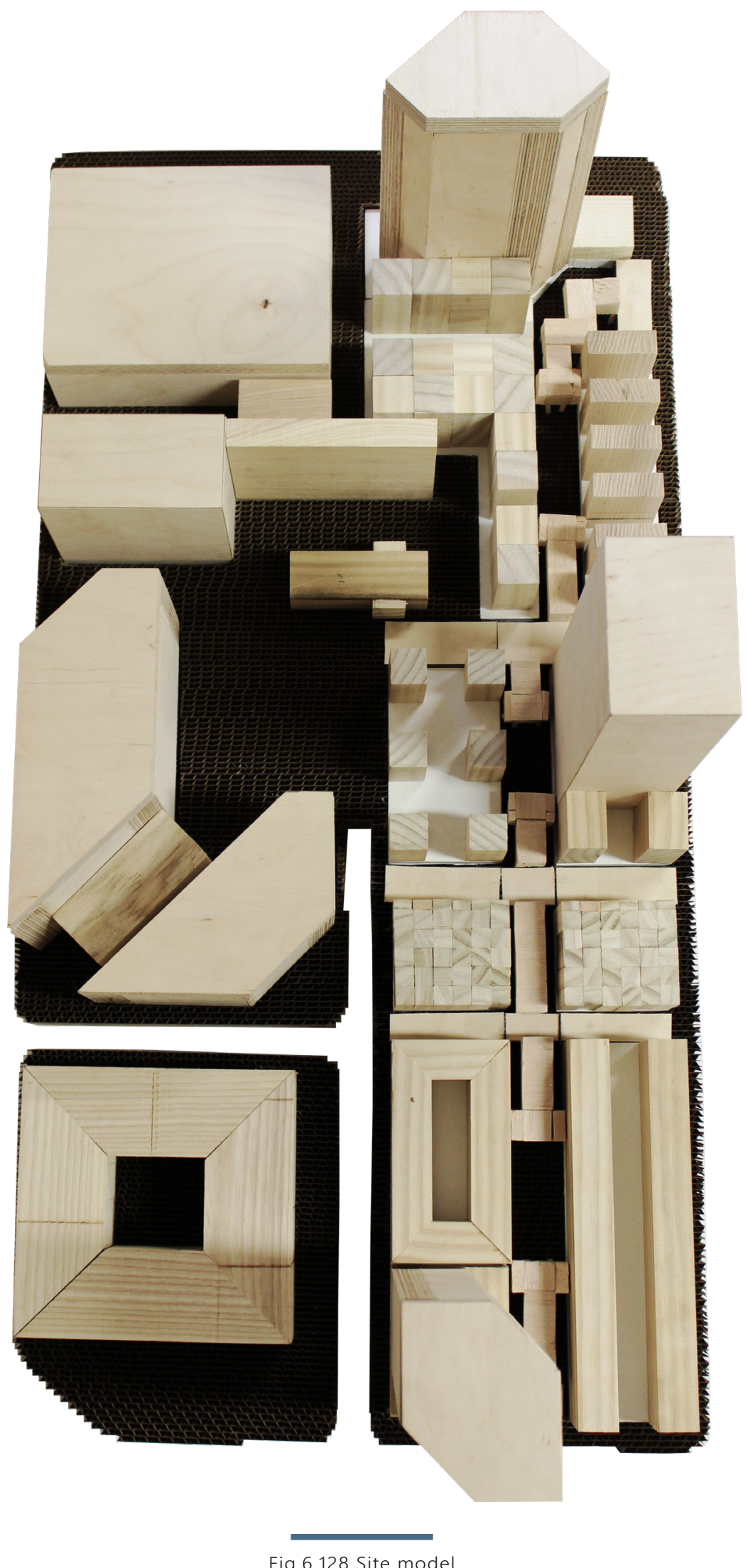

$n$
0
$N$

Fig.6.128 Site model 

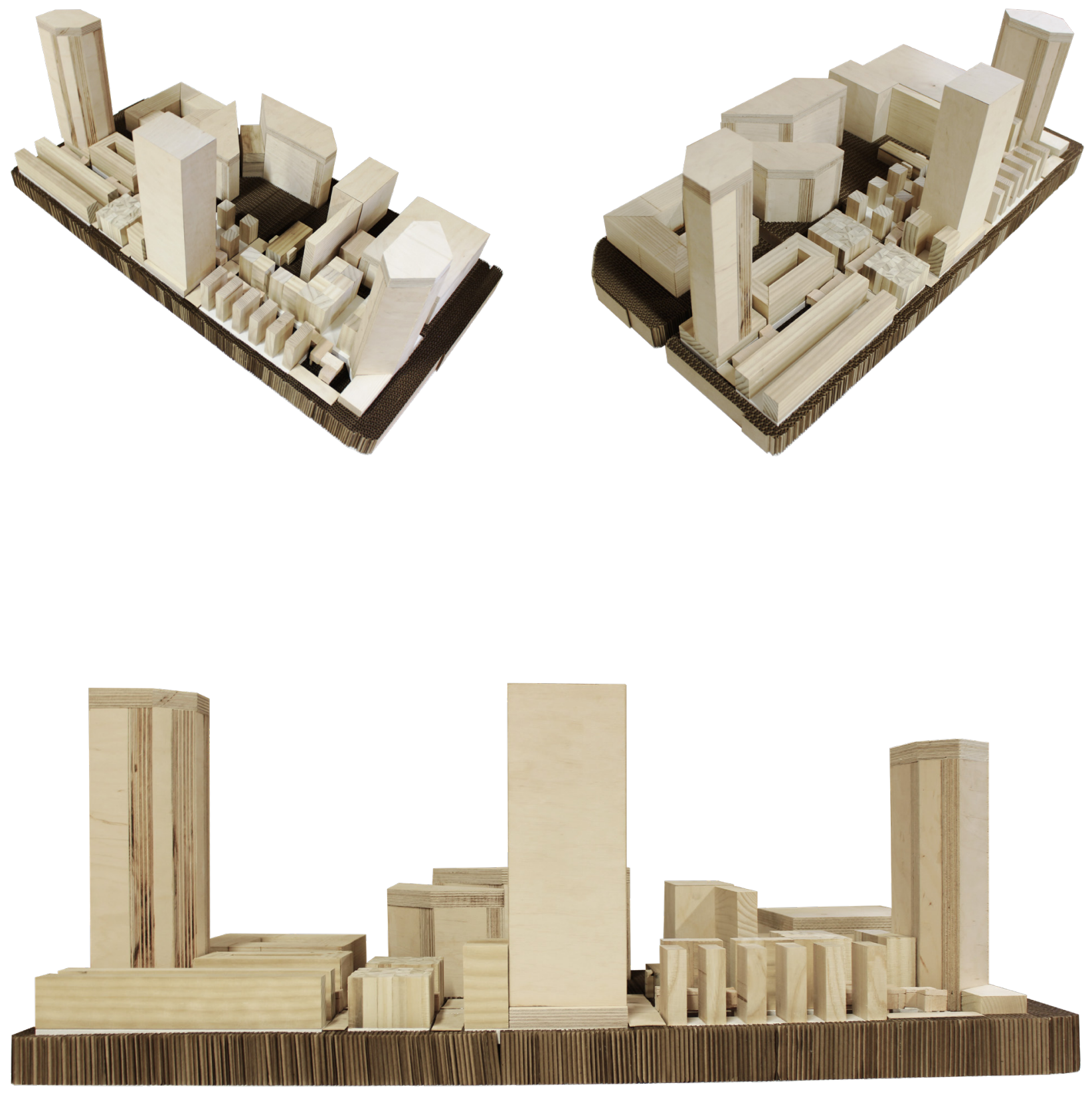


\section{END NOTES}

1 n.d. "Retail." Oxford Dictionaries. Accessed June 13, 2018. https://en.oxforddictionaries.com/ definition/retail.

2 Chuihua Judy Chung, Jeffrey Inaba, Rem Koolhaas, and Sze Tsung Leong. Project on the City II: The Harvard Guide to Shopping (Cologne: Taschen, 2001), 133.

$3 \quad$ Ibid., 71.

4 Avery Trufelman. "The Gruen Effect." 99\% Invisible, May 5, 2015. Accessed May 18, 2018. https://99percentinvisible.org/episode/thegruen-effect/.

$5 \quad$ Vera Simone Bader, and Andres Lepik, eds. World of Malls: Architectures of Consumption (Berlin: Hatje Cantz, 2016), 6.

6 Chung. Project on the City II: The Harvard Guide to Shopping, 132.

$7 \quad$ lbid

8 M. Jeffrey Hardwick. Mall Maker: Victor Gruen, Architect of an American Dream (Philadelphia: University of Pennsylvania Press, 2004), 5.

9 Christoph Grunenberg and Max Hollein, eds. Shopping: A Century of Art and Consumer Culture (Berlin: Hatje Cantz Publishers, 2002), 62.

Hardwick. Mall Maker: Victor Gruen, Architect of an American Dream, 5.
Shopping, 194.

12

Pauline Fowler. "The Toronto Eton Centre and its Precedent, the Galleria in Milan." Fifth Column 3, no. 3-4 (1983): 84. http:// ezproxy.lib.ryerson.ca/login?url=https:// search-proquest-com.ezproxy.lib.ryerson.ca/ docview/55141582 ?accountid= 13631 .

Timothy Mennel. "Victor Gruen and the Construction of Cold War Utopias." Journal of Planning History 3, no. 2 (2004): 123. doi:10.1177/1538513204264755.

14 Ibid., 133.

15 Bader. World of Malls: Architectures of Consumption, 20.

16 Chung. Project on the City II: The Harvard Guide to Shopping, 408.

Eberhard H. Zeidler. Buildings Cities Life: An Autobiography in Architecture (Toronto: Dundurn, 2013), 168. Michael McMordie. "Eaton Centre." The Canadian Encyclopedia, July 2, 2006. Accessed November 15, 2017. https://www. thecanadianencyclopedia.ca/en/article/eatoncentre/.

Zeidler. Buildings Cities Life: An Autobiography in Architecture, 167. Canadian Architect 22, no. 5 (1977): 31. http:// 
ezproxy.lib.ryerson.ca/login?url=https:// search-proquest-com.ezproxy.lib.ryerson.ca/ docview/54926667 ?accountid $=13631$.

n.d. "Building Types Study 513: Shopping Malls in the Center City." Architectural Record 163, no. 3 (1978): 120. http://ezproxy. lib.ryerson.ca/login? url=https://searchproquest-com.ezproxy.lib.ryerson.ca/ docview/54918493? accountid= 13631 . lbid., 118.

Eberhard H. Zeidler. "The Toronto Eaton Centre, Phase II; Architect: Bregman and Hamann; Zeidler Partnership." Canadian Architect 24, no. 11 (1979): 25. http:// ezproxy.lib.ryerson.ca/login?url=https:// search-proquest-com.ezproxy.lib.ryerson.ca/ docview/54934843? accountid=13631.

n.d. "The Toronto Eaton Centre: Phase 1," 40.

Fowler. "The Toronto Eton Centre and its Precedent, the Galleria in Milan," 85.

Zeidler. "The Toronto Eaton Centre, Phase II; Architect: Bregman and Hamann; Zeidler Partnership," 30. n.d. "Census 2016: Age and Sex; Type of Dwelling." City of Toronto. City Planning, Research and Information, May 4, 2017. Accessed November 7, 2017. https://web.toronto.ca/wp-content/ uploads/2017/10/96d7-2016-Census-
Backgrounder-Age-Sex-Dwelling-Type.pdf.
28

29

30 n.d. "10 Retailer Investments for an Uncertain Future." PwC Global, 2017. Accessed November 7, 2017. www.pwc.com/2017totalretail. n.d. "Census 2016: Age and Sex; Type of Dwelling." John David Hulchanski. The Three Cities within Toronto: Income Polarization Among Toronto's Neighbourhoods, 1970-2005 (Toronto: Cities Centre, 2010).

Darrell K. Rigby. "The Future of Shopping." Harvard Business Review (2011): 4-12. http:// www.wipro.com/documents/the-future-ofshopping.pdf.

n.d. "10 Retailer Investments for an Uncertain Future."

n.d. "Census 2016: Age and Sex; Type of Dwelling." Ibid.

n.d. "10 Retailer Investments for an Uncertain Future."

Ibid.

Igal Charney, Pierre Filion, and Rachel Weber. "Downtowns that Work: Lessons from Toronto and Chicago." Canadian Journal of Urban Research 24, no. 2 (2015): 22. Accessed May 25, 2018. http://ezproxy. lib.ryerson.ca/login?url=https://searchproquest-com.ezproxy.lib.ryerson.ca/ docview/1769724011? accountid=13631. 
Ibid., 25. Ibid., 27.

n.d. "Getting to 8,000: Building a healthier rental market for the Toronto Area." Evergreen, October, 2017. Accessed February 10, 2018. https://www.evergreen.ca/tools-publications/ getting-to-8000-building-a-healthier-rentalmarket-for-the-toronto-area/. n.d. "CHBA Points to "Missing Middle" in Housing Affordability Crunch." Canadian Home Builders' Association, March 3, 2017. Accessed February 3, 2018. https://www.chba.ca/CHBA/News/ CHBA_Points_to_Missing_Middle_in_Housing_ Affordability_Crunch.aspx. Ibid.

Cherise Burda, Graham Haines, and Shaun Hildebrand. "Bedrooms in the Sky: Is Toronto Building the Right Condo Supply?" Ryerson City Building Institute, November 7, 2017. Accessed February 3, 2018. https://www. citybuildinginstitute.ca/reports/.

44 Ibid. lbid. n.d. "CHBA Points to "Missing Middle" in Housing Affordability Crunch." n.d. "10 Retailer Investments for an Uncertain Future."

eslie Young. "Shoppers still spending at Canada's biggest malls, researchers say." Global News, September 16, 2017. Accessed February 10, 2018. https://globalnews.ca/news/3748177/ canada-malls-retail-success/. Darrell K. Rigby. "The Future of Shopping." Harvard Business Review (2011): 4. http://www.wipro. com/documents/the-future-of-shopping.pdf. Ibid.

Derek Thompson. "What in the World Is Causing the Retail Meltdown of 2017?" The Atlantic, April 10, 2017. Accessed February 10, 2018. https://www.theatlantic.com/ business/archive/2017/04/retail-meltdownof-2017/522384/.

n.d. "10 Retailer Investments for an Uncertain Future."

Anna Johannson. "This Startup Believes The Future Of Retail Is Permanent Pop-Up Shops." psfk, June 1, 2017. Accessed February 10, 2018. https://www.psfk.com/2017/06/this-startupbelieves-the-future-of-retail-is-permanentpop-up-shops.html. 


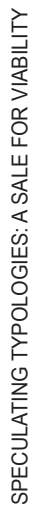
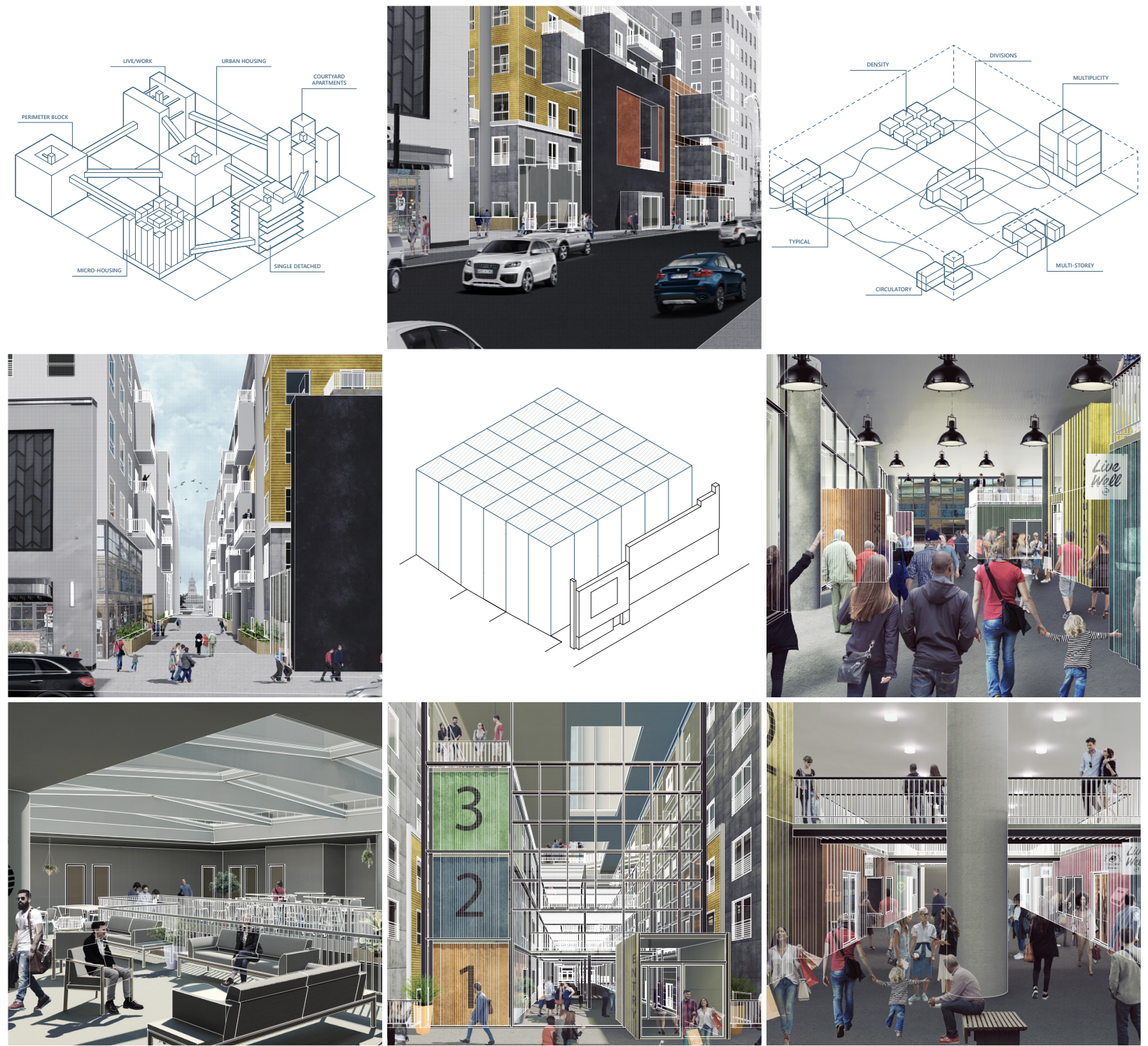

Fig.7.1 Collage of Speculating Typologies: A Sale for Viability 
The design approach undertaken for this thesis, Speculating Typologies: A Sale for Viability, shifts from designing for the immediate needs to designing for the near future; it is a speculative scenario based on the projected data for Toronto. It evolved from an interest in science fiction and its discussion of possible architectural futures which was explored further through various typologies to mitigate its inevitable obsolescence within the city fabric.

This thesis asks the following question: can obsolescence within architectural typologies be seen as an opportunity to reform the existing programs for their future viability? It is an interplay of speculation and necessity that is presented through two typologies: housing and retail. By avoiding the planned obsolescent nature of consumer society and selectively choosing the defining parts of the existing programs needed in the future, a new space that is able to support the foreseen circumstances and be viable through that time can be created. It argues for a possible utopic outcome, a speculative alternative for the existing urban shopping mall typology. Retail is a conscious decision making activity that can easily be swayed by new products meanwhile housing establishes a private space that continues to shrink as cities expand to accommodate more inhabitants. Both programs are categorized for their adaptive nature to accommodate the users with spaces that will avoid obsolescence by evolving over time. By combining various programs under the opportunistic urban shopping mall layout, a village defined by multiple interconnected neighbourhoods and a flexible shopping experience is created to redefine the existing structure. The overlap of programs on top of the existing framework informed the scenarios that could possibly unfold in the near future of Toronto, introducing new spatial function.

Speculating Typologies: A Sale for Viability is defined by its science fiction inspiration to project alternative visions for architectural typologies. This brings to light a necessary willingness to experiment with design and understand that obsolescence is inherent in all architectural typologies. In turn this should be seen as an opportunity rather than a problem. Adapting the city fabric with a new physical experience acknowledges its inevitable obsolescence that is temporarily evaded by speculations. 

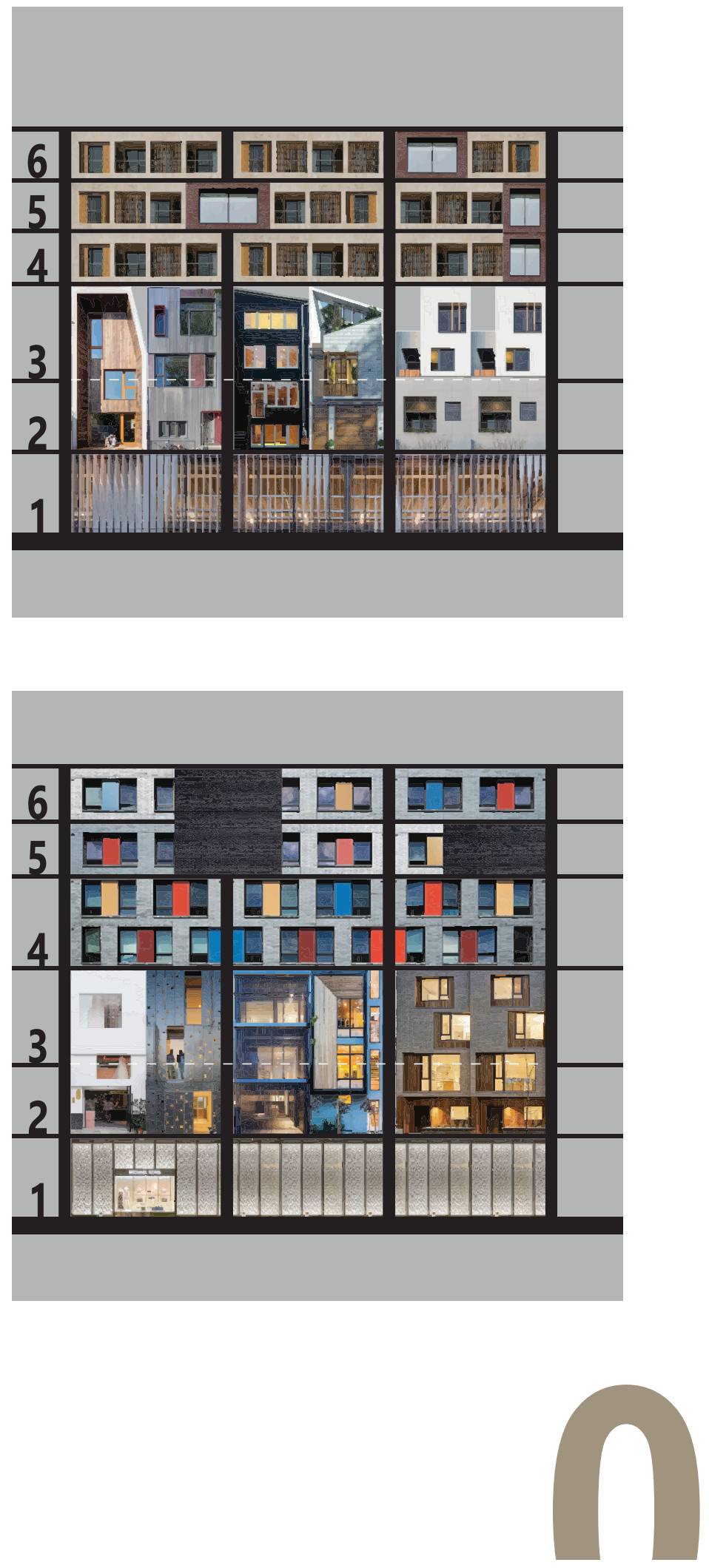

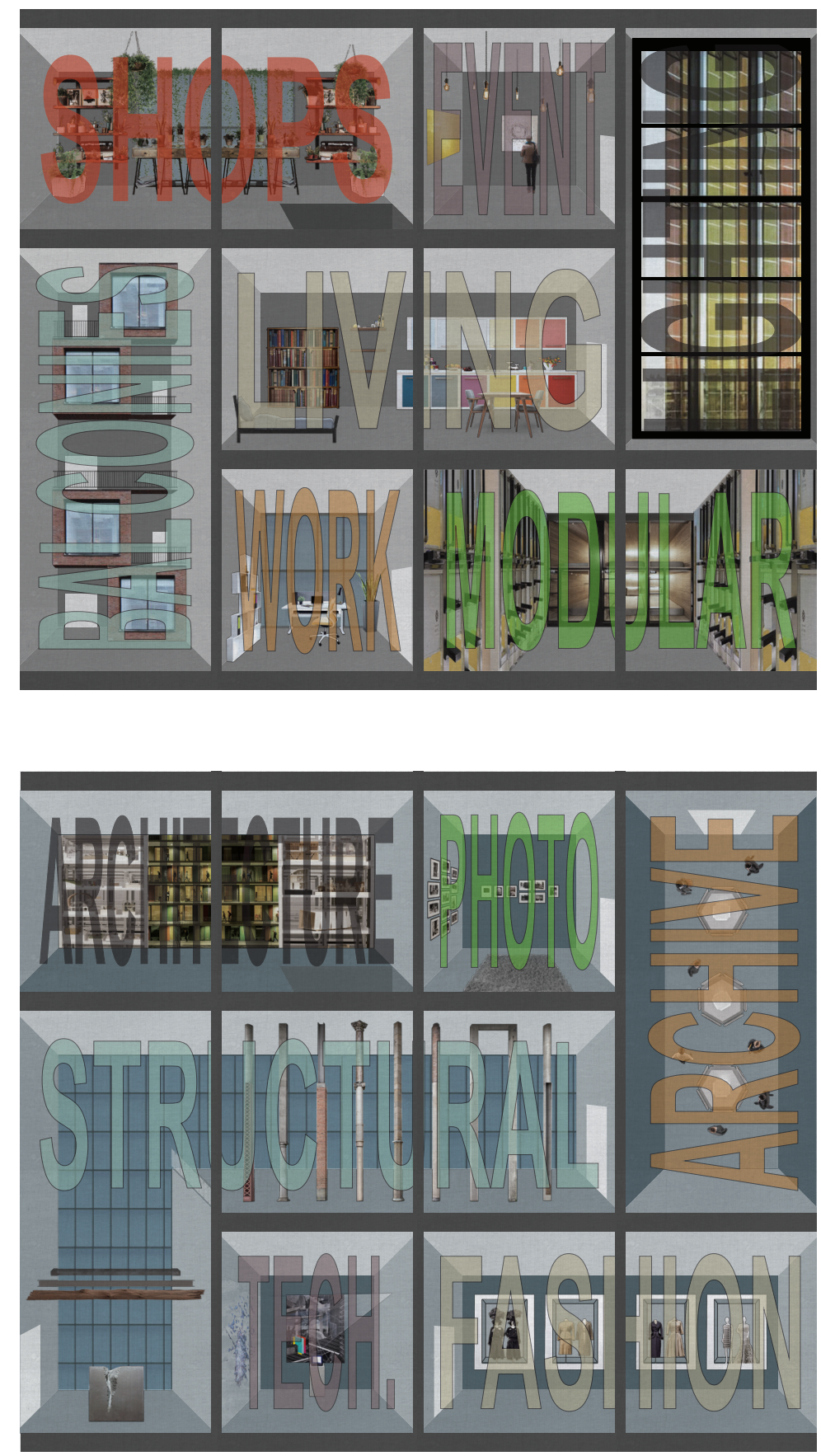


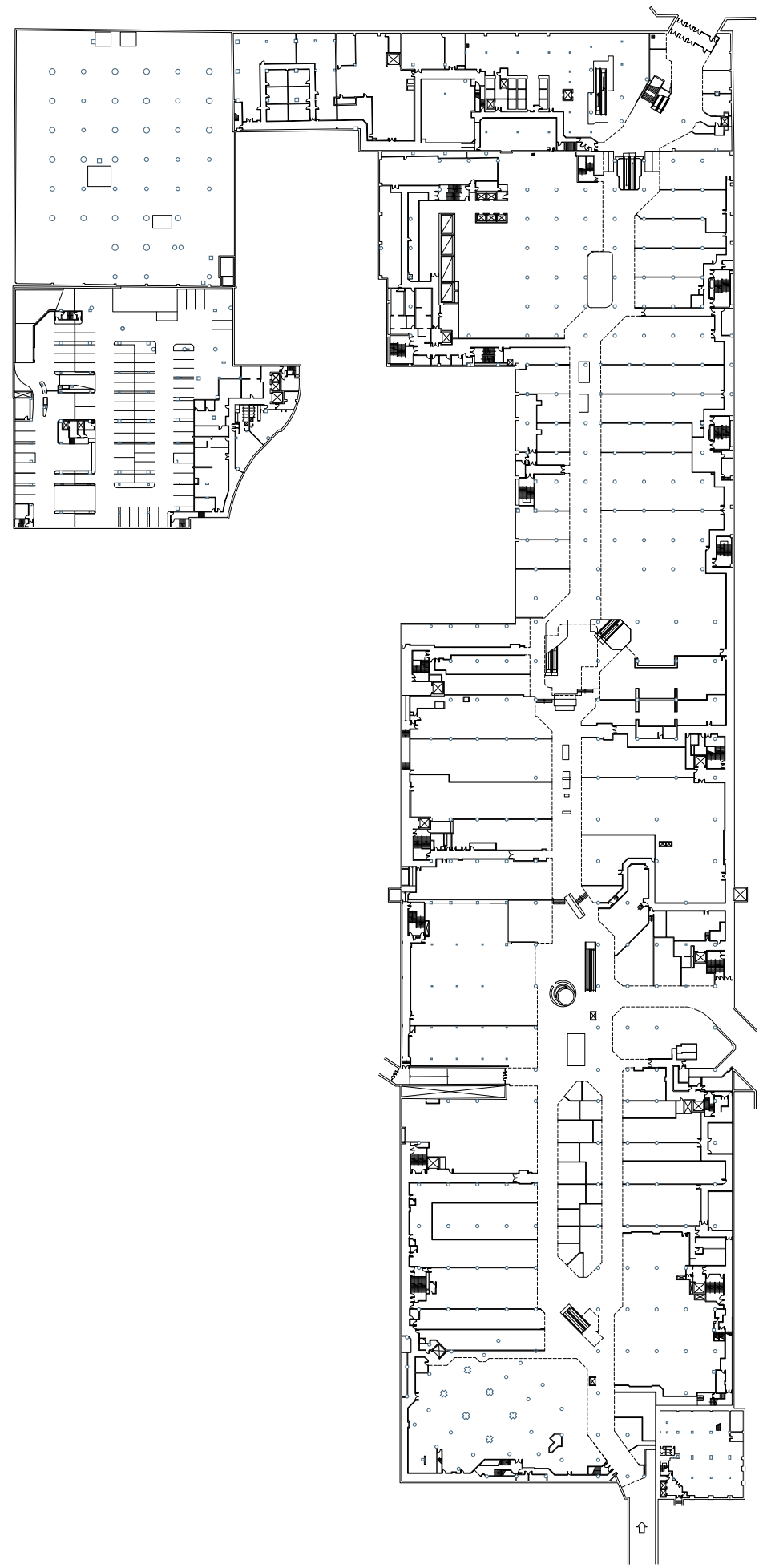




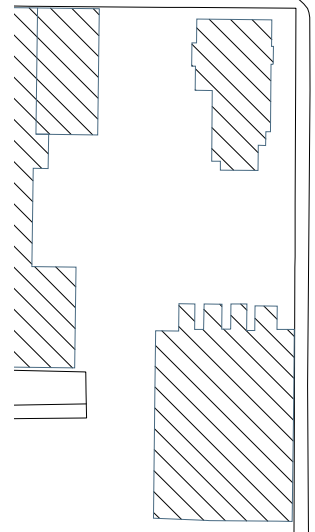

HAGERMAN ST
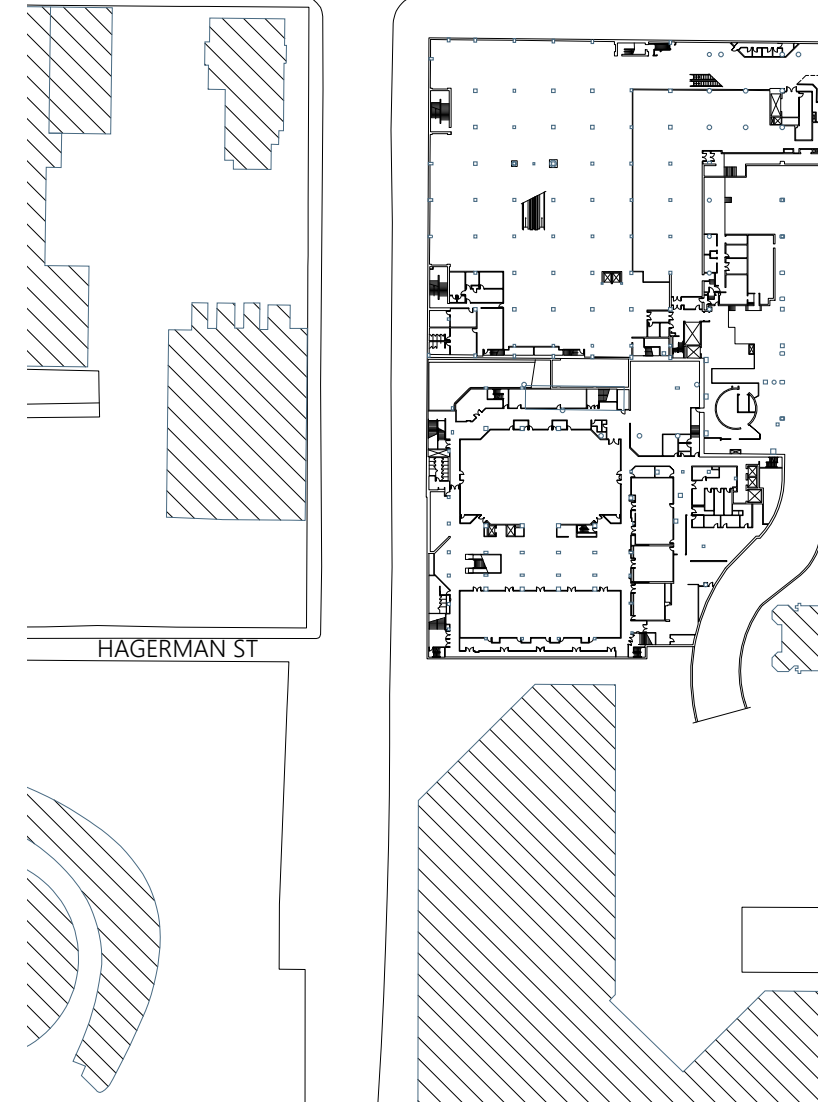

(1)

$------$
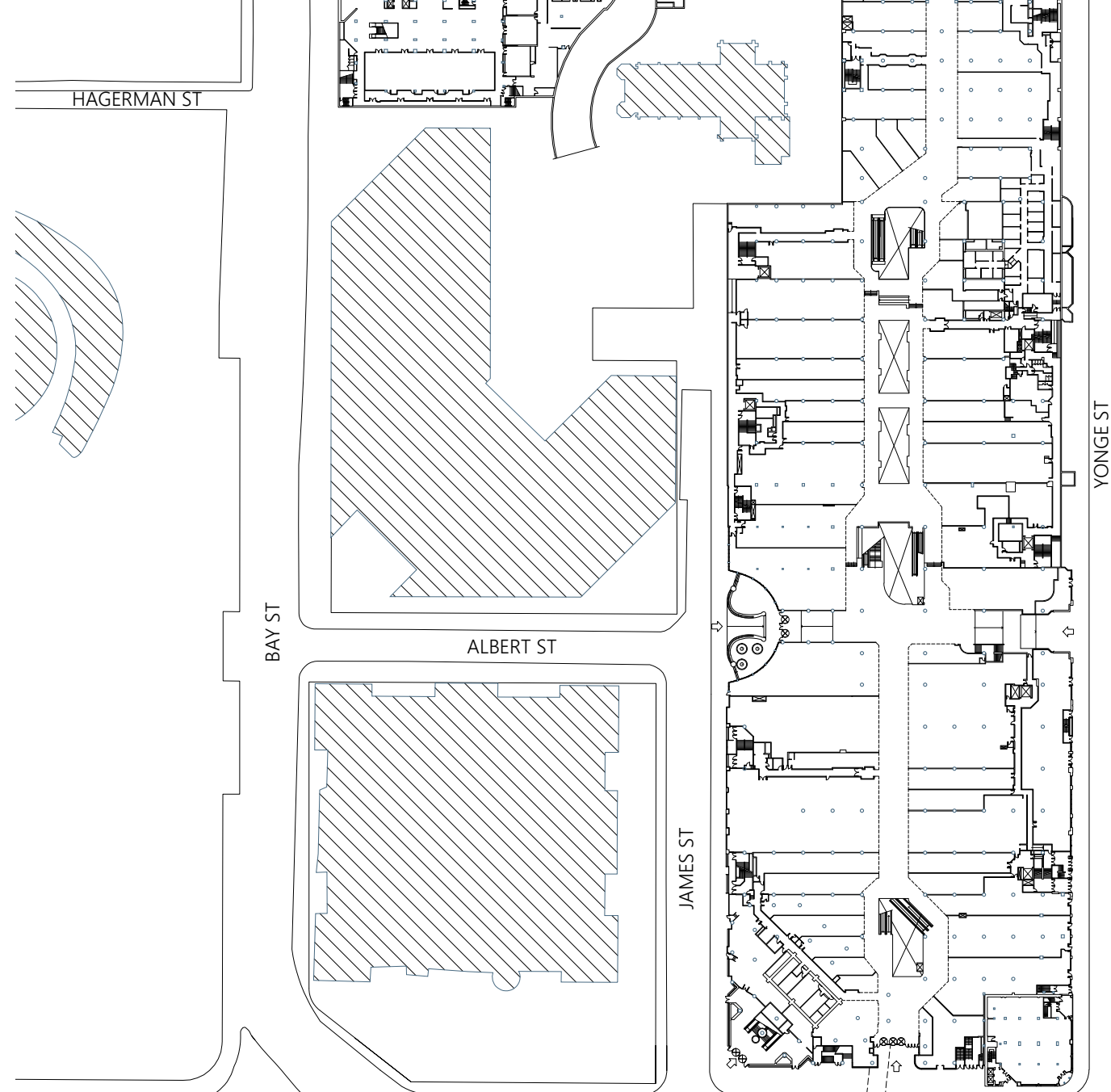

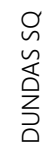

QDEENSTWN

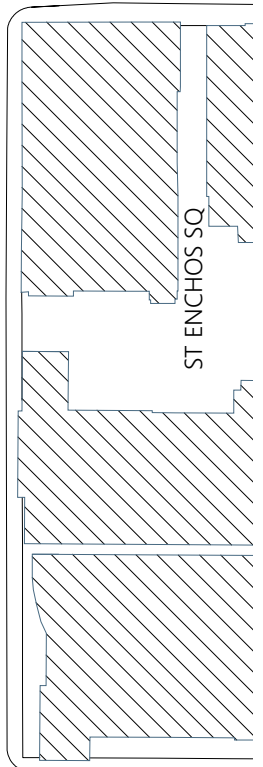




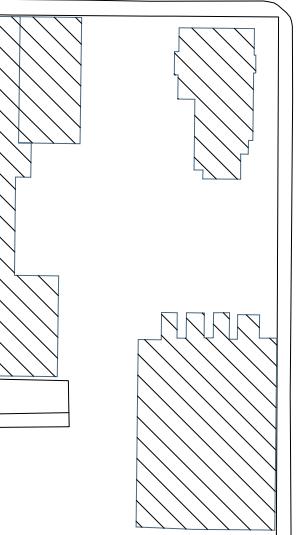

HAGERMAN ST
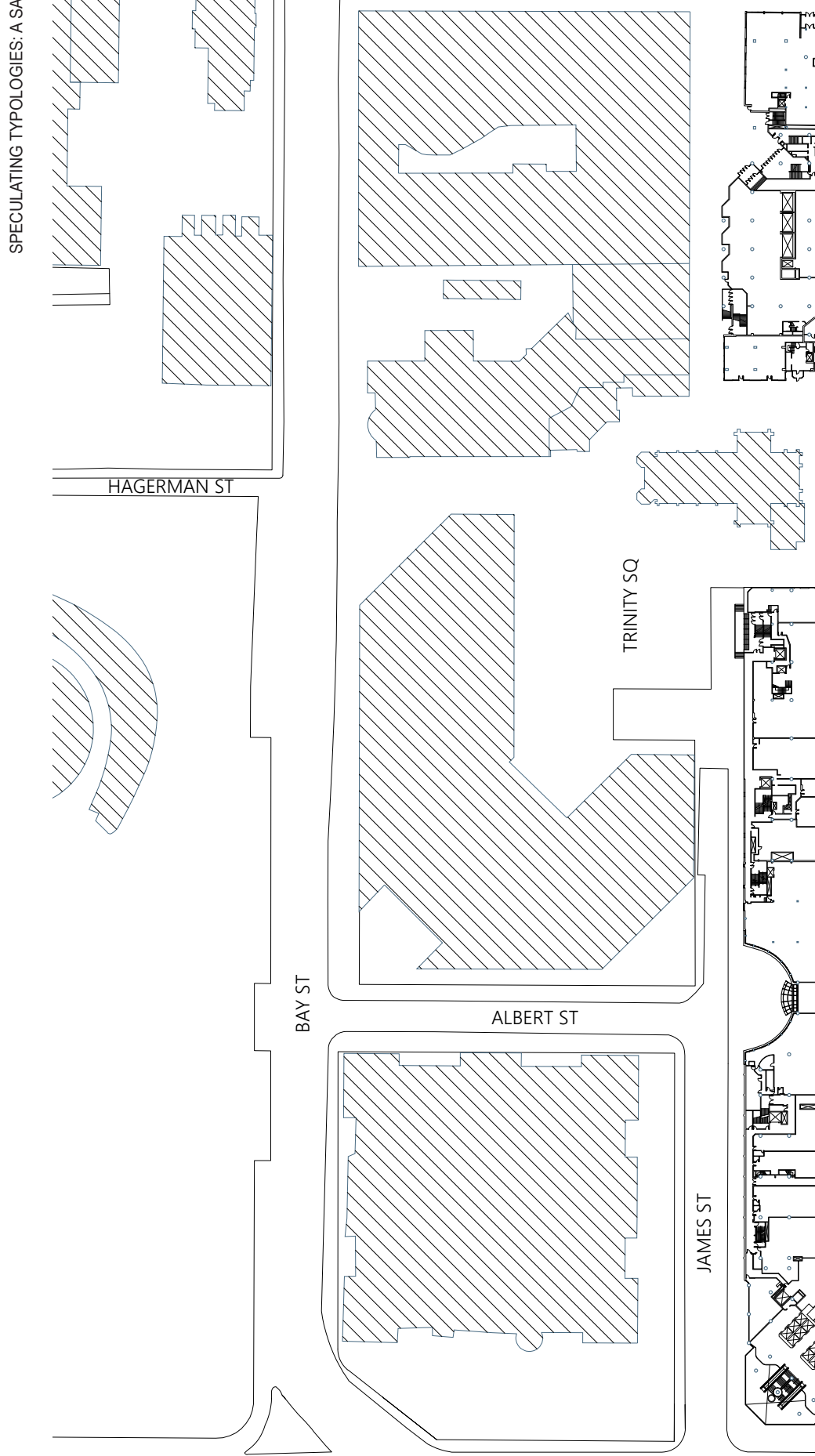

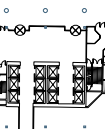
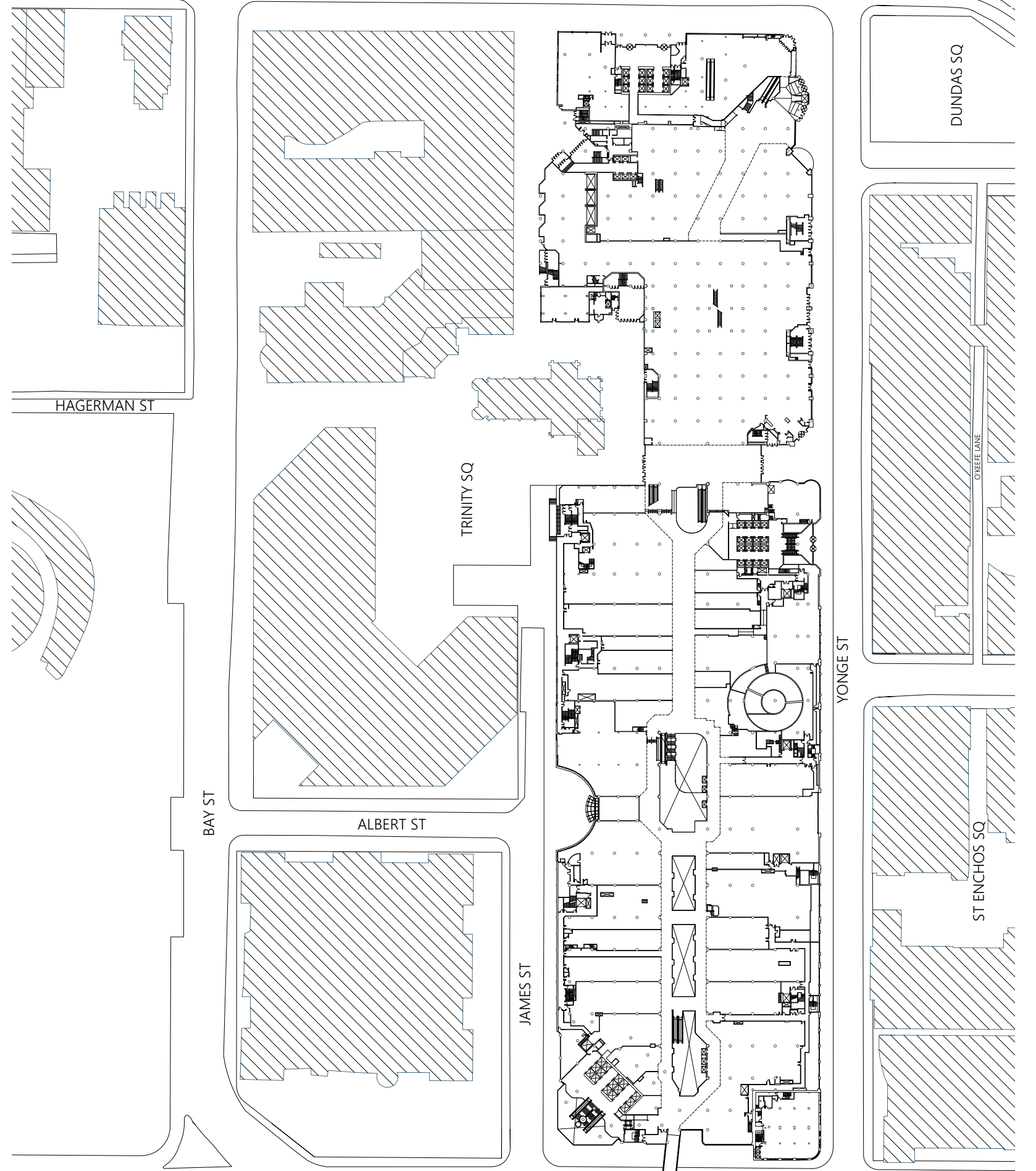

- QUEEENSTWY-.....-
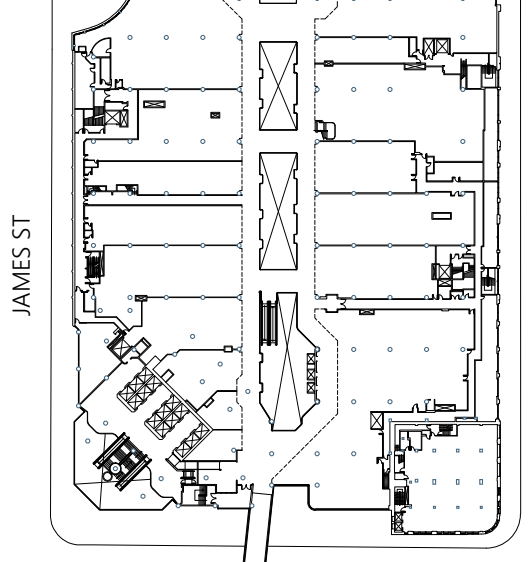

5
嵅
O
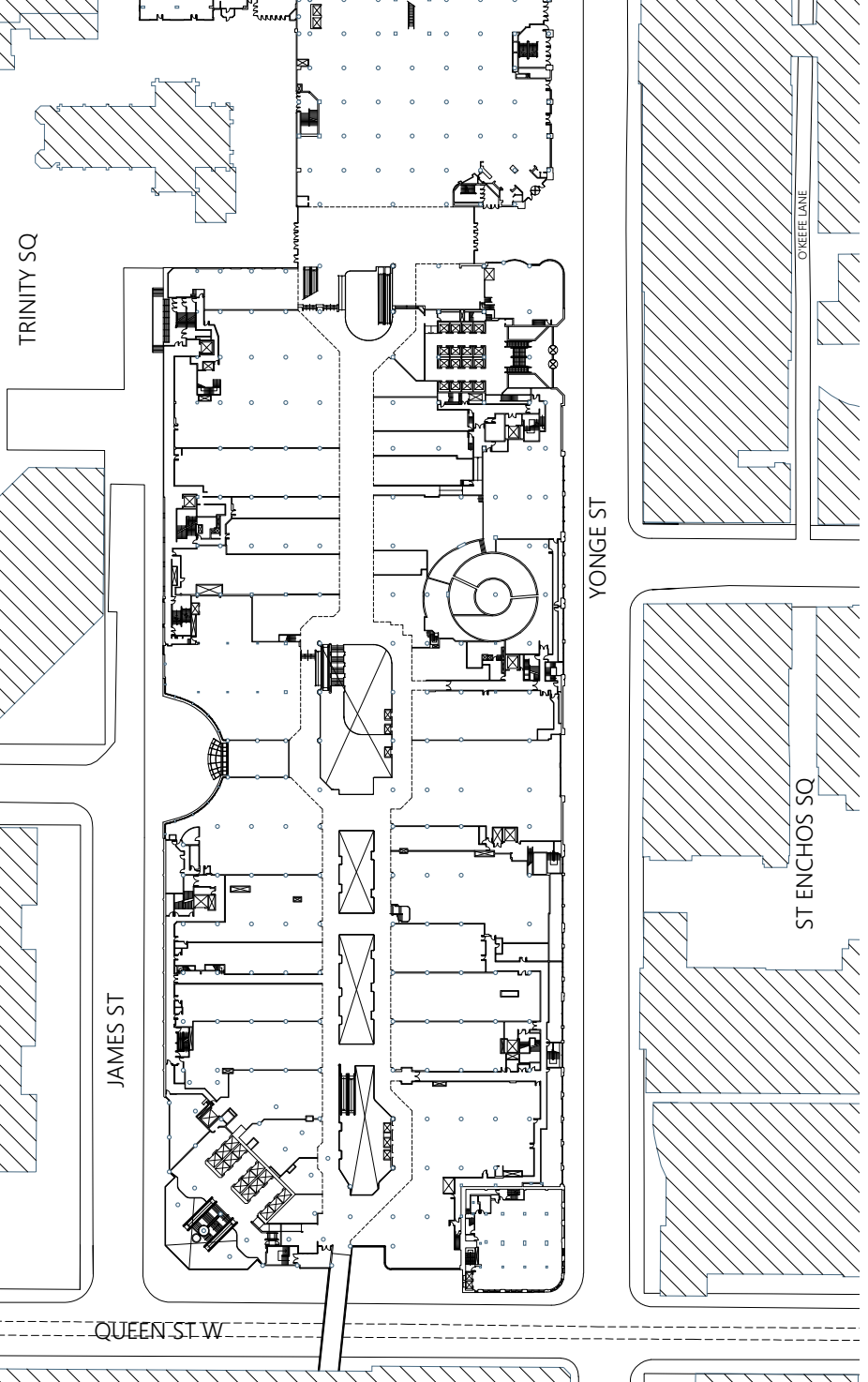


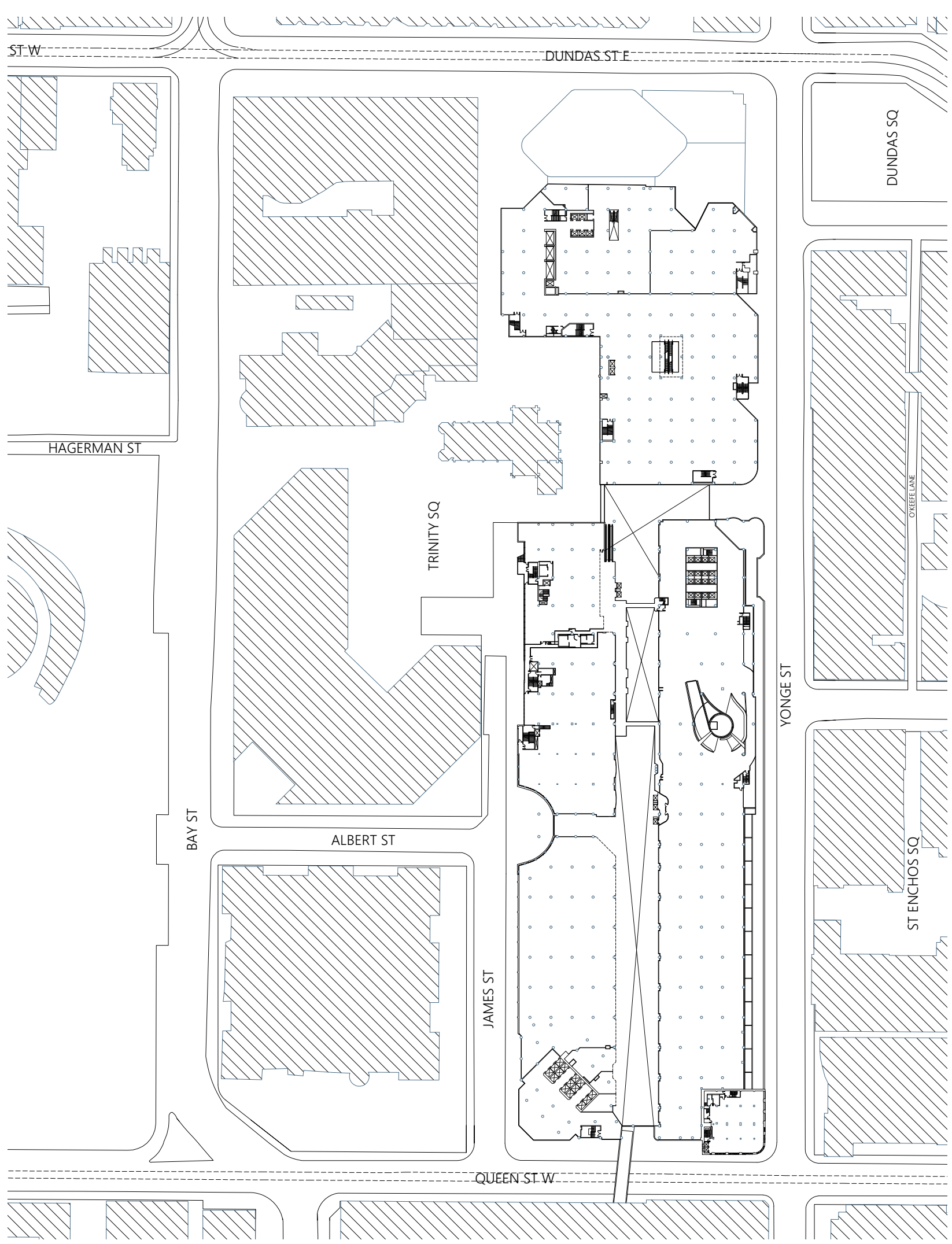

Fig.8.6 Existing level 4 


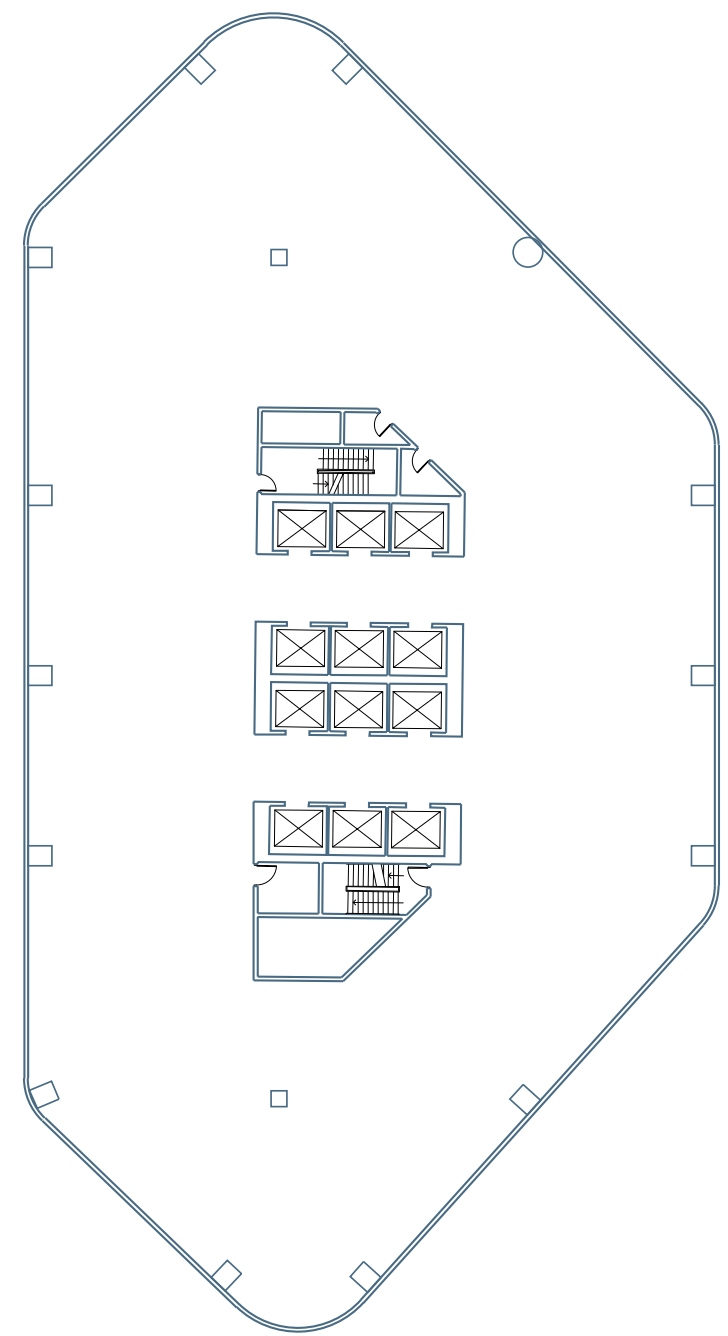




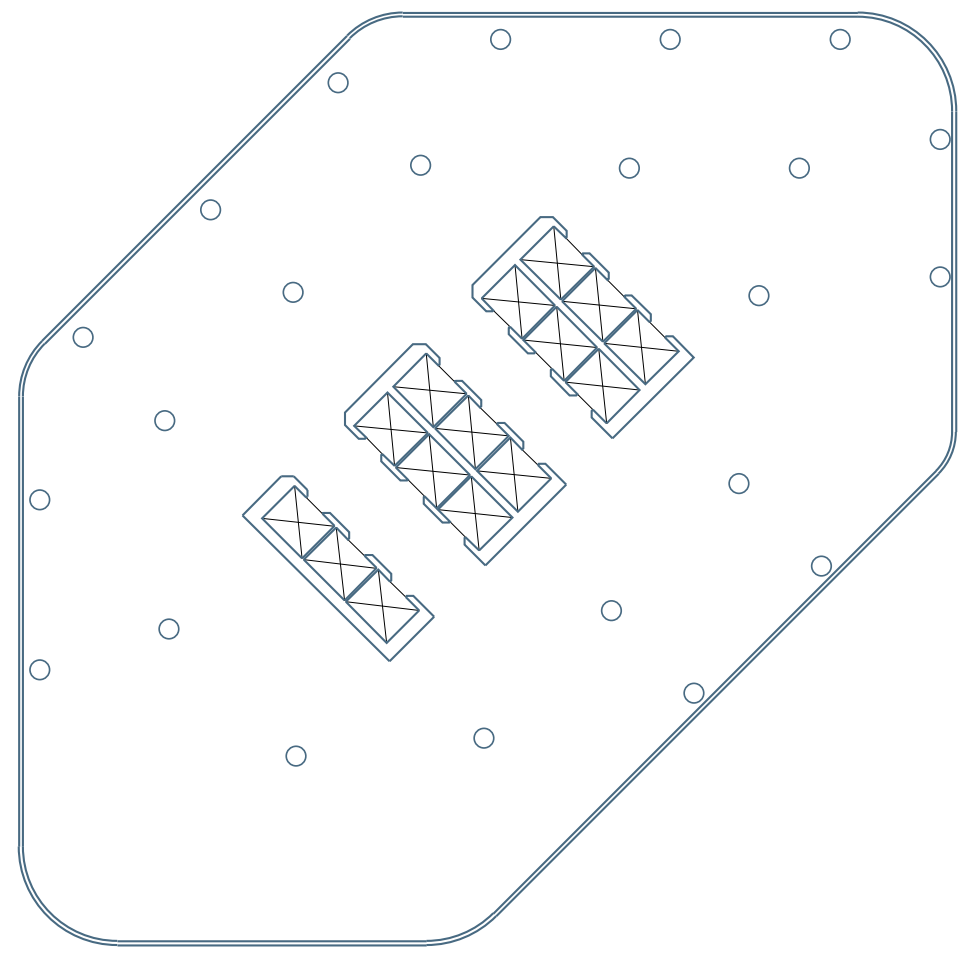




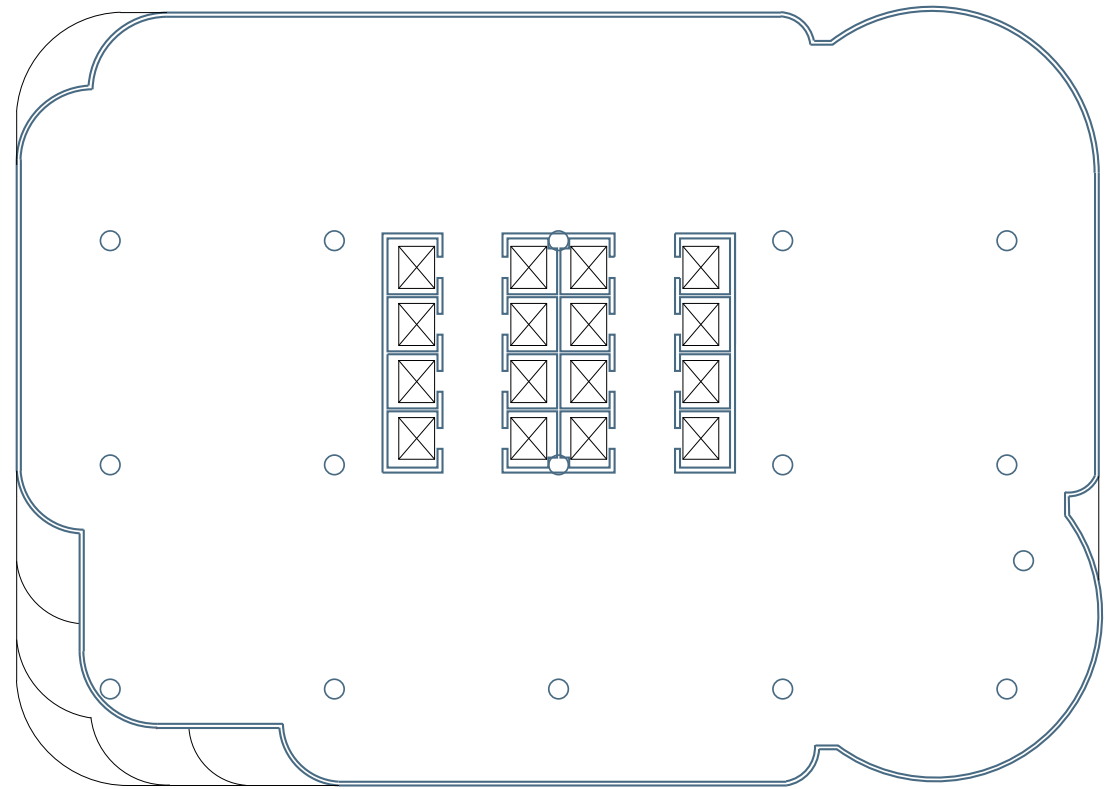




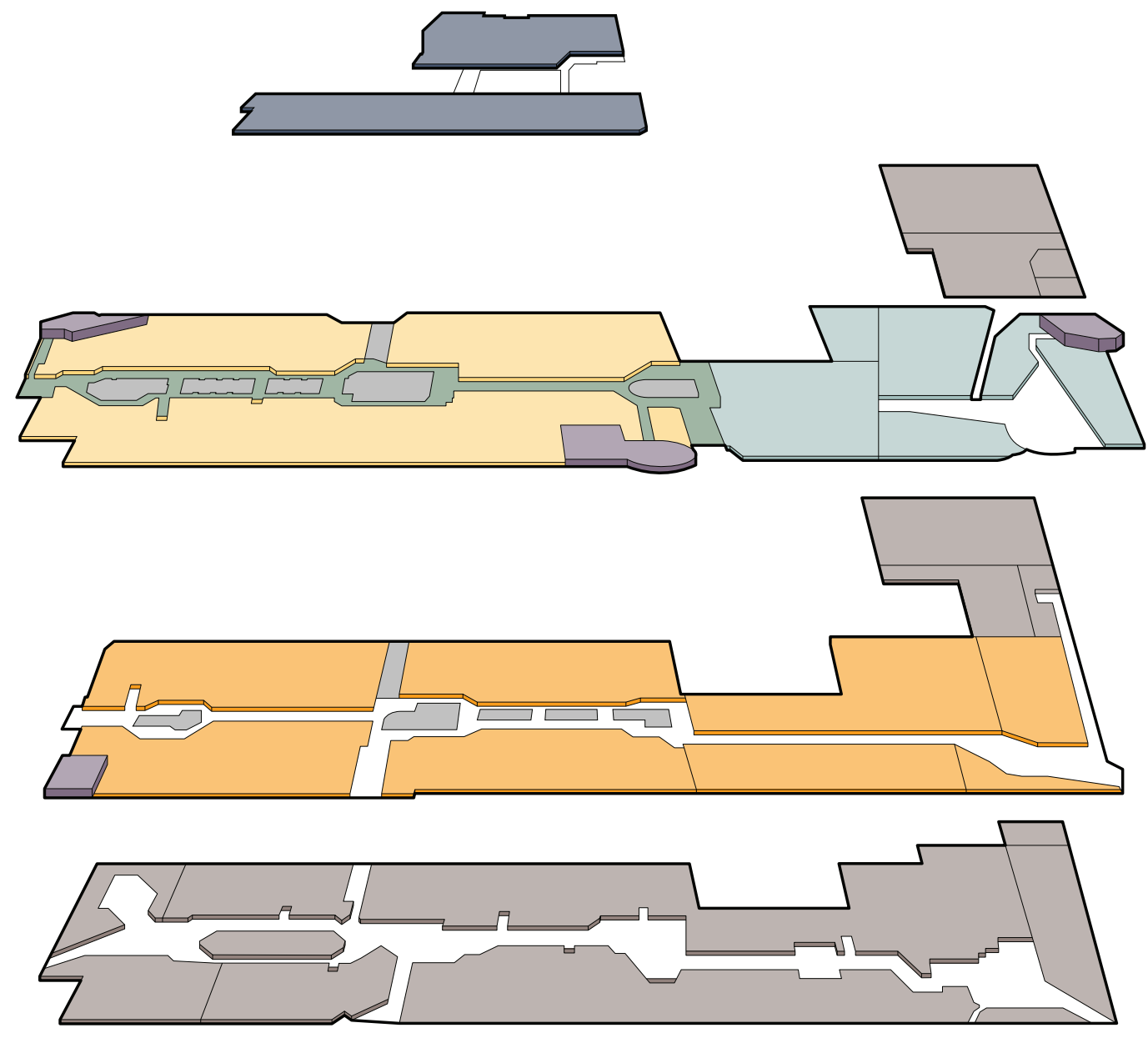

- Big-box stores

- Small Businesses

- Education

- Social Space

- Level Connectors

- Townhouses

- Affordable Housing

- Existing Towers

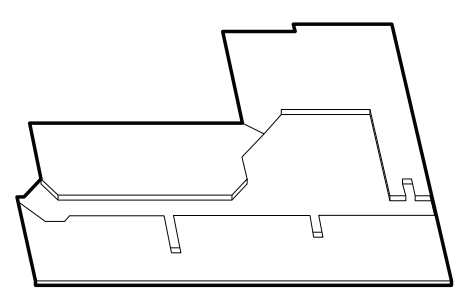

Fig.8.10 Earlier master plan layout 


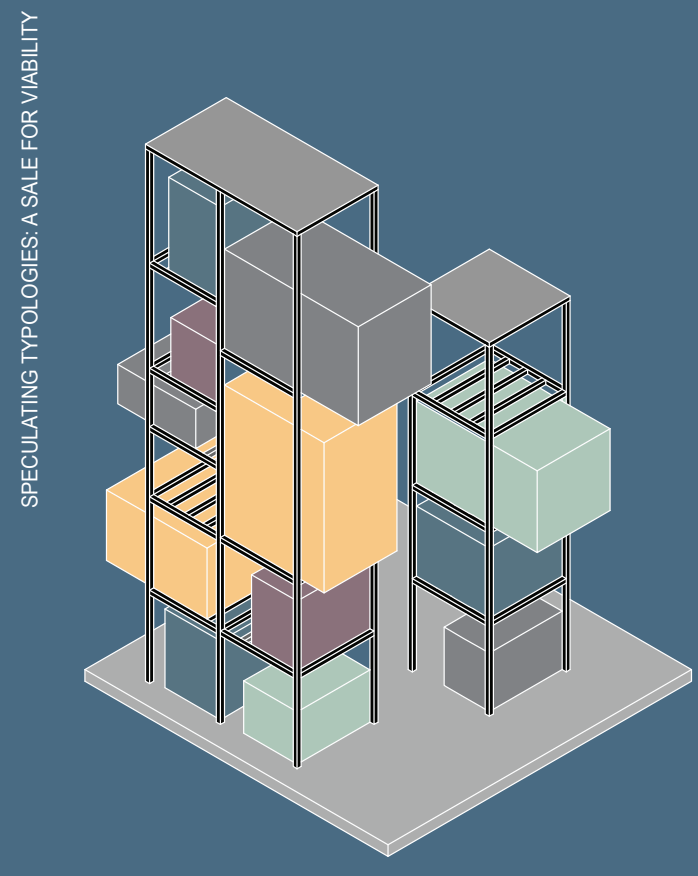

Fig.8.11 Diagrammatic interpretation of "The Fun Palace"

Fig.8.12 Physical model of the "The Fun Palace" interpretation

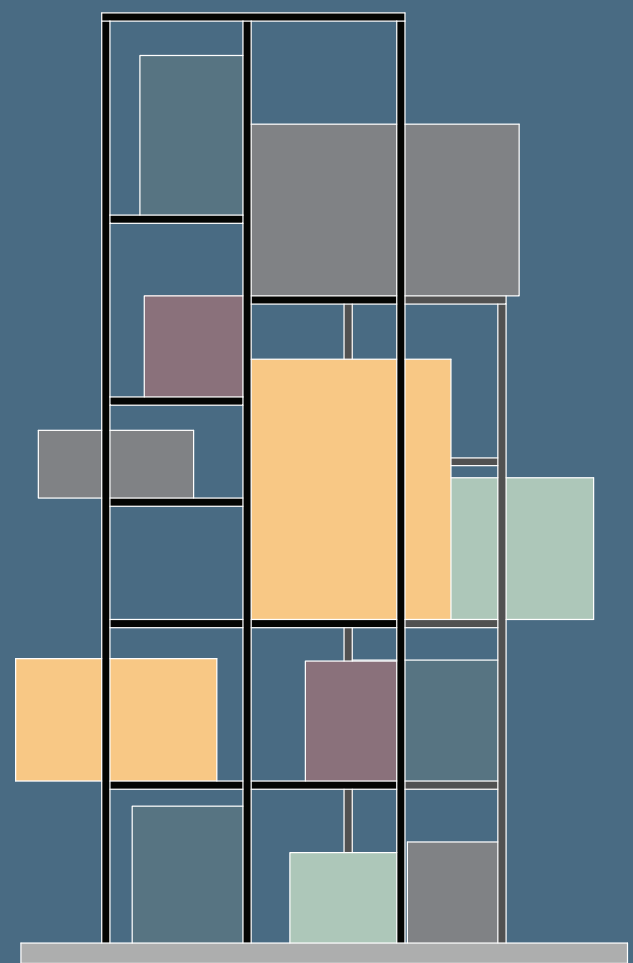

\subsection{2}

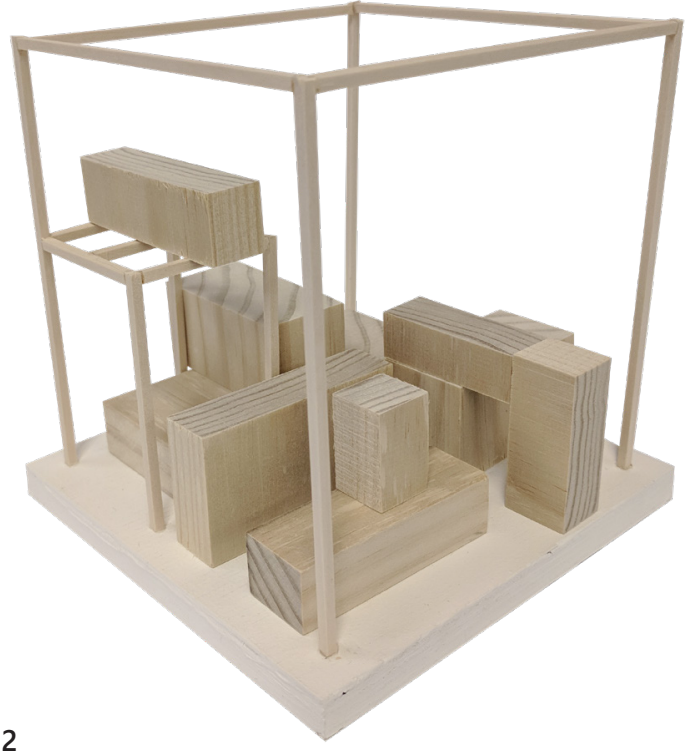


"So that is another rule for the whole nature of architecture: it must create new appetites, new hungers - not solve problems, architecture is too slow to solve problems."

- Cedric Price

\section{1 "THE FUN PALACE" \\ DESIGNED BY CEDRIC PRICE AND JOAN LITTLEWOOD}

\section{USERS}

The Fun Palace, an entertainment and cultural complex, was an unrealized project designed by Cedric Price in collaboration with Joan Littlewood. It challenges the conventional notion of the built form. His influence on modern architecture is considerable through unconventional unbuilt works. The primary aim was to create a design that constructs an ever-changing environment by involving the users in the conception of the needed program. The design was not envisioned for the purpose of supporting the program and users, but rather to enable to explore human behaviour in an array of possibilities within the skeletal framework. Absence in the program creates the opportunity for unlimited routes that facilitate the physical experience.

The post-WWII period experienced a growth in technology. As a result, Price proposed a design that uses technology and adapts programmatically to individual needs by staying in a constant state of construction. It was a large toolkit of design that promoted the involvement of all users, who momentarily forget about their autonomous lives for a social experience and learning. He believed that obsolescence would not only happen, but should happen. If a program is not sufficient enough to support its users, it should either be demolished for a better solution or transformed radically to re-establish its purpose.

It is within human nature to desire change to improve the quality of the subject in question. In the case of design and construction, nothing is perfect, but rather in a constant state of attempting to achieve perfection. The rapid pace at which technology and human needs change will continue to place the built work at risk. A solution to avoid destroyed built form would be to develop a construction form that continuously adapts to the changes in external and internal environments. Densification of the city will put the viability and the quality of the physical realm in question, and to resolve that Prince's exploration creates a fixed skeletal framework for a building where the program can be placed or removed according to the users of the structure. The amount of open space surrounding the blocks, required height and size of the program, and the program itself is determined based on the user input. If the future of architecture lies in the hands of the users, what tactical methods can be implemented to further encourage this behaviour? Flexibility of the constructed works determines its lifespan within the city, and as the city continues to evolve it becomes critical to question if these transformative toolkits of design are enough to make the future city viable. 


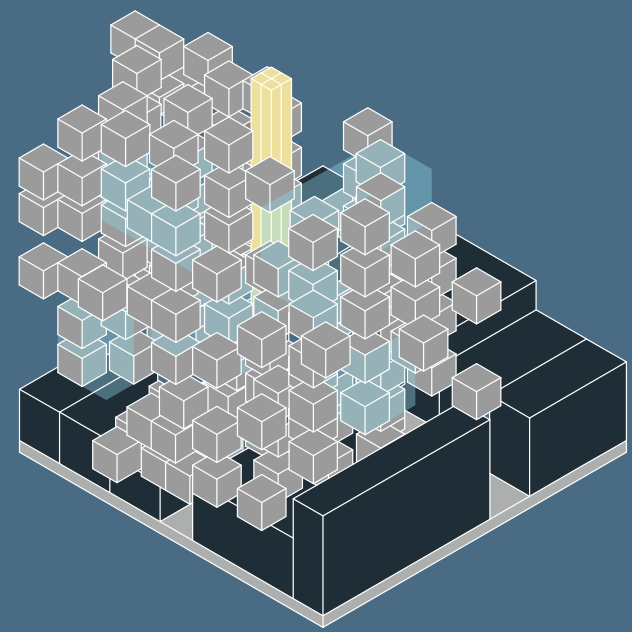

Fig. 8.13

Fig. 8.14
Diagrammatic interpretation of "Clusters in the air" Physical model of the "Clusters in the air" interpretation

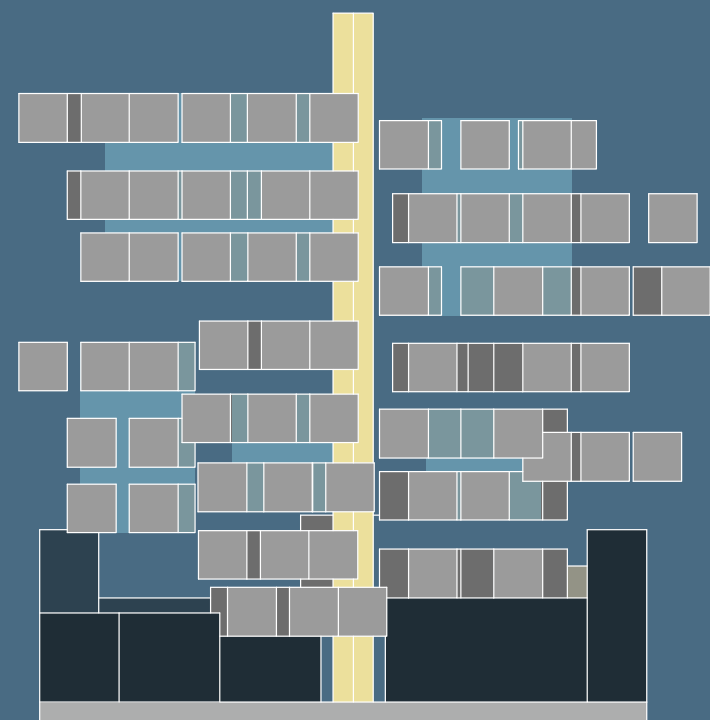


"Those who can foresee the coming changes become leaders. If you just follow the trends, you become short-sighted."

\section{- Arata Isozaki}

\section{2 "CLUSTERS IN THE AIR" BY ARATA ISOZAKI}

\section{AVAILABILITY}

Clusters in the Air, designed by Arata Isozaki, is an unrealized project that condenses housing in a new structural form in Tokyo, Japan. The post-WWII period in the 1960s, experienced a substantial economic growth, that resulted in the investigation of housing solutions to support overpopulation within the city fabric. In Japan, specifically, the solution focused on the continuing changes people face. Architecture was reconceived as biological, in terms of its existence, where its mechanics would continuously work together and have the ability to adapt alongside the rapid urban growth. In this sense, the proposal put forward by Isozaki is a representation of the biological form, a tree, that envisions cantilevered housing branching off from the central spine. It is a city separate from the chaos of growth faced by the existing city below.

The proposal coexists within the existing infrastructure and matches the classic Metabolist approach to design large scale construction in which vertical components become the anchor that holds the changeable horizontal parts. As the city is entangled with building restrictions and limited plots of land, Isozaki, by proposing these clusters on the smaller lots, is attacking the existing city from above. Its image alone can deduce the future consequences of the physical form. The lack of sunlight, unable to penetrate through the height of the towers, would alone endanger the living conditions on the ground plane and eventually turn the existing infrastructures obsolete. This vision of the future city is an active life form that is repeatedly transformed by the people who wish to escape the chaos, but in reaction it produces obsolete structures that were once active and possibly cherished by the community.

Overly populated cities are sometimes defined by economic growth and shortage of building lots. Many cities in India, for example, are overrun by slums to shelter the people who cannot afford the standard living amenities, instead creating their own informal homes in the space that is available to them. Often these slums are removed to make space for a more profitable program. In the process of creating a new structure the existing fabric is made obsolete and destroyed to benefit the city growth. The exploration here proposes the idea of the Clusters in the Air at a lower altitude, where the form is shaped over the existing construction. It slowly branches outwards according to the needs at hand and is flexible to unexpected changes. Is the end goal to preserve everything that exists with new overgrowing adaptable design whereby the city never becomes obsolete? 

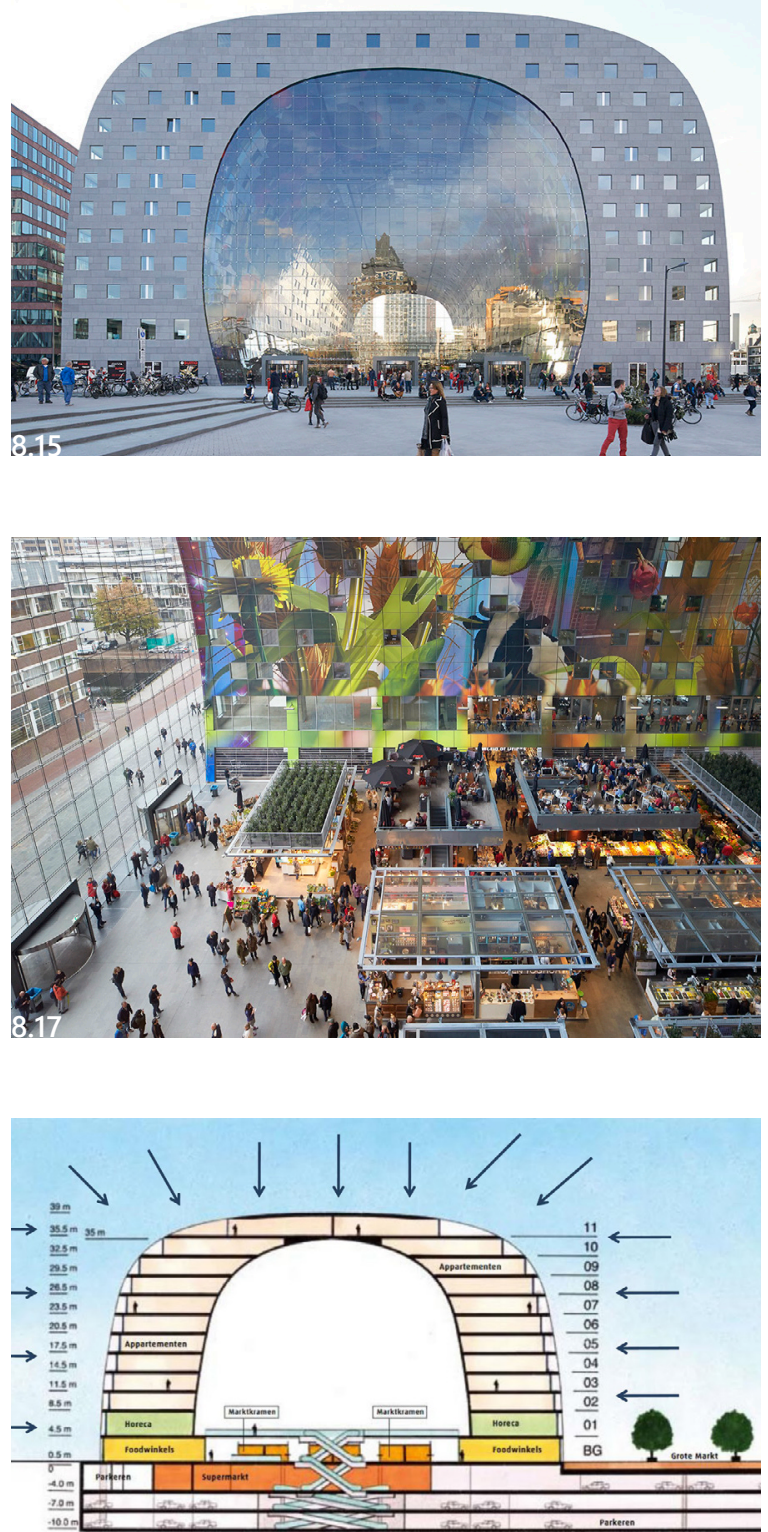
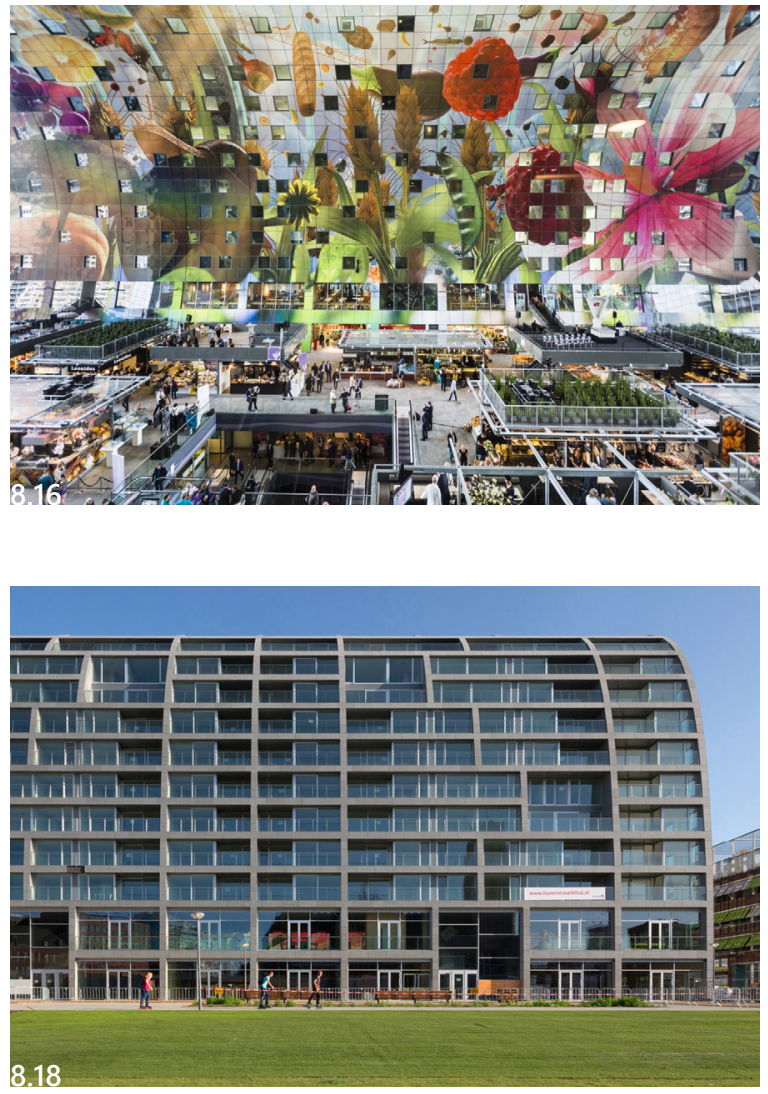

Fig.8.15 Markhthal Rotterdam exterior

Fig.8.16 View of the second market level

Fig.8.17 Aerial view between the entrance and retailer

Fig.8.18 Residential balconies

Fig.8.19 Markhthal Rotterdamn section 
"Rotterdam lacked a large interior space at that time and here it was, the city's living room."

- Jan Knikker

\section{3 MARKTHAL ROTTERDAM}

MVRDV

\section{EXCHANGE}

Ordinarily, the idea of seeing a market directly outside of a residence window seems absurd, however it creates a unique culinary and living experience that encourages user interaction and engages two separate programs within a whole. Such is the condition in Markthal Rotterdam. It is a 40 metre high, 70 metre wide and 120 metre long vault covered with a botanical mural that contains approximately 100 produce stalls on ground level, 1,200 parking spots in the lower levels, and is surrounded by 228 apartments. ${ }^{1}$ The form was derived from a study of Europe's covered food markets, where the resulting design had to be as open as possible to becoming a tourist attraction as well as be closed off from the external environment. ${ }^{2}$ As an icon of the city, the building presents how two very different program, public and private, can cohesively exist under one roof, while accommodating a spectrum of users.

The building is a sustainable combination of food, leisure, living and parking, that strategically separates two opposite programs of private and public use. ${ }^{3}$ The stalls vary in services and produce, including cheeses, ice cream parlours, restaurants, food vendors, and grocery, where a few have chosen to expand to the second level. The inhabitants of the apartments, on the other hand, have six separate elevator entrances and staircases on boarders that gradually change in size and location due to the curved form. ${ }^{4}$ All units have expansive balconies and angled windows that connect the inhabitants to both

the urban context and the ongoing activities on the lower levels, while permitting natural light into their space.

Markthal Rotterdam is strongly rooted in the city's history. It is located parallel to the late medieval Laurens Church and is located at a former dike along the river, whose remains are now part of a permanent archaeology exhibit along the central staircase. ${ }^{5}$ The structure presents an uncommon program combination to create a single experience that is always visible to the residents and the users of the public realm. It may be occupied throughout the day, inviting the public in with its lush mural and tall transparent façade. 

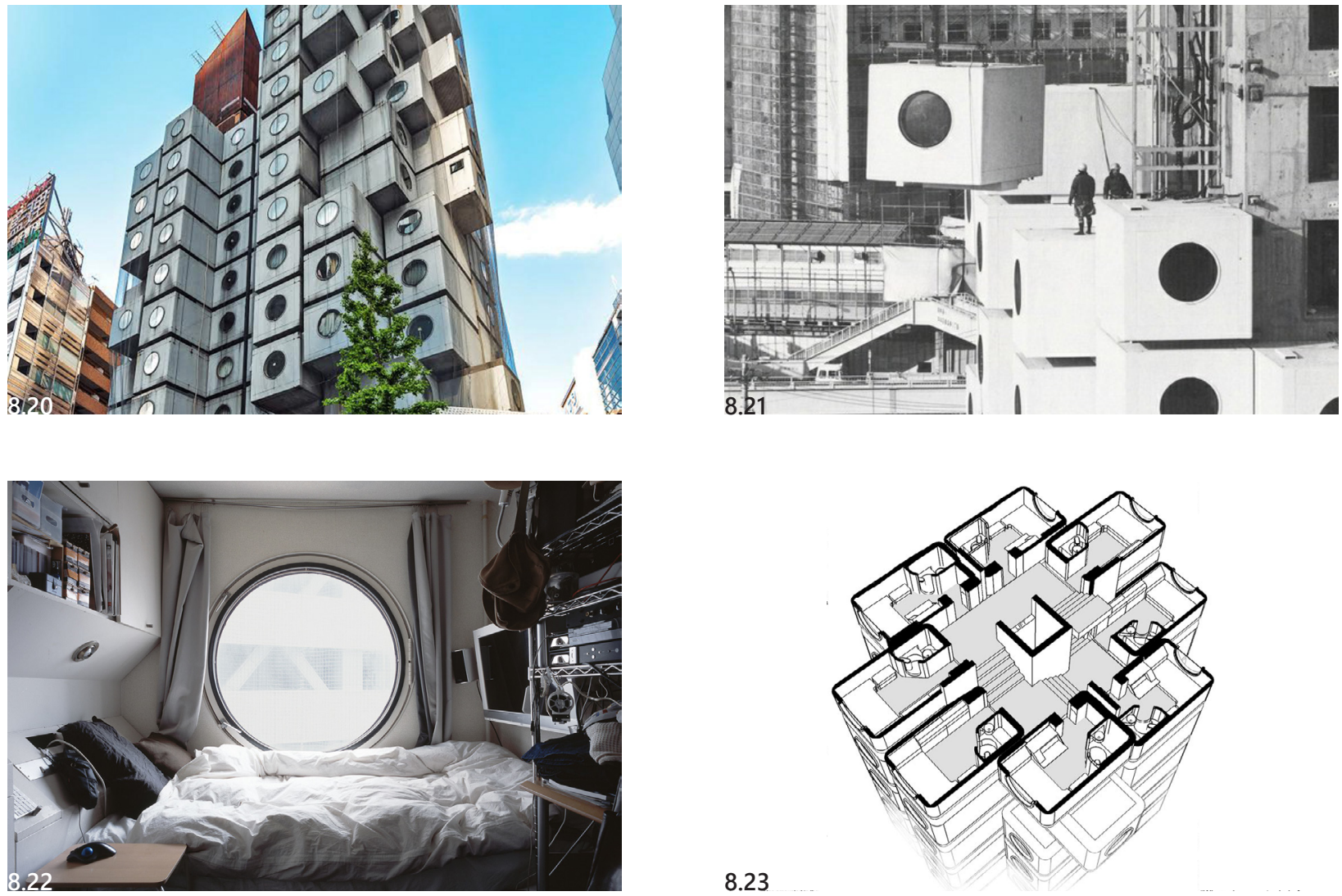

8.23
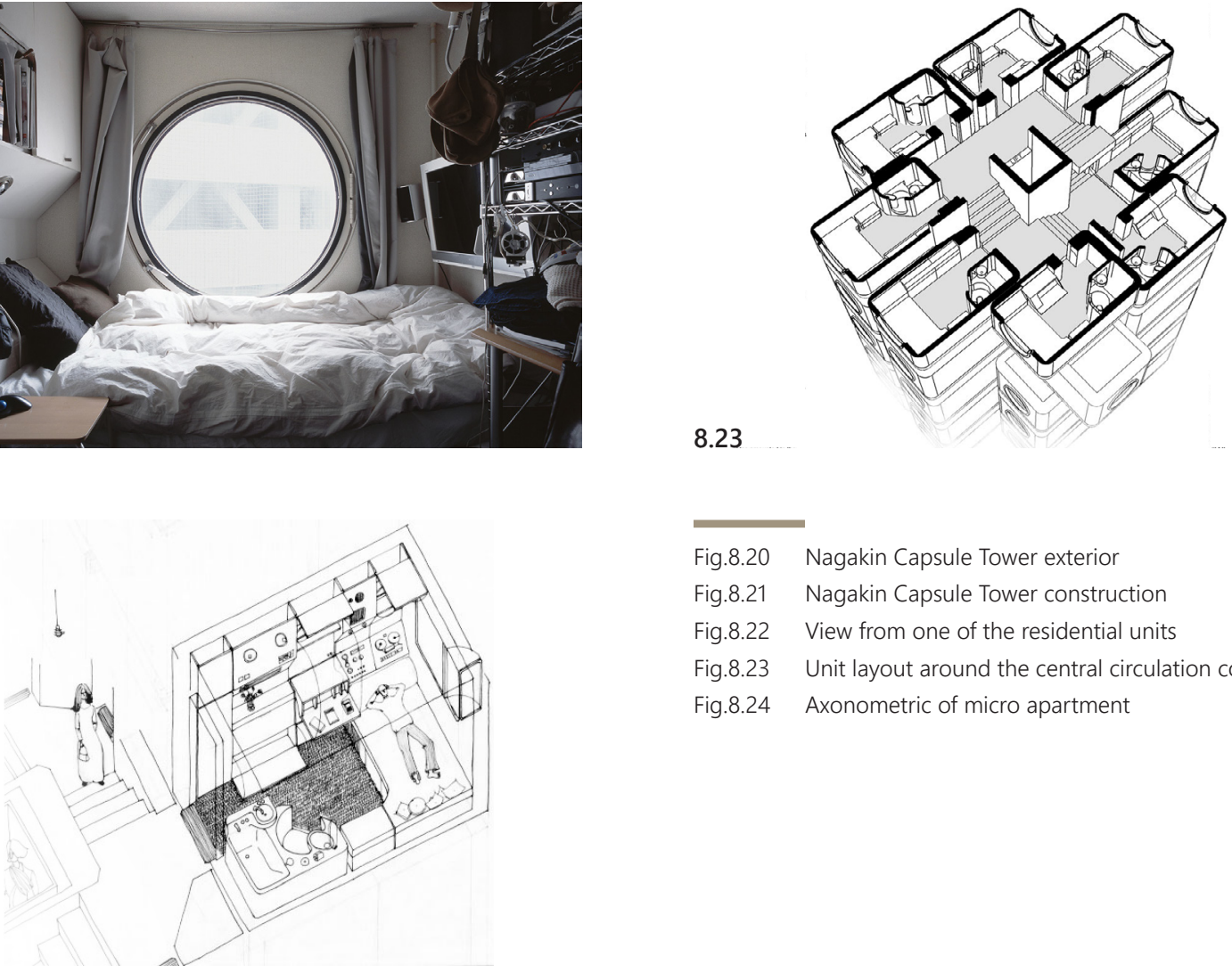

Fig.8.20 Nagakin Capsule Tower exterior

Fig.8.21 Nagakin Capsule Tower construction

Fig.8.22 View from one of the residential units

Fig.8.23 Unit layout around the central circulation core

Fig.8.24 Axonometric of micro apartment 
"The architecture of Metabolism was based on the image of a living cell. Capsule architecture was an architectural expression of the living cell."

- Kisho Kurokawa

\subsection{NAKAGIN CAPSULE TOWER}

\section{KISHO KUROKAWA}

\section{A DAPTABILITY}

The Nagakin Capsule Tower, constructed in 1972 as the world's first fully built modular unit building, introduced adaptable self-contained residential units that dared to envision the future living conditions in Japan. ${ }^{6}$ Kisho Kurokawa imagined a world where people would no longer need a single dwelling but instead owned five different units that could be occupied at different moments over a certain period. ${ }^{7}$ When initially designed, the target audience for the pods included international businesspeople and the people who commuted from outside the urban core for work. It was built as an experimental project to support a new, postwar lifestyle, encouraging change and renewal in the dynamic urban fabric of Tokyo. ${ }^{8}$ Approximately sized at ten square metres each, the capsules were intended to support single occupancy in the form of an apartment or a studio space, but could also accommodate families by connecting multiple units.

In conceiving of the organic capacities of architecture, the Metabolist movement's concepts were rooted in adaptability, exchangeability, and impermanence. The units were built compactly with a variety of components that aimed to provide a basic outfitted space to support the lifestyle of a modern urban person in the city. ${ }^{9}$ Its layout makes it difficult to move around the apartment but not impossible, since human scale and movement were strictly observed and accounted for prior to its conception. ${ }^{10}$ The overall design can be read as a compelling prototype embedded in a number of flaws that became clear after a period of time. Nothing created can be considered perfect and timelessly viable, hence this design, at best, reflects one of many responses to rapid transformation of modern cities and advancements in technology.

Due to the dispersal of ownership and capsules between many people, the maintenance of the building is difficult to achieve as a whole. ${ }^{11}$ This form of discontinuity contradicts the initial intentions behind the prototype, which was to have an adaptable system that is capable of being updated with the evolving technology. The tenants' unwillingness to comply with the upkeep process and mass removal process of changing the capsules is what led to many disputes discussed today, which has now put the building at risk for demolition. 

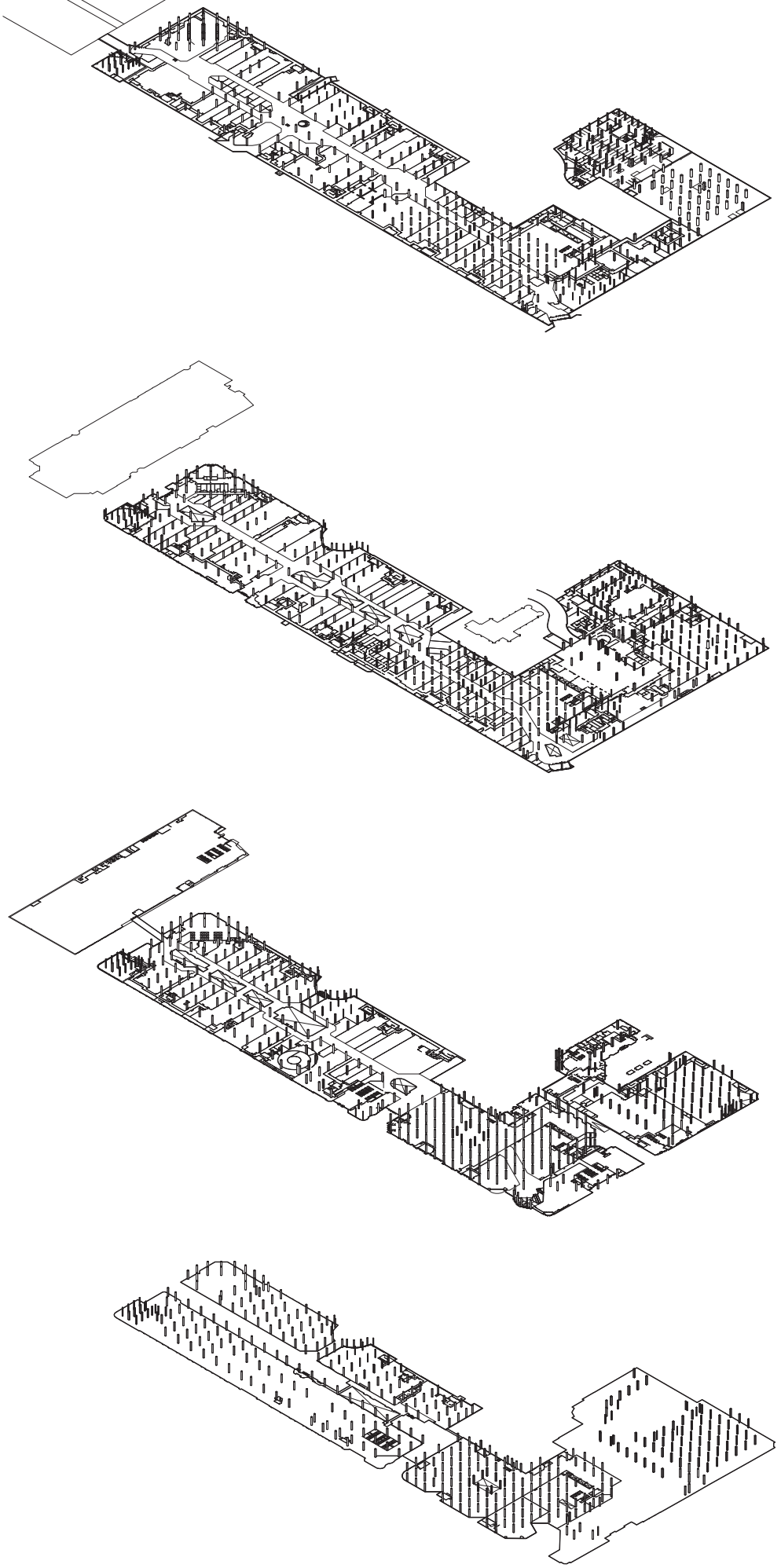

Fig.8.25 Existing Structure of Eaton Centre 


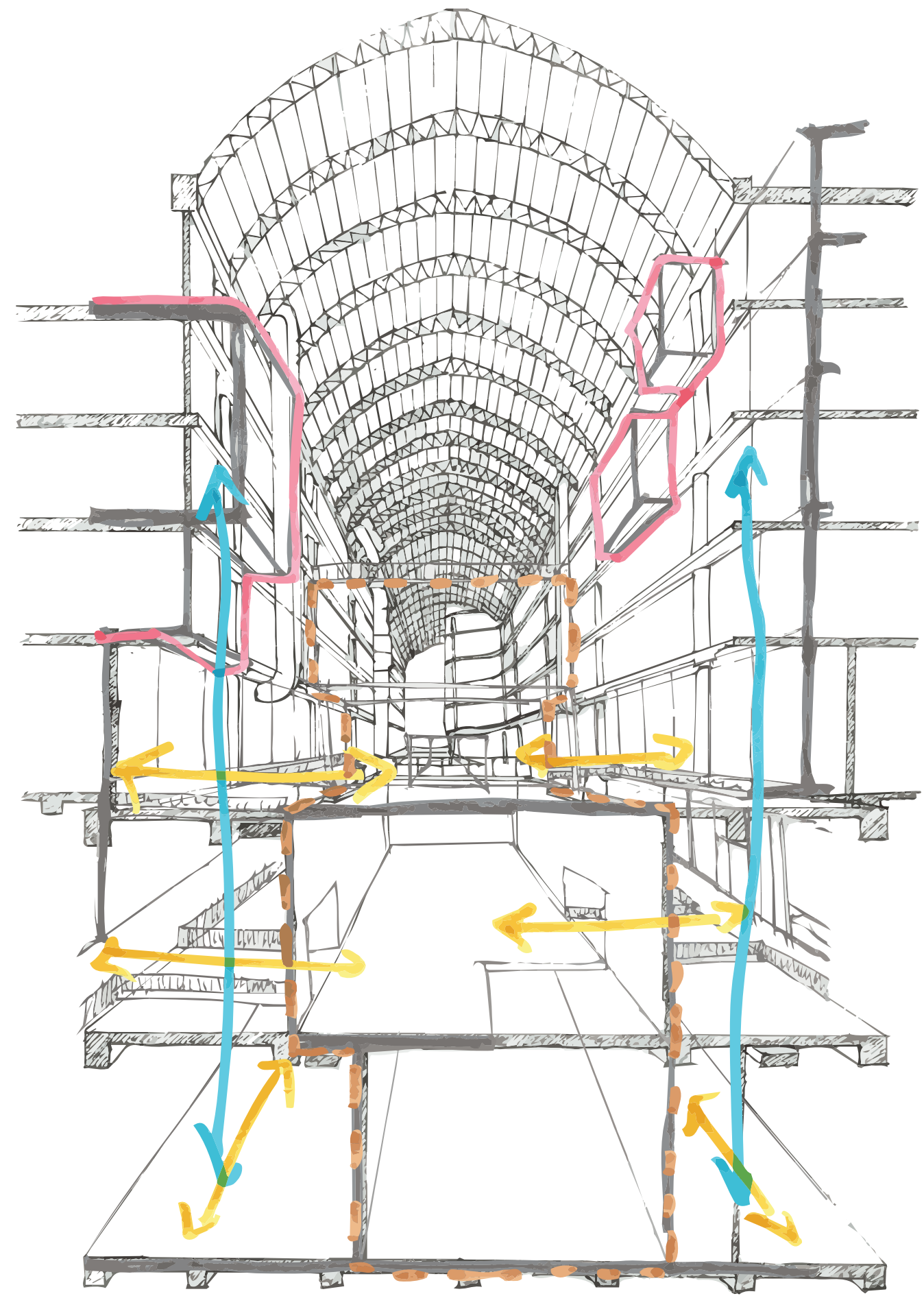

Fig.8.26 Sectional exploration drawing 


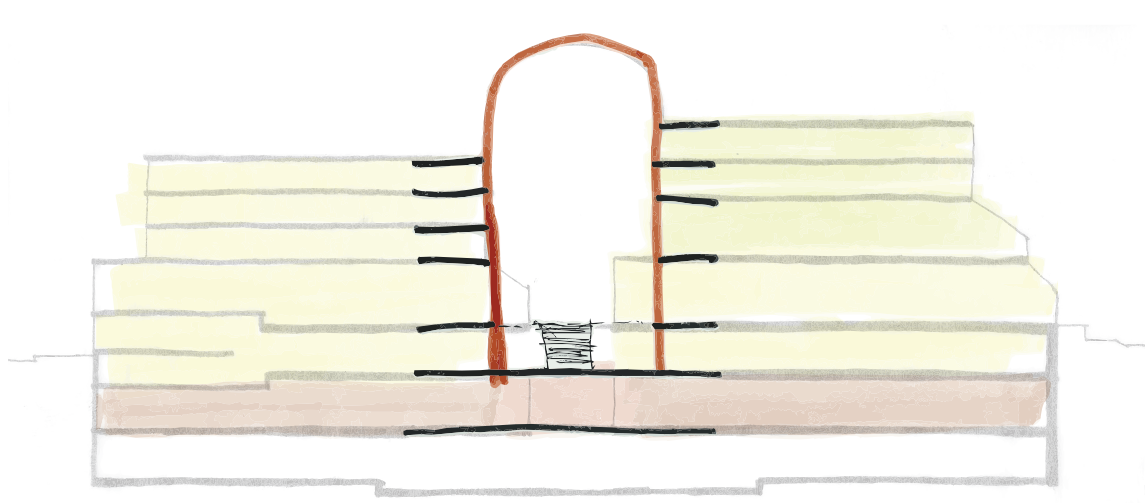

Extending the arcade to second level
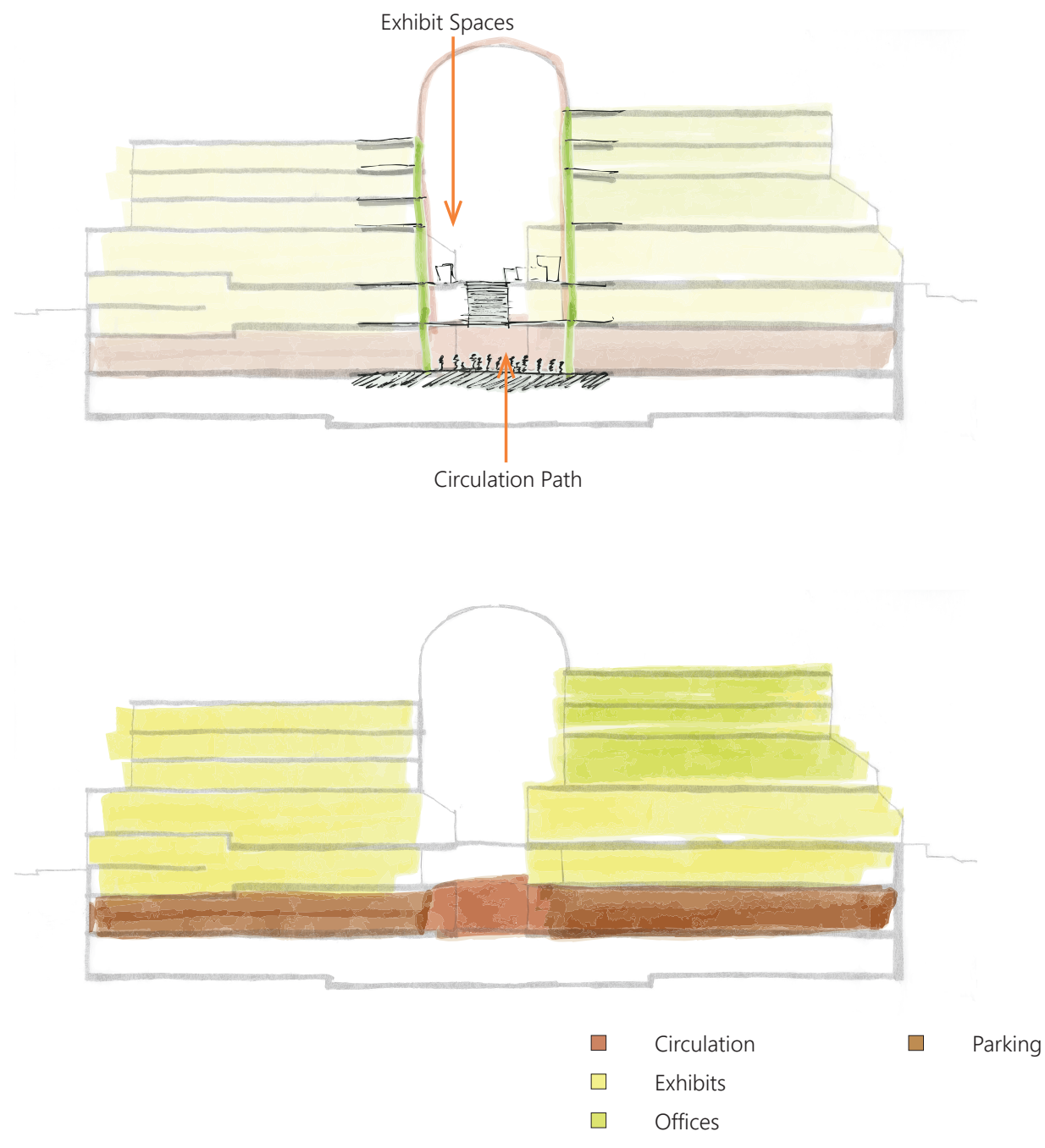

Fig.8.27A Program Exploration Drawings 


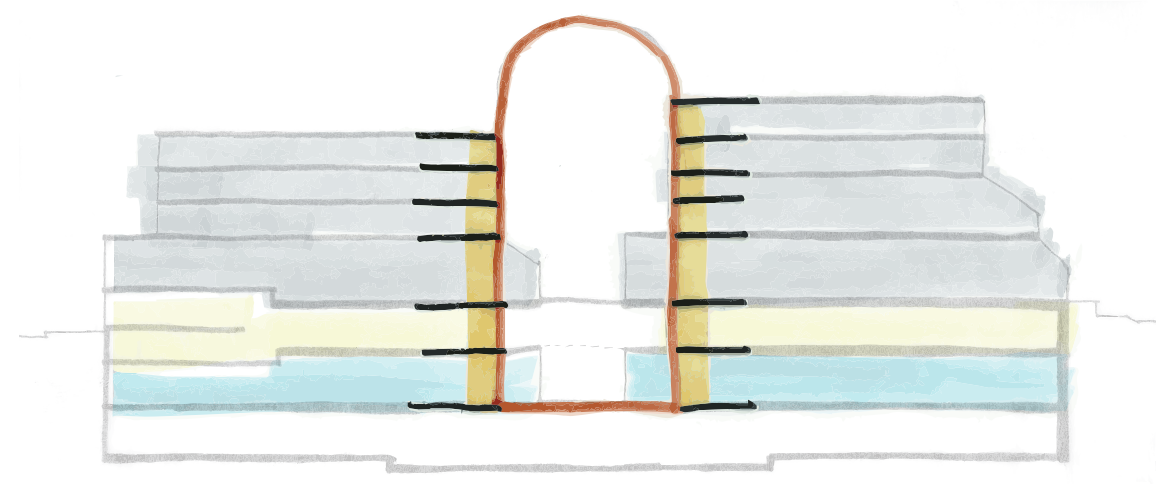

Extending the arcade to first level
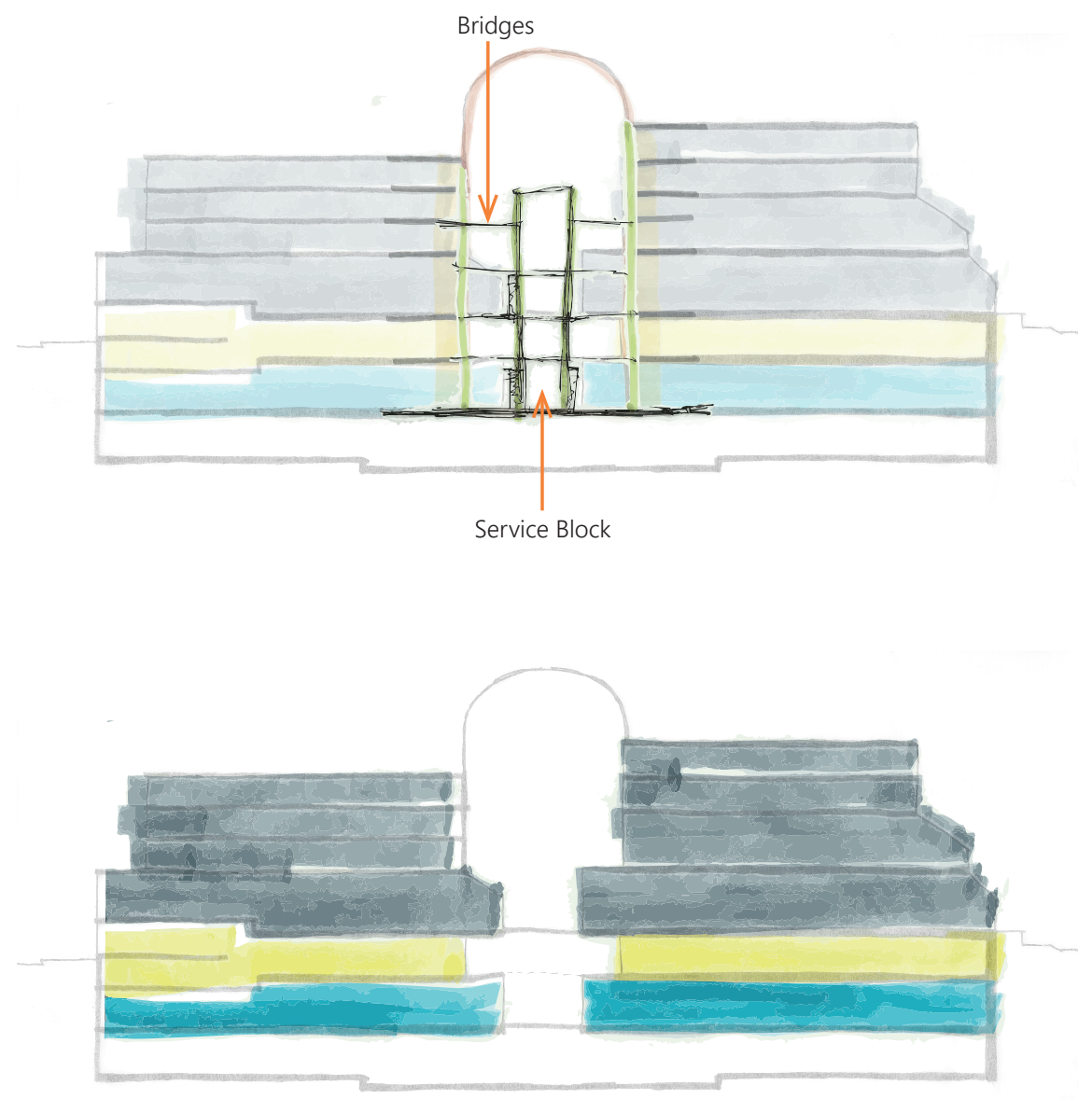

$\square \quad$ Big-box Stores
$\square \quad$ Housing

$\square \quad$ Private Businesses 

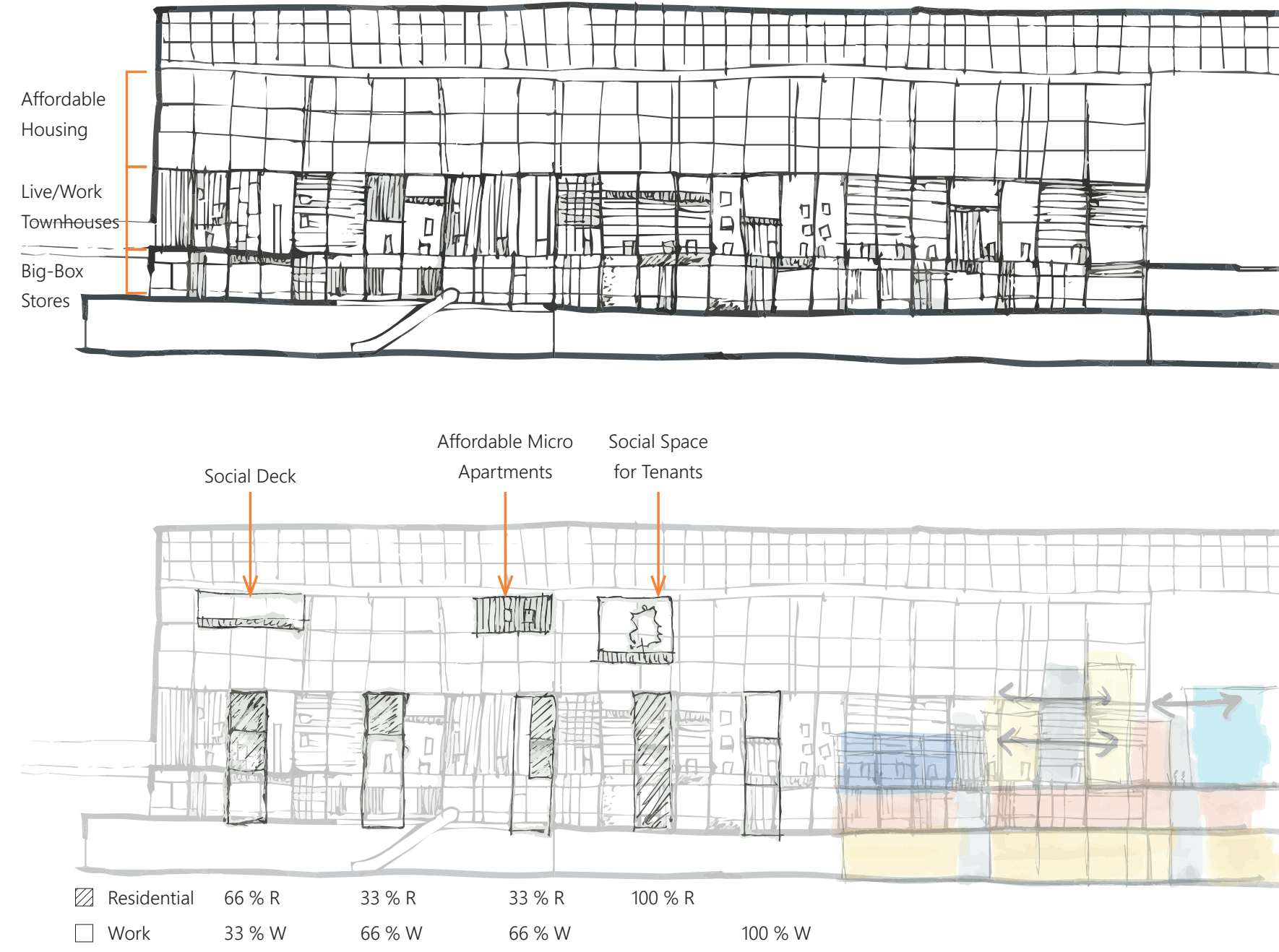

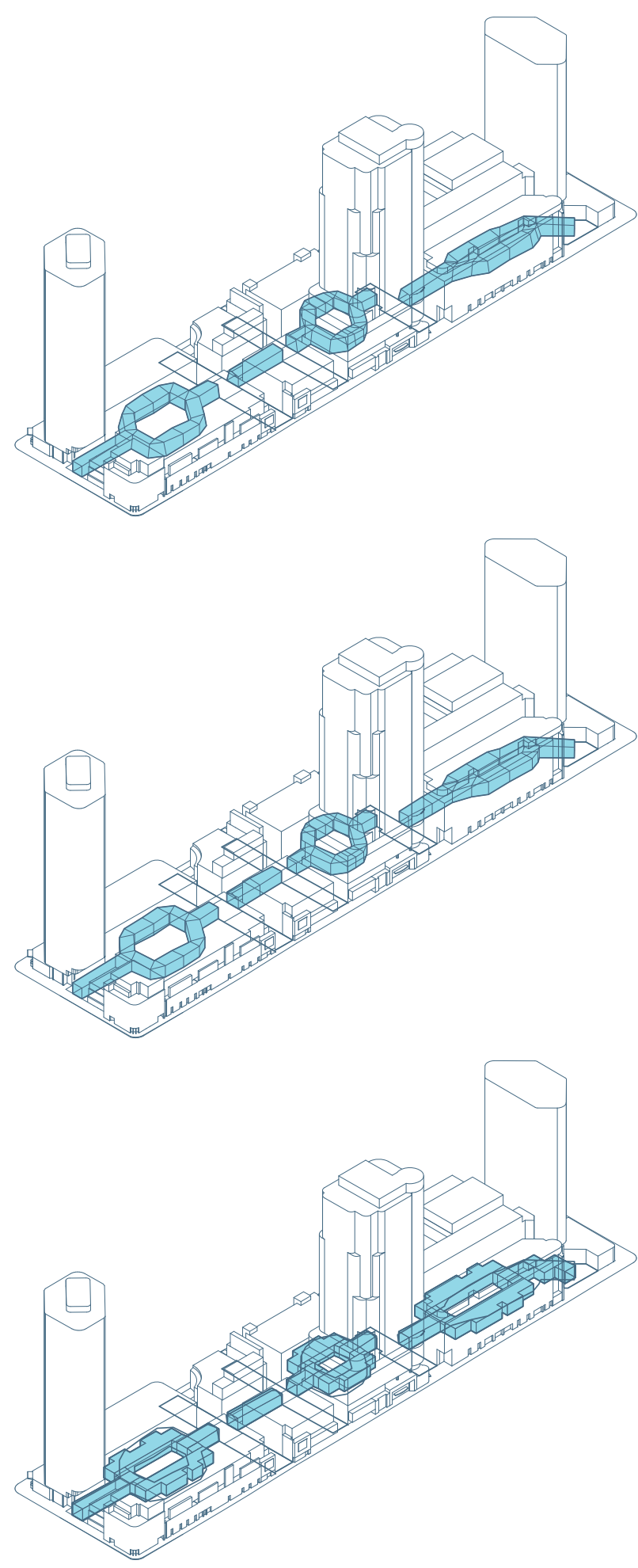


\section{END NOTES}

1 Rob Bevan. "Vegetal Vault." The Architectural Review 237, no. 1415 (2015): 58. http:// ezproxy.lib.ryerson.ca/login?url=https:// search-proquest-com.ezproxy.lib.ryerson.ca/ docview/1646467384? accountid=13631

2 n.d. "Market Hall." MVRDV. Accessed November 1, 2017. https://www.mvrdv.nl/projects/ markethall/.

$3 \quad$ Ibid

4 n.d. "Markthal Rotterdam / MVRDV." ArchDaily. October 8, 2014. Accessed November 1, 2017. https://www.archdaily.com/553933/markthalrotterdam-mvrdv.

5 n.d. "Landmark in the City." Architecture + Design 32, no. 4 (2015): 103. http://ezproxy. lib.ryerson.ca/login?url=https://searchproquest-com.ezproxy.lib.ryerson.ca/ docview/1704728679? accountid=13631.

$6 \quad$ Zhongjie Lin. "Nakagin Capsule Tower: Revisiting the Future of the Recent Past." Journal of Architectural Education 65 (2011): 13. doi:10.1111/j.1531-314X.2011.01158.

7 n.d. "Kisho Kurokawa: Nakagin Capsule Tower Building." Design Boom, November 18, 2011. Accessed November 1, 2017. https:// www.designboom.com/architecture/kishokurokawa-nakagin-capsule-tower-building/.

8 Lin. "Nakagin Capsule Tower", 21.
$9 \quad$ Ibid., 19.

n.d. "Nakagin Capsule Tower in Tokyo / Kisho Kurokawa." ArchEyes, March 3, 2016. Accessed November 1, 2017. http://archeyes.com/ nakagin-capsule-tower-kisho-kurokawa/.

11 Ibid 


\section{B I B L I O GRAPHY}

n.d. "10 Retailer Investments for an Uncertain Future." PwC Global, 2017. Accessed November 7, 2017. www.pwc. com/2017totalretail.

Abramson, Daniel M. Obsolescence: An Architectural History (Chicago: The University of Chicago Press, 2016).

Ahn, Keehyun, Isak Chung, Eungee Cinn, Richard Enos, Da Eun Jeong, Seungbum Kim, and Sung Hong Kim. On the Korean Front Line: The Far Game, Constraints Sparking Creativity (Seoul: SPACE Books, 2016).

Andolfo, Thomas S., M. A. I., and S. R. A. "The "Mall" in "Mall"." Valuation 18, no. 3 (2013): 12-13. http://ezproxy.lib.ryerson.ca/login?url=https:// search-proquest-com.ezproxy.lib.ryerson.ca/ docview/1448810422? accountid=13631.

Araoz, Gustavo F. "World-Heritage Historic Urban Landscapes: Defining and Protecting Authenticity." APT Bulletin: The Journal of Preservation technology 39, no. 2-3 (2008): 33-37.

Arrhenius, Thordis, Erik Langdalen, and Jorge OteroPailos. Experimental Preservation (Zurich: Lars Müller Publishers, 2016).

Aureli, Pier Vittorio. The Possibility of an Absolute Architecture (London: The MIT Press, 2011).

Bachelard, Gaston. The Poetics of Space. Translated by Maria Jolas. Boston: Beacon Press, 1994.

n.d. "Back to the Future: Visionary architecture in postwar Japan." Taschen, 2017. Accessed November 15, 2017. https://www.taschen.com/pages/en/catalogue/ architecture/all/06769/facts.koolhaas_obrist_project_ japan_metabolism_talks.htm.

Bader, Vera Simone, and Andres Lepik, eds. World of Malls: Architectures of Consumption (Berlin: Hatje Cantz, 2016).

Ballard, J. G. 2006. Kingdom Come. London: Fourth Estate.

—. 2001. The Best Short Stories of J. G. Ballard. New York: Picador .

Brand, Stewart. 1995. How Buildings Learn: What Happens After They're Built. New York: Penguin Books.

Bevan, Rob. "Vegetal Vault." The Architectural Review 237, no. 1415 (2015): 56-67. http://ezproxy.lib.ryerson.ca/ login?url=https://search-proquest-com.ezproxy.lib. ryerson.ca/docview/1646467384? accountid=13631.

Briggs, Robert. "The future of prediction: speculating on William Gibson's meta-science-fiction." Textual Practice 27, no. 4 (2013): 671-693. doi:http://dx.doi.org /10.1080/0950236X.2012.738702.

n.d. "Building Types Study 513: Shopping Malls in the Center City." Architectural Record 163, no. 3 (1978): 117-132. Accessed May 25, 2018. http://ezproxy.lib.ryerson.ca/ login?url=https://search-proquest-com.ezproxy.lib. ryerson.ca/docview/54918493? accountid=13631.

Burda, Cherise, Graham Haines, and Shaun Hildebrand. "Bedrooms in the Sky: Is Toronto Building the Right Condo Supply?" Ryerson City Building Institute, November 7, 2017. Accessed February 3, 2018. https:// 
www.citybuildinginstitute.ca/reports/.

Cairns, Stephen, and Jane M. Jacobs. Buildings Must Die: A Perverse View of Architecture (New York: The MIT Press, 2014).

Carter, Maria. "What it's like to live inside America's oldest shopping mall." Country Living, October 19, 2016. Accessed November 1, 2017. http://www.countryliving. com/real-estate/a40217/living-in-americas-oldestmall/.

Cecchini, Arnaldo. "The future of the city from Science to Science Fiction and back (and beyond)." City, Territory and Architecture 1, no. 5 (2014): 1-9. doi:10.1186/21952701-1-5.

n.d. "Census 2016: Age and Sex; Type of Dwelling." City of Toronto. City Planning, Research and Information, May 4, 2017. Accessed November 7, 2017. https://web. toronto.ca/wp-content/uploads/2017/10/96d7-2016Census-Backgrounder-Age-Sex-Dwelling-Type.pdf.

Chapman, Jonathan. "Design for (Emotional) Durability." Design Issues 25, no. 4 (2009): 29-35. http://www.jstor. org/stable/20627827.

Charney, Igal, Pierre Filion, and Rachel Weber. "Downtowns that Work: Lessons from Toronto and Chicago." Canadian Journal of Urban Research 24, no. 2 (2015): 20-42. Accessed May 25, 2018. http://ezproxy.lib.ryerson.ca/login?url=https:// search-proquest-com.ezproxy.lib.ryerson.ca/ docview/1769724011?accountid=13631. n.d. "CHBA Points to "Missing Middle" in Housing Affordability Crunch." Canadian Home Builders' Association, March 3, 2017. Accessed February 3, 2018. https://www.chba.ca/CHBA/News/CHBA_Points_to_ Missing_Middle_in_Housing_Affordability_Crunch. aspx.

Chung, Chuihua Judy, Jeffrey Inaba, Rem Koolhaas, and Sze Tsung Leong, eds. Project on the City II: The Harvard Guide to Shopping (Cologne: Taschen, 2001).

n.d. "City of Imagination." City of Darkness. Accessed November 1, 2017. http://cityofdarkness.co.uk/cityof-imagination/.

Cole, Sam. "Dare to Dream: Bringing Futures into Planning." APA Journal 67, no. 4 (2001): 372-383. doi:10.1080/01944360108976246.

Coleman, Nathaniel. "Building Dystopia." Rivista MORUSUtopia e Renascimento, no. 4 (2017): 181-192. http:// www.revistamorus.com.br/index.php/morus/article/ view/180/157.

-. "The Problematic of Architecture and Utopia." Utopian Studies 25, no. 1 (2014): 1-22. doi:10.5325/ utopianstudies.25.1.0001.

-. "Utopia and Modern Architecture?" Architectural Research Quarterly 16, no. 4 (2012): 339-348. doi:10.1017/S1359135513000225.

n.d. "Common Ground / URBANTAINER." ArchDaily, February 16, 2017. Accessed March 6, 2018. https:// www.archdaily.com/805302/common-ground- 
urbantainer.

n.d. "Common Ground." Urbantainer. Accessed March 6, 2018. http://www.urbantainer.com/?mies portfolio $=708-2$.

n.d. "Common Ground." Archello. Accessed March 6, 2018. https://archello.com/project/common-ground.

Contandriopoulos, Christina. "Architecture and Utopia in the 21st-Century." Journal of Architectural Education 67, no. 1 (2013): 3-6. doi:10.1080/10464883.2013.771 021.

Crainer, Stuart. "Digital Post and Beyond: The Future Post Office?" Business Strategy Review 22, no. 2 (2011): 7-9. doi:10.1111/j.1467-8616.2011.00743.x.

Ellard, Colin. Places of the Heart: The Psychogeography of Everyday Life (New York: Bellevue Literary Press, 2015).

Fixler, David N. "Is It Real and Does It Matter? Rethinking Authenticity and Preservation." Journal of the Society of Architectural Historians 67, no. 1 (2008): 11-13.

Fletcher, John. "James Graham Ballard." In British Novelists Since 1960, edited by Jay L. Halio. Dictionary of Literary Biography Vol. 14. Detroit: Gale, 1983. Literature Resource Center (accessed June 10, 2018).

Fowler, Pauline. "The Toronto Eton Centre and its Precedent, the Galleria in Milan." Fifth Column 3, no. 3-4 (1983): 84-86. http://ezproxy.lib.ryerson.ca/ login?url=https://search-proquest-com.ezproxy.lib. ryerson.ca/docview/55141582?accountid=13631.
Architecture and Interpretation: Essays for Eric Fernie (Woodbridge: The Boydell Press, 2012).

n.d. "Getting to 8,000: Building a healthier rental market for the Toronto Area." Evergreen, October, 2017. Accessed February 10, 2018. https://www.evergreen. ca/tools-publications/getting-to-8000-building-ahealthier-rental-market-for-the-toronto-area/.

Gleick, James. Time Travel: A History (New York: Pantheon Books, 2016).

Grunenberg, Christoph, and Max Hollein, eds. Shopping: A Century of Art and Consumer Culture (Berlin: Hatje Cantz Publishers, 2002).

Hancock, Philip, André Spicer, and Zhongyuan Zhang. "Hyper-Organizational Space in the Work of J. G. Ballard." Organization 15, no. 6 (2008): 889910. doi:https://doi-org.ezproxy.lib.ryerson. $\mathrm{ca} / 10.1177 / 1350508408095819$.

Harbison, Robert. Eccentric Spaces (London: The MIT Press, 2000).

- Ruins and Fragments: Tales of loss and rediscovery (London: Reaktion Books Ltd., 2015).

Hardwick, M. Jeffrey. Mall Maker: Victor Gruen, Architect of an American Dream (Philadelphia: University of Pennsylvania Press, 2004).

Harlan, Wilson D. J. G. Ballard (Modern Masters of Science Fiction) (Champaign: University of Illinois Press, 2017). https://ebookcentral-proquest-com.ezproxy.lib. ryerson.ca/lib/ryerson/detail.action?docID $=5161247$. 
Harter, Seth. "Hong Kong's Dirty Little Secret." Journal of Urban History 27, no. 1 (2000): 92-113. doi:10.1177/009614420002700106.

Heathcott, Joseph. "Planning Note: Pruitt-Igoe and the Critique of Public Housing." Journal of the American Planning Association 78, no. 4 (2012): 450-451. doi:10. 1080/01944363.2012.737972.

Hulchanski, John David. The Three Cities within Toronto: Income Polarization Among Toronto's Neighbourhoods, 1970-2005 (Toronto, Ontario: Cities Centre, 2010).

Huyssen, Andreas. Present Pasts: Urban Palimpsests and the Politics of Memory (Stanford: Stanford University Press, 2003).

Jackson, John Brinckerhoff. A Sense of Place, a Sense of Time (London: Yale University Press, 1994).

- The Necessity for Ruins and Other Topics (Massachusetts: University of Massachusetts Press, 1980).

Jacoby, Sam. "Type versus typology." The Journal of Architecture 20, no. 6 (2015): 931-937. doi:10.1080/13 602365.2015 .1115600 .

Jerome, Pamela. "An Introduction to Authenticity in Preservation." APT Bulletin: The Journal of Preservation Technology (Association for Preservation Technology International) 39, no. 2-3 (2008): 3-7.

Johannson, Anna. "This Startup Believes The Future Of Retail Is Permanent Pop-Up Shops." psfk, June 1, 2017. Accessed February 10, 2018. https://www.psfk. com/2017/06/this-startup-believes-the-future-of- retail-is-permanent-pop-up-shops.html.

Jones, Francis M. "A Study in Obsolescence." The Town Planning Review 38, no. 3 (1967): 187-201. http://www. jstor.org/stable/40102561.

Kim, Young, and Lauren Teague. "Urbantainer breaks down the negative stereotypes of modular building." Frame, March 21, 2017. Accessed March 5, 2018. https://www. frameweb.com/news/urbantainer-breaks-down-thenegative-stereotypes-of-modular-building.

n.d. "Kisho Kurokawa: Nakagin Capsule Tower Building." Design Boom, November 18, 2011. Accessed November 1, 2017. https://www.designboom.com/architecture/ kisho-kurokawa-nakagin-capsule-tower-building/.

Kwinter, Sanford. Architectures of Time: Toward a Theory of the Event in Modernist Culture (London: The MIT Press, 2002).

Lai, Jimenez. Citizens of No Place: An Architectural Graphic Novel (New York: Princeton Architectural Press, 2012). Lam, Sharon. "In the Shadow of the Kowloon Walled City." Salient, September 15, 2015. Accessed November 1, 2017. http://salient.org.nz/2015/09/in-the-shadowof-the-kowloon-walled-city/.

Lambot, lan. "Self Build and Change: Kowloon Walled City, Hong Kong." Architectural Design 87, no. 5 (2017): 122-129. doi:10.1002/ad.2225.

n.d. "Landmark in the City." Architecture + Design 32, no. 4 (2015): 96-104. http://ezproxy.lib.ryerson.ca/ login?url=https://search-proquest-com.ezproxy.lib. 
ryerson.ca/docview/1704728679?accountid=13631.

Levine, Neil. "Building the Unbuilt: Authenticity and the Archive." Journal of the Society of Architectural Historians (University of California Press) 67, no. 1 (2008): 14-17.

Lin, Zhongjie. "Nakagin Capsule Tower: Revisiting the Future of the Recent Past." Journal of Architectural Education 65 (2011): 13-32. doi:10.1111/j.1531314X.2011.01158.

Lynch, Kevin. What time is this Place? (London: The MIT Press, 1972).

n.d. "Market Hall." MVRDV. Accessed November 1, 2017. https://www.mvrdv.nl/projects/markethall/.

n.d. "Markthal Rotterdam / MVRDV." ArchDaily, October 8, 2014. Accessed November 1, 2017. https://www. archdaily.com/553933/markthal-rotterdam-mvrdv.

McMordie, Michael. "Eaton Centre." The Canadian Encyclopedia, July 2, 2006. Accessed November 15, 2017. https://www.thecanadianencyclopedia.ca/en/ article/eaton-centre/.

Mennel, Timothy. "Victor Gruen and the Construction of Cold War Utopias." Journal of Planning History 3, no. 2 (2004): 116-150. Accessed July 1, 2018. doi:10.1177/1538513204264755.

n.d. "Micro Lofts at the Arcade Providence." Northeast Collaborative Architects. Accessed November 1, 2017. http://ncarchitects.com/portfolio/item/theprovidence-arcade-\%E2\%80\%A2-providence-rhode- island/.

Moylan, Tom. Scraps of the Untained Sky: Science Fiction, Utopia, Dystopia (Colorado: Westview Press, 2000).

Myrberg, Nanouschka. "False monuments? On antiquity and authenticity." Public Archaeology 3 (2004): 151161.

n.d. "Nakagin Capsule Tower in Tokyo / Kisho Kurokawa." ArchEyes, March 3, 2016. Accessed November 1, 2017. http://archeyes.com/nakagin-capsule-tower-kishokurokawa/.

Nunn, Samuel, Colin Warren, Robert Warren, and Stacy Warren. "The Future of the Future in Planning: Appropriating Cyberpunk Visions of the City." Journal of Planning Education and Research 18, no. 1 (1998): 49-60. doi:10.1177/0739456X9801800105.

O'Neill, D. Kevin. "When Form Follows Fantasy: Lessons for Learning Scientists From Modernist Architecture and Urban Planning." The Journal of the Learning Sciences 25, no. 1 (2016): 133-152. doi:10.1080/10508406.2015 .1094736

Orr, Leonard. "The Utopian Disasters of J. G. Ballard." CLA Journal 43, no. 4 (2000): 479-93. http://www.jstor.org/ stable/44325010.

Picon, Antoine, and Karen Bates. "Anxious Landscapes: From the Ruin to Rust." Grey Room, no. 1 (2001): 6483. http://www.jstor.org/stable/1262551.

n.d. "Planned Obsolescence." Oxford Dictionaries. Accessed November 15, 2017. https://en.oxforddictionaries. 
com/definition/planned_obsolescence.

Plena, Tabula. Forms of Urban Preservation. Edited by Bryony Roberts. Zurich: Lars Müller Publishers, 2016.

Psarra, Sophie. Architecture and Narrative: The Formation of Space and Cultural Meaning (New York: Routledge, 2009).

n.d. "Retail." Oxford Dictionaries. Accessed June 13, 2018. https://en.oxforddictionaries.com/definition/retail.

Rigby, Darrell K. "The Future of Shopping." Harvard Business Review (2011): 4-12. http://www.wipro.com/ documents/the-future-of-shopping.pdf.

Rossie, Aldo. The Architecture of the City. Translated by Diane Ghirardo and Joan Ockman. London: The MIT Press, 1982.

Rothfeld, Becca. "J.G. Ballard's Eerily Accurate Dystopias." The New Republic, March 14, 2018. Accessed June 10, 2018. https://newrepublic.com/article/147456/jgballards-eerily-accurate-dystopias.

Roxburgh, Helen. "Seoul occupancy: city adapts to accommodate its singletons." Financial Times, April 28, 2017. Accessed March 3, 2018. https://www.ft.com/ content/b9440e12-25ba-11e7-a34a-538b4cb30025.

Sadler, Simon. Archigram: Architecture without architecture (Cambridge: MIT Press, 2005).

Sargent, Lyman Tower. Utopianism: A Very Short Introduction (New York: Oxford University Press, 2010). n.d. "Songpa Micro Housing / SsD." ArchDaily, December 11, 2014. Accessed March 3, 2018. https://www. archdaily.com/576302/songpa-micro-housing-ssd.

n.d. "Songpa Micro-Housing." SsD. Accessed March 4, 2018. http://www.ssdarchitecture.com/works/ residential/songpa-micro-housing/.

n.d. "Songpa Micro-Housing." World-Architects, August 17, 2015. Accessed March 3, 2018. https://www.worldarchitects.com/it/architecture-news/reviews/songpamicro-housing.

n.d. "The Toronto Eaton Centre: Phase 1." Canadian Architect 22, no. 5 (1977): 30-50. Accessed November 3, 2017. http://ezproxy.lib.ryerson.ca/login?url=https:// search-proquest-com.ezproxy.lib.ryerson.ca/ docview/54926667? accountid= 13631 .

Thompson, Derek. "What in the World Is Causing the Retail Meltdown of 2017?" The Atlantic, April 10, 2017. Accessed February 10, 2018. https://www.theatlantic. com/business/archive/2017/04/retail-meltdownof-2017/522384/.

Till, Jeremy. Architecture Depends (London: The MIT Press, 2013).

Todoran, Smaranda Maria. "Addendum to the Arcadian Myth: Science Fiction and Contemporary Utopian Discourse in Architecture." Philobiblon 21, no. 1 (2016): 120-131. http://ezproxy.lib.ryerson.ca/ login?url=https://search-proquest-com.ezproxy.lib. ryerson.ca/docview/1803443102?accountid=1363.

Trufelman, Avery. "The Gruen Effect." 99\% Invisible, May 5, 2015.Accessed May 18,2018.https://99percentinvisible. 
org/episode/the-gruen-effect/.

Watkin, David. The Rise of Architectural History (London: The Architectural Press, 1980).

Whiteley, Nigel. "Toward a Throw-Away Culture. Consumerism, 'Style Obsolescence' and Cultural Theory inthe 1950s and 1960s." Oxford Art Journal 10, no. 2 (1987): 3-27. http://www.jstor.org/stable/1360444.

Yates, Frances. The Art of Memory (London: The Bodley Head, 2014).

Young, Leslie. "Shoppers still spending at Canada's biggest malls, researchers say." Global News, September 16, 2017. Accessed February 10, 2018. https://globalnews. ca/news/3748177/canada-malls-retail-success/.

Zeidler, Eberhard H. Buildings Cities Life: An Autobiography in Architecture (Toronto: Dundurn, 2013).

Zeidler, Eberhard H. "The Toronto Eaton Centre, Phase II; Architect: Bregman and Hamann; Zeidler Partnership." Canadian Architect 24. no. 11 (1979): 24-31. Accessed November 3, 2017. http://ezproxy.lib.ryerson.ca/ login?url=https://search-proquest-com.ezproxy.lib. ryerson.ca/docview/54934843? accountid=13631.

Zukin, Sharon. Naked City: The death and life of authentic urban places (New York: Oxford University Press, 2010). 



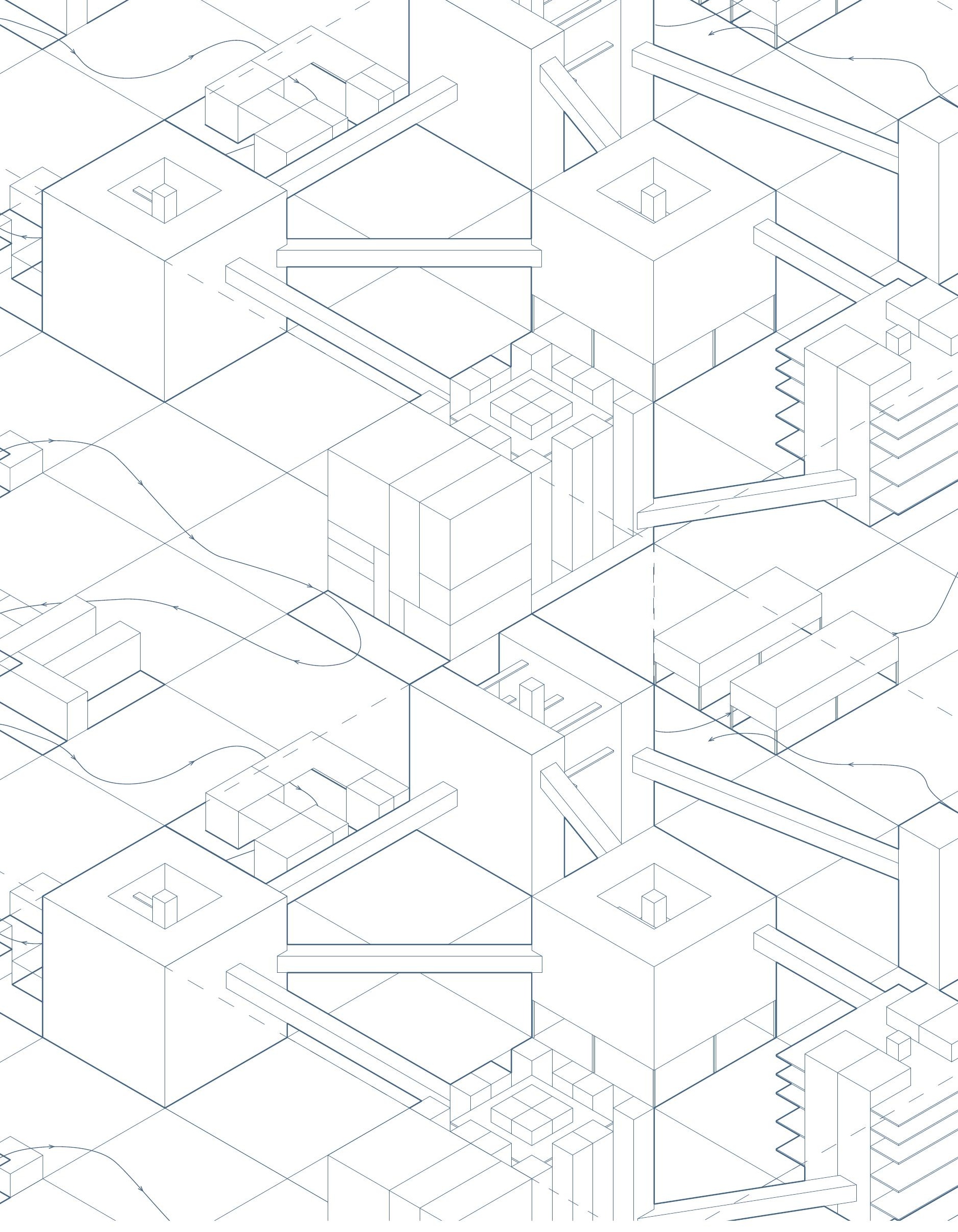

